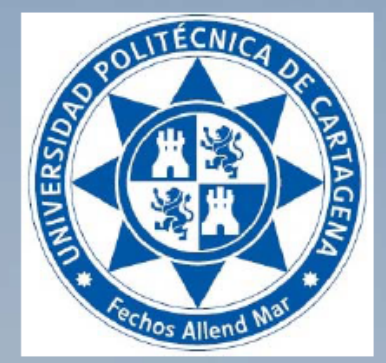

Universidad Politécnica de Cartagena

Departamento de Ciencia y Tecnología Agraria

\title{
Control Biológico de Meloidogyne incognita en Pimiento (Capsicum annuum)
}

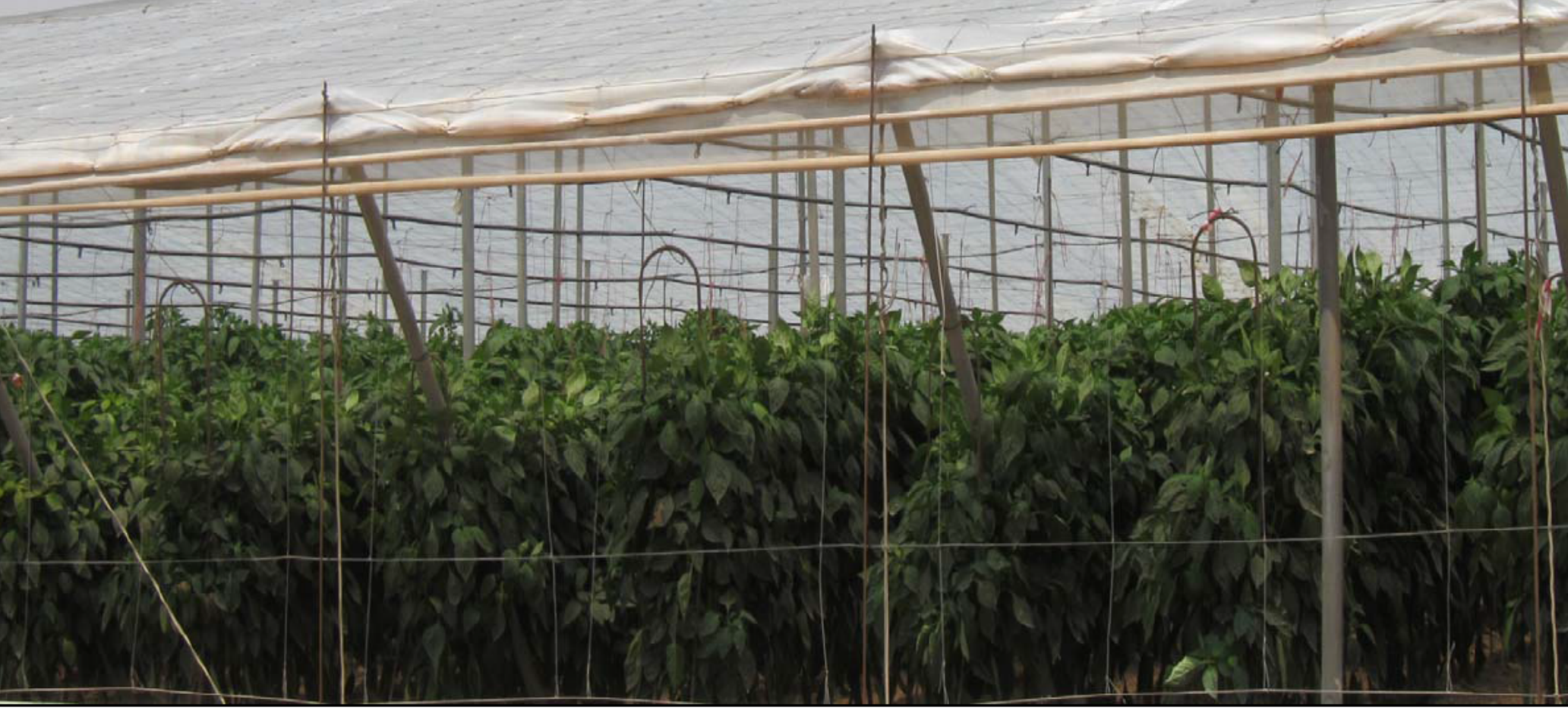

Ana María Requena Candela

2013 


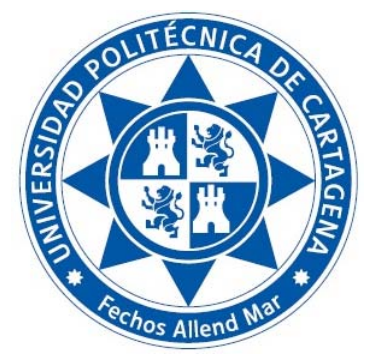

Universidad Politécnica de Cartagena

Departamento de Ciencia y Tecnología Agraria

\title{
Control Biológico de Meloidogyne incognita en Pimiento (Capsicum annuum)
}

\author{
Ana María Requena Candela \\ Directoras \\ C. Egea-Gilabert, M.E. Candela y M.E. Requena
}




\section{CONFORMIDAD DE DEPÓSITO DE TESIS DOCTORAL POR LA COMISIÓN ACADÉMICA DEL PROGRAMA}

D. Francisco Artés Hernández, Presidente/a de la Comisión Académica del Programa

Téenicas Avanzadas en Investigación y Desarrollo Agrario y Alimentario.

\section{INFORMA:}

Que la Tesis Doctoral titulada, "Control biológico de Meloydogine incognita en pimiento (Capsicum annuum)", ha sido realizada por $\mathrm{D}^{\mathrm{a}}$. Ana $\mathrm{M}^{\mathrm{a}}$ Requena Candela, bajo la dirección y supervisión de las Dras Catalina Egea Gilabert, $\mathbf{M}^{\mathbf{a}}$ Emilia Candela Castillo y $\mathbf{M}^{\mathrm{a}}$ Emilia Requena Candela.

En reunión de la Comisión Académica de fecha $5 / 7 / 3 / 3$, visto que la mencionada tesis doctoral tiene acreditados los indicios de calidad, requeridos para el depósito de tesis doctorales, regulados en el artículo 32 del Reglamento de Estudios Oficiales de Máster y Doctorado de la UPCT, y la autorización del Director de la misma, se acordó dar la conformidad para que a dicha tesis le sea autorizado, por la Comisión de Doctorado, su depósito.

La Rama de conocimiento por la que esta tesis ha sido desarrollada es:

XCiencias

$\square$ Ciencias Sociales y Jurídicas

$\square$ Ingeniería y Arquitectura

En Cartagena, a 19 de julio de 2013

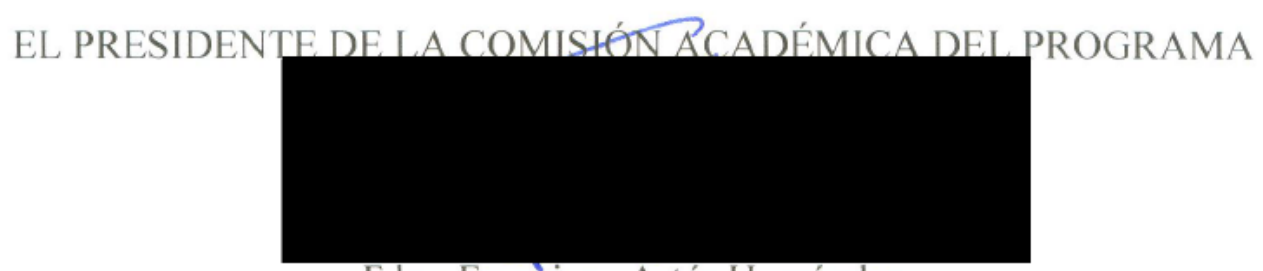

Fdo.: Francisco Artés Hernández 


\section{Universidad}

Politécnica

de Cartagena

DT-16

\section{CONFORMIDAD DE SOLICITUD DEAUTORIZACIÓN DE DEPÓSITO DE TESIS DOCTORAL POR EL/LA DIRECTOR/A DE LA TESIS}

$\mathrm{D}^{\mathrm{a}}$ Catalina Egea Gilabert, $\mathrm{D}^{\mathrm{a}} \mathrm{M}^{\mathrm{a}}$ Emilia Candela Castillo y $\mathrm{D}^{\mathrm{a}} \mathrm{M}^{\mathrm{a}}$ Emilia Requena Candela---- Directoras de la Tesis doctoral -Control biológico de Meloidogyne incognita en pimiento (Capsicum annuum)- de

\section{INFORMA:}

Que la referida Tesis Doctoral, ha sido realizada por D ${ }^{\mathrm{a}}$ Ana Maria Requena Candela--------, dando mi conformidad para que sea presentada ante la Comisión de

Doctorado, para ser autorizado su depósito.

La rama de conocimiento por la que esta tesis ha sido desarrollada es:

X Ciencias

Ciencias Sociales y Jurídicas

Ingeniería y Arquitectura

En Cartagena, a 18 de Julio de 2013

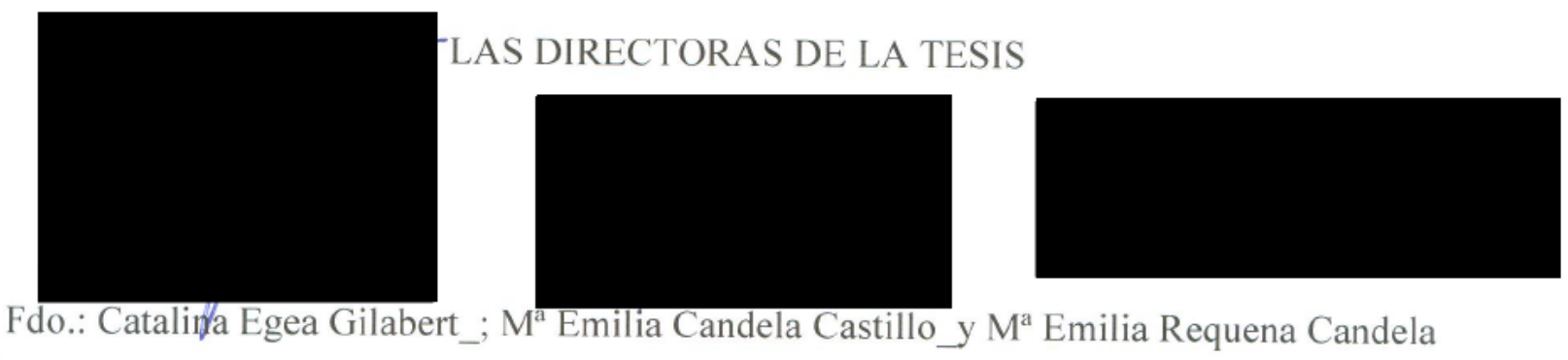




\section{Publicaciones Originales de la Tesis}

\section{Publicaciones en revistas cientificas listadas en JCR}

- $\quad$ Requena, A.M., Candela, M.E., Requena, M.E., Egea-Gilabert, C. (2011). Hostpathogen interaction of root-knot nematode Meloidogyne incognita on pepper in the southeast of Spain. European Journal of Plant Pathology. 131:511-518.

- Requena, A.M., Candela, M.E., Requena, M.E., Egea-Gilabert, C. (2013). Biological control of Meloidogyne incognita in pepper through combined applications of antagonist microorganisms. Enviado a Plant Pathology

\section{Comunicaciones a Congresos}

- Requena, A.M., González-Ramiro, L., Ezziyyani, M., Egea-Gilabert, C., Requena, M.E. y Candela, M.E.

Título: Control Biológico de Meloidogyne incognita mediante un formulado de Paecilomyces lilacinus y Trichoderma harzianum en plantas de pimiento de Capsicum annuum.

Congreso: XV Congreso de la Sociedad Española de Fitopatología (SEF)

Publicación: Actas del Congreso Organizador SEF 2010

Lugar de celebración: Vitoria (España) 
Deseo expresar mi más sincero agradecimiento a:

A las Dras. Catalina Egea Gilabert, $\mathrm{M}^{\mathrm{a}}$ Emilia Candela Castillo y $\mathrm{M}^{\mathrm{a}}$ Emilia Requena Candela, directora y co-directoras de este trabajo, por su constante y atenta supervisión de mi labor, por sus enseñanzas y consejos tan valiosos que me han proporcionado durante todos estos años y, también, por su dedicación a la labor de investigar que son un ejemplo a seguir para todos los que trabajamos con ellas. Sinceramente, ha sido un honor trabajar a vuestro lado y espero que los que vengan detrás de mí sepan apreciar lo maravillosas que sois y la dedicación tan grande que les dais a la gente que está bajo vuestra dirección.

A mi estimada Consuelo Pérez, por sus enseñanzas y consejos que tanto me han ayudado en el desarrollo del trabajo.

A mis compañeros y amigos de investigación: Mohamed, Roció, Elisa, Derlin, Agustín, Ana y Pepita sin cuya colaboración este trabajo no hubiera sido posible.

Al personal del CAID: Almudena, José Antonio y Manolo por su trato personal tan afable y por el interés en el cuidado de las plantas en el invernadero.

A mis padres y hermano, por sus valiosos consejos y apoyo moral que han hecho posible que no decaiga mi ilusión por terminar este trabajo.

A mi hermana, por sus enseñanzas, dedicación y paciencia que siempre me ha brindado en todos estos años que ha durado el trabajo.

A mi suegra, por sus palabras sabias y de apoyo que siempre me da en tiempos difíciles. A mi marido, por su incondicional apoyo y amor que ha sido determinante para terminar el trabajo.

Esta Tesis está dedicada a mi Familia que sin ellos esto no hubiera sido posible. 
舫 mi Familia 


\section{Resumen}

Las enfermedades causadas por nematodos suponen unas pérdidas muy importantes para el sector hortícola, por lo que conseguir un control adecuado de este patógeno es fundamental.

En este trabajo se ha identificado el nematodo causante de la enfermedad de la "agalla de la raíz” en las plantas de pimiento analizadas en el campo de Cartagena, como Meloidogyne incognita, mediante técnicas moleculares y de histopatología. Asimismo se ha estudiado la relación entre la población inicial de nematodos y el crecimiento de plántulas de pimiento bajo plástico, obteniendo la tasa de reproducción del nematodo en pimiento en condiciones de cultivo y, siendo el límite de tolerancia (T) de la planta a $M$. incógnita de 1,5 huevos y $\mathrm{J}_{2}$ por $\mathrm{ml}^{-1}$.

Para el control biológico de $M$. incognita se han probado microorganismos antagonistas del patógeno de manera individual o en combinaciones. El uso de microorganismos aislados ha resultado ser poco efectivo. La combinación de dos hongos como Paecilomyces lilacinus y Trichoderma. harzianum produjo un control de la enfermedad entorno al 70\%, aunque el mayor inconveniente fue la poca persistencia en el suelo de estos hongos. La combinación de tres antagonistas (P. lilacinus, T. harzianum y Bacillus firmus) resultó que la inclusión de la bacteria no mejoró la efectividad de la combinación de los dos hongos antagonistas, pues fue solo del 46,6\%, aunque hay que tener en cuenta que concentración del inoculo inicial para esta experiencia fue el doble que la anterior. En general, la concentración inicial de inoculo del nematodo en el suelo, es determinante para alcanzar una efectividad elevada en el control de la enfermedad. El uso del formulado Nemaout que contiene bacterias promotoras del crecimiento y aminoácidos de origen vegetal, es el que produjo los mejores resultados en el control de la enfermedad. En conclusión, debido a sus componentes, la combinación de antagonistas puede usarse como preventivo aunque si el inóculo inicial de nematodos en el suelo de cultivo es elevado, estos antagonistas deberían de ser aplicados en el momento del trasplante y luego a la mitad de la estación de cultivo. Nemaout, sin embargo puede ser más efectivo antes del trasplante.

Finalmente se analizaron los compuestos excretados por los hongos $T$. harzianum y $P$. lilacinus en los cultivos "in vitro" confirmando su actividad nematicida (90,5\% en mortandad de $\mathrm{J}_{2}$ ). Los extractos metabólicos concentrados de las suspensiones miceliares de $T$. harzianum produjeron una mortandad del $100 \%$ de los $\mathrm{J}_{2}$. 


\begin{abstract}
Diseases caused by nematodes pose very significant losses for the horticultural sector, so achieve an adequate control of this pathogen is essential.

The present study has identified the nematode causing disease "root gall" in pepper plants analyzed in the area "Campo de Cartagena”, as Meloidogyne incognita, using molecular techniques and histopathology. Also we have studied the relationship between initial population of nematodes and growth of pepper seedlings under plastic, obtaining the reproduction rate of the nematode in pepper in growing conditions and, being the limit of tolerance (T) of the plant to $M$. incógnita de 1.5 eggs and $\mathrm{J}_{2}$ per $\mathrm{ml}^{-1}$.

For biological control of $M$. incognita, pathogenic antagonist microorganisms were tested individually or in combinations. The use of isolated microorganisms has proved ineffective. The combination of two fungi as Paecilomyces lilacinus and Trichoderma. harzianum produced a disease control around 70\%, although the biggest drawback was the low soil persistence of these fungi. The combination of three antagonists ( $P$. lilacinus, T. harzianum and Bacillus firmus) proved that the inclusion of the bacteria did not improve the effectiveness of the combination of the two antagonistic fungi, because it was only $46.6 \%$, although it should be note that initial inoculum concentration was twice than the last experience. In general, the initial concentration of nematode inoculum in soil is crucial to achieve high effectiveness in controlling the disease. The use of Nemaout, formulated containing plant growth promoting bacteria and plant aminoacids is the one that produced the best results in controlling the disease. In conclusion, due to its components, the combination of antagonists can be used as preventive, although the initial inoculum of nematodes in soil culture is high, these antagonists should be applied at the time of transplantation and then half of the crop cycle. Nemaout, however, may be more effective before transplantation.

Finally the compounds excreted by the fungi T. harzianum and P. lilacinus in in vitro cultures were analyzed, confirming their nematicidal activity (90.5\% in mortality of $\mathrm{J}_{2}$ ). The metabolic extracts from mycelia suspensions concentrates of $T$. harzianum produced a $100 \%$ mortality of $\mathrm{J}_{2}$.
\end{abstract}




\section{Índice}

I. INTRODUCCIÓN ................................................................................................. 4

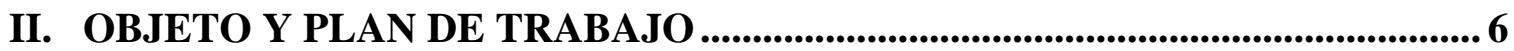

III. ANTECEDENTES BIBLIOGRAFICOS............................................................

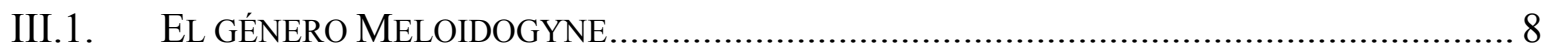

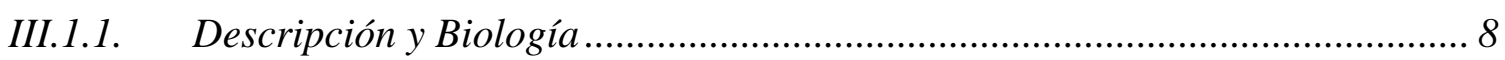

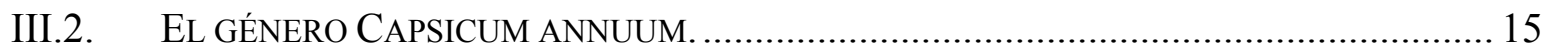

III.2.1. Descripción botánica y taxonomía …........................................................... 15

III.3. IMPORTANCIA DEL CONTROL AGRO-ECOLÓGICO DE PLAGAS Y ENFERMEDADES ....... 21

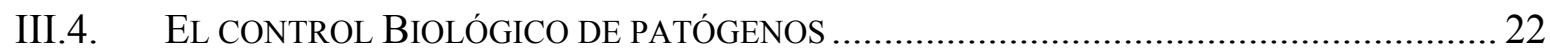

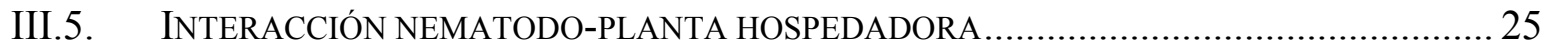

III.6. AGENTES DE BIOCONTROL PAECILOMYCES LILACINUS Y TRICHODERMA

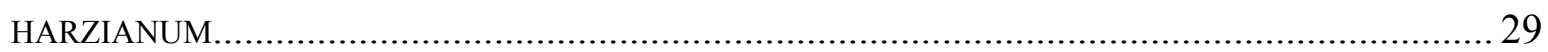

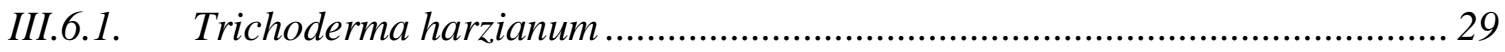

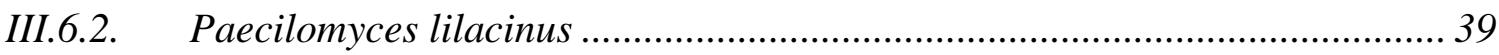

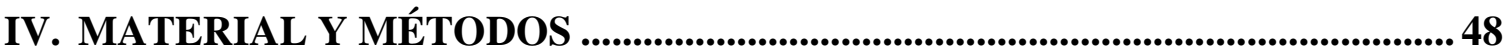

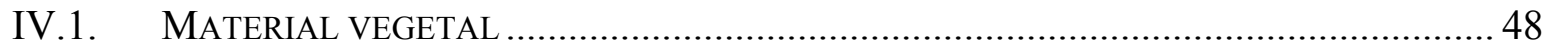

IV.1.1. Capsicum annuum cv. California Wonder .................................................... 48

IV.1.2. Solanum lycopersici cv. Marmande............................................................ 49

IV.2. MATERIAL FÚNGICO (TRICHODERMA HARZIANUM Y PAECILOMYCES LILACINUS) Y

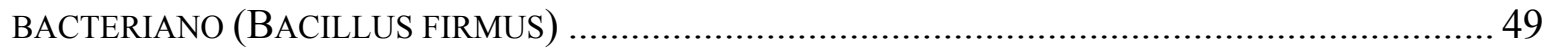

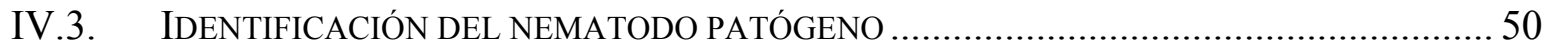

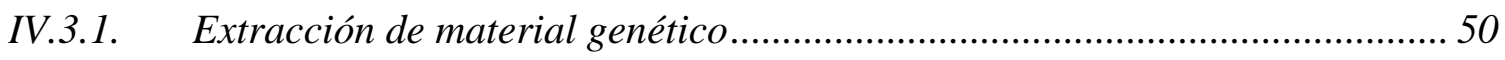

IV.3.2. Identificación de la región de interés mediante PCR.......................................51

IV.4. ESTUdio DE LA INTERACCIÓN DE CAPSICUM ANNUUM-MELOIDOGYNE INCOGNITA.

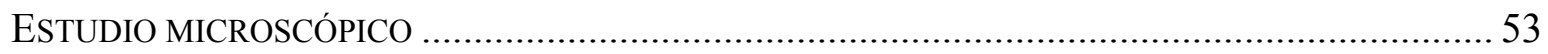

IV.5. OBTENCIÓN DEL INÓCULO DEL NEMATODO MELOIDOGYNE INCOGNITA A PARTIR DE PLANTAS DE PIMIENTO Y MANTENIMIENTO EN PLANTAS DE PIMIENTO Y TOMATE.................. 53

IV.6. OBTENCIÓN Y CUANTIFICACIÓN DE HUEVOS Y JUVENILES $\left(\mathrm{J}_{2}\right)$.............................. 54

IV.7. DETERMINACIÓN DEL LÍMITE DE TOLERANCIA DE PIMIENTOS AL NEMATOdO

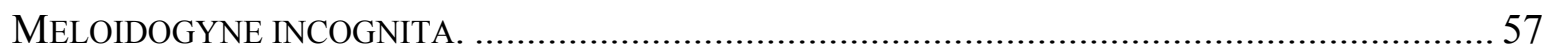

IV.8. CONFRONTACIÓN “IN VITRO” EN PLACA DE P. LILACINUS, T. HARZIANUM Y B.

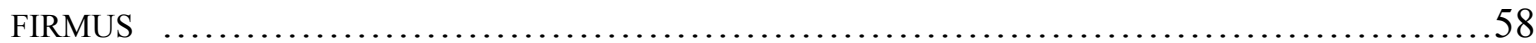

IV.9. ENSAyOS DE BiOCONTROL "IN VIVO" ENTRE LOS AGENTES P. LILACINUS, T. 
HARZIANUM Y EL NEMATODO M. INCOGNITA.

IV.9.1. Preparación del inóculo de los microorganismos antagonistas seleccionados para los ensayos "in vivo".

IV.9.2. Ensayo con el agente de biocontrol P. lilacinus y el nematodo M. incognita. .60

IV.9.3. Ensayo con dos agentes de biocontrol P. lilacinus, T. harzianum y el nematodo M. incognita. 60

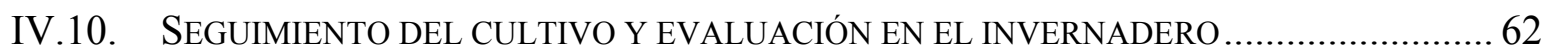

IV.11. ENSAYOS CON LA COMBINACIÓN DE ANTAGONISTAS TH2413, PL243 Y BF342 Y CON EL FORMULADO NEMAOUT

IV.11.1. Producción y aplicación de los antagonistas P. lilacinus, T. harzianum y B.

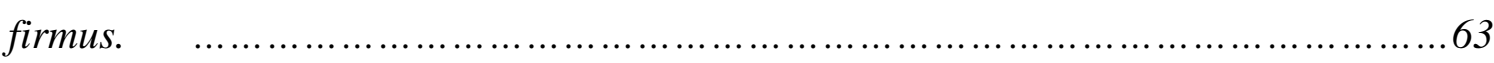

IV.11.2. Producción y aplicación del formulado Nemaout 63

IV.11.3. Aplicación de la combinación de antagonistas TH2413, PL243 y BF342 y del formulado Nemaout. 64

IV.12. PRODUCCIÓN, EXTRACCIÓN, SEPARACIÓN E IDENTIFICACIÓN DE COMPUESTOS EXCRETADOS (VERTIDOS) DE P. LILACINUS Y T. HARZIANUM 65

IV.12.1. Producción de vertidos antipatógenos de P. lilacinus y T. harzianum .......... 65

IV.12.2. Extracción de compuestos de los vertidos de P. lilacinus y T. harzianum..... 65

IV.12.3. Separación mediante cromatografía en capa fina (TLC)............................... 65

IV.12.4. Bioensayos "in vitro" de los vertidos de T. harzianum....................................66 66

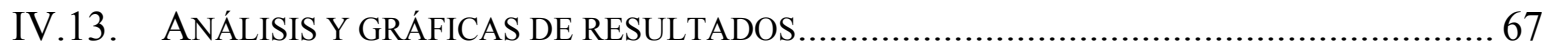

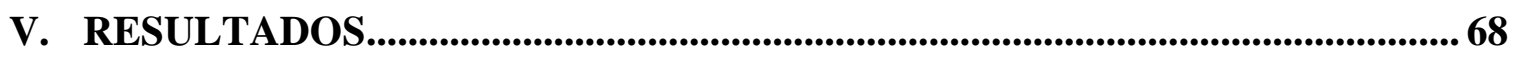

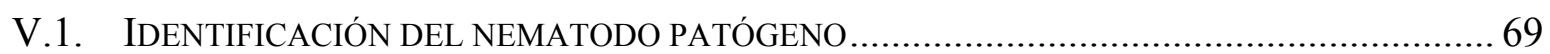

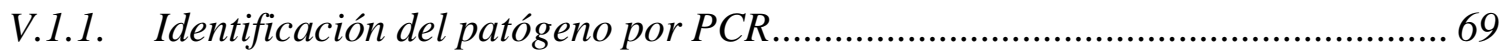

V.2. ESTUDIO DE LA INTERACCIÓN CAPSICUM ANNUUM-MELOIDOGYNE INCOGNITA.

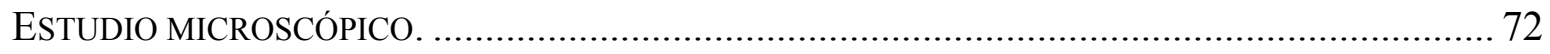

V.3. INÓCUlo DEL NEMATOdo MELOIDOGYNe INCOGNITA A PARTIR DE PLANTAS DE PIMIENTO Y MANTENIMIENTO EN PLANTAS DE PIMIENTO Y TOMATE …................................ 76

V.4. ANÁLISIS DEL LÍMITE DE TOLERANCIA DE PIMIENTO-MELOIDOGYNE INCOGNITA........ 77

V.5. ANÁLISIS DE LA CONFRONTACIÓN “IN VITRO” DE LOS ANTAGONISTAS. .......................80

V.6. ENSAyo CON EL AGENTE DE BIOCONTROL P. LILACINUS Y EL NEMATOdo M.

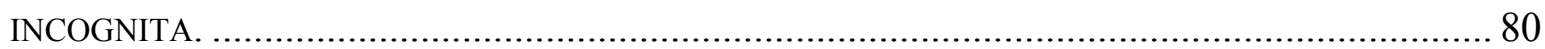

V.7. ENSAYO CON DOS AGENTES DE BIOCONTROL P. LILACINUS Y T. HARZIANUM Y EL

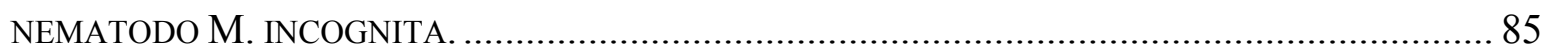

V.7.1. Ensayo sin reposición de P. lilacinus y T. harzianum ....................................... 85

V.7.2. Ensayo con reposición de P. lilacinus y T. harzianum ........................................ 89 
V.8. ANÁlisis DE LA EFICACIA DE LA COMBINACIÓN DE AGENTES DE BIOCONTROL PAECILOMYCES LILACINUS, TRICHODERMA HARZIANUM Y BACILLUS FIRMUS Y DEL FORMULADO NEMAOUT CONTRA MELOIDOGYNE INCOGNITA.

V.8.1. Compatibilidad "in vitro" de los antagonistas que forman la combinación..... 93

V.8.2. Efecto de la combinación de los 3 antagonistas y del producto Nemaout sobre el crecimiento de las plantas de pimiento, infectadas con $M$. incognita

V.8.3. Efecto de la combinación TH2413, PL243 y BF342 o del producto Nemaout sobre la productividad de las plantas de pimiento infectadas con M. incognita.....

V.9. ESTUDIOS "IN VITRO" DE LOS VERTIDOS DE P. LILACINUS Y T. HARZIANUM 102

V.9.1. Estudios de los compuestos excretados de P. lilacinus y T. harzianum sobre juveniles de $M$. incognita 102

V.10. ESTUDIOS "IN VITRO" DE LOS VERTIDOS DE T. HARZIANUM .................................... 103

V.10.1. Estudio de los vertidos de T. harzianum sobre huevos de M. incognita ....... 103 V.10.2. Estudio del extracto completo de T. harzianum sobre juveniles (J2) de M.

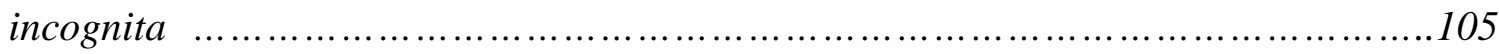

V.10.3. Separación mediante cromatografía en capa fina (TLC) de extractos de T. harzianum.

V.10.4. Estudio de la actividad antifúngica del extracto completo de T. harzianum 111 V.10.5. Estudio de la actividad antinematicida de fracciones del extracto de $T$. harzianum. 


\section{INTRODUCCIÓN}

España es el principal productor Europeo y el sexto en el ámbito mundial de diferentes variedades cultivadas de pimiento, siendo Murcia una de las primeras regiones de cultivo, produciendo numerosas variedades de gran valor socioeconómico como las que se utilizan para su consumo en fresco y se cultivan en invernaderos.

Entre las enfermedades que atacan a las plantaciones de pimiento, las de mayor asiduidad son las ocasionadas por los patógenos del suelo, que pueden hacer inviable su cultivo al provocar endemismos difíciles de erradicar en las parcelas de cultivo. Un factor de intensidad entre las enfermedades persistentes es cuando los suelos de cultivo forman parte de invernaderos y se realiza una agricultura intensiva a lo largo del año. Uno de los patógenos responsables de estas graves enfermedades son los nematodos, los cuales están acaparando mucha importancia desde que se prohibió el uso de desinfectantes del suelo como el Bromuro de Metilo (protocolo de Montreal, obligatorio para Europa desde el año 2005 e implementado en la unión europea por el Reglamento CE 2037/2000) y no se ha hallado otro pesticida tan potente, aunque por otra parte tan dañino sobre los microorganismos beneficiosos del suelo y sobre la capa de ozono que provoca un efecto carcinógeno sobre los humanos.

Aunque la desaparición del $\mathrm{MeBr}$ es grave, el problema se agudiza pues la CEE ha revisado la legalidad de cientos de sustancias activas constituyentes de 
pesticidas y ha desautorizado numerosas de las que existían en el mercado en 1993. Efectivamente a partir de la publicación de la directiva 91/414/EEC la Comisión Europea retiró el $74 \%$ de las existentes en el 93 permitió únicamente 71 materias activas fungicidas y 16 agentes microbianos de biocontrol. Este hecho implica que para poder conseguir cultivos rentables hay que utilizar nuevas estrategias.

Los nematodos, patógenos de estudio de este trabajo, tienen la problemática de infectar los cultivos con huevos que pueden enterrarse profundamente en el suelo y eclosionar e infectar con sus larvas (los llamados juveniles o $\mathrm{J}_{2}$ ) las plantas recién emergidas y particularmente sensibles. Además la concentración del inóculo, si no se desinfecta profundamente el suelo, se incrementa año tras año hasta hacer inviable el cultivo de sus plantas hospedadoras.

En el pimiento, planta objeto de nuestro estudio, uno de los nematodos que pueden infectar con virulencia su cultivo es el responsable de la enfermedad de la agalla de la raíz provocada por las especies del género Meloidogyne, entre ellas Meloidogyne incognita. Aunque para la lucha contra este nematodo se han probado nuevos nematicidas, su alto costo y sobre todo los efectos tóxicos antes apuntados han propiciado la búsqueda de alternativas menos dañinas. Actualmente hay multitud de investigación sobre esas posibles alternativas que pasan desde el uso de extractos vegetales a agentes de biocontrol o la adición de enmiendas orgánicas al suelo, conocida como biofumigación, que se puede aplicar junto a la solarización del suelo en zonas de intensa incidencia solar como la que tiene lugar en la vertiente mediterránea del sureste español.

El control biológico mediante el uso de microorganismos antagonistas es una de las alternativas que más atención ha recibido en los últimos años. Así, el control biológico surge como respuesta a la búsqueda de formas de control de patógenos, en la que prima la calidad de las cosechas y el respeto a los recursos naturales y humanos.

Para la aplicación de medidas de control biológico como alternativa a los tratamientos químicos es preciso conocer la interacción pimiento-nematodo y la interacción pimiento-nematodo-agente de biocontrol. Por lo que, en este estudio, determinaremos esas interacciones entre Capsicum annuum var. California Wonder, Meloidogyne incognita y agentes de biocontrol, entre ellos hongos antagonistas y bacterias que puedan proporcionar el control de la enfermedad. 


\section{OBJETO Y PLAN DE TRABAJO}

Los objetivos principales de este estudio se describen a continuación:

1.- Identificación del nematodo agallador de la raíz presente en plantas de pimiento del Campo de Cartagena mediante histopatología de los tejidos infectados y análisis de ADN por técnicas de PCR con cebadores específicos de Meloidogyne ssp.

2.- Estudio de la relación entre la población inicial de nematodos y el crecimiento de plántulas de pimiento bajo plástico, obteniendo la tasa de reproducción del nematodo en pimiento en condiciones de cultivo.

3.- Estudio de la interacción entre los agentes de biocontrol Paecilomyces lilacinus raza 251 y Trichoderma harzianum con el patógeno Meloidogyne ssp., en cultivo de Pimiento (Capsicum annum) de la variedad California Wonder, bajo condiciones controladas.

4.- Estudios "in vitro" del efecto de los extractos metabólicos de Paecilomyces lilacinus raza 251 y Trichoderma harzianum 2413 contra el nematodo Meloidogyne incognita aislados de raíces de pimiento (California Wonder).

Las estrategias de trabajo seguidas en esta investigación se describen en los siguientes puntos: 
$1^{\mathrm{o}}$.-Aislamiento del nematodo procedente de plantas de pimiento de una parcela infectada del Campo de Cartagena, Murcia, para reproducir al patógeno en condiciones de laboratorio.

$2^{\circ}$.-Identificación del patógeno por análisis de ADN por PCR con cebadores específicos para Meloidogyne ssp.

$3^{\text {o }}$.- Estudio histopatológico de cortes de raíces infectadas y sanas inmersas en parafina y observación al microscopio óptico.

$4^{\text {o }}$ - Multiplicación del patógeno, en raíces de Pimiento var. California Wonder, para su uso como inoculante en los ensayo "in vivo" e "in vitro".

$5^{\circ}$.- Cultivo de plántulas de pimiento para los ensayos del límite de tolerancia y control biológico de Meloidogyne incognita, con previa desinfección del material de siembra (tierra, semilleros, macetas y semillas).

$6^{\circ}$.- Infección de plántulas de pimiento sanas con al menos dos meses de edad para los estudios de tolerancia y control del patógeno.

$7^{\circ}$.-Análisis del límite de tolerancia del pimiento al patógeno a partir de la densidad de inóculo inicial y el crecimiento de la plántula.

$8^{\circ}$.-Evaluación del potencial de simbiosis entre los agentes de biocontrol Paecilomyces lilacinus y Trichoderma harzianum.

$9^{\circ}$.- Evaluación de Paecilomyces lilacinus y Trichoderma harzianum "in vivo" para el control de la colonización del patógeno en las raíces de las plantas de pimiento.

$10^{\circ}$.-Evaluación del potencial de simbiosis entre los agentes de biocontrol Paecilomyces lilacinus, Trichoderma harzianum y Bacillus firmus.

$11^{\circ}$.- Evaluación de Paecilomyces lilacinus, Trichoderma harzianum, Bacillus firmus y un producto biológico (Nemaout) "in vivo" para el control de la colonización del patógeno en las raíces de las plantas de pimiento.

$12^{\circ}$.-.Producción de extractos fúngicos de $P$. lilacinus y T. harzianum

$13^{\circ}$.- Evaluación de los efectos de los extractos de Paecilomyces lilacinus y Trichoderma harzianum frente al patógeno Meloidogyne ssp

$14^{\circ}$.- Separación y Evaluación de fracciones de los extractos fúngicos con posible actividad fúngica y nematicida. 


\section{ANTECEDENTES BIBLIOGRÁFICOS}

\section{III.1. El género Meloidogyne}

\section{III.1.1. Descripción y Biología}

Los nematodos pertenecen al reino Animal y aunque parecen gusanos son distintos taxonómicamente de los verdaderos. La mayoría de las miles de especies de nematodos conocidas viven libremente en el agua o en el suelo y se alimentan de microorganismos, plantas o animales pero algunos atacan y parasitan organismos vivos. Varios cientos de estas especies se alimentan de plantas vivas obteniendo su alimento con lanzas o estiletes. Esto produce enfermedades a lo ancho de todo el mundo, llegando a causar pérdidas del $14 \%$ de las cosechas. Los nematodos que parasitan las plantas son pequeños, de 300 a 1000 micrómetros aunque algunos pueden tener hasta $4 \mathrm{~mm}$ de largo por 15-35 micrómetros de ancho y este pequeño diámetro los hace invisibles al ojo desnudo pero pueden verse fácilmente bajo un microscopio. Su reproducción es por huevos.

Entre los nematodos que atacan las raíces de las plantas, los de la especie Meloidogyne spp, son los responsables de la enfermedad de la agalla de la raíz. Estos nematodos se encuentran en todo el mundo especialmente en zonas cálidas y desde luego en invernaderos. El nematodo Meloidogyne incognita es un parásito que infecta las raíces y ataca a un amplio rango de plantas cultivadas, causando un daño económico elevado en todo el mundo (Whitehead, 1998). 


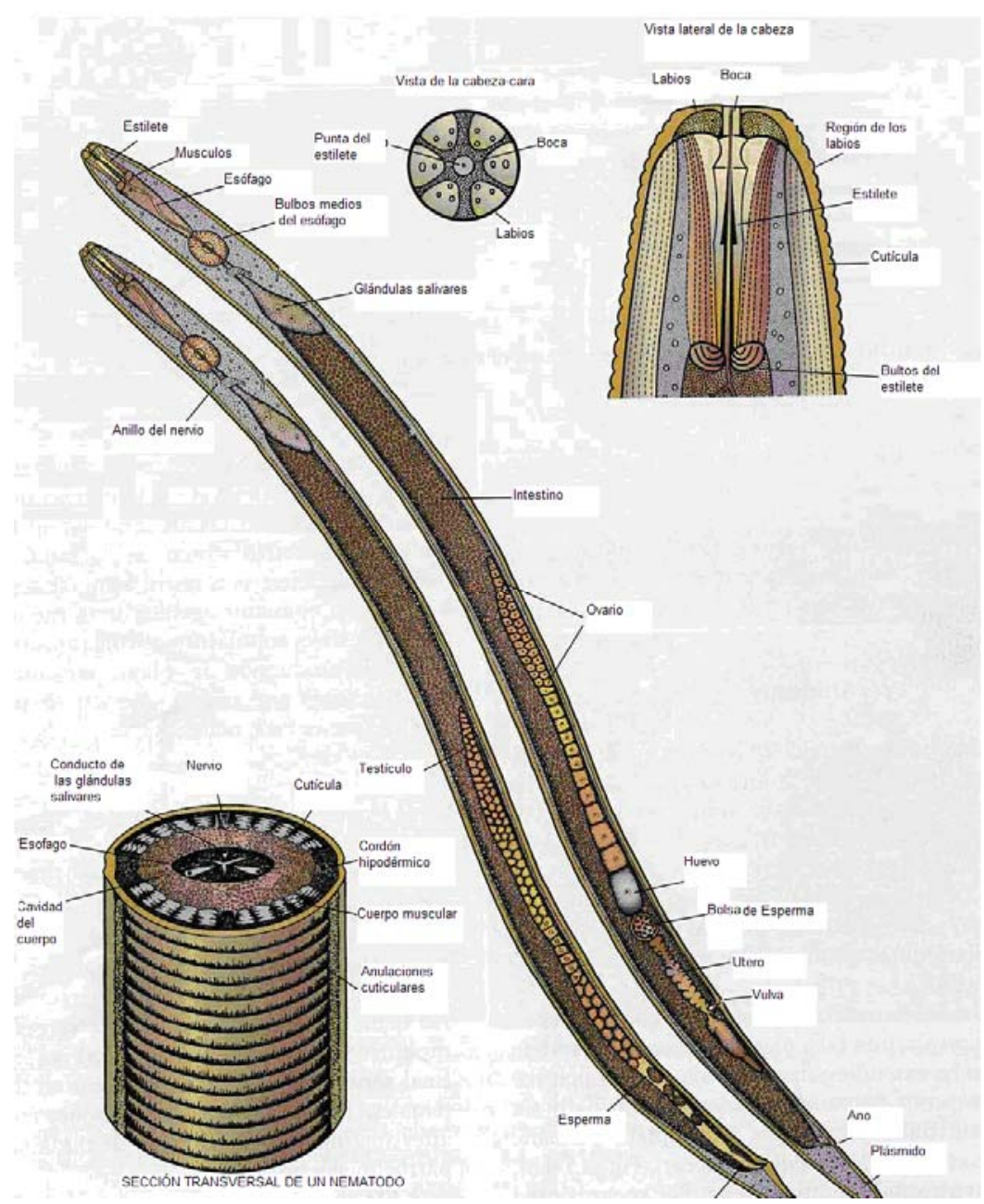

Fig.-III.1.- Morfología y principales características de nematodos típicos parásitos de plantas, hembra y macho. Agrios (2005).

Los nematodos de la agalla de la raíz dañan a las plantas porque desvitalizan las puntas de las raíces causando la formación de hinchamientos a lo largo de las raíces. Esos efectos no solo privan a la planta de nutrientes sino que también desfiguran y reducen el valor de mercado de innumerables productos hortícolas. Cuando la infección de las plantas susceptibles tiene lugar en el estado de plántula, las pérdidas son especialmente importantes, llegando incluso a causar la completa destrucción de la cosecha. La infección de plantas maduras tiene efectos más suaves aunque también puede llegar a reducir la producción considerablemente. Los síntomas de la planta son una reducción del crecimiento y del número de hojas, siendo estas más pequeñas y de color verde pálido o amarillas, y marchitamiento de la planta siendo éste más pronunciado en tiempo cálido. De todas formas, los síntomas más típicos de la enfermedad son los que aparecen en el sistema radicular 
de las plantas, cuando se desarrollan las típicas agallas en las raíces, las cuales pueden multiplicar varias veces el diámetro de una raíz sana.

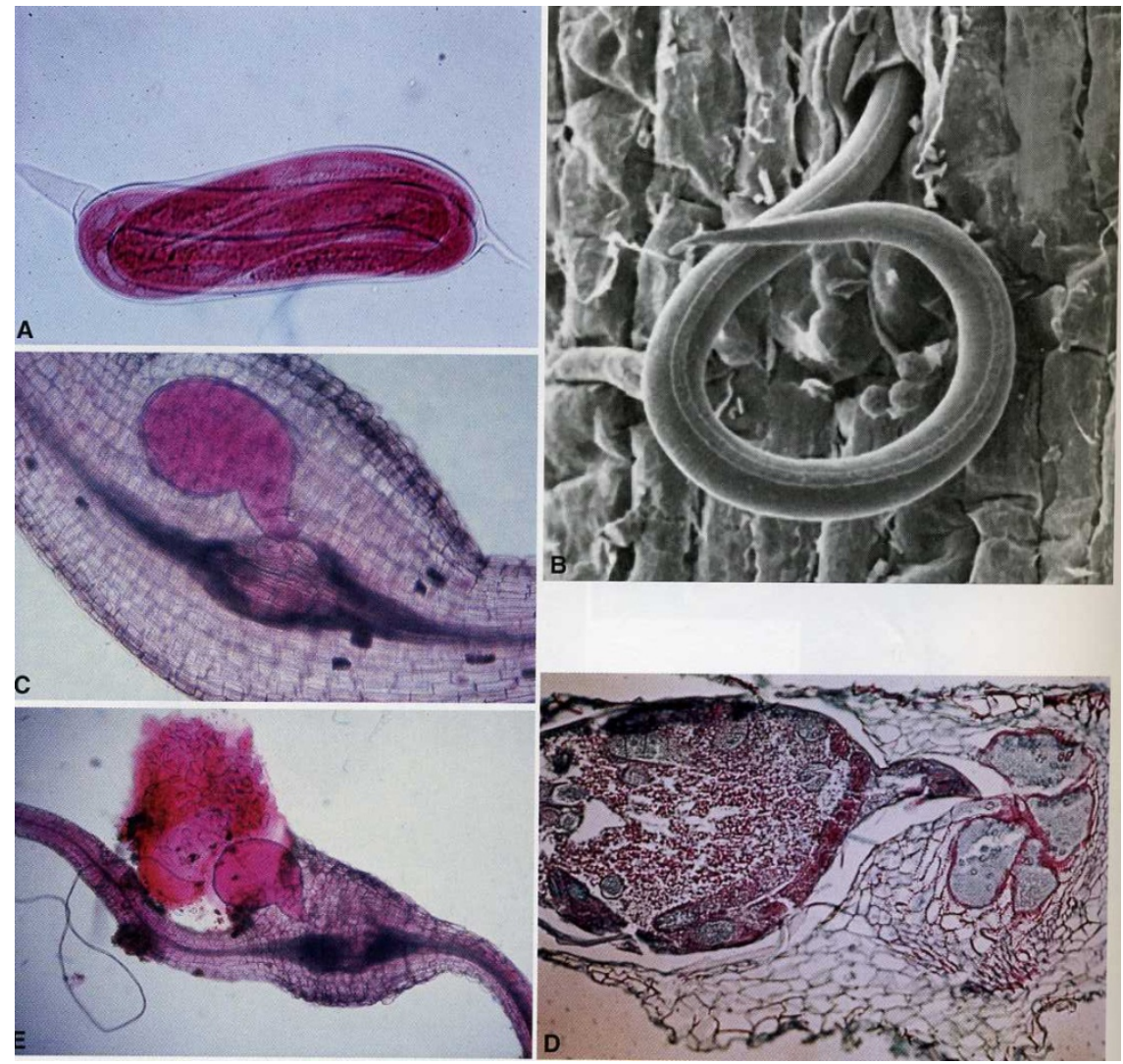

Fig.-III.2.- Estados en el ciclo de vida de un nematodo de la agalla de la raíz. Agrios (2005). (A) Huevo de nematodo con un juvenil secundario $\left(\mathrm{J}_{2}\right)$ listo para eclosionar. (B) $U n$ $\mathrm{J}_{2}$ penetrando en una raíz. (C) Una hembra dentro de una raíz formando “células gigantes” para su alimentación. (D) Sección longitudinal de hembra de Meloidogyne alimentándose en células gigantes. (E) Hembra poniendo huevos en el exterior de la raíz.

Una vez adultos, las hembras y los machos del nematodo Meloidogyne spp son fácilmente distinguibles. Los machos tienen forma de gusano y miden de 1,2 a 1,5 $\mathrm{mm}$ de largo y de 30 a $36 \mathrm{~mm}$ de diámetro. Las hembras tienen forma de pera midiendo de 0,4 a $1,3 \mathrm{~mm}$ de largo y de 0,27 a $0,75 \mathrm{~mm}$ de ancho. Cada hembra pone alrededor de 500 huevos en una sustancia gelatinosa.

Los nematodos hembras obtienen nutrientes de la planta vía células gigantes y eventualmente producen masas de huevos (Fig.-III.2). El primer y el segundo estado juvenil $\left(\mathrm{J}_{2}\right)$ son tipo gusano y se desarrollan en el interior de los huevos. Son la nueva generación y los $\mathrm{J}_{2}$ al eclosionar de los huevos se introducen en el suelo y se esparcen hacia raíces frescas, iniciando así la fase secundaria de la epidemia (Bridge \& Starr, 2007). 
El segundo estado juvenil $\left(\mathrm{J}_{2}\right)$ es el único infectivo del nematodo y si una vez en el suelo encuentra un hospedador susceptible, se introduce en la raíz, se convierte en sedentario y crece delgado como una salchicha comenzando la infección. El nematodo se alimenta de las células que están alrededor de su cabeza, insertando su estilete y segregando saliva en ellas. La saliva estimula el alargamiento de las células y también altera su contenido, parte del cual es absorbido por el nematodo a través de su estilete. El nematodo muda por segunda vez y produce el tercer estado juvenil el cual es más robusto y después de una tercera muda produce el cuarto estado juvenil diferenciándose ya si son machos o hembras. En ellos se produce la cuarta y última muda y el macho sale de la raíz como un macho adulto tipo gusano que vive libre en el suelo mientras que las hembras se quedan en las células radiculares y se hinchan creciendo en grosor hasta adquirir una forma de pera. Una vez que la hembra alcanza la madurez, con o sin fertilización por el macho, produce huevos que son depositados en una masa gelatinosa protectora dentro o fuera del tejido radicular, dependiendo de la posición de la hembra. Los huevos eclosionan inmediatamente, pero unos pocos pueden depositarse en el suelo donde pasan el invierno en estado latente y eclosionar después en primavera.

Un ciclo de vida se completa en 25 días a $27^{\circ} \mathrm{C}$ pero es más largo a temperatura más baja o más alta. Cuando los huevos eclosionan, los $\mathrm{J}_{2}$ infectivos migran a las partes adyacentes de la raíz y causan nuevas infecciones en la misma raíz o en raíces de otras plantas. La mayoría de los nematodos causantes de la agalla de la raíz se encuentran en la zona radicular entre los 5 y los $25 \mathrm{~cm}$ por debajo de la superficie. Se esparcen mediante el agua o aferrados a los aperos agrícolas o en plantas de almacenamiento infectadas.

El desarrollo de la enfermedad de Meloidogyne ssp tiene lugar cuando los $\mathrm{J}_{2}$ entran en la raíz y se desplazan hasta alcanzar las zonas de crecimiento, y se colocan en el cilindro vascular en desarrollo. Mientras, las células que han sido atravesadas por los juveniles en su camino hacia el interior, comienzan a alargarse. A los dos o tres días del establecimiento de los juveniles, las células radiculares alrededor de su cabeza se agrandan, su núcleo se divide pero no se produce nueva pared celular e incluso la pared celular existente entre las células se rompe y desaparece, lo que da lugar a las células gigantes. El alargamiento y la coalescencia 
de las células continúa durante dos o tres semanas y las células gigantes invaden el tejido circundante de manera irregular. Cada agalla contiene usualmente de tres a seis células gigantes las cuales se han producido por las sustancias contenidas en la saliva secretada por los nematodos en las células gigantes, durante su alimentación. Las células gigantes atraen nutrientes de las células vecinas y sirven como células de alimentación para el nematodo.

El hinchamiento de la raíz tiene lugar por el alargamiento excesivo y la división de todos los tipos de células alrededor de las gigantes y por el alargamiento de los nematodos. Cuando las hembras se agrandan y ponen su saco de huevos, empujan hacia fuera, fracturan la corteza celular y dependiendo de la posición del nematodo en relación con la superficie de la raíz, se colocan en la superficie de la raíz o permanecen completamente cubiertos.

Además de los daños causados a las plantas por las agallas que producen los nematodos, el daño en las plantas infectadas se incrementa por ciertos hongos parásitos los cuales atacan las raíces debilitadas y las hipertrofian. Más aún, algunos hongos como Fusarium, Rhizoctonia y el oomiceto Pythium crecen y se reproduce mucho más rápido en las agallas que en otras áreas de la raíz, induciendo así una ruptura más rápida de los tejidos radiculares.

Varias especies de Meloidogyne como $M$. incognita, M. arenaria, $M$. chitwoodi, M. fallax, M. hapla, y M. javanica infectan las cosechas de países cálidos y tienen un amplio espectro de plantas hospedadoras (Sikora \& Fernández, 2005). Meloidogyne spp completa una o dos generaciones durante una estación de crecimiento bajo las condiciones ambientales del Mediterráneo (Lamberti, 1979) y el mayor o menor deterioro del crecimiento de las cosechas está muy influenciado por la especie del nematodo y/o por la raza fisiológica en el suelo de siembra. Debido a esto, para diseñar las medidas de control que pueden ser efectivas en el contexto de un manejo integrado y sostenible de la enfermedad, es esencial la identificación y caracterización de la raza patogénica de Meloidogyne spp. y la estimación de su densidad poblacional en el suelo.

Esto es esencialmente importante para los nematodos porque la resistencia de la planta hospedadora, la cual podría reducir la población inicial de nematodos hasta el umbral de tolerancia, es muy escasa entre las hortícolas (Sasser \& Carter, 1985), y lo que parece que está perfectamente establecido es que la extensión del 
deterioro del crecimiento por los nematodos, está claramente influenciado por la densidad de la población de nematodos en el trasplante, para lo que se requiere una densidad de población mínima que se denomina $(\mathrm{T})$ tolerancia límite, para que tenga lugar la pérdida de producción (Seinhorst, 1979).

En la Fig.III.-3 se muestra el ciclo de la enfermedad causada por nematodos del género Meloidogyne. El ciclo empieza en los huevos que se depositaron en suelos infectados. Cuando se dan las condiciones de humedad y proximidad de plantas hospedadoras, en los huevos se desarrollan los nematodos en los estadios llamados juveniles, que en la primera muda van del juvenil I $\left(\mathrm{J}_{1}\right)$ al II $\left(\mathrm{J}_{2}\right)$. En este estadio no se distinguen los machos de las hembras, pero es el estadio que puede vivir libre en el suelo y el único infectivo, capaz de atacar las raíces de su planta hospedadora. Ya en su interior forman las células gigantes de alimentación que darán lugar a las agallas. En la $2^{\mathrm{a}}$ muda en el interior de las agallas se diferencian machos de hembras y se forman los $\mathrm{J}_{3}$. En la $3^{\mathrm{a}}$ muda se dan los $\mathrm{J}_{4} \mathrm{y}$ en la $4^{\mathrm{a}}$ muda ya adultos, el macho sale de la raíz y la hembra forma un saco de huevos que los va liberando al exterior. Mientras, las raíces se han llenado de agallas, las cuales cuando son viejas pueden contener muchas hembras poniendo huevos y causando nuevas infecciones.

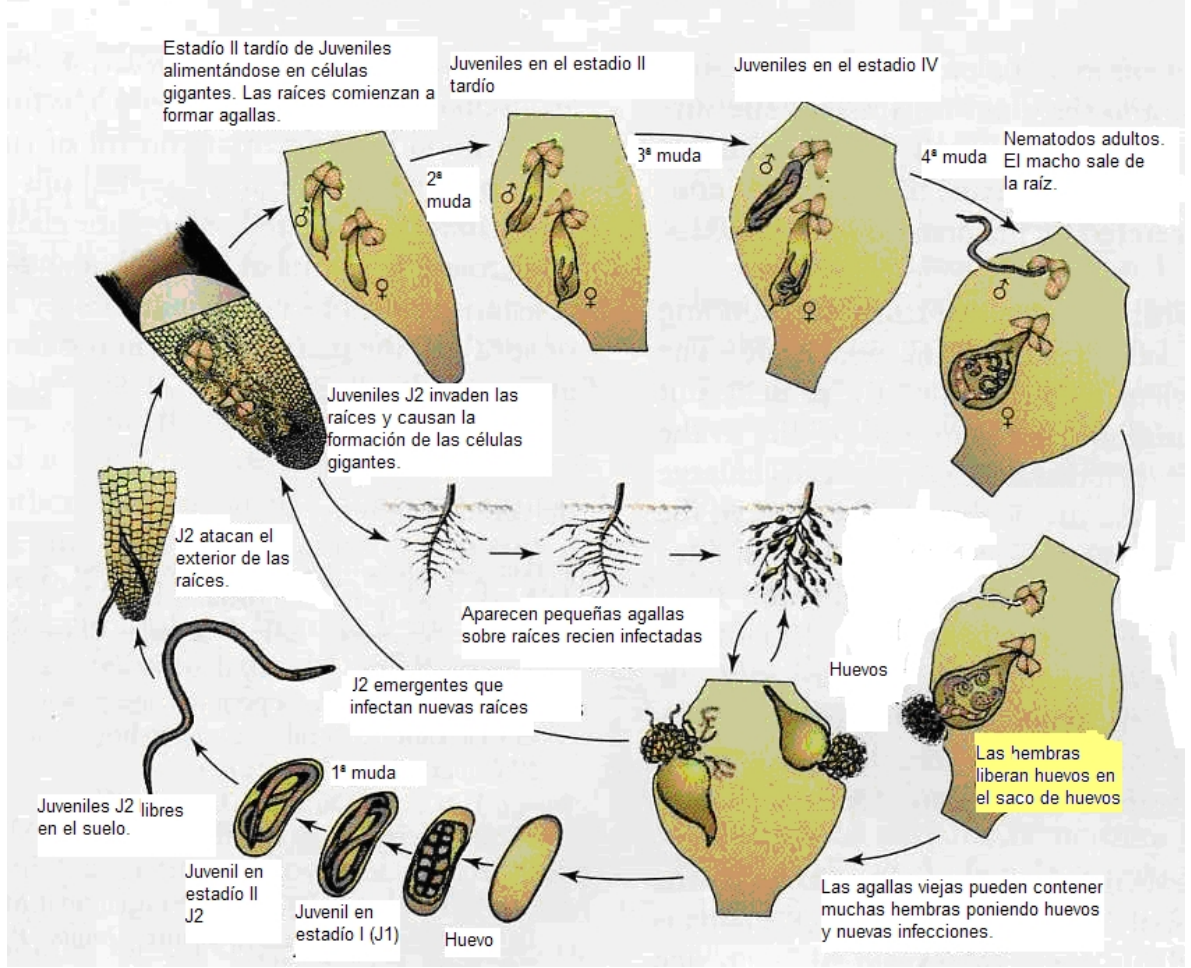

Fig.-III.3.- Ciclo de la enfermedad de la agalla de la raíz causada por nematodos del género Meloidogyne. Agrios, (2005). 
Cuando los nematodos infectan las plantas éstas muestran un pobre crecimiento y son menos productivas pues al afectar el sistema radicular, las raíces son menos eficientes en absorber agua y nutrientes. Además las células radiculares infectadas por nematodos son más susceptibles al ataque de otros patógenos del suelo con una alteración no solo de su pared sino también de su contenido citoplasmático.

Las pérdidas causadas por los nematodos pueden tratarse al fumigar el suelo con productos químicos. El problema es que la mayoría de los nematicidas tienden a ser bastante tóxicos y suelen ser volátiles con poca especificidad y dañinos para la salud animal y el medio ambiente. En los invernaderos, la agalla de las raíces se puede controlar de forma efectiva cuando se esteriliza el suelo con vapor de agua o se fumiga con nematicidas químicos pero hay que recordar que para que den resultado, las fumigaciones deben repetirse en cada estación. También puede ayudar a disminuir las pérdidas debidas a los nematodos prácticas culturales como la rotación de cultivos, la solarización y actualmente la biosolarización que combina ésta con la adición de ciertos compuestos orgánicos como residuos vegetales de diferentes especies de plantas (Chitwood, 2002). Esta práctica ayudaría también a disminuir desechos al reciclar material vegetal residual.

Una forma más segura de control es la utilización de variedades resistentes o el uso de plantas transgénicas que producen inhibidores de ciertas proteinasas de los nematodos, pero estas variedades mejoradas no siempre existen en la mayoría de los cultivos, y finalmente hay otra forma de control biológico o biocontrol en el que se utilizan microorganismos antagonistas de los nematodos para disminuir la eclosión de huevos o el $\mathrm{n}^{\mathrm{o}}$ de $\mathrm{J}_{2}$ infectivos. Entre ellos se ha probado la adición de endosporas de la bacteria Pasteuria penetrans, la cual es un parásito obligado de algunos nematodos parásitos de plantas, o también con preparaciones de hongos como Trichoderma harzianum, Dactylella ovoparasitica o Paecilomyces lilacinus, estos dos últimos conocidos hongos nematófagos que parasitan los huevos de Meloidogyne. También se ha probado la adición de esporas de los hongos de las micorrizas arbusculares Gigaspora y Glomus y actualmente se han obtenido buenos resultados al añadir a suelos infectados aceites esenciales o aminoácidos extraídos de algunas plantas, consiguiendo con ello incrementar la resistencia local o sistémicamente inducida, en las plantas tratadas (Elbadri, 2008; Oka, 2012). 


\section{III.2. El género Capsicum annuum.}

\section{III.2.1. Descripción botánica y taxonomía}

El pimiento es una angiosperma de la familia Solanaceae cuyo nombre científico es Capsicum annuum, Leonian. Reino Plantae. División Magnoliophyta. Clase Magnoliopsida. Familia Solanaceae. Género Capsicum.

En la actualidad se distinguen dos grandes grupos de pimientos en base a sus características morfológicas: plantas de flor morada que incluyen especies silvestres, C. eximium y C. cardenasii junto a la cultivada $C$. pubescens, y plantas de flor blanca silvestre $C$. baccatum y cultivadas $C$. annuum, $C$. frutescens y $C$. chinense (Morrison y col., 1986) siendo estas últimas las de mayor importancia socioeconómica y como fuente de varios elementos nutritivos (Tabla III.1 y III.2). Las plantas del género Capsicum son herbáceas y anuales aunque pueden rebrotar y volver a producir en su segundo año; tienen forma de frutos variables, pero en general tienen forma de baya hinchada (Costa, 1989). Según las características del fruto tales como forma, tamaño, color, sabor y destino comercial, se puede clasificar el pimiento en los siguientes grupos (Maroto, 1989).

- Variedades dulces, suelen tener frutos grandes cuadrangulares 0 rectangulares con una depresión basal, caracterizados por un pericarpio grueso de color rojo o amarillo que se destinan generalmente al consumo en fresco y a la industria de la conserva, por ejemplo, Yolo Wonder, California Wonder, Lamuyo.

- Variedades para la obtención de pimentón, la variedad más utilizada en la región de Murcia es la variedad "bola", posee frutos subesféricos caracterizados por un pericarpio semicarnoso de color rojo.

- Variedades con sabor picante, caracterizadas por poseer frutos largos y delgados con alto contenido de un alcaloide denominado capsaicina (Capsicum pubescens "Chili").

El pimiento, como planta hortícola de amplia difusión, tiene hojas pecioladas, ovales o elípticas en disposición alterna. El sistema radicular es pivotante y alcanza bastante profundidad de 0,5 a 1,25 metros; tiene numerosas raíces adventicias, que en sentido horizontal pueden alcanzar de 0,5 a 1 metro de longitud. Las flores son autógamas, con un pequeño porcentaje de alogamia que no supera el $10 \%$. Para que se produzca la floración, es necesario que la planta tenga un cierto grado de 
madurez, que no se consigue hasta que la planta tiene alrededor de 10 hojas. Los tallos son frágiles y se parten con facilidad, necesitan tutores cuando se cultivan en invernadero. Las flores suelen aparecer solitarias en cada nudo del tallo, en las axilas de las hojas; tienen simetría radiada, con cinco estambres soldados al tubo de la corola, erectos y con pedúnculos cortos.

Hasta la aparición de los cultivos en invernadero, el fruto, fuente de varios elementos nutritivos (Tabla III. 1 y 2), se recolectaba generalmente entre los meses de junio y septiembre. Hoy en día bajo cultivos intensivos se recolecta durante todo el año. El peso y tamaño de los frutos también varía entre las variedades. De los que se cultivan en el invernadero, el peso oscila entre 100 y 250 gramos por unidad. Las semillas son redondeadas de $(2-5 \mathrm{~mm})$ y se insertan sobre una placenta cónica de disposición central. La altura media que alcanzan las plantas de pimientos es variable y puede ir de 0,5 a 1,25 metros y tienen capacidad de adaptarse a distintos tipos de suelos, pero presentan un factor limitante, la temperatura baja, ya que precisa una estación cálida para su desarrollo. El pimiento se utiliza, fundamentalmente, para consumo en fresco, en conserva y como especia (pimentón y oleorresina) para adicionar a salsas y encurtidos, o como materia prima para la obtención de productos farmacéuticos, medicinales o cosméticos. Actualmente se han desarrollado plantaciones específicas atendiendo a su explotación y destino.

Y como hemos señalado y según las características del fruto hay diferentes variedades, (Bailey, 1977) reconoce sólo una especie, Capsicum annuum, mientras que Bosland (1992, 1994) distinguió cinco especies cultivadas: Capsicum annuum (Fig. III. 4 A), Capsicum pubescens (Fig. III. 4 B), Capsicum chinense (Fig. III. 4 C), Capsicum frutescens (Fig. III. 4 D) y Capsicum bacatum (Fig. III. 4 E). 

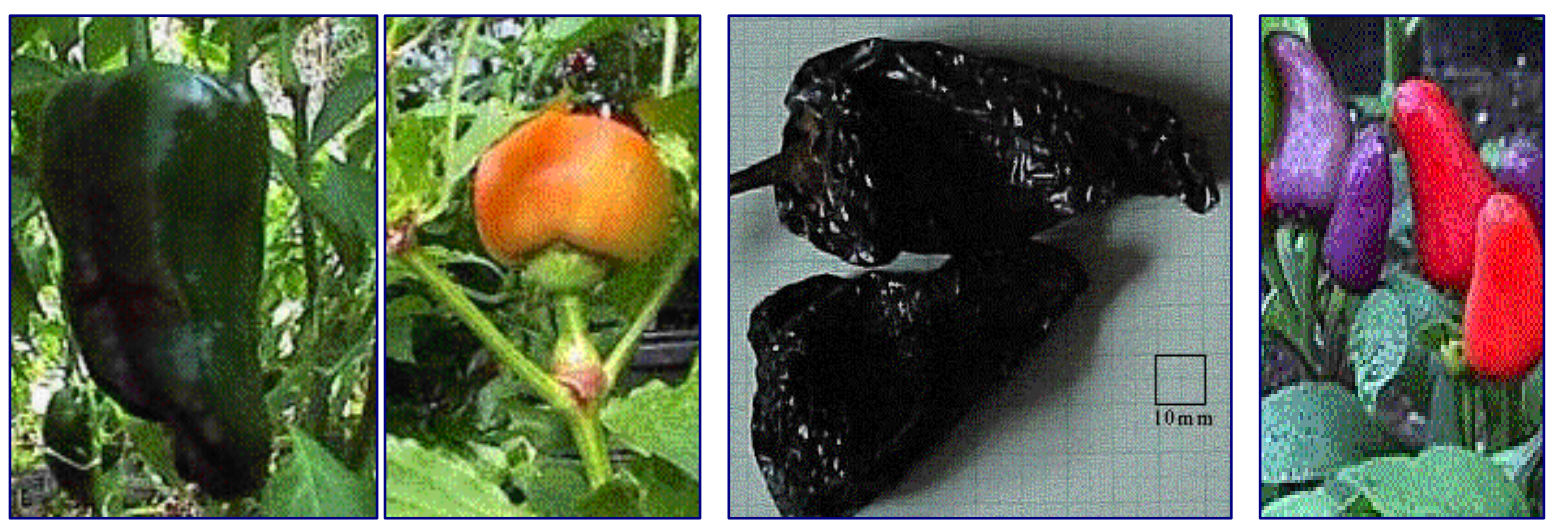

[A]
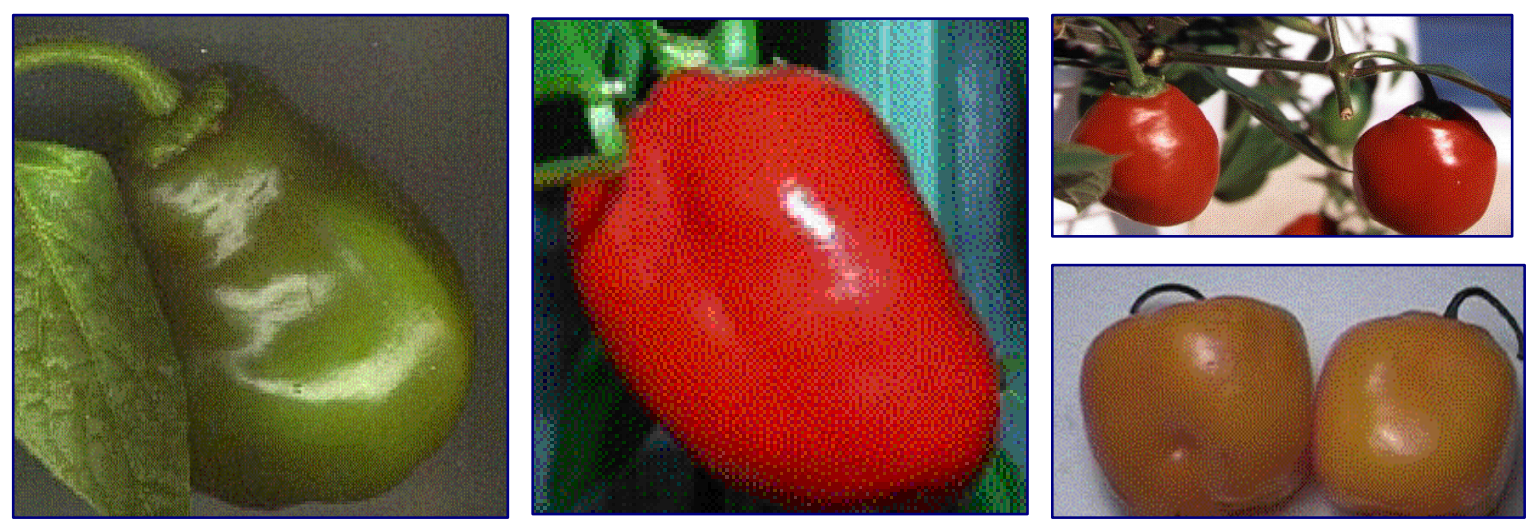

[B]
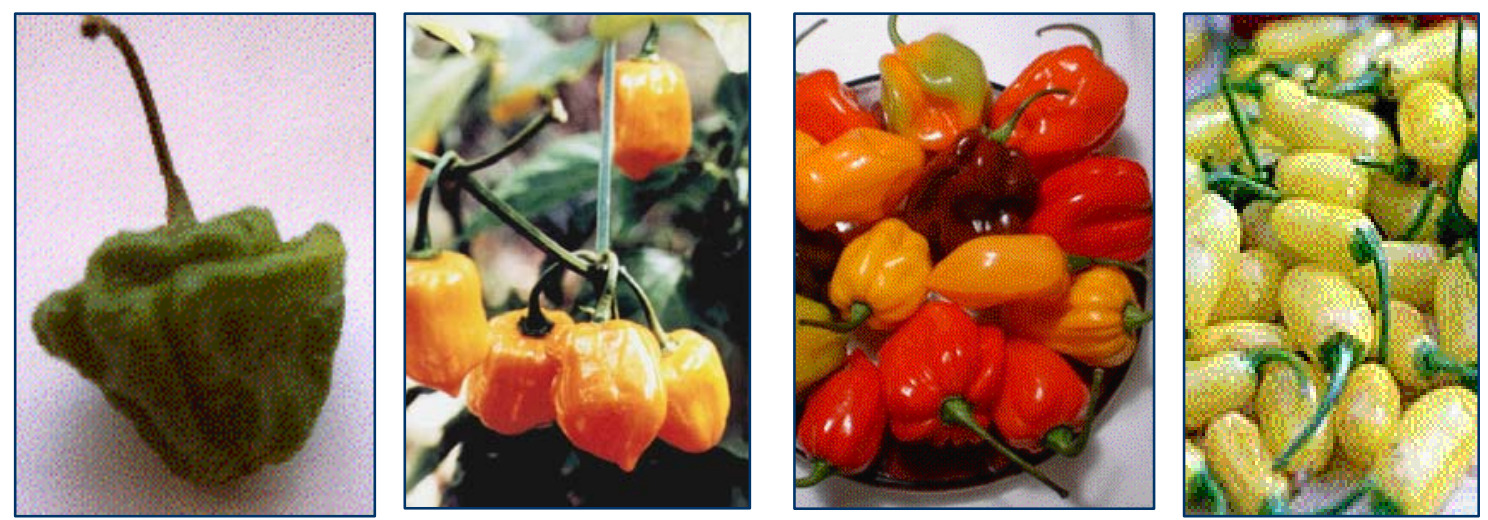

[C]

Fig.-III.4.- Frutos de diferentes variedades de pimiento [A] Capsicum annuum, [B] Capsicum pubescens y [C] Capsicum chinense 

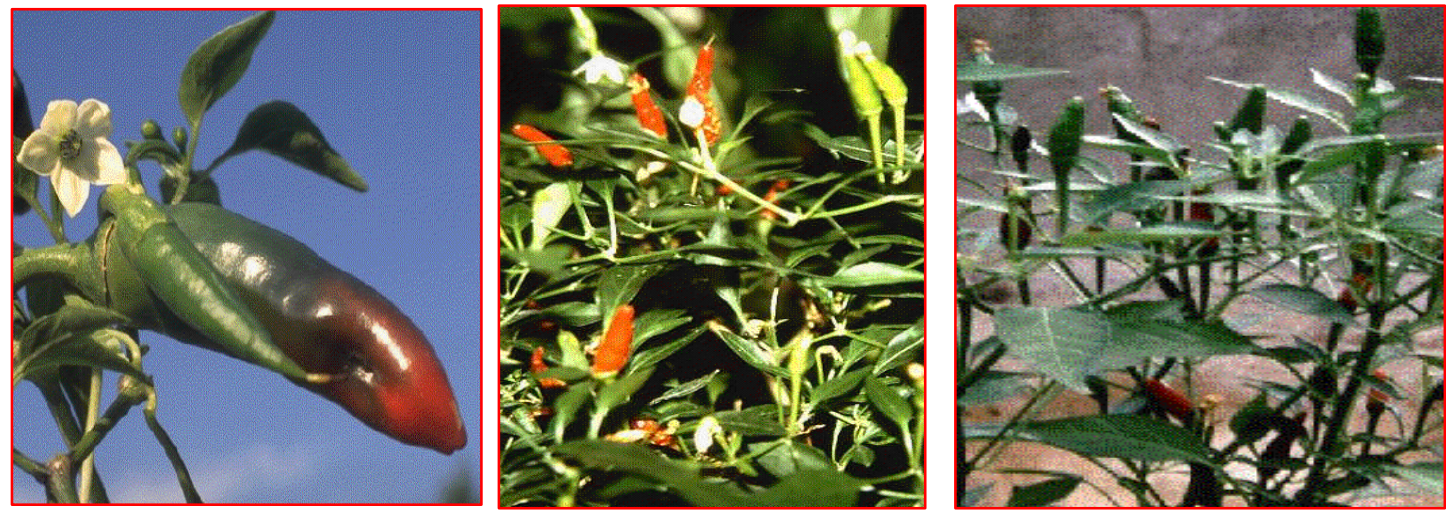

[D]
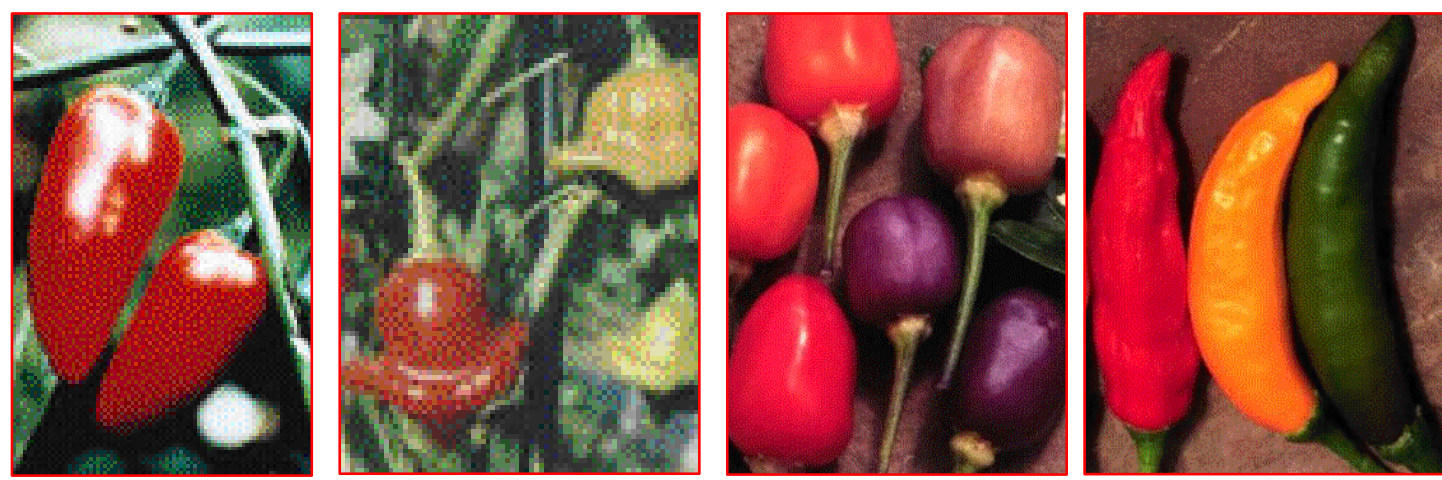

[E]
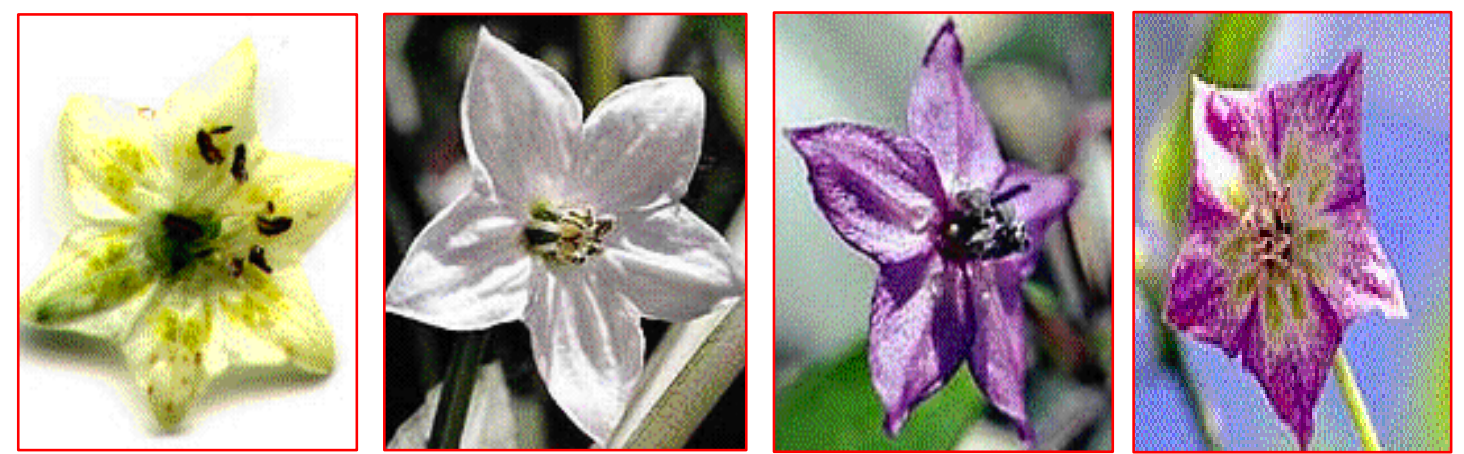

Fig.-III.5.- Frutos de diferentes variedades de pimiento [D] Capsicum frutescens y [E] Capsicum bacatum y algunas flores de pimiento. 


\begin{tabular}{|l|l|l|}
\hline & Capsicum penduolum & Capsicum pubescens \\
\hline Energía & $3,39 \mathrm{Kcal}$. & $30 \mathrm{Kcal}$ \\
Humedad & $8,06 \%$ & $91,96 \%$ \\
Proteínas & $7,37 \mathrm{~g}$ & $1,22 \mathrm{~g}$ \\
Grasas & $4,86 \mathrm{~g}$ & $0,10 \mathrm{~g}$ \\
Carbohidratos & $78,57 \mathrm{~g}$ & $0,26 \mathrm{~g}$ \\
Fibra & $15,64 \mathrm{mg}$ & $1,56 \mathrm{mg}$ \\
Calcio & $145 \mathrm{mg}$ & $18 \mathrm{mg}$ \\
Fósforo & $2,96 \mathrm{mg}$ & $27 \mathrm{mg}$ \\
Hierro & $14,6 \mathrm{mg}$ & $0,7 \mathrm{mg}$ \\
Vitamina A & $401 \mathrm{mg}$ & $41 \mathrm{mcg}$ \\
Vitamina B-1 & $0,25 \mathrm{mg}$ & $0,05 \mathrm{mg}$ \\
Vitamina B-2 & $0,71 \mathrm{mg}$ & $0,23 \mathrm{mg}$ \\
Niacina & $1,64 \mathrm{mg}$ & $0,78 \mathrm{mg}$ \\
Vitamina C & $46 \mathrm{mg}$ & $10 \mathrm{mg}$ \\
Deshechos & $36 \%$ & $19,37 \%$ \\
\hline
\end{tabular}

Tabla III.1.- Valor nutritivo de una muestra de $100 \mathrm{~g}$ de la variedad Capsicum penduolum y Capsicum pubescens.

\begin{tabular}{|l|l|l|l|}
\hline & & $\underline{\text { PV }}$ & $\underline{\text { PRM }}$ \\
\hline \multirow{6}{*}{} & Agua & $93(\%)$ & $88(\%)$ \\
& Energía & $25 \mathrm{Kcal}$. & 40 \\
& Proteínas & $0,9 \mathrm{~g}$ & 2,0 \\
& Lípidos & $0,0 \mathrm{~g}$ & 0,2 \\
& Carbohidratos & $5,3 \mathrm{~g}$ & 9,5 \\
& Fibra & $1,2 \mathrm{~g}$ & 1,8 \\
& $\mathrm{Ca}$ & $6,0 \mathrm{mg}$ & 1,8 \\
& $\mathrm{P}$ & $22,0 \mathrm{mg}$ & 46,0 \\
& $\mathrm{Fe}$ & $1,33 \mathrm{mg}$ & 1,20 \\
& $\mathrm{Na}$ & $3,0 \mathrm{mg}$ & 7,0 \\
& & & \\
& $\mathrm{~K}$ & $195 \mathrm{mg}$ & 340 \\
& $\mathrm{~A}$ & $530 \mathrm{IU}$ & 770 \\
& $\mathrm{~B}_{6}$ & $0,16 \mathrm{mg}$ & 0,28 \\
& $\mathrm{~B}_{1}$ & $0,09 \mathrm{mg}$ & 0,09 \\
& $\mathrm{~B}_{2}$ & $0,05 \mathrm{mg}$ & 0,09 \\
& $\mathrm{~B}_{3}$ & $0,55 \mathrm{mg}$ & 0,95 \\
& $\mathrm{C}$ & $128 \mathrm{mg}$ & 242 \\
\hline \multirow{5}{*}{ Vitaminas } & \multicolumn{2}{|l}{} \\
& &
\end{tabular}

Tabla III.2.- Valor nutritivo de una muestra de $1900 \mathrm{~g}$ de pimiento verde (PV) y rojo New Mixcan (RNM) (Bosland \& Votaca, 1999).

La variedad utilizada en este estudio es California Wonder (Fig.-III.6), pimiento para consumo en fresco; variedad semi-precoz, que produce frutos de forma cuadrada, con $10 \mathrm{~cm}$. de longitud y unos $9 \mathrm{~cm}$. de diámetro. Fruto de color 
verde oscuro brillante y rojo en su madurez, con carne gruesa y dulce. Planta de estación cálida. El trasplante se realiza en surcos separados $70-90 \mathrm{~cm}$ y $25-40 \mathrm{~cm}$. entre plantas.

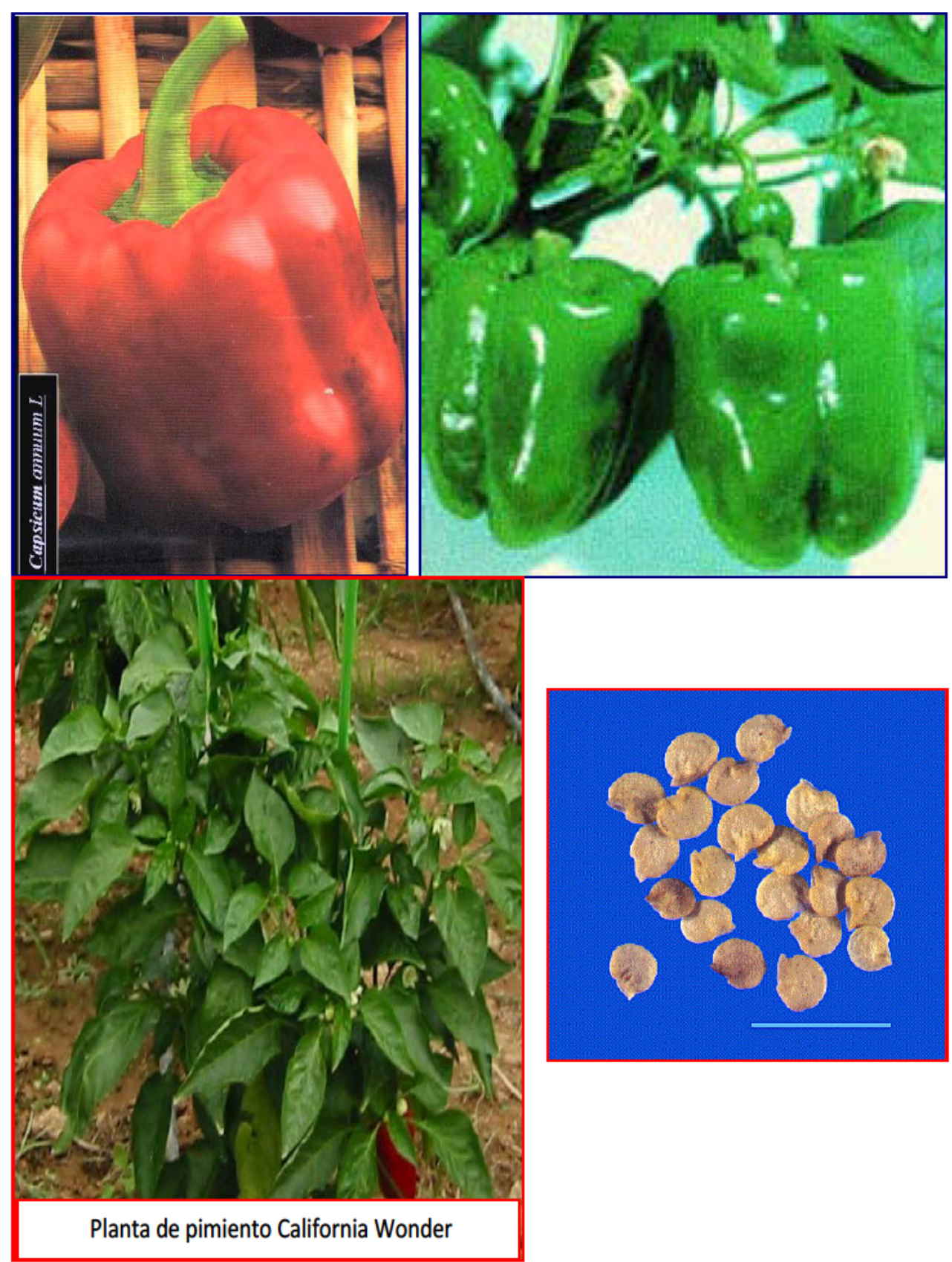

Fig.-III.6.- Frutos, planta y semillas del pimiento California Wonder, estudiada en este trabajo.

La notable sensibilidad de la variedad California Wonder, al nematodo Meloidogyne incognita y su importancia económica nos ha llevado a utilizarla como material vegetal objeto de nuestro investigación en su interacción con el patógeno. 


\section{III.3. Importancia del control agro-ecológico de plagas y enfermedades}

Realmente en Agricultura Ecológica no se puede pretender en ningún caso, eliminar o controlar por completo la plaga o la enfermedad, más que nada porque hasta la fecha, no se ha conseguido una formulación de antagonistas que lo logre, pero sí que se debe pretender mantener unos niveles equilibrados de estas, de tal forma que los daños que provoquen sean asumibles económica y ecológicamente.

A pesar de que todos los elementos se integran para que el desarrollo de plagas y enfermedades esté siempre dentro de los límites señalados anteriormente, estos pueden alterarse por la aparición espontánea de plagas y enfermedades. Los métodos de control que persiguen reforzar el equilibrio del sistema productivo lo hacen en uno o varios aspectos, y tradicionalmente son clasificados en:

1. Control físico

2. Control Biológico

3. Utilización de biopreparados

4. Utilización de productos vegetales

5. Utilización de productos minerales

6. Combinación de varios de los anteriores

En general, los medios de control físico tratan ganar equilibrio reforzando la capacidad de cerrarse el sistema (mallas antimosca o antitrips). Los medios de control biológico pretenden reforzar el equilibrio del sistema mediante un incremento de la complementariedad de los fitófagos (uso de insectos o depredadores) y por último la utilización de biopreparados (formulado de microorganismos beneficiosos), productos vegetales (adición de la materia orgánica) y minerales. Nosotros pensamos que todos los métodos de control pretenden, en realidad, corregir los desequilibrios presentes en el sistema cuando falla el resto de estrategias tanto de manejo como de diseño. 


\section{III.4. El control Biológico de patógenos}

Consiste en la utilización de microorganismos naturales o modificados, para reducir los efectos de organismos indeseables, favoreciendo al mismo tiempo el desarrollo de los organismos útiles para el hombre, plantas y microorganismos beneficiosos. Para lograr el control biológico se pueden seguir tres vías: Exploración en el propio medio de los agentes de biocontrol, introducción o liberación masiva de agentes de control y manipulación del ambiente para favorecer el desarrollo de los antagonistas naturales presentes en el mismo.

Actualmente se admite la definición de control biológico como la enunciada por Baker \& Cook, (1974). Según estos autores " el control biológico es la reducción de la intensidad o las actividades productoras de enfermedades de un patógeno o parásito, en su estado activo de resistencia o reposo, lograda de manera natural o a través de la manipulación del ambiente, del hospedador o de antagonistas del patógeno o plaga que se quiere controlar". Se trata de una definición muy amplia en cuanto al tipo de control fuera del químico y hace referencia a la utilización de microorganismos antagonistas para el control de enfermedades, entendiéndose por antagonistas, aquellos organismos que interfieren en la supervivencia o desarrollo de los patógenos.

No es fácil determinar con precisión los mecanismos que intervienen en las interacciones entre los antagonistas y los patógenos. En general, los antagonistas no tienen un único modo de acción y la multiplicidad de modos de acción es una característica a seleccionar en un antagonista.

Los principales mecanismos mediante los cuales los antagonistas ejercen su acción para controlar el desarrollo de patógenos fueron descritos por Baker \& Cook, (1983).

- Competencia por el espacio o nutrientes: Desigual comportamiento de dos o más organismos ante un mismo requerimiento, siempre y cuando la utilización del mismo por uno de los organismos reduzca la cantidad disponible para los demás. La competencia más común es por nutrientes como la descrita por Droby et al. (1987) que estudiaron el mecanismo antagónico de una cepa de Pichia guilliermondii cuando lo aplicaron sobre heridas de pomelos para controlar el ataque de Penicillium digitatum.

- Antibiosis: Producción de sustancias tóxicas como compuestos tóxicos 
solubles volálites, enzimas y otros agentes que producen lisis por parte de un microorganismo para otros microorganismos (Fravel, 1988). La antibiosis es uno de los mecanismos antagónicos más estudiado entre los microorganismos, pero, sin embargo, no es deseable que sea el único mecanismo de acción de un antagonista porque al igual que con los fungicidas o insecticidas químicos, existe el riesgo de aparición de cepas de patógenos resistentes al antibiótico.

\section{- Interacciones directas con el patógeno:}

* Micoparasitismo y Lisis enzimática:

* Inducción de la resistencia: Recientemente, se demostró que no sólo los patógenos atenuados son capaces de inducir reacciones de resistencia, sino también los microorganismos saprófitos agentes de biocontrol. Varios microorganismos pertenecientes al género Trichoderma, Bacillus y Pseudomonas (Maurhofer y col., 1998; Wei y col., 1996; Yeyidia y col., 1999) usados en el biocontrol de algunas enfermedades de plantas, muestran que se pueden activar los mecanismos de resistencia de las plantas.

Más recientemente, los autores Yang et al., (2007) analizaron los mecanismos patogénicos de los hongos nematófagos y los agruparon en 3 categorías de acuerdo a sus diferentes mecanismos de acción: hongos que atrapan nematodos, hongos parásitos y hongos tóxicos.

Los hongos que atrapan nematodos los capturan por sus estructuras hifales características y penetran en sus hospedadores mediante la degradación enzimática de la cutícula de los nematodos y mediante presión mecánica. Los autores Khan et al. (2006) ensayaron la combinación de dos hongos, Paecilomyces lilacinus y Monacrosporium lysipagum sobre masas de huevos Meloidogyne javanica (Treub) Chitwood sobre tomate. Y concluyen que Monacrosporium lysipagum fue capaz de capturar y matar nematodos migradores como los juveniles y que la combinación de ambos hongos redujo el número agallas y el número de juveniles de $M$. javanica. También varias enzimas extracelulares hidrolíticas están implicadas en el proceso, entre ellas las serin-proteasas, colagenasas y quitinasas, que pueden estar implicadas en la penetración de la cutícula del nematodo y en la digestión de las células del hospedador.

Los hongos parásitos infectan nematodos principalmente por esporas ingestivas o por esporas adhesivas. Los huevos de los nematodos tienen una cáscara 
que es la principal barrera a las infecciones. Las cáscaras de los huevos están compuestas por tres capas: Viteline, la externa, una intermedia de quitina y una interna de lipo-proteína. Antes de la penetración, las esporas y las estructuras de penetración tales como apresorios deben primero adherirse a la superficie de los huevos y en algunos casos, producir un mucílago que hace de adhesivo para ayudar a la penetración de la cáscara del huevo por el hongo. Luego vierten enzimas extracelulares que pueden servir para inmovilizar nematodos y otras para degradar la cutícula del nematodo en las siguientes horas. Los autores Nguyen et al. (2009) purificaron dos quitinasas extracelulares de Paecilomyces variotti DG-3 (hongo que parasita huevos de nematodo). Las enzimas purificadas son monómeros de $32 \mathrm{KDa}$ (Chi32) y 46KDa (Chi46). Chi32 degrada oligómeros de quitina como una quitina tipo exo y Chi46 como una quitinasa tipo endo. Las quitinasas degradan la capa de quitina de la cubierta de los huevos y este es el mecanismo para parasitar en el interior de las células del hospedador. Otras enzimas con actividad quitinasa se han encontrado en Trichoderma y en Bauveria bastiana y también en otros Paecilomyces, y en Verticillium y en Pochonia. Otras enzimas con actividad contra nematodos se han encontrado en Trichoderma por los autores Sharon et al. (2007) que estudiaron el parasitismo de dos especies de Trichoderma (T. asperellum y $T$. atroviride) sobre Meloidogyne javanica y el papel de la matriz gelatinosa. Concluyendo que los huevos y los $\mathrm{J}_{2}$ son paralizados poco después de que se adhirieran los conidios y que la matriz gelatinosa indujo inmovilización de los $\mathrm{J}_{2}$ específica debido a los metabolitos de T. asperellum-203, 44 y los de T. atroviride que inmovilizaron los $\mathrm{J}_{2}$. Las hembras y las masas de huevos fueron parasitadas por T. asperellum-203 lo cual demuestra la actividad de biocontrol de este hongo. Trichoderma spp. produce numerosas enzimas que pueden degradar la capa de proteína-quitina que constituye la cáscara del huevo de $M$. incognita como la Pra1:Serin-proteasa (Suarez, 2004). La Psb1 está implicada en el parasitismo de nematodos por género (Spiegel, 2007) y la SprT: Serin-proteasa sintetizada $T$. pseudokoningii produce el arrugado e inhibición de huevos y mata $\mathrm{J} 2$ de $M$. incognita (Chen, 2009). 


\section{III.5. Interacción nematodo-planta hospedadora}

Son muchas las aportaciones científicas que se pueden encontrar en las bases de datos bibliográficas sobre la interacción entre los nematodos productores de agallas de las raíces y sus plantas hospedadoras. Si queremos actualizar su conocimiento hay que establecer unos hitos clasificatorios de los tipos de estudios y su propósito. En primer lugar, podemos analizar los estudios sobre la relación hospedador-parásito en la enfermedad con diversas plantas hospedadoras.

Los autores Chan \& López (1992) analizaron el efecto de las diferentes densidades iníciales de Meloidogyne incognita sobre el crecimiento del tomate en invernadero durante 65 días. Concluyendo que el índice de reproducción del nematodo varía con la dosis inicial pero no encontraron correlación entre la tasa de reproducción del nematodo y el índice de agallamiento producido en las raíces de tomate.

Casi una década más tarde, los autores Castillo et al. (2001) estudiaron la relación entre la mora blanca con Meloidogyne arenaria y el desarrollo de la enfermedad. Caracterizaron el nematodo patógeno, utilizando observaciones morfométricas, análisis electroforéticos de la esterasa e inoculaciones artificiales de diferentes razas de nematodos. Concluyeron que las agallas inducidas por los nematodos son esféricas y normalmente contienen una o más hembras, machos y masas de huevos. Los sitios de alimentación se caracterizan por el desarrollo de células gigantes con citoplasma granular y núcleos hipertrofiados y que las células del citoplasma gigantes se agregan a lo largo de la pared celular y los tejidos vasculares que aparecen desorganizados. También, midieron la cantidad inicial (Pi) de huevos $+\mathrm{J}_{2} / \mathrm{cm}^{3}$ de suelo en una serie desde 0 a 1024 y relacionaron $P i$ con el peso fresco de la parte aérea y la altura de las plantas de 3 meses.

Los autores Di Vito et al. (2004) estudiaron el análisis de las relaciones hospedador-parásito entre Meloidogyne incognita y espinacas. Analizaron la histología de la infección y las tasas de reproducción, así como la relación entre enfermedad y dosis de inóculo de nematodos. Cuando relacionaron densidades de inóculo inicial y final, a los 50 días de infección, con el peso y altura de las plantas, obtuvieron resultados notablemente diferentes con respecto a los datos obtenidos en otras plantas.

Similares planteamientos realizaron los autores Vovlas et al. (2008) que 
estudiaron la patogenicidad y las relaciones hospedador-parásito de la enfermedad de la agalla de la raíz en apio causada por Meloidogyne incognita. Analizaron la histopatología de las células de las raíces del apio en plantas con amarilleamiento y decaimiento de la parte aérea y gran deformación del sistema radicular y aplicando el modelo de Seinhorst, relacionaron el peso y la altura de las plantas afectadas con la densidad de población de nematodos. Hallaron el límite de tolerancia.

En ese mismo año, los autores Proite et al. (2008) analizaron el desarrollo pos-infección y la histopatología de Meloidogyne arenaria raza 1 sobre tres especies de Arachis spp. consideradas susceptibles, moderadamente susceptibles y resistentes. Comprobaron que la penetración y el desarrollo del nematodo en las especie resistentes es más reducido que en las susceptibles. En las resistentes observaron una reacción hipersensible con formación de zonas necróticas en el cilindro vascular y que no se formaban células gigantes ni tampoco el nematodo se desarrollaba hasta el segundo estado, a diferencia de lo que ocurría en las plantas susceptibles.

Los autores Pegard et al. (2004) analizaron las características histológicas de resistencia a 3 especies de nematodos productores de la agalla de la raíz, $M$. arenaria, $M$. incognita y $M$. javanica, en relación con la acumulación de compuestos fenólicos en Capsicum annuum. Sugirieron que los compuestos fenólicos como el ácido clorogénico pueden estar implicados en la resistencia de CM334 cuando analizaron estos compuestos por HPLC. Después de comparar sus datos con los publicados, concluyeron que el tiempo en el inicio de la respuesta defensiva y el mecanismo de resistencia, varían con el genotipo del pimiento, con los genes de resistencia $\left(\mathrm{Me}_{1}, \mathrm{Me}_{3}\right.$ etc.) y con la especie de nematodo.

Los autores Djian-Caporalino et al. (2007) analizaron conocidos genes de resistencia de especies de Capsicum a Meloidogyne spp. Algunos genes (Me4, Mech1 y Mech2) son específicos para ciertas especies o poblaciones de Meloidogyne, mientras que otros (Me1, Me3 y Me7) son efectivos contra un amplio rango de especies del nematodo incluyendo, $M$. arenaria, $M$. javanica y $M$. incognita que son las especies más comunes de Meloidogyne en el mediterráneo y en áreas tropicales. Concluyendo que estos genes son los responsables de las diferentes respuestas en las células radiculares y dependen de la línea de pimientos y de la especie del nematodo. 
Los autores Caillaud et al. (2008) revisaron las investigaciones con base molecular más recientes sobre la interacción planta-nematodos de la agalla de la raíz, constatando que la producción de las grandes células de alimentación es la base del éxito para el desarrollo del nematodo y probablemente lo hacen manipulando elementos fundamentales del desarrollo de las células vegetales.

Otro hito consiste en los estudios de interacción entre el nematodo patógeno y hongos micorrícicos. Los autores Karssen et al. (1995) desarrollaron dos métodos para identificar especies de Globodera y de Meloidogyne usando electroforesis en geles de poliacrilamida (PAGE). Las proteínas de quistes de Globodera se identificaron usando isoelectroenfoque (IEF) y tinción con plata y las proteínas de hembras jóvenes de Meloidogyne se separaron usando PAGE en diferentes gradientes y tinción enzimática con las isoenzimas específicas para Meloidogyne, estearasa y malato deshidrogenasa.

Los autores Estañol et al. (1999) analizaron la interacción entre Meloidogyne chitwoodi y tres especies del hongo micorrícico Glomus sp. con respecto a su incidencia en la producción de maíz medido como materia seca de plantas jóvenes. Concluyendo que las especies de los hongos micorrícicos probados, prácticamente no colonizaron las variedades de maíz e incluso comprobaron que la producción de materia seca disminuyó, aunque al combinar los hongos con el nematodo, la presencia del hongo hace que el número de hembras presentes en las raíces del maíz sea menor que sin la adición de las micorrizas.

Los autores Castillo et al. (2006) investigaron la protección de plantones de olivos contra el nematodo de la agalla de la raíz, al inocular las plántulas con los hongos micorrícicos como Glomus intraradices, G. mosseae o G. viscosum. Concluyendo que el establecimiento de la simbiosis produce un mayor crecimiento de las plantas y reduce la severidad de las agallas en las raíces así como la reproducción de los nematodos.

Los autores Cortada et al. (2008), analizaron la respuesta de 10 rizomas de tomate (con el gen $\mathrm{Me}$ de resistencia a nematodos), a un inóculo de una raza de Meloidogyne javanica que es avirulenta al Me. La presencia del locus Mi en los rizomas y cultivares resistentes se confirmó usando PCR con los marcadores codominantes REX-1 y Mi23. Vieron que había una gran variabilidad de la inefectividad de los nematodos (masa de huevos) y también fue muy variable la 


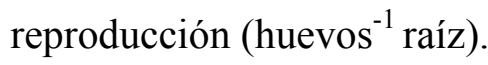

Un tercer hito consiste en los estudios del nematodo, su establecimiento en el suelo, su migración o su cultivo para inocular. Los autores Hussey \& Barker (1973) realizaron un estudio comparativo de 5 métodos para preparar inóculo de especies de Meloidogyne y llegaron a la conclusión de que el mejor método es obtener huevos de las masas de huevos, disueltas con $0,53 \%$ o $1,05 \%$ en hipoclorito de sodio $(\mathrm{NaOCl})$. Los huevos así aislados funcionan mejor como inóculo que las larvas, que los fragmentos de masas de huevos o que los recogidos por centrifugación, pues la separación mecánica disminuye el nivel de infección.

Los autores Bailey et al. (2008) estudiaron la dinámica de la patozona de $M$. incognita en la rizosfera de plantas de tomate en presencia o ausencia del hongo nematófago Pochonia chlamydosporia. Comprobaron que la probabilidad de la infección no es constante dentro de la patozona sino que depende de la distancia entre el inóculo y la planta hospedadora.

También, los autores Wesemael \& Moens (2008) analizaron la distribución vertical del nematodo Meloidogyne chitwoodi en varias plantas y bajo condiciones de campo con el objeto de adquirir conocimiento de su movilidad en la rizosfera y desarrollar una adecuada estrategia de muestreo. Concluyeron que a $30-40 \mathrm{~cm}$ de profundidad es donde se concentra la mayor cantidad de nematodos pero también se puede encontrar nematodos a los $70 \mathrm{~cm}$ y que para obtener unos datos repetitivos, el análisis de las muestras de nematodos debe realizarse inmediatamente después de la cosecha, sobre todo cuando ha sido un cultivo largo.

Para obtener y cuantificar nematodos hay diversos métodos según los autores Mashela et al. (2007) si se utilizan huevos (limpios y desinfectados con $\mathrm{NaOCl}$ al $1 \%$ ) pero ya incubados durante 5 días, se pueden obtener los $\mathrm{J}_{2} \mathrm{y}$ así la inoculación es más segura, pudiéndose utilizar unos $6800 \mathrm{~J}_{2}$ para obtener el mismo efecto que los 10.000 huevos. El método de eclosionar los huevos lo obtienen de una modificación del de Baermann según (Hussey \& Barker, 1973; Rodríguez-Kábana \& Pope, 1981).

Otros autores utilizaron la inmersión de todo el sistema radicular en una solución de 0,1g/1 de Erioglucine de Aldrich Chemical Company durante dos horas (Omwega et al., 1988) para medir las masas de huevos que se tiñen de azul. Para determinar el número de huevos por planta se extraen los huevos de dos 
submuestras de raíces de 10 gr, mediante su inmersión en una solución de $\mathrm{NaOCl}$ al $5 \%$ durante diez minutos. Los huevos se expresan por gramo de peso fresco.

Otra técnica para teñir por tamizado del suelo las masas de huevos de Meloidogyne incognita es la de Dickson \& Struble (1965). Se le pasa una corriente de agua para desalojar y suspender las masas de huevos contenidas en diferentes porciones de suelo y se usa Phloxine B que tiñe la matriz gelatinosa de alrededor de los huevos de color rojo brillante con lo que se puede distinguir las masas de huevos de otro material.

\section{III.6. Agentes de biocontrol Paecilomyces lilacinus y \\ Trichoderma harzianum.}

\section{III.6.1. Trichoderma harzianum}

Hace más de dos décadas que se está investigando intensamente en la utilidad de diversos microorganismos tales como Trichoderma spp., Bacillus spp., Pseudomonas spp., Aspergillus spp. Paecilomyces spp. etc. para reducir los daños causados por los patógenos en los cultivos, tales como los nematodos, sin el empleo abusivo de productos químicos, y con ello el gran impacto medio ambiental que estos ocasionan.

Los autores Ghisalberti y Sivasithamparam (1991) han hecho una revisión de los compuestos antimicrobianos producidos por Trichoderma spp. Desde 1971 en que Denis y Webster describieron las propiedades como antagonista de Trichoderma, en términos de producción de compuestos antimicrobianos. Se ha demostrado que las especies de este hongo producen compuestos volátiles y novolátiles capaces de inhibir el crecimiento miceliar de un gran número de hongos y que las sustancias antifúngicas varían con el aislado. Se vio que los aislados activos estaban asociados con un olor a coco identificado como 6-n-pentil-2H-pyran-2-one (6PP,1). También se identificaron antibióticos volátiles como carbon-dioxide y etanol. En medio líquido también se ha encontrado la producción de los compuestos: 1,2 pentaketidos; 3,4, 5 y 6 octaketidos; 7 y 8 desconocidos; 9, 10, 11 y 12 aminoácidos y 13 y 14 péptidos.

Numerosos trabajos describen a distintas razas de Trichoderma como un hongo colonizador del sistema radicular de las plantas que produce una interacción 
en la rizosfera, lo que conduce a un desarrollo elevado del sistema radicular y de la parte aérea y consecuentemente a una elevación de la productividad de la cosecha (Meera et al., 1994). Y también se ha descrito la inducción de resistencia sistémica en la planta (Yedidia et al., 1999).

Los autores Sharon et al., (2001) evaluaron al hongo Trichoderma harzianum sobre el control del nematodo agallador de las raíces Meloidogyne javanica, en tomate. Cuando al suelo de cultivo se le hizo un pre-tratamiento con preparaciones de Trichoderma-turba-salvado, las agallas se redujeron y el peso fresco de la parte aérea de los tomates infectados con nematodos se incrementó. Además, concluyeron que los tratamientos del suelo con Trichoderma afectaban a la penetración del nematodo en las raíces, más que al desarrollo del nematodo en el interior de la raíz.

También, los autores Siddiqui \& Shaukat (2004) analizaron plantas de tomate infectadas con $M$. javanica con el propósito de determinar la influencia de $T$. harzianum sobre la actividad de biocontrol que ejerce la bacteria Pseudomonas fluorescens (raza CHAO) y un compuesto que ésta produce 2,4diacetylphloroglucinol (DAPG) contra $M$. javanica. Cuando el medio de cultivo de $P$. fluorescens se enmendó con filtrados de T. harzianum (CF) o con extractos metabólicos de $\mathrm{CF}$ en suelo de arena -arcilla causó una gran reducción en la densidad de la población de nematodos en las raíces de tomate. Por lo que concluyeron, que el antagonista $T$. harzianum mejora el biocontrol sobre el nematodo agallador de la raíz que lleva a cabo la rizobacteria antagonista $P$. fluorescens tanto in vitro como bajo condiciones de invernadero.

Unos años más tarde, los autores Sikora et al. (2007) demostraron que el control biológico usando microorganismos endofíticos es altamente eficiente cuando se usa contra endoparásitos sedentarios y migratorios, los cuales completan su ciclo de vida en el interior de la planta hospedadora, como los nematodos tipo Meloidogyne spp.

Otra vertiente de estudios sobre Trichoderma como agente de biocontrol de nematodos ha sido la caracterización de enzimas extracelulares involucradas en la infección contra nematodos diferenciándose en dos clases, en función de sus propiedades bioquímicas. Clase I: proteasas de hongos que atrapan nematodos y Clase II proteasas de hongos parasíticos. El hongo T. harzianum parasita huevos y 
larvas de $M$. incognita. Las hifas penetran en los huevos y en las cutículas de las larvas mediante la disolución de capas de quitina por acción enzimática de las quitinasas. El hongo también puede proliferar en el interior del organismo y producir metabolitos tóxicos (Dos Santos et al., 1992). Los enzimas producidos por T. harzianum tales como glucanasas, quitinasas y proteasas, parece que juegan un importante papel en el parasitismo (Haran et al., 1996).

Las colagenasas son enzimas que pueden catalizar la hidrólisis de colágeno y gelatina y el colágeno es el principal constituyente de la cutícula del nematodo (Blaxter y Robertson, 1998). La colagenasa producida por ciertos hongos juega un importante papel en la infección contra nematodos, pero las publicaciones sobre producción de colagenasa por hongos nematófagos son muy raras. Entre ellas están los Arthrobotrys spp (Tosi et al., 2001). Otras enzimas hidrolíticas implicadas en la infección de nematodos por hongos son las que tienen actividad lipolítica y degradan la capa de lípidos (Perry y Trent, 1986).

Los autores Suarez et al., (2004) trabajaron en la caracterización de enzimas hidrolíticas producidas por T. harzianum CECT 2413 obteniendo la secreción de varias enzimas hidrolíticas inducidas bajo condiciones de antagonismo. En cultivos con quitina hallaron una proteína mayoritaria que llamaron PRA1 y una vez aislada, fue caracterizada como proteasa-serina con actividad tripsina. Cuando se adicionó PRA1 pura a huevos de $M$. incognita el número de eclosiones se redujo significativamente, pero este efecto nematicida se mejoró cuando se usó filtrados del cultivo del hongo. Los resultados sugieren que las proteínas presentes en los filtrados del cultivo de T. harzianum son responsables de la degradación de la capa de proteína-quitina en las cáscaras de los huevos, lo que afecta al desarrollo embriogénico normal de $M$. incognita. Estos datos refuerzan la teoría de que la actividad anti-nematodo principal de los Trichoderma spp. tiene lugar en el suelo y no en el interior de las raíces (Brants et al., 2000).

También, los autores Siddiqui et al. (2005) estudiaron el biocontrol del nematodo $M$. incognita en tomate usando la bacteria Pseudomonas fluorescens mutada en el gen AprA (que codifica una proteasa extracelular) y encontraron que supernadantes de cultivos de la cepa CHA0 inhibían la eclosión de huevos e indujeron la mortalidad de juveniles del nematodo con lo que concluyeron que la proteasa AprA contribuye al biocontrol. 
Más recientemente, los autores El-Hasan et al., (2009) identificaron un compuesto antifúngico de un aislado de T. harzianum, el Viridiofungin A, así como otros metabolitos antifúngicos que tenían actividad en diferentes patógenos de plantas.

Para analizar el potencial de especies de Trichoderma para controlar nematodos los autores Yang et al. (2010) evaluaron 329 aislados y uno de ellos el vertido de la raza YMF1.02647 vieron que era el que causaba más del 90\% de mortalidad. La identificación del compuesto nematicida (que extraen con acetato de etilo) resulta ser Trichodermin de acuerdo a los datos espectroscópicos.

Otra clase de estudios realizados por diferentes autores ha sido el uso de una combinación de diferentes antagonistas para el control de nematodos. Los autores Meyer et al. (2000) utilizaron la bacteria Burkholderia cepacia (raza Bc-2) y el hongo Trichoderma virens (raza Gl-3) para analizar su actividad contra el nematodo Meloidogyne incognita. Usaron filtrados de cultivo de Bc-2 y Gl-3 que contenían factores extracelulares y comprobaron que se inhibo la eclosión de huevos y la movilidad de los J2. Fraccionamientos por tamaño de los factores analizados demostraron que no existía actividad quitinasa o proteasa de los filtrados de los cultivos de Bc-2 y Gl-3, sugiriendo que los factores inhibitorios en los ensayos in vitro eran no-enzimáticos. En conclusión, la bacteria viva no disminuye los huevos $+\mathrm{J} 2$ pero sí extractos de su medio de cultivo esterilizados.

Los autores Loganathan et al. (2010) testaron los efectos de la aplicación de varios agentes de biocontrol: Trichoderma spp. (8 aislados), Pseudomonas fluorescens (4 aislados) y Bacillus subtilis (2 aislados) contra el hongo de la pudrición de la cabeza, Sclerotinia sclerotiorum y contra el nematodo de la agalla de la raíz Meloidogyne incognita. Estudios in vitro demostraron que 3 aislados de Trichoderma inhiben el micelio del hongo así como que tienen habilidad para eclosionar huevos del nematodo. La mezcla del bioformulado (agentes de biocontrol en una formulación de talco) con quitina redujo la incidencia de la enfermedad por Sclerotinia y por el nematodo además de aumentar la productividad en condiciones de campo. El mecanismo asociado a la reducción de la incidencia se puede asociar a la inducción de proteínas de defensa (PAL, PO: peroxidada, PPO: polifenoloxidasa y quitinasa).

También, se han realizado estudios de combinaciones de antagonistas con 
extractos de plantas, como los trabajos realizados por Rao et al. (1997). Estos autores, utilizaron tortas de Neem (Azadiracha indica) y el hongo T. harzianum, solos y en combinación, contra el nematodo $M$. incognita en tomate. Cuando se usaron en combinación, enmendando el suelo, se obtuvo un significativo incremento en el crecimiento de las plantas y en la reducción de las agallas sobre las raíces de tomate y también una significativa reducción de la población final del nematodo comprobando el favorable efecto de la enmienda del suelo con Neem sobre el crecimiento del hongo de biocontrol T. harzianum.

Un año más tarde, los mismos autores, Rao et al. (1998), utilizaron extractos acuosos de Neem (Azadiracha indica,) castor (Ricinus communis) y pongamia (Pongamia pinnata) junto con el hongo T. harzianum, solos y en combinación, para evaluar la eficacia de esas plantas como sustratos para producir masa del agente de biocontrol T. harzianum contra el nematodo M. incognita. Concluyeron que el extracto acuoso al 5\% de neem dio la concentración más elevada de masa de $T$. harzianum. Si además de extractos de neem al 10\% se añadían al suelo con detergente $\left(0,5 \mathrm{ml}\right.$ de teepol a $500 \mathrm{ml}$ de suspensión de esporas con 9.9 $\times 10^{3}$ esporas $/ \mathrm{ml}$ ) se obtuvo, a los 30 días, un aumento de la altura de las plantas y el peso debido a la colonización de raíces por T. harzianum. También se analizaron otras plantas contando el $\mathrm{n}^{\mathrm{o}}$ de agallas y el $\mathrm{n}^{\mathrm{o}}$ de hembras parasitadas por el hongo, obteniéndose que la mejor combinación fue castor (Ricinus communis)+ T.harzianum que redujo el $\mathrm{n}^{\mathrm{o}}$ de agallas al $57 \%$.

Los autores Shaban \& El-Komy (2000) usaron conidios de Trichoderma harzianum y de T. pseudokoningii (Rifai) para hacer pellets de alginato con o sin $10 \%$ de celulosa como materia base alimenticia. Las formulaciones se compararon respecto a la habilidad de Trichoderma para sobrevivir y proliferar en un suelo lodo-arcilloso ( $50 \%$ de contenido de humedad) con fumigaciones de alcohol alílico $(0,05,0,1$ y $0,2 \mathrm{ml} / 1000 \mathrm{ml}$ de extensión). Para aislar y contar los aislados de Trichoderma recogido del suelo se utilizó el medio de Trichoderma E (TME) de Papavizas \& Lumsden (1982) que contiene $200 \mathrm{ml}$ de jugo V8, $1 \mathrm{~g}$ de glucosa y completado hasta 1 litro de agua destilada a la que se le agrega $6 \mathrm{ml}$ de $\mathrm{NaOH} 1 \mathrm{~N} \mathrm{y}$ el fungicida: penta-cloro-nitrobenceno (PCNB) autoclavado. También realizaron una experiencia para contrastar el número de Trichoderma utilizando el medio Czapek-glucosa conteniendo Rosa de bengala a una concentración de 1:5000. Los 
resultados que se obtuvieron mostraron que los efectos promotores de Trichoderma para dosis diferentes del alcohol arílico fumigado, aumentan después de un período de incubación de dos meses. Los conidios atrapados en alginato con o sin celulosa e introducidos en el suelo, sobreviven mejor que los conidios agregados directamente al suelo después de un período de incubación de tres meses. El suelo estéril proporciona un medio ambiente más favorable para la proliferación y supervivencia de los conidios inmovilizados con respecto al suelo no estéril y la adición de celulosa al 10\% aumenta la supervivencia de los conidios atrapados más que los preparados $\sin$ celulosa. La fumigación del suelo inhibe la presencia de otras especies fúngicas, sin embargo, la inoculación del suelo con alginato inmoviliza conidios o suspensiones conidiales que tuvieron tal efecto inhibidor, pero en menor extensión.

Un análisis de la combinación de los bioagentes Glomus mosseae y $T$. harzianum y del pesticida Furadan sobre la reproducción y el potencial infectivo de M. incognita sobre Pogostemon cablin (patchouli) han concluido que el nematodo reduce considerablemente el resultado del aceite esencial del patchouli. Con los tratamientos con $T$. harzianum se consigue un aumento del crecimiento, de la biomasa y de aceite de patchuli Los post-tratamientos con Trichoderma producen una reducción considerable de $M$. incognita en comparación con los tratamientos con Furadan. G. mossease también actúa bien pero es menos efectivo que Furadan. T. harzianum se puede considerar adecuado para reducir la enfermedad de la agalla de la raíz en $P$. cablin. Los tratamientos con G. mosseae (10 clamidosporas/ g de suelo) y T. harzianum ( $2 \times 10^{8} \mathrm{CFU} / \mathrm{g}$ de suelo), se hacen añadiéndolos al suelo antes del transplante y la infección se hace con 1000 juveniles J2 de M. incognita, recién eclosionados, por maceta a la semana del transplante. Los resultados se miden a los 120 días de la inoculación y aunque T. harzianum reduce la infección, es mejor el Furadan (Pandey, y col., 2009).

Se ha realizado el estudio de los efectos de 5 aditivos sobre el nematodo Meloidogyne incognita y sobre el hongo Fusarium oxysporum que ocasionan agallas y marchitamiento, respectivamente, sobre la planta Vigna radiata (Haseeb et al, 2005). Los aditivos fueron: 2 productos químicos: CARBOFURAN (a 1mg/kg de suelo), y BAVISTIN (a $1 \mathrm{mg} / \mathrm{kg}$ de suelo), 1 de semillas trituradas de Neem (Azadirachta indica) (a $50 \mathrm{mg} / \mathrm{kg}$ de suelo), 1 del hongo T. harzianum (a $50 \mathrm{ml} / \mathrm{kg}$ 
de suelo) y 1 de la rizobacteria Pseudomonas fluorescens (a $50 \mathrm{ml} / \mathrm{kg}$ de suelo). Los resultados muestran que todos los tratamientos mejoran el crecimiento de la planta pero que especialmente el carbofuran y las semillas de $A$. indica produjeron más rendimiento en comparación con Bavistin y P. fluorescens. Carbofuran fue el de mayor efectividad contra el nematodo y Bavistin contra el hongo. Para preparar el inóculo de T. harzianum (mantenido en PDA a $27^{\circ} \mathrm{C}$ ), se prepara el sustrato de semillas de sorgo. Semillas sanas se sumergen en una solución al $5 \%(\mathrm{~m} / \mathrm{V})$ de sacarosa y se dejan 16 horas, luego se cuelan y se ponen en un erlenmeyer de 500 $\mathrm{ml}$ obteniéndose $200 \mathrm{~cm} 3$ de semillas de sorgo/ frasco. Estos se esterilizan en autoclave y se inoculan con 1 disco de $T$. harzianum crecido en PDA y recogido de la periferia de cultivos de 5 días en crecimiento activo. Se ponen en un incubador a $27^{\circ} \mathrm{C}$ y se deja que crezca el hongo con agitación periódica de los matraces para que la superficie de todas las semillas de sorgo se colonicen con más de $10^{8} \mathrm{CFU} / \mathrm{g}$ de cultivo. Para la experiencia se usaron macetas de $18 \mathrm{~cm}$ de diámetro rellenas con mezcla autoclavada de suelo areno-arcilloso (70\% arena, $22 \%$ seda y $8 \%$ arcilla a pH: 7,5)-compost (4:1). En los experimentos, se usa el suelo autoclavado al que se le añade el tratamiento de químicos o microorganismos y se siembra una semilla por maceta. A los 4 días cuando las plántulas tienen dos hojas verdaderas, se inoculan con $2000 \mathrm{~J} 2$ de $M$. incognita y con $2 \mathrm{ml}$ de suspensión de esporas de $F$. oxysporum, en agujeros de $1 \mathrm{~cm}$ hechos alrededor de la base de la planta y luego tapados con suelo. Los resultados se miden a los 60 días de la inoculación.

Cuando se analizan diferentes aislados de Trichoderma para utilizarlos como agentes de biocontrol contra nematodos parásitos de plantas, los autores Spiegel et al. (2007) utilizaron 7 aislados, escogidos en función de su modo de acción y encontraron que todos biocontrolan al nematodo agallador de la raíz $M$. incognita. La actividad nematicida se examinó in vitro, en cámaras de crecimiento y en micro-macetas con 3 cultivos: pepino, lechuga y tomate. Todos los aislados incrementan el peso fresco de las plantas y reducen el índice de agallamiento. $T$. harzianum coloniza J2 y huevos del nematodo y también coloniza los agujeros que realizan los $\mathrm{J} 2$ al penetrar las raíces. Las masas de huevos cubiertas con la matriz gelatinosa y las hembras en las raíces, también son colonizadas por el hongo. Se demuestra que la proteinasa Prb1 y otras proteasas están implicadas en el parasitismo del nematodo, así como también en la inducción de actividad 
quitinolítica durante el parasitismo sobre los huevos de nematodos y las masas de huevos.

Cuando Bokhari (2009) estudió la eficacia de especies de Trichoderma para controlar nematodos, analizando filtrados de cultivo del antagonista, concluye que todos los filtrados del cultivo de Trichoderma son eficaces para controlar los nematodos que infectan las berenjenas. In vitro la reducción de las hembras y las masas de huevos es significativa en una semana e in vivo, la adición de los filtrados fue más significativa sobre los huevos que sobre las larvas, lo cual quiere decir que la acción del hongo consiste en producir metabolitos tóxicos e inhibir la penetración del nematodo y su desarrollo.

Otra forma de luchar contra $M$. incognita es la realizada por Sögüt y Elekçioglu (2007) que analizaron el efecto de la solarización del suelo (durante seis semanas, de Julio a Septiembre) junto con la adición de Trichoderma, el fungicida Dazomet (400 kg/ha) o estiércol fresco de pollo (12 t/ha) como alternativas al Bromuro de metilo. Las experiencias las realizaron en Turquía sobre pimientos, en invernaderos con infección de 105-1513: J2 por $50 \mathrm{ml}$ de suelo. La solarización del suelo durante seis semanas hizo que se elevara la temperatura del suelo $8,4{ }^{\circ} \mathrm{C}$ (de 32,2 a 42,3) a una profundidad de $10 \mathrm{~cm}$. Concluyen que la infección de los nematodos se controló eficientemente hasta el 16 de Mayo mientras que en suelo no tratado empezó a subir a partir de Febrero y que ni los rendimientos de pimientos ni el coste de los tratamientos fueron significativamente diferentes con respecto a los obtenidos al usar Bromuro de metilo.

La utilización de bioagentes fúngicos para combatir la enfermedad del agallamiento de raíces en tomate provocada por el nematodo $M$. incognita ha sido estudiada por Goswami et al. (2008). Usaron hongos aislados de huevos infectados por el nematodo como Acremonium strictum y T. harzianum. También utilizaron otros bioagentes como Aspergillus niger, P. lilacinus y Rhizoctonia solani. Concluyen que A. niger es tóxico contra el nematodo mientras que A. strictum y $T$. harzianum son capaces de parasitar huevos y también ser oportunistas con propiedades tóxicas. Confeccionan un formulado de polvo de talco que lleva esporas de los antagonistas que primero crecen en PDB sobre los que se añaden granos de sorgo esterilizados $+5 \%$ de dextrosa. Estos se secan y se le añade $5 \%$ de carboximetil celulosa que se tritura hasta un polvo de talco que contiene $2 \times 10^{8}$ 
cfu/gramo de los hongos antagonistas. En los ensayos sobre eclosión de $\mathrm{J}_{2}$, en el control eclosionan un total de 280 huevos $\left(\mathrm{J}_{2}\right)$ y con el filtrado de A. strictum, 57 que representa una disminución del $79.6 \%$ de huevos eclosionados. Con $T$. harzianum eclosionan 162, con P. lilacinus 140 , con A. niger 88 y con las mezclas, A. strictum+T.harzianum 60, y con T.harzianum $+P$. lilacinus 90. En los ensayos sobre plantas lo más eficiente es el uso de la combinación $T$. harzianum $+A$. strictum pues llegan a reducir el número de agallas/planta de 95 a 28 y la población de nematodos en el suelo de 3.400 a $690 / 500 \mathrm{~g}$ de suelo.

Cuando se usan extractos de esporas de T. harzianum, a concentraciones de $10^{2}-10^{8}$ esporas/ml, para el control biológico de M. javanica, los autores Sahebani y Hadavi (2008) comprobaron que decrece la infección por el nematodo. Comprobaron que T. harzianum fue capaz de penetrar la matriz de la masa de huevos y disminuir la eclosión de los huevos observando incremento de enzimas como POX, PPO y PAL a los seis días de la inoculación. Los filtrados de cultivos de T. harzianum crecidos en salvado de trigo humedecido con solución de sal, suplementado con quitina coloidal, mostraron actividad quitinasa. La máxima actividad de quitinasa se obtuvo a los cuatro días de la inoculación en un medio suplementado con quitina coloidal $(1,15 \mathrm{U} / \mathrm{min}$ por $\mathrm{ml})$. Los resultados de incremento de actividad quitinasa, sugieren que existe parasitismo directo de los huevos, mediante la quitinasa extracelular, lo cual podría ser el indicador de la capacidad de infección de los huevos, así como también de la inducción de defensa, que conduce a la resistencia sistémica. Con estos resultados se puede concluir que el parasitismo de los huevos y el incremento de resistencia en las plantas hospedadoras, pueden constituir los dos principales mecanismos, responsables de la supresión de la infección, usados por T. harzianum contra el nematodo.

Para determinar el compuesto activo responsable de la capacidad inhibitoria de hongos de biocontrol, los autores Chen et al. (2009) analizaron $T$. pseudokoningii SMF2. Utilizaron un extracto crudo de Trichoderma raza SMF2 el cual, en un fermento sólido, exhibe fuerte actividad nematicida contra $M$. incognita. Del extracto crudo purifican una proteasa serina SprT que tiene una masa molecular de $31 \mathrm{kDa}$ a pH óptimo de 8,5 y Temp de $60-65^{\circ} \mathrm{C}$. La cutícula del nematodo tratada con la proteasa SprT se arruga y esta proteasa también mata J2 e inhibe la eclosión de los huevos de $M$. incognita sugiriendo su implicación en el proceso nematicida. 
Al clonar el cDNA del gen que codifica la proteasa comprobaron que se asemeja a otras serin proteasas con actividad nematicida de Trichoderma. El hongo se mantiene en PDA y para obtener la producción del enzima y el ensayo de actividad nematicida se fermenta en un medio sólido que contiene: $6 \mathrm{~g}$ de trigo, $4 \mathrm{~g}$ de salvado y $15 \mathrm{ml}$ de una disolución de sales inorgánicas que lleva: [\% (w/v): $\mathrm{KH}_{2} \mathrm{PO}_{4}, 1,25 ;\left(\mathrm{NH}_{4}\right)_{2} \mathrm{SO}_{4}, 1,25 ; \mathrm{MgSO}_{4}, 0,3 ; \mathrm{CaCl}_{2}, 0,3 \%$ ] que se deja a $28^{\circ} \mathrm{C}$ durante 5 días. Al cabo de ellos el fermento sólido se extrae con diez veces agua destilada estéril a temperatura ambiente y se usa para actividad nematicida y purificación de la proteasa. El ensayo de la actividad nematicida se realizó a partir de solución de la proteasa purificada del extracto crudo (se concentra por ultracentrifugación pasando por membranas Millipore de 10.000 Da de exclusión) hasta $50 \mathrm{U}$ de actividad proteasa. Se toman $100 \mu \mathrm{l}$ de esta enzima preparada con tampón PBS (20 mM, pH 7,2). Se usan $50 \mathrm{~J}_{2}$ o huevos en el primer estadio que se añaden a la disolución del enzima y se incuban a $28^{\circ} \mathrm{C}$ durante $24 \mathrm{~h}$. Entonces se cuentan los $\mathrm{J}_{2}$ muertos. Los huevos de la solución enzimática se recogen y se lavan con agua estéril 3 veces y se incuban en agua estéril y a lo largo de 16 días se cuentan los $\mathrm{J}_{2}$ con lo que se va sumando el porcentaje de eclosión de los huevos y calculando el porcentaje acumulado según (Suarez et al., 2004).

Para aumentar la eficacia de agentes de biocontrol contra el nematodo $M$. incognita los autores Sharma \& Pandey. (2009) analizaron varios hongos antagonistas como T. harzianum, Paecilomyces lilacinus y Arthrobotrys oligospora además de un producto orgánico natural (Neem). Concluyeron que los agentes fúngicos controlan la población de nematodos y aumentan el crecimiento de la planta analizada, la planta medicinal Withania somnifera. De P. lilacinus se sabe que es un hongo que parasita huevos y los infecta por penetración directa de la hifa. Esta se ramifica (se empalma) y crece a través de la cáscara del huevo (Khan et al., 2006). Se ha sugerido que el parasitismo está asociado con la enzima serin-proteasa la cual tiene actividad nematicida y que actúa degradando la cáscara de los huevos previniendo la eclosión (Zareen et al., 2001). El hongo P. lilacinus es uno de los agentes de biocontrol potenciales el cual puede colonizar la materia orgánica del suelo y desarrollarse en la rizosfera de las plantas. T. harzianum parasita huevos y larvas de $M$. incognita. Las enzimas producidas por T. harzianum tales como glucanasas, quitinasas y proteasas, parecen que juegan un importante papel en el 
parasitismo (Haran et al., 1996).

En un ensayo reciente, los autores Abd-Elgawad y Kabeil, (2010) han analizado la eficacia de un nematicida, el carbofuran y dos antagonistas, el hongo $T$. harzianum y la bacteria Serratia marcescens contra el nematodo M. incognita en dos cultivares de tomate. Concluyeron que el más efectivo es el carbofuran y después la bacteria $S$. marcescens y por último el hongo T. harzianum porque decre

cen el desarrollo del nematodo y los parámetros de su reproducción. También, que aunque el carbofuran es el que mayor incremento da de los parámetros de crecimiento de la planta y la mayor supresión de la multiplicación del nematodo, el nematicida químico puede ser sustituido por los microorganismos antagonistas.

Actualmente, los autores Kamala \& Indira (2012) han analizado las propiedades del hongo $T$. harzianum como fungicida. Constatan que las propiedades como antagonista se basan en que es capaz de actuar con varios mecanismos como micoparasitismo, antibiosis, reducción de la habilidad saprofítica, inducción de resistencia en la planta hospedadora, competencia por los nutrientes y por el espacio y reducción de la diseminación de las esporas del patógeno. La activación de tales mecanismos implica la producción de metabolitos específicos como factores de crecimiento de las plantas, enzimas hidrolíticos, sideróforos, antibióticos, permeadas de carbón y de nitrógeno, etc. En el trabajo se muestra una tabla relacionando la efectividad de especies de Trichoderma contra varios patógenos y sus plantas hospedadoras y en otra tabla se relatan los metabolitos bioactivos producidos por diversos aislados de especies de Trichoderma y la actividad biológica desarrollada.

\section{III.6.2. Paecilomyces lilacinus}

En la literatura nos encontramos diversos estudios del hongo nematófago Paecilomyces lilacinus. Entre ellos nos encontramos trabajos que nos hablan sobre el manejo y multiplicación del hongo, como los realizados por los autores Cabanillas et al. (1989) que analizaron la influencia del transporte y del almacenamiento de Paecilomyces lilacinus en su supervivencia y protección relativa de tomate contra el ataque de Meloidogyne incognita. Ellos prepararon esporas de P. lilacinus en cinco formulados: alginato (pellets), tierra de diatomeas (gránulos), granos de trigo, suelo y suelo-mas-quitina y concluyen que la mayor 
viabilidad del hongo se consigue en trigo y en los gránulos de diatomeas es intermedia en los pellets de alginato y baja en los suelos, cuando se almacena a $25 \pm 2^{\circ} \mathrm{C}$

Los autores Zaki et al. (1994) realizaron un experimento con el filtrado del hongo P. lilacinus sobre la inhibición de la eclosión de huevos de Meloidogyne javanica. Las observaciones sobre los efectos nematicidas fueron la inmovilidad de los $\mathrm{J}_{2}$. La mayor inmovilidad se observó en filtrados fúngicos pero recogidos en tampón de $\mathrm{pH}=8$, mejor que en agua solo. Concluyendo que los efectos sobre los $\mathrm{J}_{2}$ fueron nematostáticos y no nematicidas.

Los autores Kuhnhold et al. (2006) pusieron a punto un bioensayo in vivo para identificar resistencia de la remolacha azucarera al nematodo del tallo Ditylenchus dipsaci. Establecieron un protocolo sobre un cultivo monoxénico de discos de zanahoria que produce un gran número de nematodos para inocular, concluyeron que si se utiliza un agente gelificante como carboximetil celulosa al $1 \%$ se produce un incremento en la penetración de los nematodos con respecto a cuándo se usa agua solo.

Otros estudios sobre P. lilacinus que nos encontramos en la literatura, son aportaciones de este hongo a diferentes cultivos para el control de la enfermedad provocada por nematodos. Los autores Cayrol et al. (1989) estudiaron las propiedades nematicidas de un filtrado de cultivos del hongo nematófago Paecilomyces lilacinus. Analizando: a) el medio de cultivo (de malta, de CzapekDox, de Arconteil y de Mac Coy), b) constante exposición a la luz o en oscuridad, c) en agitación o en reposo, d) aireado o no (incidencia de aire estéril al medio líquido, mediante una bomba de acuario durante $5 \mathrm{~min}$ al día), e) $\mathrm{pH}$ y f) varios períodos de incubación $(6,8,10,12$ y 15 días). El inóculo del hongo procedía de esporas de P. lilacinus que crecieron durante dos meses en un medio de $15 \mathrm{~g}$ de agar y $20 \mathrm{~g}$ de malta por litro de agua. Se inócularon $10^{5}$ esporas por ml de medio líquido en erlenmeyer de 500 con $300 \mathrm{ml}$ del medio de cultivo. Se probaron $\mathrm{J}_{2}$ de varios nematodos, entre ellos, Meloidogyne spp. Los test se hicieron en placas de 24 pocillos con $1 \mathrm{ml}$ del filtrado a probar puro o diluido en agua destilada estéril (1/2; $1 / 4 ; 1 / 8 ; 1 / 10 ; 1 / 20 ; 1 / 30)$ y se agregaron 50 nematodos en $20 \mu 1$ de agua, midiendo la toxicidad como los nematodos paralizados (que no se mueven cuando se pinchan con una aguja fina). El filtrado se obtuvo pasando el medio líquido de cultivo, 
primero por papel Whatman $n^{0} 2$ esterilizado y luego un filtro millipore de $0,22 \mu \mathrm{m}$.

Los mejores resultados de actividad fitotóxica son con filtrados de cultivos de 15 días cultivados sin agitación y con aeración, constantemente expuestos a la luz (aunque ésta no influye) y con medio de cultivo de malta, sin importar la concentración. Lo más importante del medio de cultivo de malta fue evitar filtrar el líquido después de autoclavarlo y no quitar el floculante marrón que se forma pues, los nutrientes esenciales que contiene, son absolutamente esenciales para la producción de toxinas por el hongo. Es mejor un $\mathrm{pH}$ ácido $(3,7)$. Los $\mathrm{J}_{2}$ fueron todos paralizados cuando se sumergían dos horas a la mayor dilución testada (1/30) en filtrados de cultivos de 15 días. La producción de toxinas es mayor cuando el hongo está en su máximo período de crecimiento. El pH del filtrado es 4,2 y se bajó añadiendo algunos $\mu \mathrm{l}$ de $\mathrm{NaOH} 0,01 \mathrm{~N}$ que no tenía efecto sobre los $J_{2}$. Los resultados de la reversibilidad de los efectos tóxicos de los filtrados indicaron que el efecto paralizante ya se nota a partir de los 30 min pero pueden recobrar la movilidad si se les traslada a agua. Sólo los tratamientos de 72 horas son los que realmente matan a los nematodos. En la discusión se aportan datos de que otros hongos no se comportan igual. Unos necesitan cultivos agitados y otros producen las toxinas durante su período de crecimiento inicial, luego como las condiciones necesarias para la máxima producción de toxinas son muy variables de un hongo a otro (medios y condiciones de cultivo, edad), es necesario testar estos parámetros para su optimización. Los autores afirman que el mecanismo de toxicidad de los metabolitos excretados por P. lilacinus puede ser neurotrópico sobre los receptores nerviosos del nematodo. También es interesante los resultados de especificidad de los metabolitos tóxicos, ya que solo afectan a un limitado número de especies de nematodos, fundamentalmente a especies de fitofagos: Meloidogyne arenaria, incognita y javanica y a Heterodera rostochiensis.

Los autores Holland et al. (1999) estudiaron la infección de Meloidogyne javanica por Paecilomyces lilacinus usando huevos y juveniles en el $3^{\circ}$ y $4^{\circ}$ estadio del nematodo y hembras. Muestran fotografías al microscopio óptico y electrónico de huevos infectados por las hifas del hongo y se pueden observar los apresorios y una extensa red de hifas del hongo que han formado conidióforos y siguen creciendo sobre los huevos del nematodo.

También, los autores Badi et al. (2001) analizaron 40 aislados fúngicos para 
comprobar su potencial en reducir la infección del nematodo $M$. incognita en tomate. Hallaron que un Deuteromiceto y 10 Basidiomicetos mostraron una reducción significativa de las agallas. Los aislados demostraron ser comparables en efectividad al nematicida Aldicarb aplicado a una concentración de 1 ppm. Dos aislados basidiomicetos BAS 90019 y OMP 90170 redujeron la penetración de juveniles en raíces de tomate y su actividad en el suelo sugiere que su modo de acción es la producción de metabolitos con actividad nematicida.

Como la quitina es un componente importante de la lámina media de las cáscaras de huevos de nematodos cuando los hongos parásitos producen quitinasas tienen expedita la puerta para atravesar la cáscara y causar la infección de los huevos. La actividad quitinasa se observó en sobrenadantes de cultivos del hongo nematófago $P$. lilacinus en un medio mínimo que contenía quitina, obteniéndose hasta 6 proteínas distintas (Khan et al., 2003).

Los autores Kobayashi et al. (2003), a partir de hongo Paecilomyces lilacinus aislaron y purificaron un enzima con una elevada actividad para realizar transglucosilación con la cual sintetizar oligosacáridos conteniendo uniones $\alpha-1,3-y$ $\alpha-1,2$-. La enzima unida a la célula responsable de la síntesis, se extrajo por

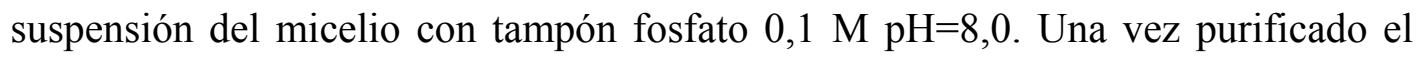
enzima tenía un peso molecular de 54.000 Da y un pI de 9,1. El enzima fue más activo a $\mathrm{pH}=5$ y a $65^{\circ} \mathrm{C}$. El enzima hidroliza maltosa, nigerosa y kojibiosa y también almidón soluble y amilasa, pero no actúa sobre $p$-nitrofenil, $\alpha$-glucósidos ni sobre iso-maltosa.

Los autores Park et al. (2004) analizaron la bioactividad de una colección de aislados de Paecilomyces lilacinus midiendo su actividad nematicida en base a la mortalidad y la inhibición de la reproducción del nematodo Caenorhabditis elegans. Analizaron, también, la actividad proteasa y quitinasa de los filtrados de cultivos de $P$. lilacinus y los resultados sugieren que leucinostatinas (producidas por el hongo en cultivo) son indicadores de la actividad nematicida mientras que la actividad quitinasa debe estar relacionada con el parasitismo.

Trabajos similares llevaron a cabo los autores Kiewnick \& Sikora (2006a) que analizaron el control biológico de Meloidogyne incognita por Paecilomyces lilacinus raza 251 en tomate. Analizaron la relación dosis-respuesta y concluyen que una simple aplicación antes del trasplante de las plantas de $1 \times 10^{6} \mathrm{CFU} / \mathrm{g}$ de 
suelo es suficiente para biocontrolar el nematodo y que no afecta que el producto esté disuelto en glucosa o se añada sin ella.

En ese mismo año, los mismos autores Kiewnick \& Sikora (2006b) analizaron la eficacia del producto comercial PL215 compuesto por Paecilomyces lilacinus raza 251 para el control del nematodo Meloidogyne hapla Chitwood típico de países nórdicos. Vieron su eficacia en diferentes dosis en relación con diferentes temperaturas llegando a la conclusión de que la más eficaz para el biocontrol del nematodo es la óptima de crecimiento del hongo, $25^{\circ} \mathrm{C}$.

Los autores Rumbos et al. (2008) estudiaron la persistencia en el suelo, bajo condiciones controladas de Paecilomyces lilacinus raza 251. Analizan los efectos de la dosis de aplicación, el tipo de sustrato así como la presencia de la planta hospedadora. Concluyen que no hay incremento de colonias después de la aplicación del hongo al suelo, al contrario, lo que se observó fue un declive gradual en la densidad del hongo con el paso del tiempo. Las dosis de aplicación no tuvieron un efecto significativo sobre la dinámica de la población fúngica e igualmente tampoco la disminución de la densidad de $P$. lilacinus fue afectada significativamente por la presencia del nematodo hospedador. El tipo de sustrato sí que tuvo un efecto significativo sobre la persistencia del hongo en el suelo. Persiste más tiempo en limo arcilloso y arcilla y más cuando se añade sustrato orgánico que en arena sólo.

Posteriormente, Kiewnick et al. (2011) evaluaron el agente fúngico de biocontrol Paecilomyces lilacinus raza 251 para optimizar su uso como potencial control de Meloidogyne incognita en tomate. Demostraron que un tratamiento de preplantación del suelo con la dosis más baja del formulado comercial PL251 fue suficiente para reducir las agallas y el número de masas de huevos cuando se actuó en un suelo contaminado con densidades altas de inóculo en suelo. Estos resultados demostraron que la competencia en la rizosfera no es la clave del modo de acción para el control de $M$. incognita por PL251 en tomate.

Trabajos sobre combinaciones de $P$. lilacinus y otros hongos nematófagos se han llevado a cabo por numerosos autores. Dube \& Smart Jr. (1987) utilizaron la combinación de Paecilomyces lilacinus y la bacteria Pasteuria penetrans para biocontrolar a Meloidogyne incognita, en pimiento Los resultados indicaron que el número de agallas se redujo significativamente cuando se agregó al suelo el hongo 
o la bacteria pero que no se obtuvieron mejores resultados cuando se añadieron ambos antagonistas juntos. Lo que sí se vió es que aumentaba el peso de las plantas de pimiento tratadas tanto con el hongo como con la bacteria.

Los autores Siddiqui y Mahmood (1993) analizaron el control biológico de Meloidogyne incognita y Macrophomina phaseolina por Paecilomyces lilacinus y Bacillus subtilis solos y en combinación en plantas de garbanzos, encontrando que individualmente, el tratamiento con $P$. lilacinus fue mejor contra $M$. incognita mientras que $B$. subtilis lo fue contra $M$. phaseolina y que la inoculación de $P$. lilacinus y $B$. subtilis mejoró significativamente el peso seco de los tallos de las plantas de garbanzo infectadas con el nematodo.

Los autores Zhu et al. (2006) realizaron la detección de dos hongos de biocontrol Pochonia chlamydosporia y Paecilomyces lilacinus mediante marcadores RAPD para diferenciarlos de otros 95 aislados. Obtuvieron amplicones con límite de detección de 0,2 y $0,5 \mu \mathrm{g}$. Los fragmentos elegidos para diseñar cebadores de amplificación (SCAR) se utilizan en reacciones de PCR para reconocer los correspondientes fragmentos de $\mathrm{ADN}$ de los hongos.

También, los autores Goswami et al. (2006) realizaron una aplicación integrada de agentes de biocontrol, Paecilomyces lilacinus y Trichoderma viride, con semillas de aceite de mostaza y el insecticida Furadan sobre Meloidogyne incognita, en plantas de tomate. Estos tratamientos incrementaron el crecimiento de las plantas, redujeron el número de agallas por planta, las masas de huevos en las raíces y el número de huevos en las masas de huevos. Así mismo demostraron que la adición del bioagente fúngico al suelo disminuyó significativamente la reproducción de los nematodos, con respecto al suelo no tratado.

En ese mismo año, los autores Monfort et al. (2006) estudiaron in vitro la receptividad de los suelos a los hongos nematófagos, Pochonia chlamydosporia y Paecilomyces lilacinus que parasitan los huevos de nematodos. Concluyendo que se pueden aplicar al suelo para el control biológico de nematodos, pero que su supervivencia en la rizosfera de las plantas infectadas varía mucho con la planta hospedadora y ello va a determinar la densidad del inóculo que hay que añadir al suelo para que sea eficaz.

Los autores Mendoza \& Sikora (2008) estudiaron la posibilidad de utilizar control biológico del nematodo Radopholus similis que ataca a los plátanos, 
utilizando una combinación compleja de microorganismos formada por el mutualista endófito Fusarium oxysporum (inductor de resistencia), el patógeno de huevos Paecilomyces lilacinus y la bacteria antagonista Bacillus firmus que produce toxicidad directa. Concluyen que el nematodo minador ha sido controlado sustancialmente por estos antagonistas y que la aplicación combinada de $F$. oxysporum y B. firmus fue la más efectiva.

Los autores Siddiqui y Akhtar (2008) analizaron los efectos sinérgicos de hongos antagonistas (Paecilomyces lilacinis, Pochonia chlamydosporia, Trichoderma harzianum y Gliocladium virens), rizobacterias (Pseudomonas putida) y hongos micorrícicos (Glomus intraradices) junto a un compuesto de vaca (CCM) sobre la población de Meloidogyne incognita y el crecimiento de tomate. Los resultados indicaron que el uso de los hongos antagonistas (excepto G. virens) causó un incremento en el crecimiento de las plantas de tomate y que el mayor crecimiento de las plantas inoculadas con nematodos, fueron las tratadas con $P$. lilacimnus mas el compuesto de vaca $(\mathrm{CCM})$, seguido de las tratadas con $P$. chlamydosporia y T. harzianum.

También se han realizado estudios de $\boldsymbol{P}$. lilacinus en combinación con hongos micorrícicos, como los realizados por los autores Rumbos et al. (2006) que analizaron las interacciones entre dos antagonistas adicionados en combinación, Paecilomyces lilacinus raza 251 y Glomus intraradices, para controlar a Meloidogyne incognita, en tomate. Concluyendo que ambos microorganismos son compatibles y que los dos agentes de biocontrol tienen diferentes modos de acción y sin embargo no se ven efectos aditivos o incremento alguno en la eficacia cuando se aplican en combinación.

Los autores Duan et al. (2008) describen la formulación contra nematodos de un pellet de alginato que contiene micelio de los hongos Paecilomyces lilacinus y Pochonia chlamydosporia. La durabilidad de los hongos se mejora si se conserva el formulado a baja temperatura $\left(\mathrm{de} 4^{\circ} \mathrm{C}\right.$ a $-20^{\circ} \mathrm{C}$ ) y baja humedad. Para la viabilidad no les mejora significativamente el vacío ni el $\mathrm{CO}_{2}$ pero sí una atmósfera de $\mathrm{N}_{2}$.

Los autores Aminazzuman et al. (2009) analizaron el uso de pellets de Paecilomyces lilacinus and Pochonia chlamydosporia para el biocontrol de $M$. incognita y más recientemente los autores Pandey et al. (2011) analizaron los efectos de diferentes bioformulados de Paecilomyces lilacinus contra el nematodo 
agallador de la raíz ( $M$. incognita) en la infección de tomate.

Otros autores también estudiaron el efecto de otras técnicas de control de los nematodos agalladores de raíces, como Nico et al. (2003) que analizaron el potencial de la solarización para controlar Meloidogyne incognita, en suelos de viveros de olivos en el sur de España. Concluyeron que la solarización produce un control adecuado de los huevos de $M$. incognita libre o en masa a una profundidad de $40 \mathrm{~cm}$ después de seis días de tratamiento.

Trabajos similares llevaron a cabo los autores Verdejo-Lucas et al. (2003) quienes evaluaron el uso de una combinación con Oxamil y Pochonia chlamydosporia, así como con Bromuro de metilo, en un sistema de doble cultivo de lechuga y tomate en invernadero, contra Meloidogyne javanica. No encontraron huevos sobre raíces de lechugas pero sí sobre raíces de tomates y cuando se agregó las distintas combinaciones de hongo+Oxamil se redujeron considerablemente las agallas en las raíces de tomate en todos los casos aunque el número de huevos por gramo de raíz varió dependiendo del tratamiento.

También, los autores Anastasiadis et al. (2008) estudiaron los efectos combinados en la aplicación del agente de biocontrol Paecilomyces lilacinus raza 251 con varias prácticas en el control de nematodos productores de la agalla de la raíz. Analizaron los efectos de un bionematicida formado por dos antagonistas solos o en combinación y solarización. Concluyen que la solarización solo (la hacen durante 15 días) o combinada con la adición del P. lilacinus solo (aplicado justo después de retirar el plástico) no da buen control del nematodo, pero la aplicación de $P$. lilacinus y Bacillus firmus juntos produce un control efectivo de los $J_{2}$ y de los huevos y las masas de huevos de los nematodos Meloidogyne spp. También han estudiado el efecto de Oxamyl y ven que cuando este nematicida químico se aplica dos semanas antes y durante el trasplante se obtienen resultados similares al del producto comercial que contiene $P$. lilacinus y superiores a la solarización.

Otra vertiente de estudios realizados por diversos autores son las combinaciones de $\boldsymbol{P}$. lilacinus y extractos de plantas. Los autores Mashela et al. (2007) estudiaron las interacciones de enmiendas de suelos con frutos de pepinos o de ricino y con hojas de té, analizando su capacidad de suprimir Meloidogyne incognita atacando a tomate. Concluyen que con los tratamientos, disminuye el $\mathrm{n}^{\mathrm{o}}$ de nematodos en la rizosfera y aumenta la producción de tomates, luego la adición 
de la combinación de estas plantas sirve como nematicida con efectos fertilizantes.

Los autores Javed et al. (2007) analizaron los efectos protectores de formulaciones de neem (Azadirachta indica) contra el nematodo Meloidogyne javanica en plantas de tomate. Y concluyen que los efectos tóxicos del neem no son lo suficientemente fuertes para prevenir la invasión de juveniles, aunque sí que pueden servir para inhibir la eclosión de huevos por lo que parece ser que los ingredientes activos del neem producen diferentes efectos según sea el estado de desarrollo del nematodo.

Los autores Javed et al. (2008) estudiaron el potencial del formulado compuesto por la combinación de plantas de neem y la bacteria Pasteuria penetrans para controlar el nematodo de la agalla de la raíz sobre tomate. Concluyen que la eficacia del biocontrol va a depender mucho de la densidad y distribución de las esporas bacterianas en el suelo, pero en general, la combinación de neem+esporas bacterianas disminuye el número de agallas además de aumentar el vigor de las plantas.

Los autores Thoden et al. (2009) analizaron los efectos de plantas que contienen alcaloides pirrolizidinas (APs), Ageratum houstonianum y Senecio bicolo, sobre el nematodo Meloidogyne hapla como una estrategia de control integrado en el que utilizan enmienda del suelo con plantas que contienen alcaloides. Concluyen que la enmienda de suelos con estas plantas es una práctica muy adecuada para incluirla en los procesos de control integrado, contra los nematodos productores de agallas de las raíces. 


\section{MATERIAL Y MÉTODOS}

\section{IV.1. Material vegetal}

\section{IV.1.1. Capsicum annuum cv. California Wonder}

La variedad de pimiento (Capsicum annuum) objeto de este estudio fue California Wonder, muy sensible al ataque del patógeno Meloidogyne incognita. La siembra se realizó con semillas desinfectadas en una disolución de hipoclorito sódico al $0.5 \%(\mathrm{v} / \mathrm{v})$ durante cinco minutos, se lavaron tres veces con agua destilada estéril, y se pusieron a germinar en bandejas alveolares de 60 senos (Fig.-IV.1), conteniendo una mezcla de turba y arena al 50\%. Las bandejas fueron instaladas en un módulo del invernadero de la Estación de Experimentación Agrícola de la Universidad de Murcia. Pasados tres meses, las plantas se traspasaron a macetas de $1 \mathrm{~L}$, conteniendo la misma mezcla de suelo descrita anteriormente, y se regaron cada dos o tres días, abonándose periódicamente con un fertilizante comercial NPK-17-9-28 (Solugran, COMPO, Alemania), a razón de $2 \mathrm{~g} / 1$ durante los ensayos. 


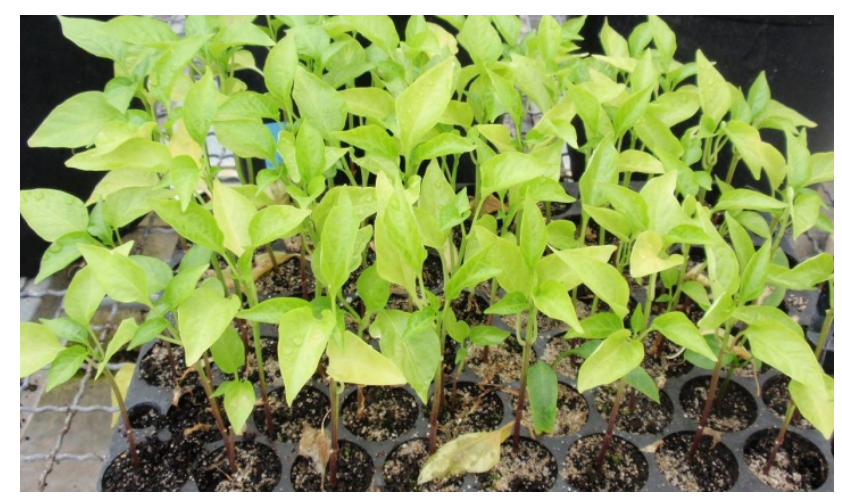

Fig.-IV.1.- Plántulas de Pimiento en semilleros de 60 alveolos en los invernaderos de la Estación Experimental.

\section{IV.1.2. Solanum lycopersici cv. Marmande}

Las plantas de tomate de la variedad Marmande son sensibles a la infección por nematodos y por esta razón se escogieron para el mantenimiento del inóculo.

Para esto se realizó la siembra de semillas desinfectadas de la misma forma que se hizo con las semillas de pimiento, y se pusieron a germinar en bandejas alveolares de 60 senos, conteniendo una mezcla de turba y arena al 50\%. Las bandejas fueron instaladas en un módulo del invernadero de la Estación de Experimentación Agrícola de la Universidad de Murcia. Pasados dos meses, las plantas se traspasaron a macetas de $1 \mathrm{~L}$, conteniendo la misma mezcla de suelo descrita anteriormente, y se regaron cada dos o tres días, abonándose periódicamente con un fertilizante comercial NPK17-9-28 (Solugran, COMPO, Alemania), a razón de 2 g/1 durante los ensayos.

Las plantas de tomate se trataron contra mosca blanca (Bemisia Tabaci y Trialeurodes vaporariorum), araña roja (Tetranychus urticae) y la Polilla del Tomate (Tuta absoluta) con 0,075 \% de Imidacloprid, Abamectina y Bacillus Thuringensis, respectivamente.

\section{IV.2. Material fúngico (Trichoderma harzianum y Paecilomyces lilacinus) y bacteriano (Bacillus firmus)}

Los microorganismos utilizados en este trabajo fueron: los hongos Trichoderma harzianum, aislado 2413 (TH2413), de la Colección Española de Cultivos Tipo (CECT), Valencia (España) y Paecilomyces lilacinus, aislado 253 (PL253), procedente de México. La bacteria utilizada fué Bacillus firmus aislado 342 (BF342) de la colección de la Dra. Candela ubicada en el Laboratorio de 
Fitopatología de la Universidad de Murcia (España). Todos se almacenaron a $-80^{\circ} \mathrm{C}$ usando el sistema de preservación Microbank de (CryobanktM, Mast Group Ltd. Merseyside, UK). Para los tests de compatibilidad "in vitro" los hongos TH2413 y PL253 se cultivaron en Agar patata dextrosa (PDA, Difco, USA) y se mantuvieron en oscuridad a $25^{\circ} \mathrm{C}$. La bacteria BF342 se cultivó en Agar soja-triptica (TSA, Oxoid Ltd., England) y se mantuvo en oscuridad a $28^{\circ} \mathrm{C}$.

\section{IV.3. Identificación del nematodo patógeno}

Plantas de pimiento (Capsicum annuum var. California Wonder) con síntomas de decaimiento, amarilleamiento y con presencia de agallas en el sistema radicular, constituyen las plantas enfermas objeto de este estudio. Las muestras contienen plantas de pimiento agalladas junto con rizosfera y una masa de suelo tomados de unos $30 \mathrm{~cm}$ de profundidad. Del suelo se obtuvieron $\mathrm{J}_{2} \mathrm{y}$ machos y las hembras se recobraron de las raíces infectadas.

Como el nematodo tiene una vida media corta, una vez extraído de las raíces infectadas hay que proceder a su estudio e identificación de manera inmediata. A lo largo de la experiencia se puede conseguir tener siempre inóculo si las plantas infectadas se plantan junto a plantas sanas (de al menos 2 meses de edad) y se unen las raíces para conseguir que éstas se infecten. Así cada 50 días se repite este proceso y se mantiene el inóculo para las distintas experiencias. Los estudios que se llevaron a cabo para la identificación de la especie de nematodos se detallan a continuación.

\section{IV.3.1. Extracción de material genético}

Se realizó una extracción de ADN de agallas de raíz de pimientos infectados que fueron recogidos en el Campo de Cartagena, con el objeto de identificar al patógeno causante de los síntomas. Para ello, se separaron las agallas del resto de la raíz y se machacaron con $\mathrm{N}_{2}$ líquido hasta obtener un fino polvo. Para la extracción de ADN, se utilizó el protocolo Isolation of Total DNA from Plant Tissue usando el kit DNeasy Plant Mini Kit de QIAGEN.

La concentración de ADN se determinó midiendo la absorbancia a $260 \mathrm{~nm}$ $\left(\mathrm{A}_{260}\right)$ en un espectrofotómetro (UV-2401 PC, UV-VIS Recording Spectrophotometer, SHIMADZU). Para comprobar la calidad del ADN se realizó 
una electroforesis en gel de agarosa (SIGMA Chem. Co.) al 1\%. Posteriormente el gel se tiñó con $10 \mathrm{ml}$ de una solución de bromuro de etidio $(10 \mathrm{mg} / \mathrm{ml})$ en $100 \mathrm{ml}$ de agua, y se observó en un procesador de geles y analizador de imágenes (Vilber Lourmat, Germany).

\section{IV.3.2. Identificación de la región de interés mediante PCR}

Las reacciones de amplificación se llevaron a cabo en un volumen de $25 \mu 1$ conteniendo 2,5 $\mu \mathrm{l}$ de tampón 10x de PCR, 1,5 $\mathrm{mM} \mathrm{MgCl}_{2}, 0,2 \mathrm{mM}$ de cada dNTP, 12,5 pmol de ambos cebadores, 1 unidad de Taq DNA polimerasa (ECOGEN, S.R.L, España) y 100 ng del ADN extraído.

Con el objetivo de identificar al patógeno se realizaron una serie de amplificaciones selectivas utilizando diferentes pares de cebadores tal y como se expone a continuación:

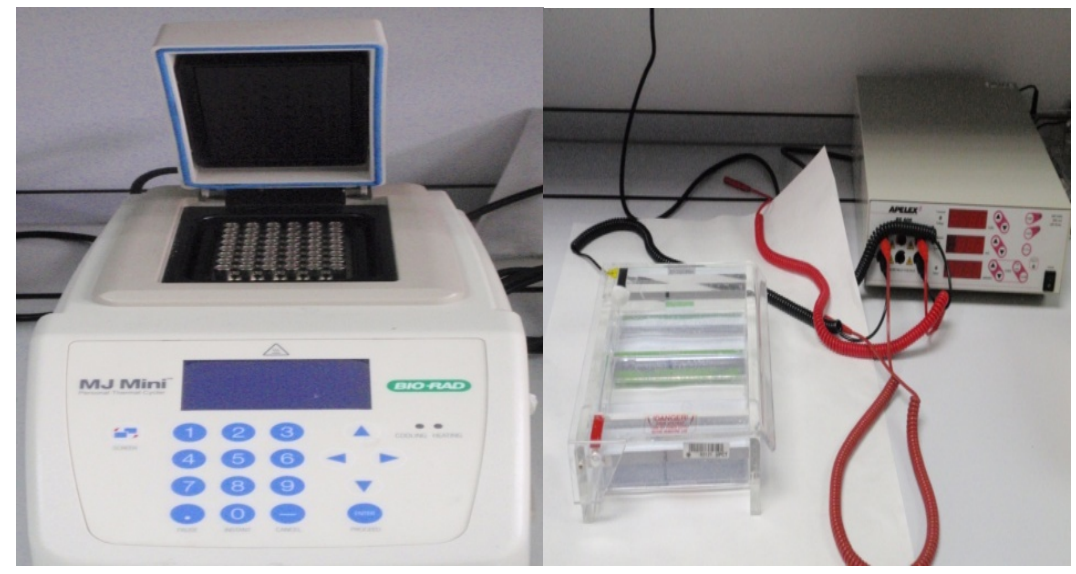

Fig.-IV.2.-Termociclador y cubeta de electroforesis utilizados para la identificación del patógeno.

\section{IV.3.2.1. Detección de nematodos (control positivo).}

Los cebadores usados fueron los descritos por Qiu et al. (2006) que amplifican una región ITS presente en el $97 \%$ de los nematodos. Estos fueron usados como control positivo de la presencia de nematodos. Las secuencias de los cebadores fueron C-f: 5'-TTGATTACGTCCCTGCCCTTT-3'

\section{C-r: 5'-TTTCACTCGCCGTTACTAAGG-3'.}

El programa que se siguió para llevar a cabo la reacción en cadena de la polimerasa fue: $3 \min$ a $94^{\circ} \mathrm{C}$, y entonces 35 ciclos de $0,5 \min$ a $94^{\circ} \mathrm{C}, 1 \mathrm{~min}$ a $58^{\circ} \mathrm{C}$, 1 min a $72^{\circ} \mathrm{C}$, y una fase final de elongación a $72^{\circ} \mathrm{C}$ durante $10 \mathrm{~min}$. El tamaño de 
banda esperado es de $800 \mathrm{pb}$.

\section{IV.3.2.2. Detección de Meloidogyne hapla y Meloidogyne chitwoodi}

Los cebadores usados fueron los descritos por Willianson et al. (1997) que amplificaban específicamente para cada una de las especies. Las secuencias de los cebadores fueron:

Para Meloidogyne hapla

MHO-f: 5'-CAGGCCCTTCCAGCTAAAGA-3'

MH1-r: 5'-CTTCGTTGGGGAACTGAAGA-3'

Para Meloidogyne chitwoodi

MC3-f: 5'- CCAATGATAGAGATAGGCAC-3'

MC1-r: 5'-CTGGCTTCCTCTTGTCCAAA-3'.

El programa fue: $3 \min$ a $94^{\circ} \mathrm{C}$, y entonces 35 ciclos de $0,5 \min$ a $94^{\circ} \mathrm{C}, 1 \mathrm{~min}$ a $58^{\circ} \mathrm{C}, 1 \mathrm{~min}$ a $72^{\circ} \mathrm{C}$, y una fase final de elongación a $72^{\circ} \mathrm{C}$ durante $10 \mathrm{~min}$. El tamaño de banda esperado es de 960 pb para M. hapla y de 400 pb para M. chitwoodi.

IV.3.2.3. Detección de M. arenaria, M. incognita y M. javanica.

Los cebadores usados fueron los descritos por Zijlstra, C. et al. (2000) que amplificaban específicamente ADN genómico de $M$. arenaria, $M$. incognita y $M$. javanica. Las secuencias de los cebadores fueron:

OPA-01:5'-CAGGCCCTTC-3'

OPA-12: 5'-TCGGCGATAG-3'

OPB-06: 5'-TGCTCTGCCC-3'.

El programa fue: 3 min a $94^{\circ} \mathrm{C}$, y entonces 35 ciclos de $0,5 \min$ a $94^{\circ} \mathrm{C}, 1 \mathrm{~min}$ a $58^{\circ} \mathrm{C}, 1 \mathrm{~min}$ a $72^{\circ} \mathrm{C}$, y una fase final de elongación a $72^{\circ} \mathrm{C}$ durante $10 \mathrm{~min}$. El tamaño de banda esperado fue de $670 \mathrm{pb}$ para M. javanica, $420 \mathrm{pb}$ para $M$. arenaria y de 1200 bp para $M$. incognita.

\begin{tabular}{llccr}
\hline Primer name & Sequence $\left(5^{\prime}-3^{\prime}\right)$ & Size of the band (bp) & Nematode & Reference \\
\hline Far & TCGGCGATAGAGGTAAATGAC & 420 & M. arenaria & Zijlstra et al. 2000 \\
Rar & TCGGCGATAGACACTACAACT & & M. incognita & Zijlstra et al. 2000 \\
Finc & CTCTGCCCAATGAGCTGTCC & 1,200 & M. javanica & Zijlstra et al. 2000 \\
Rinc & CTCTGCCCTCACATTAAG & & & \\
Fjav & GGTGCGCGATTGAACTGAGC & 670 & & \\
Rjav & CAGGCCCTTCAGTGGAACTATAC & & & \\
\hline
\end{tabular}

Tabla. IV.1.- Secuencia de nucleótidos de los cebadores usados para la identificación de nematodos 


\section{IV.4. Estudio de la Interacción de Capsicum annuum- Meloidogyne incognita. Estudio microscópico}

Se recolectaron plantas de pimiento infectadas que mostraban raíces con agallas y una vez desarraigadas se seleccionaron las raíces con agallas y después de lavarlas extensamente se cortaron en segmentos de 2 a $5 \mathrm{~cm}$.

Para una identificación inicial los fragmentos de raíces con agallas, se pusieron en un porta-objetos y una vez teñidos con fuchina, se aplastaron y se observaron bajo microscopio óptico a 10x, 40x y 60x. Se buscan huevos, hembras y juveniles de nematodo y se fotografían. Para ello, los segmentos escogidos, que incluían agallas visibles, se fijaron en una solución de formaldehído-cromo-acético durante 48 horas, luego se deshidrataron en una serie alcohólica de alcohol butírico terciario (40-70$85-90-100 \%$ ) y se embebieron en parafina fundida a $58^{\circ} \mathrm{C}$ para su observación histopatológica. Los tejidos embebidos en la parafinas se cortaron con un microtomo rotatorio, obteniéndose secciones de $5 \mu \mathrm{m}$ de espesor que se pusieron en portaobjetos de cristal, se tiñeron con safranina y verde-rápido (Johansen, 1940) y se montaron permanentemente en una solución al 40\% de xileno de ester polimetacrílico (Synocril 9122X, Cray Valley Products), (Vovlas et al., 2008). Las secciones teñidas se examinaron bajo microscopio óptico Leica DMRB y se fotografiaron.

\section{IV.5. Obtención del inóculo del nematodo Meloidogyne incognita a partir de plantas de pimiento y mantenimiento en plantas de pimiento y tomate.}

El inóculo inicial de nematodos para realizar todos los experimentos procedieron de la misma parcela infectada del Campo de Cartagena y para esto plantas de Capsicum annuum cv. California wonder infectadas se traspasaron a unos tiestos de gran tamaño, 10 litros, junto con la tierra de alrededor del sistema radicular, de manera que se transportaron las plantas enteras a las instalaciones de la Universidad de Murcia. Las macetas se rellenaron con mezcla de turba: arcilla (50:50). En estas macetas, por contacto de raíces de plantas de pimiento o de tomate 
infectadas con plantas de pimiento sanas o de tomate sanas, se multiplicaron los nematodos y se mantuvieron infectadas para su posterior uso. Las plantas se mantuvieron en el invernadero a $22 \pm 3^{\circ} \mathrm{C}$ durante todo el tiempo que duraron los ensayos regándolas convenientemente cada dos-tres días.

\section{IV.6. Obtención y cuantificación de huevos y Juveniles $\left(J_{2}\right)$}

Las plantas de pimiento infectadas se desarraigaron y sus raíces se lavaron con abundante agua para eliminar la tierra adherida. De las agallas se pueden obtener hembras adultas utilizando unas pinzas, el inóculo para las experiencias, a partir de los huevos extraídos y los nematodos juveniles $\mathrm{J}_{2}$ ( $2^{\circ}$ estadio de maduración).

Se tomaron las raíces de diez plantas infectadas, se lavaron bien con agua, y se estableció el índice de agallamiento, luego se cortaron con unas tijeras las zonas necróticas de las raíces para dejar las agallas limpias y se obtuvieron fragmentos de 2 $\mathrm{cm}$ que se pesaron. Para estimar los niveles de infección por nematodos (índice de agallamiento), se usa la carta de rangos de Bridge \& Page (1980) en la cual se relacionan el número de agallas en las raíces, su tipo y disposición desde 0 (sanas) a 10 todas las raíces con agallas (Fig.-IV.3).

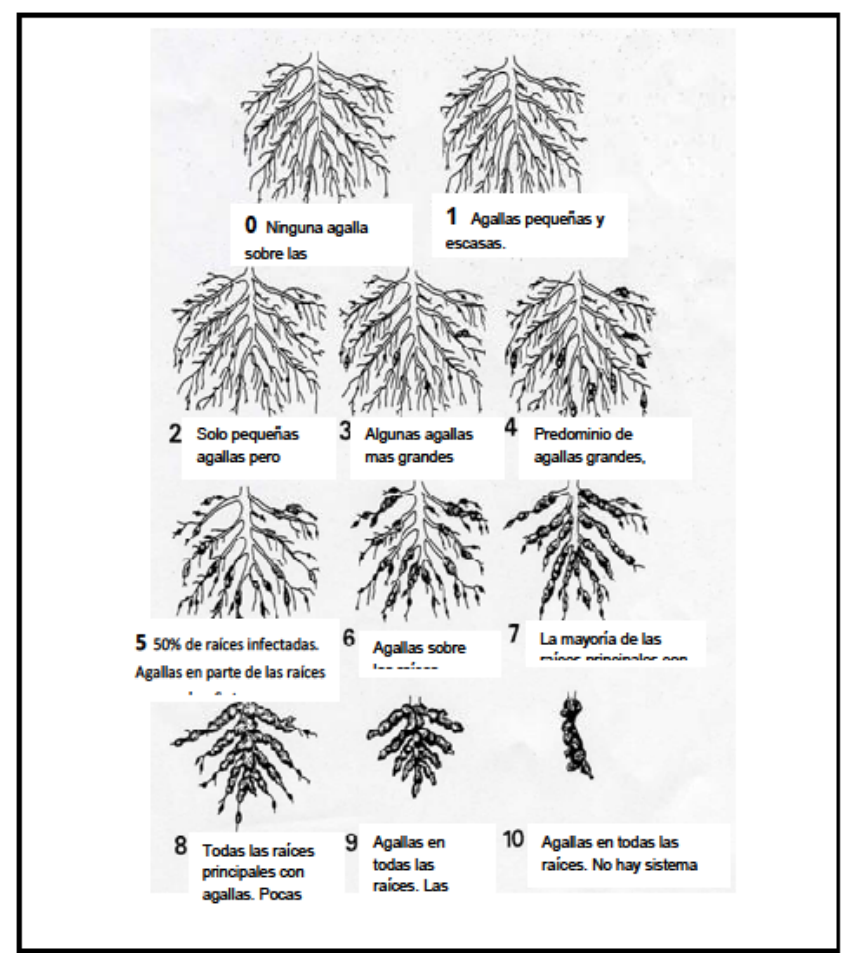

Fig.-IV.3.- Carta de niveles de agallas en raíces, producidos por nematodos tipo Meloidogyne según Bridge \& Page, (1980) 
Los trozos de raíces se llevaron a 2 litros de suspensión acuosa al 1\% de hipoclorito sódico durante 3 minutos con agitación ocasional. Al cabo de los cuales se tamizó la mezcla, se decantó por un cedazo de $2 \mathrm{~mm}$ (del cual se recoge lo que se filtra, decantando la solución, sin recoger el poso de tierra y restos vegetales). Se añadió más agua para lavar los fragmentos de raíces y se dejaron en agua durante 15 minutos para tener un buen aclarado. Finalmente se volvió a tamizar y decantar, se retiró el agua de lavado y se recogieron $500 \mathrm{ml}$ del tamizado. Los trozos de raíces se trocearon finamente con una batidora eléctrica y la disolución se dejó 24 horas para que se liberaran los huevos y $\mathrm{J}_{2}$.

Para una primera estimación del número de huevos y de $\mathrm{J}_{2}$ liberados de las raíces, se tomaron 6 alícuotas de $5 \mathrm{~g}$ de las raíces infectadas, lavadas y troceadas, se trituraron fuertemente con batidora y se resuspendieron en $100 \mathrm{ml}$ de una suspensión acuosa al 1,5\% de hipoclorito sódico durante $3 \mathrm{~min}$, después de lo cual los huevos y los $\mathrm{J}_{2}$ se liberaron, se lavaron con agua y se contaron tiñéndolos con Phloxine $\mathrm{B}$ (disolución al 2\% durante 5 minutos) según (Hussey \& Barker, 1973). Otro método de tinción es el de la fuchina ácida de Byrd et al. (1983). Después se decantó el agua y el material se pasó a un vaso que contenía $30 \mathrm{ml}$ de agua a la que se le agregó $1 \mathrm{ml}$ de colorante $(3,5 \mathrm{gr}$ de fuchina ácida, $250 \mathrm{ml}$ de ácido acético y $750 \mathrm{ml}$ de agua destilada). Esta disolución $(31 \mathrm{ml})$ se calentó a ebullición $(30 \mathrm{~s}$ a $450 \mathrm{~V}$ en microondas) y una vez enfriada a temperatura ambiente, se retiró el exceso de tinción con agua corriente y las raíces se pusieron en 20-30 ml de glicerina acidificada con 2-3 gotas de $\mathrm{HCl} 5 \mathrm{~N}$. Las raíces teñidas de esta forma se dispusieron entre dos portaobjetos, se presionó y se observó bajo la lupa (4X), las masas de huevos teñidas de rojo.

Para observar huevos y los $\mathrm{J}_{2}$ se montó una preparación de pequeñas agallas o masas de huevos recientes, depositándolos en un portaobjetos con agua. Se cubrieron con un cubreobjetos que se sujetó con la punta de los dedos por los cuatro ángulos y delicadamente se presionaron las agallas que contenían las hembras. Así podemos conseguir la salida de huevos de la agalla (que contenía la masa de huevos) y estos se observaron al microscopio a 60X. Se puede percibir la eclosión de huevos si se deja la preparación a la luz del microscopio con lo cual, de huevos maduros salen los $\mathrm{J}_{2}$, 
con su característica forma de gusano, moviéndose por la preparación.

Para obtener el inóculo de nematodos para infectar, se recogieron todas las raíces de las plantas necesarias, en nuestro caso, cuatro plantas adultas con índice de agallamiento 5-6 según Bride \& Page, (1980). Se retiraron las raíces necrosadas y las zonas con agallas que se lavaron bajo el grifo a través de un tamiz de $2 \mathrm{~mm}$ para quitar toda la tierra adherida, y se recogieron raíces hasta completar 50 g. (Fig. IV.5)

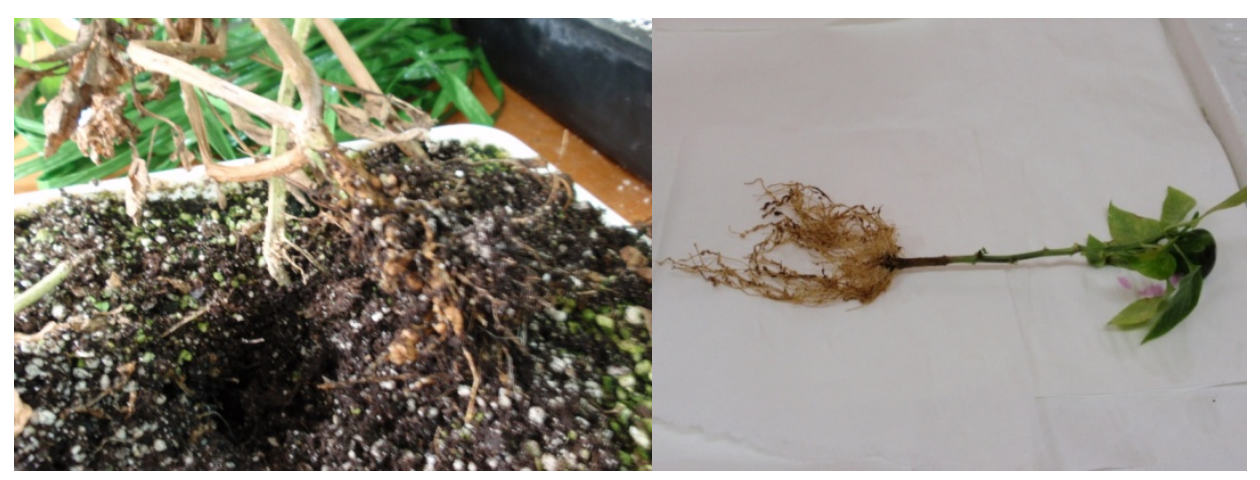

Fig.-IV.4.- Plantas de tomate y pimiento infectadas con Meloidogyne incognita para multiplicar al patógeno bajo condiciones controladas.

Se dejaron en 2 litros de disolución de lejía al 5\% durante 5 minutos y luego se volvió a lavar con agua a través del tamiz. Las raíces se trocearon en pequeños fragmentos y se dejaron en agua durante 24 horas. Al día siguiente se concentró la disolución. Primero se recogió el sobrenadante sin remover el fondo que se pasó por un tamiz de $25 \mu \mathrm{m}$ hasta dejar la disolución restante en $500 \mathrm{ml}$. Luego se filtró el resto de la disolución (que se agitó superficialmente) por decantación, pasándola a través del tamiz de $2 \mathrm{~mm}$ de tamaño de poro. Así se eliminaron los restos vegetales superiores a $2 \mathrm{~mm}$ y el limo del fondo. Se recogieron $500 \mathrm{ml}$ con las raíces limpias y se añadió a un vaso de batidora donde los fragmentos de raíz se trituraron bien y se dejaron otras 24 horas. Al cabo de las cuales se pasó por un tamiz de $150 \mu \mathrm{m}$, se recogió el tamizado y se descartó lo que no se había tamizado. Se volvió a triturar y se pasó por otro tamiz de $75 \mu \mathrm{m}$ donde también se recogió la disolución tamizada y se descartó lo que quedaba en el tamiz. Finalmente se pasó por tamiz de $25 \mu \mathrm{m}$ y se enrasó a $200 \mathrm{ml}$.

Esa disolución está muy limpia y contiene huevos $+\mathrm{J}_{2}$ de donde se obtuvo su número. Para hacer una observación microscópica, el tamizado se agitó hasta obtener una disolución homogénea y sin dejar que se posase, se recogió una alícuota de 
volumen conocido $(1 \mathrm{ml})$ que se filtraron por un tamiz de $10 \mu \mathrm{m}$. El tamizado de la alícuota se lavó con $2 \mathrm{ml}$ de agua y los nematodos $+\mathrm{J}_{2}$ que contenían se purificaron, al separar los de restos de tierra y raíces, mediante una centrifugación a 1100 x $\boldsymbol{g}$ durante 5 min en una disolución de sulfato de magnesio de gravedad específica 1,16. Para contarlos se tomó una alícuota de $1 \mathrm{ml}$ (de cada alícuota original) y se contaron bajo microscopio (60X). Estas medidas se realizaron tres veces y con todos los valores se estimó el valor medio de la cantidad de huevos $+\mathrm{J}_{2}$ de la disolución total que constituyó el inóculo, teniendo en cuenta todas las diluciones de las distintas alícuotas utilizadas.

\section{IV.7. Determinación del límite de tolerancia de pimientos al nematodo Meloidogyne incognita.}

Se prepararon macetas de $2000 \mathrm{ml}$, esterilizadas con agua y lejía durante 30 min y se rellenaron con el sustrato anteriormente descrito, esterilizado. Una vez frío se trasplantaron plántulas de pimiento, una por maceta y se infectaron con el patógeno con un rango de densidad de población creciente: 0,$0 ; 0,125 ; 0,25 ; 0,5 ; 1$, $2 ; 4 ; 8 ; 16 ; 32$ y 64 huevos y $\mathrm{J}_{2} \mathrm{~mL}^{-1}$ de suelo. Estas alícuotas se añadieron en dos agujeros opuestos entre sí y distantes unos $3 \mathrm{~cm}$ de la base de la planta. Inmediatamente se regaron con agua y se rotularon con las dosis de densidad de población inicial de nematodos $(\mathrm{Pi})$ con que se había infectado cada planta. Las macetas se dispusieron en bancos en el invernadero a $25 \pm 2^{\circ} \mathrm{C}$ en bloques al azar con 4 replicas de cada densidad de población (10), mas una de control $\sin$ infectar $(4 \times 11=$ 44) que se repitió tres veces. Las plantas se regaron con $100 \mathrm{ml}$ de agua y fertilizante $0,1 \%, \quad 20-5-32$ (N-P-K)+micronutrientes en solución hidrosoluble con una periodicidad semanal, y con agua cada dos días.

Para el análisis de resultados se utilizó el modelo de Seinhorst que relaciona la densidad inicial de la población de nematodos $(\mathrm{Pi})$ y el crecimiento de las plantas (estimado por el peso fresco del sistema aéreo y la altura de la planta) mediante la ecuación $\boldsymbol{y}=\mathbf{m}+(\mathbf{1}-\mathbf{m}) * \mathbf{z}^{\mathbf{P}-\mathbf{T}}$

Donde:

$\boldsymbol{y}$ es un parámetro que indica "la producción relativa" o el valor relativo del “crecimiento de la planta", $(y=1$ cuando $\mathrm{P}<\mathrm{T})$; 
$\boldsymbol{m}$ es la producción mínima relativa y corresponde al valor de $\boldsymbol{y}$ cuando la densidad inicial de nematodos es muy grande;

$\mathbf{P}$ es la población de nematodos a la siembra (densidad inicial de la población de nematodos), expresada en ejemplares $/ \mathrm{cm}^{3}$ de suelo;

$\mathbf{T}$ es el límite de tolerancia o población máxima que soporta una planta sin reducir su rendimiento;

$\mathbf{Z}$ es una constante $<1$ reflejando el daño del nematodo y generalmente $\mathrm{z}^{-\mathrm{T}}$ es medianamente $=1,05$ (Seinhorst, 1965 y 1979).

Para comparar la variación poblacional del nematodo, se aplicó Seinhorst empleando los resultados de las poblaciones que se inocularon a la siembra (Pi) y los que se recobraron al final del ensayo $(\boldsymbol{P} \boldsymbol{f})$. Esto nos permitió determinar el límite de tolerancia $(\boldsymbol{T})$ al nematodo, la pérdida máxima de rendimiento relativo $(\boldsymbol{m})$ y la relación entre los niveles poblaciones de los nematodos.

\section{IV.8. Confrontación "in vitro" en placa de P. Lilacinus, T. harzianum y B. firmus}

Para comprobar la compatibilidad de los antagonistas en estudio, se hicieron crecer estos, previamente, en placas petri individuales con medio PDA a $25^{\circ} \mathrm{C}$, para posteriormente realizar una confrontación. Se tomaron discos de $5 \mathrm{~mm}$ de la colonia de $P$. lilacinus o de $T$. harzianum de las colonias de 7 días de edad o de la colonia de $B$. firmus de 3 días de edad y se sembraron en confrontaciones duales en una nueva placa de PDA, dispuestos en dos puntos opuestos de la placa. Para asegurar la compatibilidad de los tres antagonistas, discos de cada uno de ellos se colocaron en los vértices de un triangulo equilátero imaginario, en una placa Petri con PDA que se repitió cinco veces. Las placas se incubaron en estufa a $25^{\circ} \mathrm{C} \pm 2^{\circ} \mathrm{C}$ y se observó el crecimiento de los antagonistas cada tres días y durante dos semanas. 


\section{IV.9. Ensayos de biocontrol "in vivo" entre los agentes $P$. lilacinus, T. harzianum y el nematodo M. incognita.}

IV.9.1. Preparación del inóculo de los microorganismos antagonistas seleccionados para los ensayos "in vivo".

\section{IV.9.1.1. Medio Vermiculita}

Se adicionó a vermiculita autoclavada dos veces, PDB, sales y agua estéril en Erlenmeyer de $500 \mathrm{ml}$ de capacidad. Se introdujo, por cada $100 \mathrm{ml}$ de medio, 1 disco de $5 \mathrm{~mm}$ de diámetro de la colonia micelial crecida en placas de PDA de P. lilacinus y T. harzianum. Se incubaron en oscuridad y en estufa a $25 \pm 2^{\circ} \mathrm{C}$ durante dos semanas.

\section{IV.9.1.2. Medio Líquido}

Se adicionó PDB, sales y agua estéril a matraces de $1000 \mathrm{ml}$ de capacidad. Se autoclavaron a $121^{\circ} \mathrm{C}$ durante 30 minutos y una vez frio se agregó 1 disco de $5 \mathrm{~mm}$ de diámetro por cada $100 \mathrm{ml}$ de medio, cortados del margen de la colonia micelial de $P$. lilacinus y T. harzianum crecida en PDA y transferidos asépticamente al matraz. Se incuban los matraces en estufa a $25 \pm 2^{\circ} \mathrm{C}$ durante dos semanas (Fig.-IV.5).

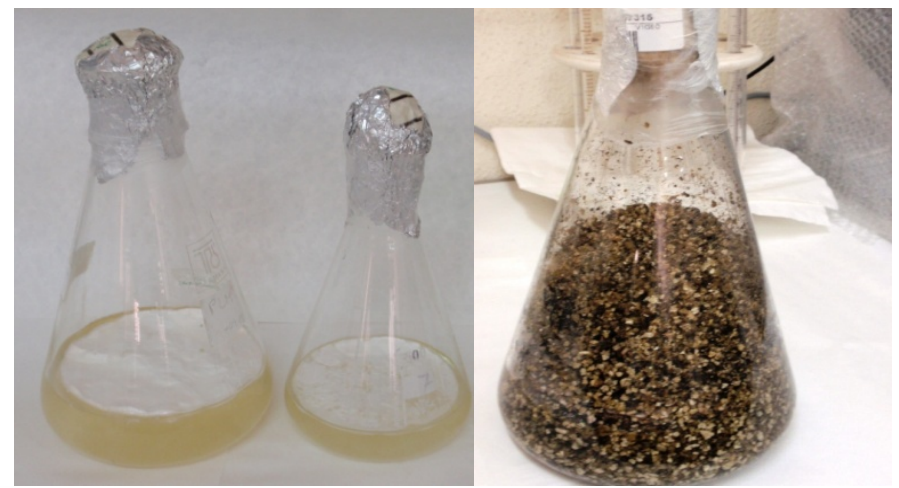

Fig.-IV.5.- Crecimiento de los hongo $P$. lilacinus raza 251 y $T$. harzianum 2413, en medio de cultivo líquido (izquierda) y en vermiculita (derecha). 
IV.9.2. Ensayo con el agente de biocontrol $P$. lilacinus y el nematodo $M$. incognita.

Para el ensayo con el agente de biocontrol $P$. lilacinus y el nematodo $M$. incognita, se prepararon macetas de plástico de 2 L de capacidad, esterilizadas previamente con una disolución de lejía al $10 \%$ y se rellenó con sustrato (arena:turba) estéril. Los tratamientos que se hicieron fueron los siguientes:

1) No inoculadas (CS): Control positivo.

2) Inoculadas con $M$. incognita $(\mathrm{CN})$ : Control negativo.

3) Inoculadas con P. lilacinus crecido en medio líquido, una semana antes del trasplante e infectadas con $M$. incognita $(\mathrm{P}+\mathrm{N})$.

4) Inoculadas con P. lilacinus crecido en medio líquido, una semana antes y durante el trasplante e infectadas con $M$. incognita $(2 \mathrm{P}+\mathrm{N})$.

5) Inoculadas con $P$. lilacinus una semana antes y durante el trasplante e infectadas con M. incognita, en vermiculita (Vermi).

La densidad inicial de nematodos (Pi) utilizada en el ensayo fue de 3000 huevos+juveniles por litro de suelo, en todos los casos. La concentración y volumen de $P$. lilacinuss utilizada en los ensayos fue de $10^{6}$ en $5 \mathrm{ml}$ por litro de suelo. La duración del ensayo fue de dos meses y las macetas se dispusieron en mesas en invernadero a $25 \pm 2^{\circ} \mathrm{C}$ y en platos en su base para evitar, en la medida de lo posible, la lixiviación de los nematodos debido al riego. Se emplearon 10 plantas por tratamiento y los tratamientos se repitieron un total de tres veces.

\section{IV.9.3. Ensayo con dos agentes de biocontrol $P$. lilacinus, $T$. harzianum y el nematodo $M$. incognita.}

Para estudiar el efecto sinérgico del uso de dos agentes de biocontrol contra el nematodo $M$. incognita, en pimiento, se plantearon dos ensayos, uno sin reposición de P. lilacinus y otro con reposición de este.

\section{IV.9.3.1. Ensayo sin reposición de P. lilacinus y $T$. harzianum}

Se prepararon macetas de plástico de 2 L de capacidad, esterilizadas previamente con una disolución de lejía al $10 \%$ y rellenadas con sustrato (arena:turba) estéril, para cada tratamiento tal y como se describe a continuación. 
1) No inoculadas (CS): Control positivo

2) Inoculadas con $M$. incognita $(\mathrm{CN})$ : control negativo

3) Inoculadas con $P$. lilacinus crecido en medio líquido e infectadas con M. incognita $(\mathrm{P}+\mathrm{N})$.

4) Inoculadas con P. lilacinus y T. harzianum crecidos en medio líquido e infectadas con $M$. incognita $(\mathrm{P}+\mathrm{T}+\mathrm{N})$.

5) Inoculadas con $P$. lilacinus y $T$. harzianum e infectadas con $M$. incognita, en vermiculita (Vermi)

La densidad inicial de nematodos (Pi) utilizada en el ensayo fue de 1500 huevos+juveniles por litro de suelo, en todos los casos. La concentración y volumen de $P$. lilacinus utilizada en los ensayos fue de $10^{6}$ conidios en $5 \mathrm{ml}$ por litro de suelo, y de $T$. harzianum fue de $10^{8}$ conidios en $2,5 \mathrm{ml}$ por litro de suelo. La duración del ensayo fue de dos meses y las macetas se dispusieron bajo invernadero a $25 \pm 2^{\circ} \mathrm{C}$ y con riego automatizado.

\section{IV.9.3.2. Ensayo con reposición de P. lilacinus y T. harzianum}

Se prepararon macetas de plástico de $2 \mathrm{~L}$ de capacidad, como anteriormente se describe, para cada tratamiento que se detalla a continuación.

1) No inoculadas (CS): Control positivo

2) Inoculadas con $M$. incognita $(\mathrm{CN})$ : control negativo

3) Inoculadas dos veces con $P$. lilacinus crecido en medio líquido e infectadas con $M$. incognita. $(2 \mathrm{P}+\mathrm{N})$

4) Inoculadas con T. harzianum crecido en medio líquido e infectadas con M. incognita. $(\mathrm{TH}+\mathrm{N})$

5) Inoculadas dos veces con P. lilacinus, inoculadas con T. harzianum e infectadas con $M$. incognita, en vermiculita (Vermi)

6) Inoculadas dos veces con P. lilacinus, inoculadas con T. harzianum crecidos en medio líquido e infectadas con $M$. incognita. $(2 \mathrm{P}+\mathrm{TH}+\mathrm{N})$

La densidad inicial de nematodos (Pi) utilizada fue de 3000 huevos+juveniles por litro de suelo, respectivamente. La concentración y volumen de P. lilacinus utilizada en los ensayos fue de $10^{6}$ conidios en $5 \mathrm{ml}$ por litro de suelo, y de $T$. 
harzianum fue de $10^{8}$ conidios en $2,5 \mathrm{ml}$ por litro de suelo. La duración del ensayo fue de dos meses y las macetas se dispusieron bajo invernadero a $25 \pm 2^{\circ} \mathrm{C}$ y con riego automatizado.

\section{IV.10. Seguimiento del cultivo y evaluación en el invernadero}

Durante la duración de los ensayos se observaron las plantas para detectar visualmente la aparición de los síntomas del ataque de los nematodos (amarillamiento y falta de crecimiento) y así establecer un mínimo de tiempo de exposición del cultivo al nematodo, para asegurar la infección en las plantas de pimiento. Para evitar la lixiviación de los nematodos inoculados en el suelo se les dotó a cada una de las macetas de ensayo de un plato de plástico en su base.

Tras 60 días después del trasplante, las plantas se desarraigaron y las raíces se lavaron para quitar toda la tierra adherida, se midió el índice de agallamiento. Se pesaron y se midió la altura de la parte foliar (superior) de las plantas. Para analizar la densidad de la población final de nematodos $(\mathrm{P} f)$ en cada maceta al final de la experiencia, se contaron los huevos $+\mathbf{J}_{2}$ tanto en suelo como en raíces y se obtuvo la suma de los nematodos recobrados al final, en suelo y raíces. En el suelo se procesaron alícuotas de $500 \mathrm{ml}$ de sustrato según el método de Coolen (1979). También se obtuvo la tasa de multiplicación de los nematodos, como la razón (Pf/Pi) para cada densidad de población inicial $(\mathrm{Pi})$ y el límite de tolerancia $\mathrm{T}$ que es la población inicial de nematodos a la cual el crecimiento de la planta no se altera.

Para las experiencias de biocontrol también se dejaron las plantas de ensayo en contacto con los nematodos y los antagonistas durante 60 días. Trascurrido este tiempo se procesaron los datos de las plantas de ensayo, se midió la altura de la planta, peso de la raíz y parte aérea, nematodos por gramo de raíz, etc, y se determinó el porcentaje de control de la enfermedad tras la aplicación de los antagonistas $P$. lilacinus y T. harzianum, en el control de nematodos. 


\section{IV.11. Ensayos con la combinación de antagonistas TH2413, PL243 y BF342 y con el formulado Nemaout}

\section{IV.11.1. Producción y aplicación de los antagonistas $P$. lilacinus, $T$. harzianum y B. firmus.}

Para obtener el inóculo fúngico se obtuvo un disco de la zona de crecimiento activo de la colonia de P. lilacinus o de T. harzianum, que habían crecido en PDA durante 10 días y se añadió $3 \mathrm{ml}$ de $\mathrm{PDB}$, se homogeneizó utilizando un asa de siembra de cristal y se recogió con una pipeta pasteur estéril. Se contaron los conidios empleando una cámara Thoma para ajustar la concentración a $1 \times 10^{8}$ conidios/ml con PDB. Para obtener el inóculo de B. firmus se hizo crecer en medio TSA sólido a $28^{\circ} \mathrm{C}$ y en oscuridad durante dos días, se añadió $3 \mathrm{ml}$ de medio Luria Broth (LB) a la placa y se recogió con una pipeta pasteur estéril. Se hizo un recuento empleando una cámara thoma y se ajustó la concentración a $1 \times 10^{7} \mathrm{CFU} / \mathrm{ml}$. Se tomó un $\mathrm{ml}$ y se transfirió a a $250 \mathrm{ml}$ de medio líquido TS en un Erlenmeyers. Se incubó durante $48 \mathrm{~h}$ at $28^{\circ} \mathrm{C}$ en un agitador rotativo at $120 \mathrm{rpm}$ en oscuridad. Finalmente la suspensión bacteriana se centrifugó a $10,000 \mathrm{x} g$ durante $15 \mathrm{~min}$ a $5^{\circ} \mathrm{C}$. El precipitado resultante se resuspendió en una disolución de Ringer estéril de 0,25 de densidad (Ringer-solution, Merck, Alemania) hasta una densidad óptica final (OD) de 2 a 560 $\mathrm{nm}$, lo cual representa, aproximadamente $1,2 \times 10^{10} \mathrm{UFC} / \mathrm{ml}$.

Cuando las disoluciones de los microorganismos se usaron para su aplicación a suelo, $P$. lilacinus se usó a una concentración de 3,6 ×10 $0^{6}$ conidios/g de suelo, T. harzianum se aplicó a 3,9 × $10^{8}$ conidios/g de suelo y B. firmus a 5,0 × $10^{7} \mathrm{UFC} / \mathrm{g}$ de suelo.

\section{IV.11.2. Producción y aplicación del formulado Nemaout}

Se ha puesto a punto un producto que llamamos Nemaout (pendiente de patente) que es un bionematicida catalogado como fortificante por la CEE y cuyos componentes biológicos son bacterias promotoras del crecimiento (Azotobacter vinelandii, Bacillus megaterium y Bacillus licheniformis) y aminoácidos de origen vegetal. El producto es líquido y cuando se utilizó para agregarlo "in vivo" a macetas con tomates se usó en dos tratamientos (1) Nemaout 1, diluido a 100x, se aplicó tres veces a 10 1/ha (10,000 plantas por ha): en el momento del trasplante ( $1 \mathrm{ml} / \mathrm{planta})$ y 
de 3 a 5 semanas más tarde a $(0,5 \mathrm{ml} /$ plant $)$; (2) Nemaout 2, de una dilución 10 x se aplicó a los mismos tiempos y dosis que el Nemaout 1 .

Para la aplicación del formulado Nemaout, se utilizaron macetas de $500 \mathrm{ml}$ (con platillos para recoger lixiviado) y rellenas con el sustrato de suelo compuesto por turba:limo:arcilla (20:70:10) que se inocularon agregando $1 \mathrm{ml}$ de una suspensión acuosa de $M$. incognita (2,000 huevos), introducida a través de 4 agujeros hechos a $3 \mathrm{~cm}$ del centro de cada maceta y a $2 \mathrm{~cm}$ de profundidad. Como control sano las plantas se trataron solo con agua. Las macetas recién infectadas se regaron hasta la capacidad de campo (a saturación) se cubrieron con plástico y se incubaron en el invernadero a $26 \pm 3^{\circ} \mathrm{C}$ durante 1 semana, antes de trasplantar las plántulas de tomate. Después de trasplantarse las macetas se cultivaron con los riegos y abono descrito anteriormente. Se realizaron tres experimentos con dos repeticiones implicando 10 plantas por tratamiento.

\section{IV.11.3. Aplicación de la combinación de antagonistas TH2413, PL243 y BF342 y del formulado Nemaout}

En el primer experimento, las plantas se trataron con los antagonistas TH2413, PL243 y BF342 de manera individual para asegurar el grado de antagonismo contra M. incognita. En el segundo experimento y tercer experimento, las plantas se trataron con la combinación de los antagonistas o con el formulado Nemaout a las dos concentraciones. En el primer y segundo experimento las plantas se recolectaron a los 60 días del trasplante y se determinó la altura y el peso fresco de la parte aérea (tallos) y de la parte radicular (raíces).

En las raíces de cada planta infectada se determinó el índice de agallamiento (severidad de la raíces agalladas, RGS) aplicando la carta de Bridge y Page (1980) sobre una escala del 0-al-10. En el tercer experimento, las plantas se dejaron crecer durante 4 meses después del trasplante y se determinó el número de frutos por planta, el valor medio de los frutos ( $\mathrm{g}$ ) y el rendimiento total como productividad en (kg por planta). 


\section{IV.12. Producción, extracción, separación e identificación de compuestos excretados (Vertidos) de P. lilacinus y T. harzianum}

\section{IV.12.1. Producción de vertidos antipatógenos de $P$. lilacinus y $\quad T$. harzianum}

Para la producción de metabolitos antipatógenos por $P$. lilacinus y $T$. harzianum se prepararon Erlenmeyer de $500 \mathrm{ml}$ conteniendo $200 \mathrm{ml}$ de caldo nutritivo de PDB y PDB + sales orgánicas e inorgánicas, previamente esterilizado en autoclave a $121^{\circ} \mathrm{C}$ durante 30 minutos. Se inocularon con un disco de $0,5 \mathrm{~cm}$ cortado con un sacabocados, del borde de la colonia en crecimiento en medio PDA de $T$. harzianum por cada $100 \mathrm{ml}$ de medio líquido. Los frascos de T. harzianum se incubaron en agitación a $120 \mathrm{rpm}$ y los frascos de P. lilacinuss en reposo, ambos a temperatura ambiente en el laboratorio y durante 1, 2, 4, 6, y 8 días.

\section{IV.12.2. Extracción de compuestos de los vertidos de $P$. lilacinus y $T$. harzianum}

Para la extracción de los compuestos, se usó acetato de etilo adicionado al caldo nutritivo en proporción (1:1), mediante un embudo de decantación. El extracto se concentró en rotavapor hasta sequedad y se resuspendió en $2 \mathrm{ml}$ de acetato de etilo, para la separación cromatografía y bioensayos fúngicos, y en agua ultra pura MilliQ, para los bioensayos de nematodos. A continuación se filtró mediante filtros milipore (Millex-Hv 0,25 $\mu \mathrm{m}$, Bedford, MA) y finalmente se conservó en ependorf de $2 \mathrm{ml}$, en oscuridad y a $4^{\circ} \mathrm{C}$ hasta su uso.

\section{IV.12.3. Separación mediante cromatografía en capa fina (TLC)}

Para la separación de los compuestos mediante cromatografía en capa fina, se colocó $100 \mu \mathrm{l}$ de a una distancia de $1 \mathrm{~cm}$ del extremo de una cromatograplaca de capa con soporte de silicagel de 60, que se consideró el origen.

Se introdujo en una cámara de cristal con base cilíndrica con $10 \mathrm{ml}$ de las fases móviles siguientes:

(1) TBME: Metanol (3:7)

(2) Cloroformo:Metanol (8:2)

(3) Una serie de soluciones de 25, 50, 75, 90\% de Acetonitrilo y agua. 
Se desarrolló la separación cromatografica y se midió la distancia alcanzada por el frente de la fase móvil $(d f)$. Se dejo secar al aire y se reveló empleando dos métodos; gases de Iodo y empleando luz ultravioleta a $360 \mathrm{~nm}$.

La distancia de las bandas obtenidas se marcó como $d b_{i}$.

Se determinó su cociente de retardo $(R f)$ con valores comprendidos entre 0 y 1 de la forma:

$$
\mathrm{Rf}=d b_{i} / d f
$$

\section{IV.12.4. Bioensayos "in vitro" de los vertidos de T. harzianum}

\section{IV.12.4.1. Estudio de la actividad antifúngica}

Con frecuencia la actividad antifúngica de los compuestos excretados de microorganismos tiene también actividad antinematicida y por esto se llevó a cabo un ensayo de actividad antifúngica de los compuestos separados mediante TLC.

Se obtuvo una suspensión conidial de placas de PDA con el patógeno fúngico Botrytis cinérea crecido durante 10 días en oscuridad a $26^{\circ} \mathrm{C}$, vertiendo $5 \mathrm{ml}$ de una solución de PDB y se homogeneizó con un asa de siembra de cristal.

La suspensión se ajustó a una concentración de $2 \times 10^{7}$ conidios $/ \mathrm{ml}$ y se añadió a una solución de PDA autoclavada y fría que se depositó sobre una cromatoplaca.

Se dejó crecer durante 7 días, se determinó su Rf, empleando luz ultravioleta a $360 \mathrm{~nm}$ y se fotografiaron los resultados.

\section{IV.12.4.2. Estudio de la actividad antinematicida}

Para detectar la actividad antinematicida de los extractos fúngicos de $T$. harzianum sobre los huevos y juveniles $\left(\mathrm{J}_{2}\right)$ del nematodo $M$. incognita, se procedió a realizar una suspensión acuosa de nematodos que contenía al menos 100 huevos/ml y se colocaron en microplacas de 6 pocillos IWAKI Scitech Div. Asahi Techno Glass, Japón. A esta suspensión se le añadió $1 \mathrm{ml}$ de cada extracto fúngico en disolución acuosa, de los diferentes tiempos de incubación 1, 2, 4, 6 y 8 días. Se contaron los huevos eclosionados durante los siguientes 3, 6, 10, 13 y 16 días empleando un microscopio óptico Optika $600 \mathrm{Ti}$ 
Para el caso de los juveniles $\left(\mathrm{J}_{2}\right)$, se utilizaron inóculos que sólo contenían juveniles de nematodos $\left(50 \mathrm{~J}_{2} / \mathrm{ml}\right)$ y se determinó su mortandad en 24, 48 y 96 horas. Se incubaron todas las microplacas a $25^{\circ} \mathrm{C}$, selladas y en oscuridad. Se repitieron los ensayos tres veces.

\section{IV.12.4.3. Estudio de la actividad antinematicida de fracciones}

Para el estudio de la actividad antinematicida de fracciones del extracto de $T$. harzianum sobre juveniles $\left(\mathrm{J}_{2}\right)$, se optimizó la separación en varias cromatografías en capa fina sobre gel de sílice (TLC) con diferentes cantidades del los vertidos de T.harzianum y se recogieron de la cromatoplaca las distintas bandas, raspándolas con una espátula para luego extraer los compuestos con una mezcla de Metanol: Cloroformo: Acetato de etilo: Acetona (2:1:1:2). Se filtró con un filtro Milipore (Millex-Hv 0,45 $\mu \mathrm{m}$, Bedford, MA) y se llevaron a sequedad en rotavapor Buchi. Se resuspendieron en agua miliQ y se añadieron a microplacas de 6 pocillos IWAKI Scitech Div. Asahi Techno Glass, Japón, que contenían una suspensión acuosa de nematodos de $50 \mathrm{~J}_{2} / \mathrm{ml}$.

\section{IV.13. Análisis y gráficas de resultados}

Se realizaron representaciones gráficas de la tasa de multiplicación de nematodos $(\mathrm{P} f / \mathrm{Pi})$ según cada densidad de población inicial $(\mathrm{Pi})$ a las que se aplicó el modelo de Seinhorst que relaciona el peso fresco del sistema aéreo y la altura de la planta, para determinar el límite de tolerancia del pimiento a este patógeno.

Se realizaron tratamientos estadísticos y gráficos de los datos recogidos de los distintos estudios de inoculaciones de uno o más antagonistas en plantas de pimiento. Para ello los datos se analizaron mediante ANOVA usando SPPSS $12.0 \mathrm{~K}$ para Windows (SSPS institute, NC, USA). La significancia de los efectos de los microorganismos antagonistas se evaluó usando el test de Duncan $(P<0.05)$. 


\section{RESULTADOS}

Los síntomas que presentan las plantas de pimiento en el campo decaimiento, amarilleo general, poca producción y agallas en el sistema radicular, nos indican la posible presencia de nematodos (Fig. V.1).

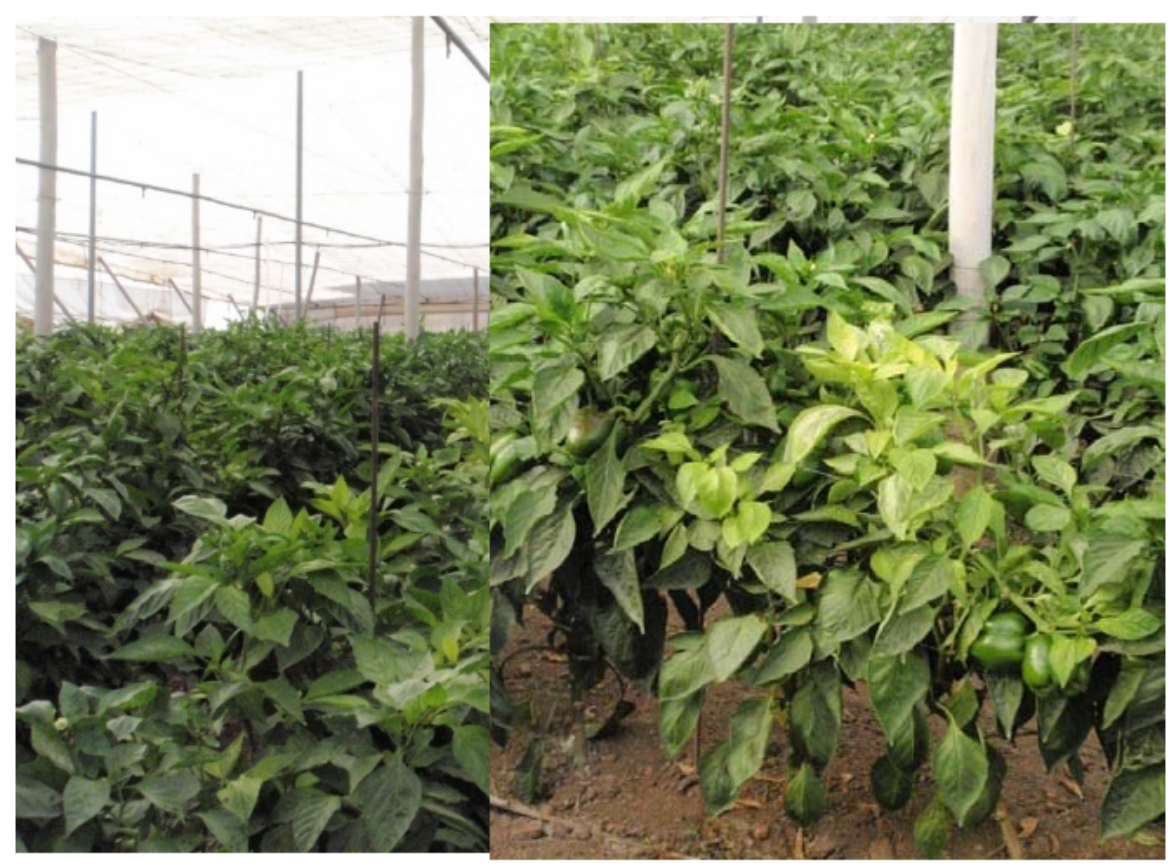

Fig. V.1.- Plantas de pimiento con síntomas de nematodos en el Campo de Cartagena que sirvieron de inóculo inicial del ensayo. 


\section{V.1. Identificación del nematodo patógeno}

\section{V.1.1. Identificación del patógeno por PCR}

Los productos de las amplificaciones realizadas con cada pareja de cebadores, separados por electroforesis se muestran a continuación:

\section{V.1.1.1. Detección de nematodos (control positivo).}

El test de DNA nos confirma la presencia del nematodo por la intensa banda de 800 pares de bases (pb) amplificada con los ITS de la mayoría de los nematodos. La amplificación usando los cebadores C-f y Cr es la que revela la banda de 800 pares de bases (Fig. V.2), con lo que concluimos que nuestro patógeno es un nematodo tal y como esperábamos.

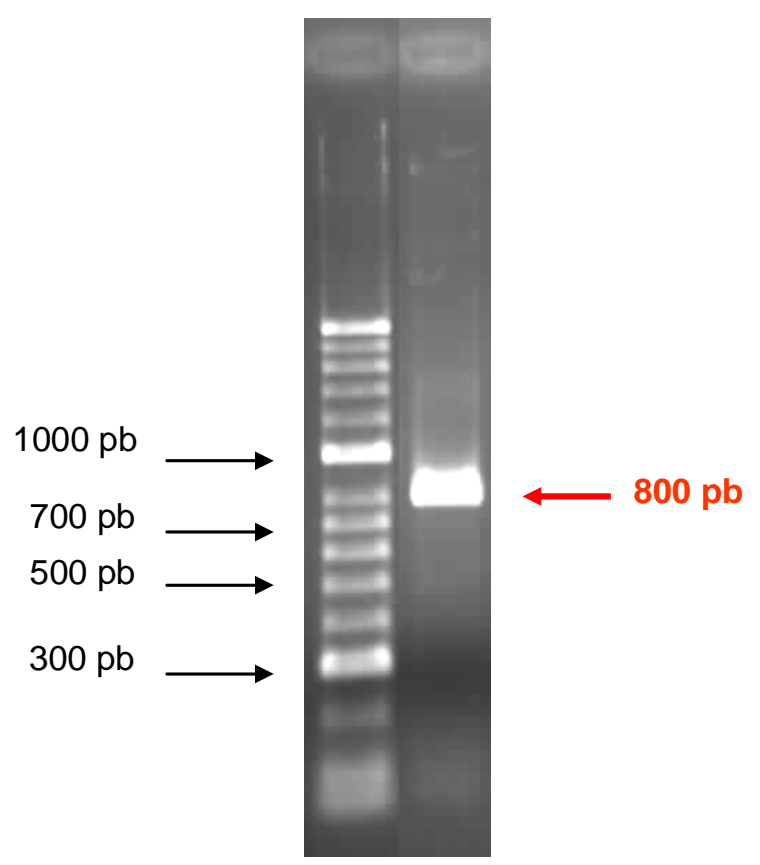

Fig. V.2.- Electroforesis de los productos de PCR usando los cebadores C-f y C-r para amplificación de la región IST de nematodos

V.1.1.2. Detección de Meloidogyne hapla y M. chitwoodi.

La amplificación usando los cebadores MHO-f y MH1-r para la detección de M. hapla (Fig. V.3) no resultó en una banda del tamaño esperado (960 bp) por lo que descartamos que sea esa especie. 


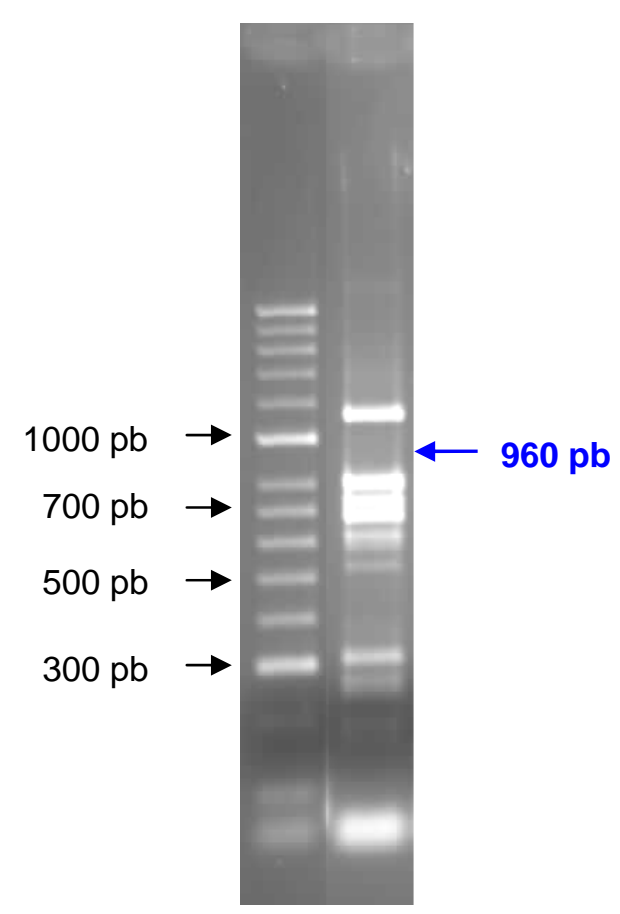

Fig. V.3.- Electroforesis de los productos de PCR usando los cebadores para detección de $M$. hapla.

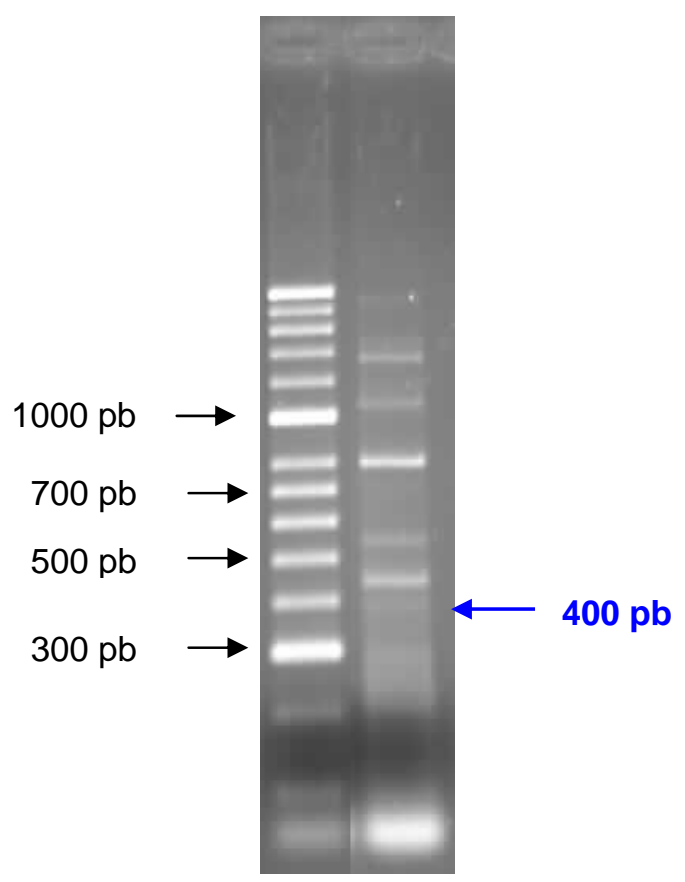

Fig. V.4.- Electroforesis de los productos de PCR usando los cebadores para detección de $M$. chitwoodi. 
La amplificación usando los cebadores MC3-f y MC1-r para la detección de $M$. chitwoodi (Fig. V.4) no resultó en una banda del tamaño esperado (400 pb) por lo que descartamos que sea esa especie.

\section{V.1.1.3. Detección de Meloidogyne arenaria, M. incognita y M. javanica}

La amplificación usando los cebadores OPA-01, OPA-12 y OPB-06 para la detección de $M$. javanica y M. arenaria (Fig. V.5) no resultó en las bandas de tamaño esperado $670 \mathrm{pb}$ y $420 \mathrm{pb}$, respectivamente. Sin embargo, si resultó una banda muy clara del tamaño esperado (1200pb) para M. incognita.

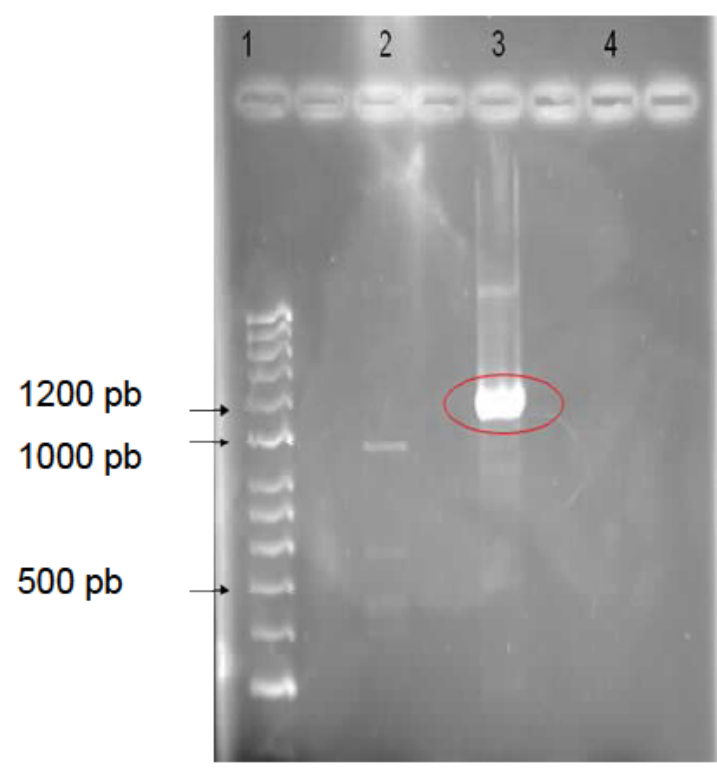

Fig. V.5.- Electroforesis de los productos de PCR usando los cebadores para detección de $M$. javanica, M. arenaria y M. incognita.

En conclusión podemos afirmar que cuando se usaron los amplificadores descritos por Zijlstra et al. (2000) para identificar las diferentes especies de Meloidogyne solo las combinaciones de los amplificadores Finc/Rinc dieron una banda amplificada con el tamaño específico de $1.200 \mathrm{pb}$, al usar el DNA de los pimientos infectados, con lo que se demostró que el nematodo que infectó al pimiento era M. incognita. 


\section{V.2. Estudio de la interacción Capsicum annuum-Meloidogyne incognita. Estudio microscópico.}

La Fig. V.6 muestra una agalla de la raíz infectada donde se distinguen numerosos huevos dentro de la matriz gelatinosa que los protege. En la izquierda se distingue un huevo de donde emergerán los juveniles infectivos.

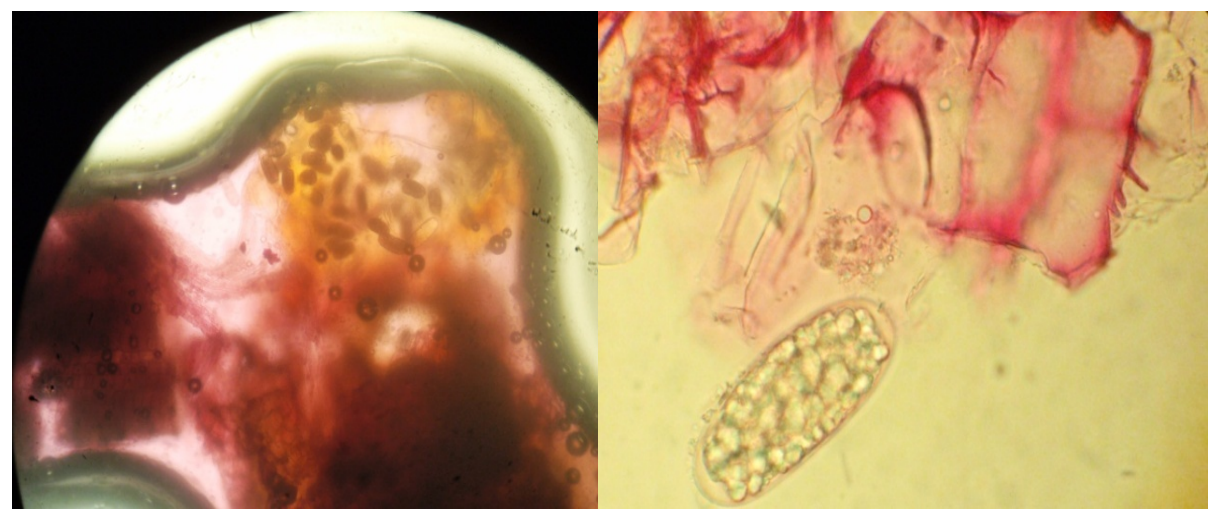

Fig. V.6.- Fragmento de una raíz con una agalla aplastada vistos al microscopio óptico. A la derecha se observan huevos rodeados de una membrana protectora $(10 \mathrm{X})$ y a la izquierda, detalle de un huevo en estado inmaduro desprendido de células vegetales.

En la Fig. V.7 se observan dos hembras de nematodo, con su típica forma de pera, teñidas de rosa con la Fuchina (izquierda) y a la derecha se muestra un juvenil recién eclosionado de un huevo.

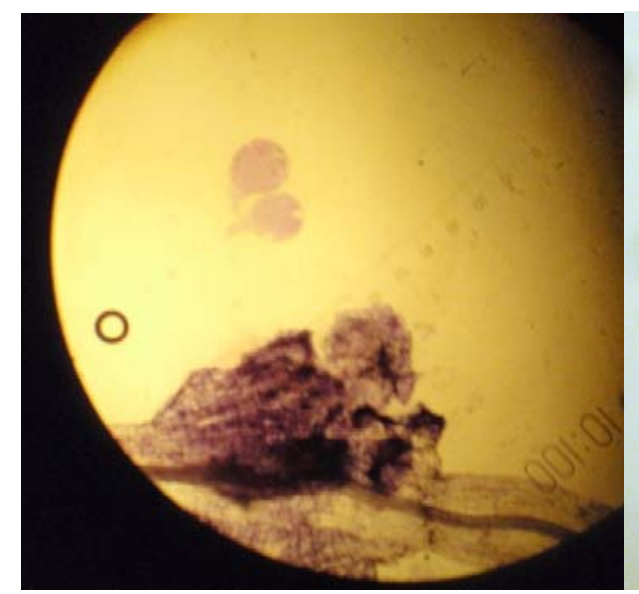

Fig. V.7.- Hembras de Meloidogyne incognita que se han soltado de una agalla en la raíz de un pimiento. Microscopio óptico 10X. Derecha detalle de un Juvenil. Microscopio óptico 60X. 
En la Fig. V.8 se observan raíces de pimiento sanas e infectadas, mostrando el típico agallamiento producido por el nematodo después de la infección. De esas agallas (Fig. V.9) se obtuvo el tejido para realizar el estudio microscópico.

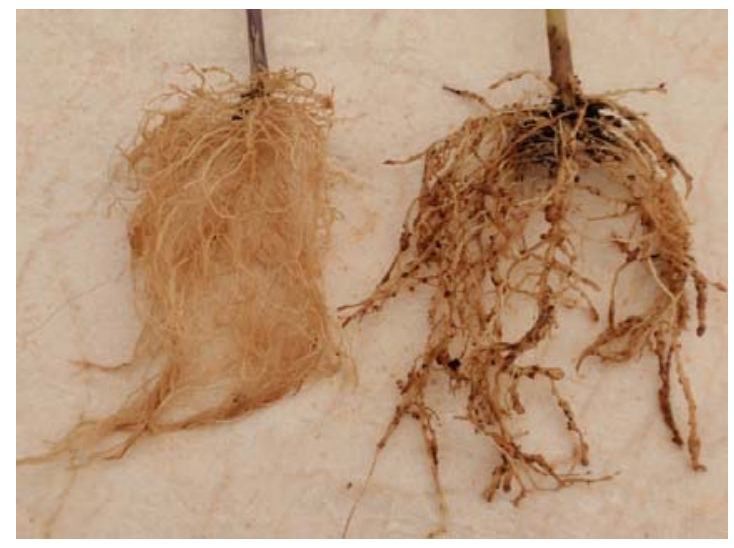

Fig.V.8.-Raíces de pimiento sana (izquierda) e infectada con el nematodo Meloidogyne incognita que forma numerosas agallas (derecha.)
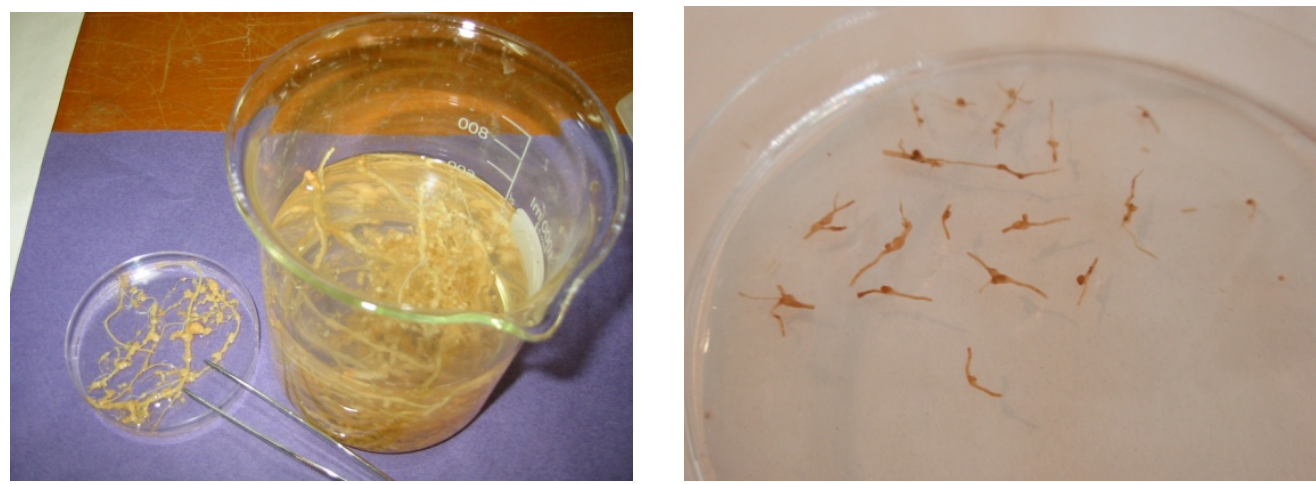

Fig.V.9.-Fragmentos de raíces de pimiento con agallas ocasionadas por el nematodo $M$. incognita. A la derecha se observan los segmentos de raíces con las agallas que se utilizan para ser incluidos en parafina y poder laminarse y observarse al microscopio.

La Fig. V.10 muestra un corte trasversal de una raíz sana de pimiento donde se distinguen el sistema vascular, floema y xilema, y las células del cortex típicas. 


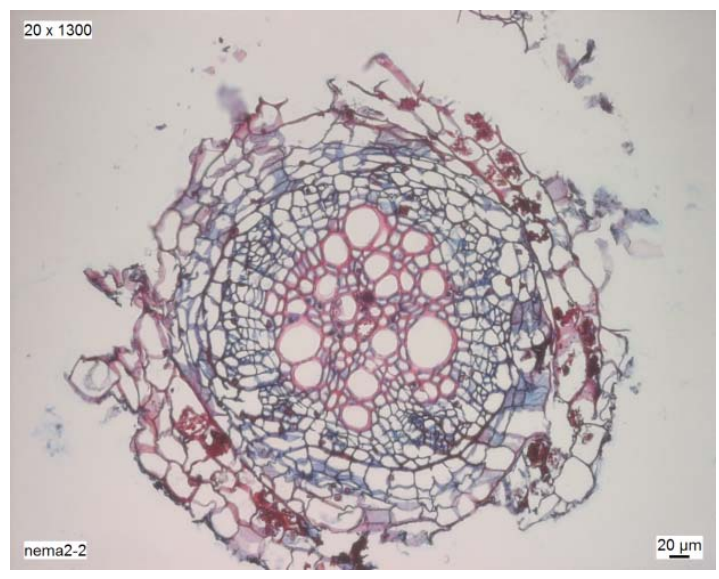

Fig.V.10.-Corte transversal de una raíz de pimiento sana teñida con verde malaquita y safranina. Se observan los vasos del xilema lignificados y los del floema más delgados, teñidos de rosa. Los de la médula están teñidos de azul.

Las Figuras V.11 a V.14 muestran los cortes histológicos de raíces de pimiento infectadas con el nematodo $M$. incognita, en ellas se observan modificaciones sustanciales en la arquitectura de las raíces. La formación de las típicas células gigantes se asocia estrechamente con los vasos del xilema como se observa en la Fig. V.11. Las células gigantes mostraron un citoplasma denso y un número variable de núcleos hipertrofiados, así como nucléolos. La hiperpaplasia de los tejidos adyacentes a las células gigantes es lo que contribuye a la formación de las agallas en las raíces.

En las Figs. V.12, V.13 y V.14 se observan modificaciones del citoplasma, del córtex, de la endodermis y del periciclo.

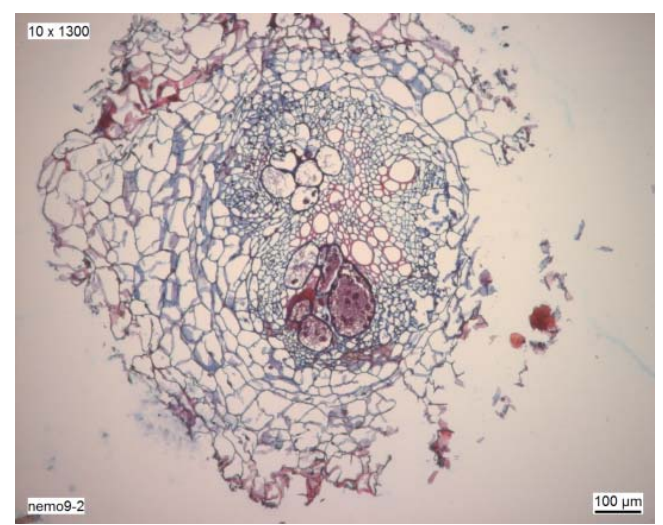

Fig.V.11.-Sección transversal de una raíz de pimiento infectada con el nematodo mostrando células gigantes (teñidas de rojo) causadas por los Juveniles del estadio IV (J4) (machos y hembras indiferenciados dentro de las células gigantes) y que producen las agallas en las raíces. 


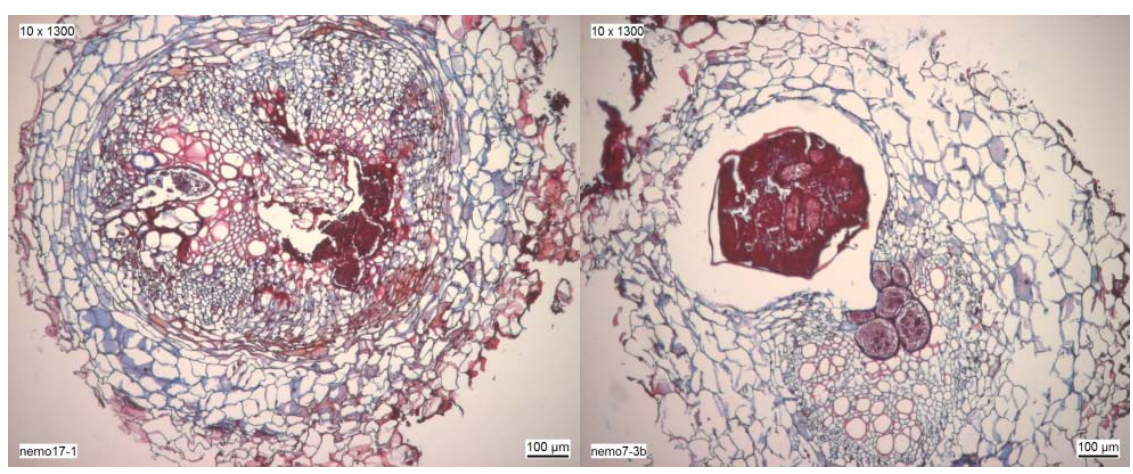

Fig.V.12.-Sección transversal de una raíz de pimiento infectada con el nematodo mostrando las células gigantes (teñidas de rojo) (derecha); una gran hembra adulta y una masa de huevos (izquierda) causadas por nematodos adultos.

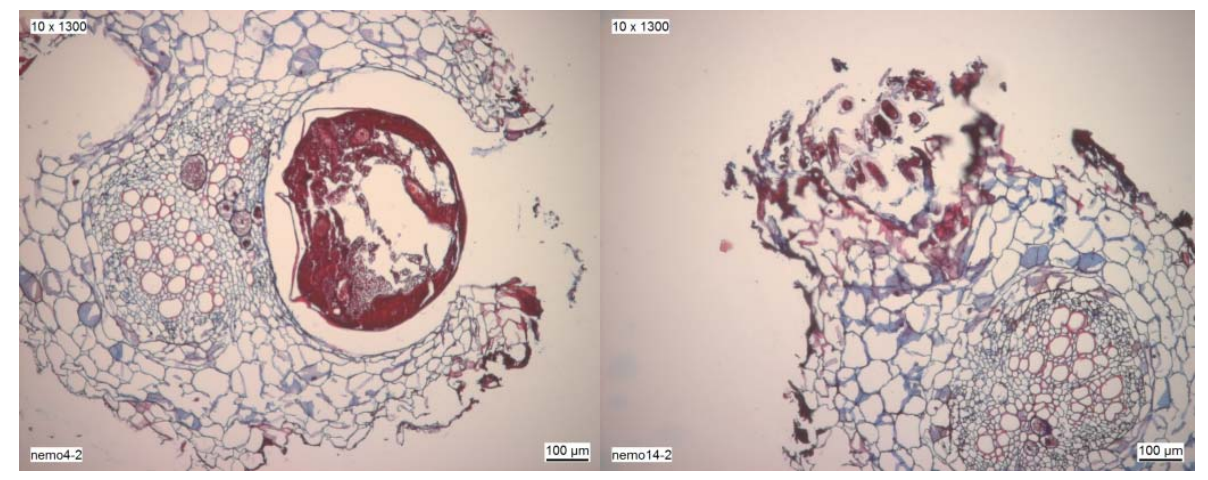

Fig.V.13.-Sección transversal de una raíz de pimiento infectada con el nematodo mostrando una gran agalla que contiene hembras y huevos y que ha roto la raíz por la zona de la agalla (derecha); una gran agalla abierta que expulsa huevos de los que emergerán Juveniles II (J2) que una vez libres en el suelo infectarán nuevas raíces.

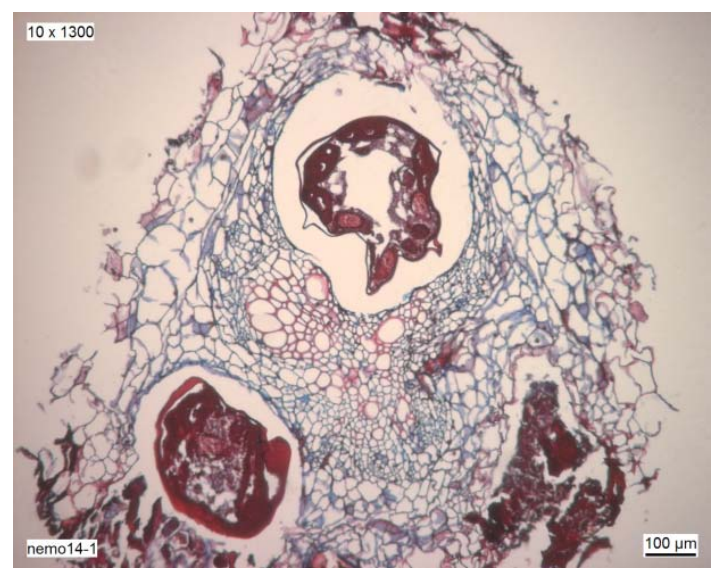

Fig.V.14.-Sección transversal de una raíz de pimiento infectada con el nematodo mostrando una raíz con agallas viejas que contiene varias hembras y sacos de huevos. 


\section{V.3. Inóculo del nematodo Meloidogyne incognita a partir de} plantas de pimiento y mantenimiento en plantas de pimiento y tomate

Tras confirmarse la presencia de nematodos en las raíces de las plantas de pimiento recogidas en el campo e infectar con ellas plantas de tomate y de pimiento se obtuvieron plantas enfermas como reservorio del patógeno. En la Fig.V.15 se muestran las plantas infectadas, conservadas en el invernadero de la UMU.

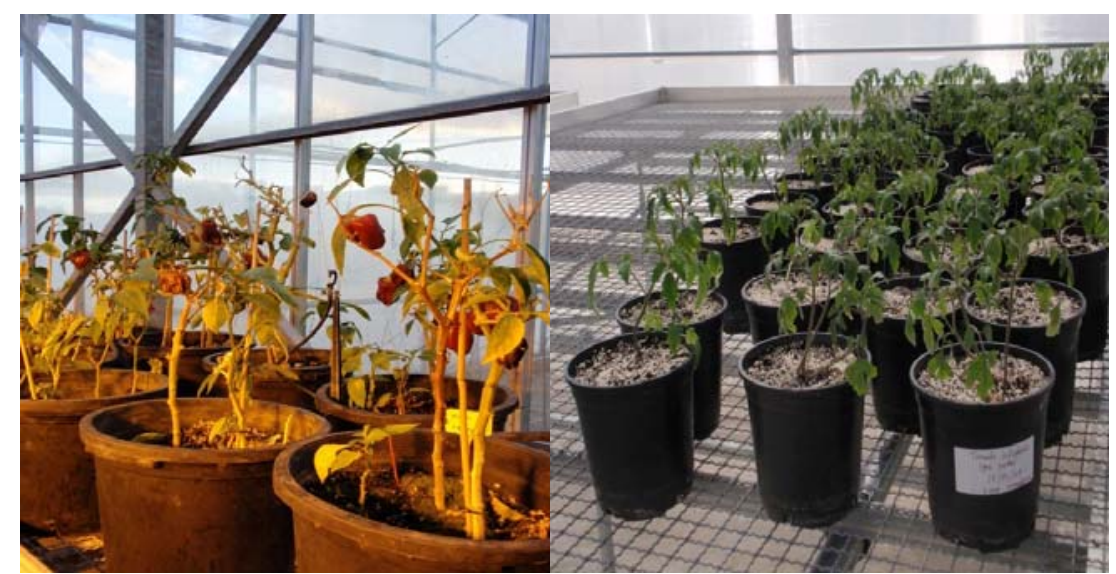

Fig. V.15.- Plantas de pimiento cv. California Wonder y de tomate cv Marmande reservorio del patógeno en las instalaciones de la Universidad de Murcia.

En la Fig. V.16 se muestran raíces de tomate donde se observan numerosas masas de huevos al ser teñidas con los distintos colorantes, para facilitar su conteo.

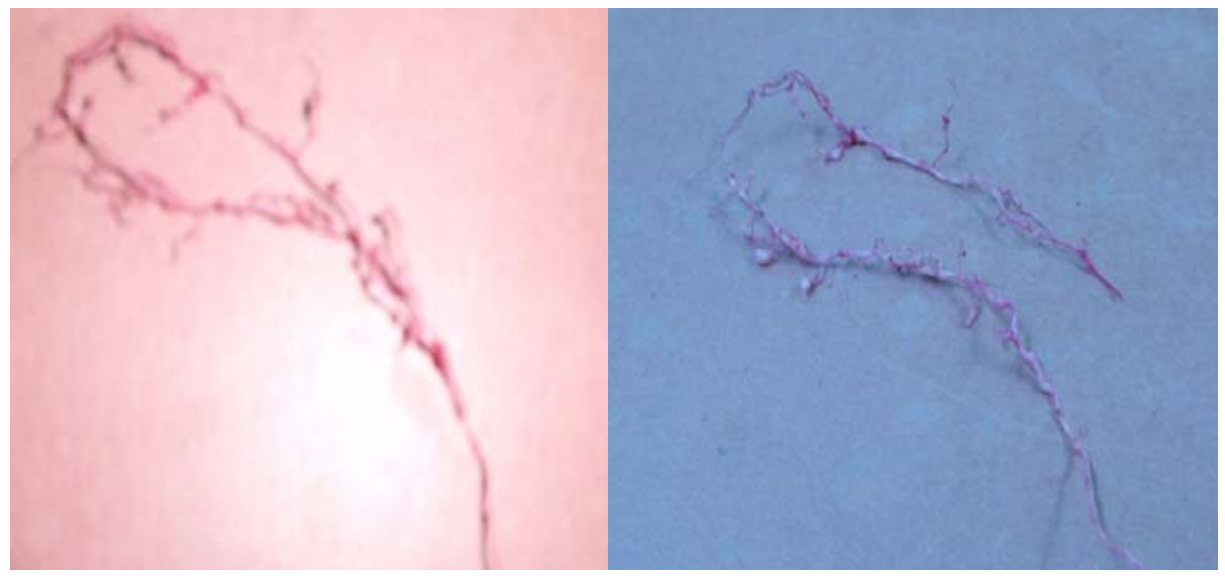

Fig.-V.16.- Raíces de tomate infectadas con Meloidogyne incognita. Se observan las masas de huevos teñidos con Fuchina ácida (izquierda) y con Phloxine B (derecha). 


\section{V.4. Análisis del límite de tolerancia de pimiento-Meloidogyne incognita}

Los síntomas de ataque de Meloidogyne incognita sobre las plantas de pimiento (decaimiento y amarilleamiento) fueron evidentes a los 40 días después de la inoculación a una población inicial de 5 huevos $+\mathrm{J}_{2} / \mathrm{ml}$ de suelo. Cincuenta días después de la inoculación, todas las plantas inoculadas con más de diez huevos $+\mathrm{J}_{2} /$ $\mathrm{ml}$ de suelo mostraron síntomas y un decaimiento claro y progresivo.

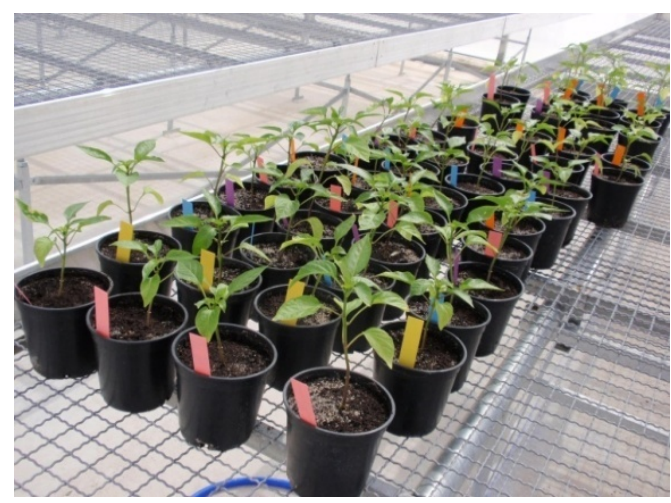

Fig.-V.17.- Plantas de pimientos de 3 meses, recién infectadas con diversas dosis de huevos $+\mathbf{J}_{2}$ de Meloidogyne incognita creciendo en invernadero.

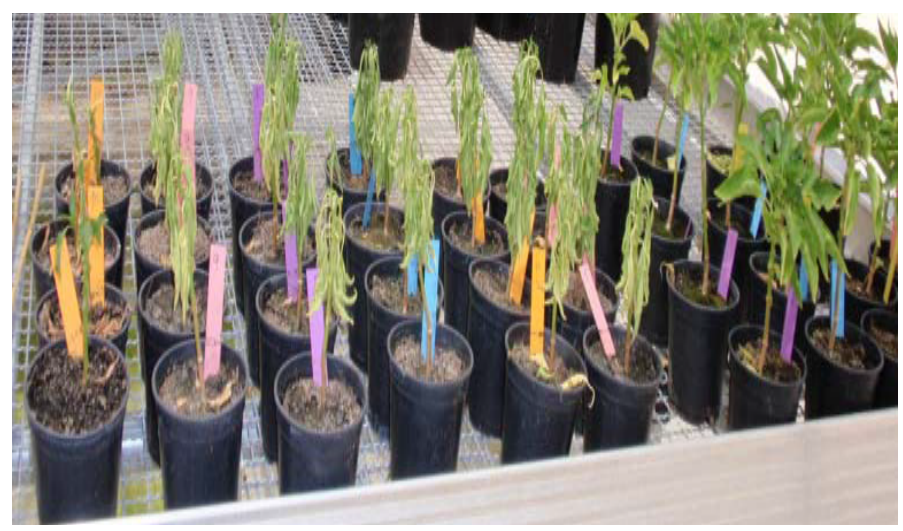

Fig.-V.18.- Plantas de pimiento a los 60 días de la infección con Meloidogyne incognita. Se observan plantas muertas desde las macetas 5 inoculadas con $\mathrm{Pi}=2$ (huevos $+\mathrm{J}_{2} / \mathrm{ml}$ de suelo).

En la Fig. V.19 se presentan las raíces de las plantas infectadas de pimiento preparadas para estimar el número de huevos y juveniles presentes en cada tesis de ensayo. 


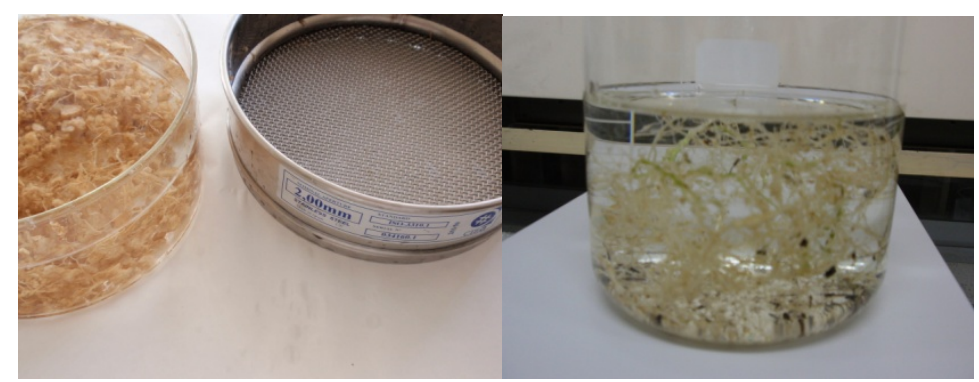

Fig.-V.19.- Raíces de pimiento con agallas ocasionadas por Meloidogyne incognita. Recién cortadas (izq.) y tamizadas a través de $2 \mathrm{~mm}$ y lavadas (derecha.)

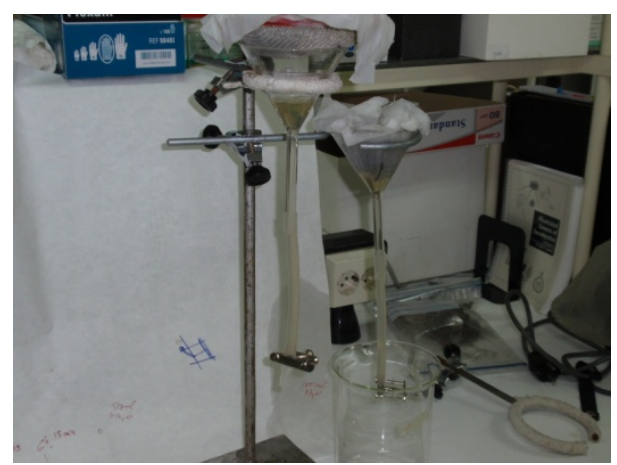

Fig.-V.20.- Aplicación del método de Baermann para obtener huevos y $\mathrm{J}_{2}$ de Meloidogyne incognita.

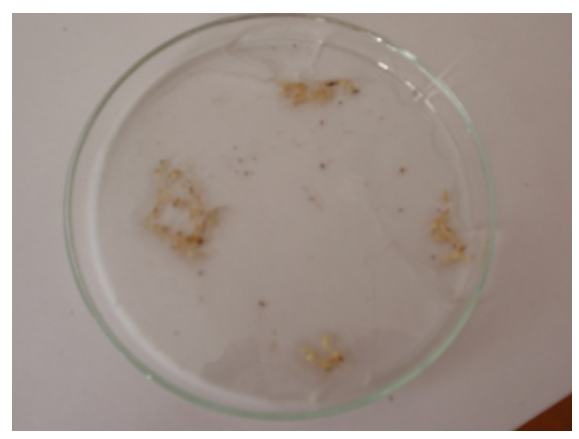

Fig.-V.21.- Masas de huevos de Meloidogyne incognita después de tratarlas con hipoclorito sódico al 5\% durante 3'y mantenidos en agua durante 24 horas. 


\begin{tabular}{|c|c|c|c|}
\hline $\begin{array}{c}\text { Densidad de } \\
\text { población } \\
\text { inicial (Pi) }\end{array}$ & RGS & $\begin{array}{c}\text { Densidad de } \\
\text { población final (Pf) }\end{array}$ & $\begin{array}{c}\text { Tasa de reproducción } \\
\text { (Pf/Pi) }\end{array}$ \\
\hline 0 & $0,0 \mathrm{j}$ & $0,0 \mathrm{k}$ & $0,0 \mathrm{k}$ \\
\hline 0,125 & $0,0 \mathrm{j}$ & $23,1 \mathrm{j}$ & $184,8 \mathrm{~g}$ \\
\hline 0,25 & $0,3 \mathrm{i}$ & $70,8 \mathrm{i}$ & $283,2 \mathrm{~b}$ \\
\hline 0,50 & $1,1 \mathrm{~h}$ & $120,5 \mathrm{~h}$ & $241,0 \mathrm{a}$ \\
\hline 1 & $2.3 \mathrm{~g}$ & $210,7 \mathrm{~g}$ & $210,7 \mathrm{f}$ \\
\hline 2 & $3,2 \mathrm{f}$ & $436,2 \mathrm{f}$ & $218,1 \mathrm{e}$ \\
\hline 4 & $5,7 \mathrm{e}$ & $1261,8 \mathrm{e}$ & $274,7 \mathrm{c}$ \\
\hline 8 & $6,3 \mathrm{~d}$ & $2197,5 \mathrm{~d}$ & $177,9 \mathrm{~h}$ \\
\hline 16 & $7,4 \mathrm{c}$ & $2846,3 \mathrm{c}$ & $116,7 \mathrm{i}$ \\
\hline 32 & $8,8 \mathrm{~b}$ & $3734,1 \mathrm{~b}$ & $65,8 \mathrm{j}$ \\
\hline 64 & $9,7 \mathrm{a}$ & $4211,8 \mathrm{a}$ & \\
\hline
\end{tabular}

Tabla V.1.-Relación entre la densidad de población inicial (Pi) de Meloidogyne incognita el grado de agallamiento, la densidad de población final (Pf) y la tasa de reproducción (Pf/Pi) en plantas de pimiento después de 50 días de inoculación. RGS es el índice de agallamiento. Los datos son el valor medio de 2 ensayos, cada uno con 6 plantas réplicas de tratamientos.

El límite de tolerancia (T) para pimientos cv. California Wonder a $M$. incognita se estima como 1,5 huevos $+\mathrm{J}_{2} / \mathrm{ml}$ de suelo para la altura y el peso de las plantas. El valor mínimo relativo (m) para la altura de las plantas y el peso de la parte aérea fue 0,16 a $P i \geq 64$ huevos $+\mathrm{J}_{2} / \mathrm{ml}$ de suelo. La reproducción máxima de los nematodos (Pf/Pi) fue 315,4 a una densidad inicial de población (Pi) de 4 huevos $+\mathrm{J}_{2}$ / $\mathrm{ml}$ de suelo. 


\section{V.5. Análisis de la confrontación “in vitro" de los antagonistas.}

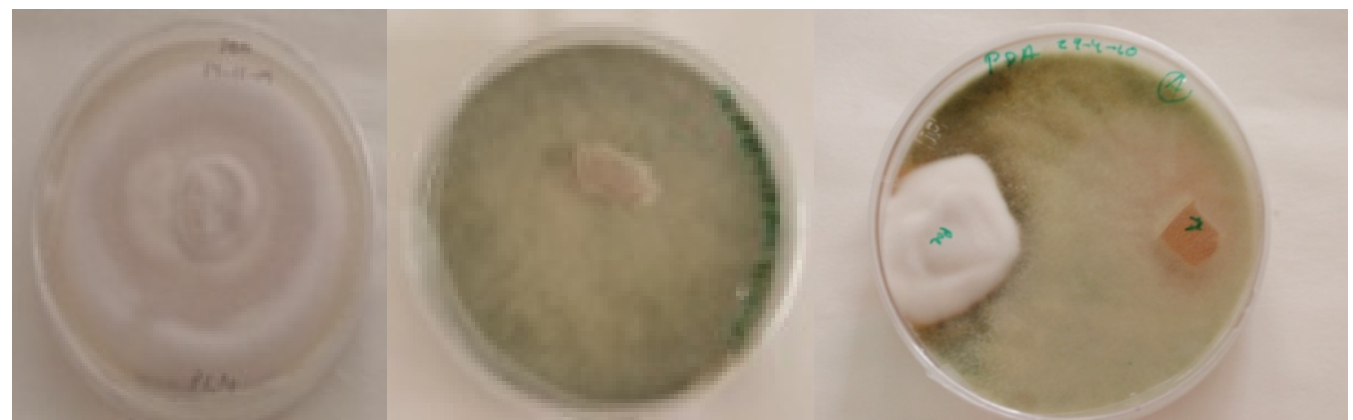

Fig.V.22.- Colonias de los dos hongos en estudio, Paecilomyces lilacinus (izquierda) y Trichoderma harzianum (centro), y en la derecha, la confrontación in vitro de ambos hongos, todos cultivados en medio PDA.

Al enfrentar los dos agentes de biocontrol "in vitro", en placas de PDA, se observa que aunque $T$. harzianum limita el crecimiento de $P$. lilacinus al competir por el medio de cultivo no son antagonistas entre sí, porque en ningún momento $T$. harzianum crece sobre P. lilacinus y no lo invade. Es una cuestión de la velocidad de crecimiento. T. harzianum es más rápido en crecer y llena la placa de cultivo mucho antes que $P$. lilacinus. Conociendo estas características, cuando se vayan a utilizar juntos, $P$. lilacinus debe añadirse antes a la rizosfera de las plantas en tratamiento para que cuando se adicione $T$. harzianum no impida el crecimiento de $P$. lilacinus. Como el mecanismo de cada hongo suma su efecto para obtener una combinación más favorable, el uso combinado de ambos, como estrategia de control del nematodo, es perfectamente posible.

\section{V.6. Ensayo con el agente de biocontrol P. lilacinus y el nematodo M. incognita.}

Los parámetros analizados en las plantas de pimiento infectadas con $M$. incognita y tratadas con P. lilacinus fueron: Altura de la parte aérea, Peso aéreo, Peso de la raíz, índice de agallamiento (RGS) y el número de huevos de nematodos por gramo de raíz. Los resultados se muestran en la Fig.V.23 y en la Tabla V.2 


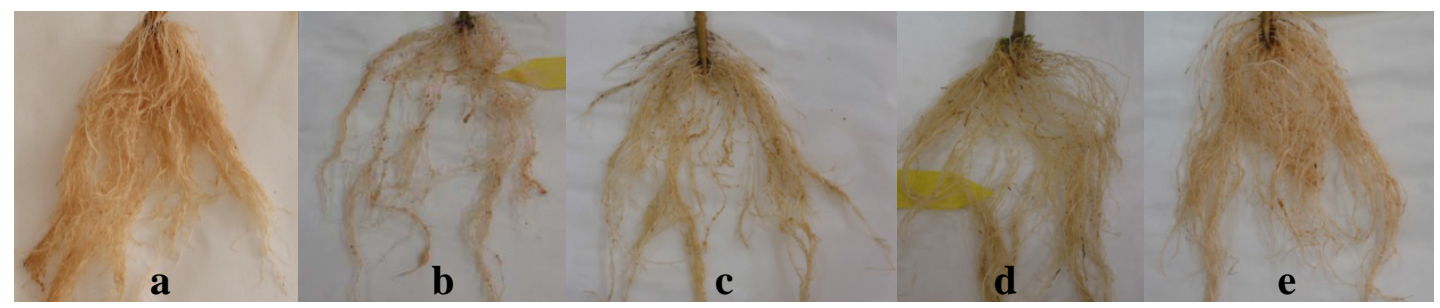

Fig.V.23.- Sistema radicular de pimiento con diferentes tratamientos; (a) no-infectada y notratada (control sano), (b) infectada y no-tratada (control infectado), (c) infectada y tratada con $P$. lilacinus, (d) infectada y tratada dos veces con $P$. lilacinus, (e) infectada y tratada dos veces con $P$. lilacinus, en vermiculita.

\begin{tabular}{|c|c|c|c|c|c|c|}
\hline $\begin{array}{c}\text { Tratamientos } \\
\text { efectuados }\end{array}$ & $\begin{array}{c}\text { Altura de la } \\
\text { planta } \\
\mathbf{( c m )}\end{array}$ & $\begin{array}{c}\text { Peso fresco } \\
\text { parte aérea } \\
\mathbf{( g )}\end{array}$ & $\begin{array}{c}\text { Peso fresco } \\
\text { de la raíz } \\
\mathbf{( g )}\end{array}$ & $\mathbf{R G S}$ & $\begin{array}{c}\mathbf{N}^{\mathbf{0}} \text { de huevos } \\
\text { (g peso }^{-\mathbf{1}} \text { ) }\end{array}$ & $\begin{array}{c}\text { Efectivida } \\
\text { d control } \\
\mathbf{( \% )}\end{array}$ \\
\hline $\mathbf{C S}$ & $31,53 \pm 1,3 \mathrm{c}$ & $15,42 \pm 2,1 \mathrm{~b}$ & $8,69 \pm 0,8 \mathrm{c}$ & 0 & 0 & \\
\hline $\mathbf{C N}$ & $19,08 \pm 1,4 \mathrm{a}$ & $8,02 \pm 1,6 \mathrm{a}$ & $3,86 \pm 0,7 \mathrm{a}$ & $7,00 \pm 2,7 \mathrm{a}$ & $835,85 \pm 2,3 \mathrm{a}$ & \\
\hline $\mathbf{P}+\mathbf{N}$ & $25,58 \pm 3,4 \mathrm{ab}$ & $14,18 \pm 0,8 \mathrm{~b}$ & $7,01 \pm 0,6 \mathrm{bc}$ & $6,25 \pm 1,8 \mathrm{~b}$ & $627,86 \pm 1,6 \mathrm{a}$ & 24,88 \\
\hline $\mathbf{2 P}+\mathbf{N}$ & $24,63 \pm 2,3 \mathrm{ab}$ & $13,77 \pm 1,3 \mathrm{~b}$ & $6,70 \pm 0,4 \mathrm{~b}$ & $5,00 \pm 0,9 \mathrm{bc}$ & $503 \pm 2,7 \mathrm{ab}$ & 39,82 \\
\hline Vermi & $28,82 \pm 3,0 \mathrm{bc}$ & $14,93 \pm 1,0 \mathrm{~b}$ & $8,12 \pm 0,7 \mathrm{bc}$ & $4,00 \pm 1,3 \mathrm{c}$ & $471,51 \pm 1,4 \mathrm{~b}$ & 43,59 \\
\hline
\end{tabular}

Tabla.V.2.-Valor medio $( \pm \mathrm{SE})$ de parámetros de crecimiento (parte aérea y raíz), RGS (índice de agallamiento y número de huevos por gramo de raíz de plantas de pimiento para los diferentes (CS: Control sano; $\mathrm{CN}$ : Control infectado con $M$. incognita; $\mathrm{P}+\mathrm{N}$ : inoculado con $\boldsymbol{P}$. lilacinus e infectado con $M$. incognita; $2 \mathrm{P}+\mathrm{N}$ : inoculado dos veces con $P$. lilacinus e infectado con M. incognita; Vermi: inoculado dos veces con $P$. lilacinus e infectado con $M$. incognita, en vermiculita).

Los datos de la Fig.V.23 muestran que el tratamiento con P. lilacinus sobre plantas infectadas no es efectivo cuando se añade el hongo directamente a las raíces aun cuando se trate dos veces y proceda de un cultivo en vermiculita. La disminución del número de huevos en las raíces llega a tener una efectividad del 43,59\%. Esta mejoría no es suficiente para que la planta obtenga un desarrollo adecuado aunque hay que tener en cuenta que la concentración del inóculo inicial de $M$. incognita fue 3000 huevos $+\mathbf{J}_{2}$. 


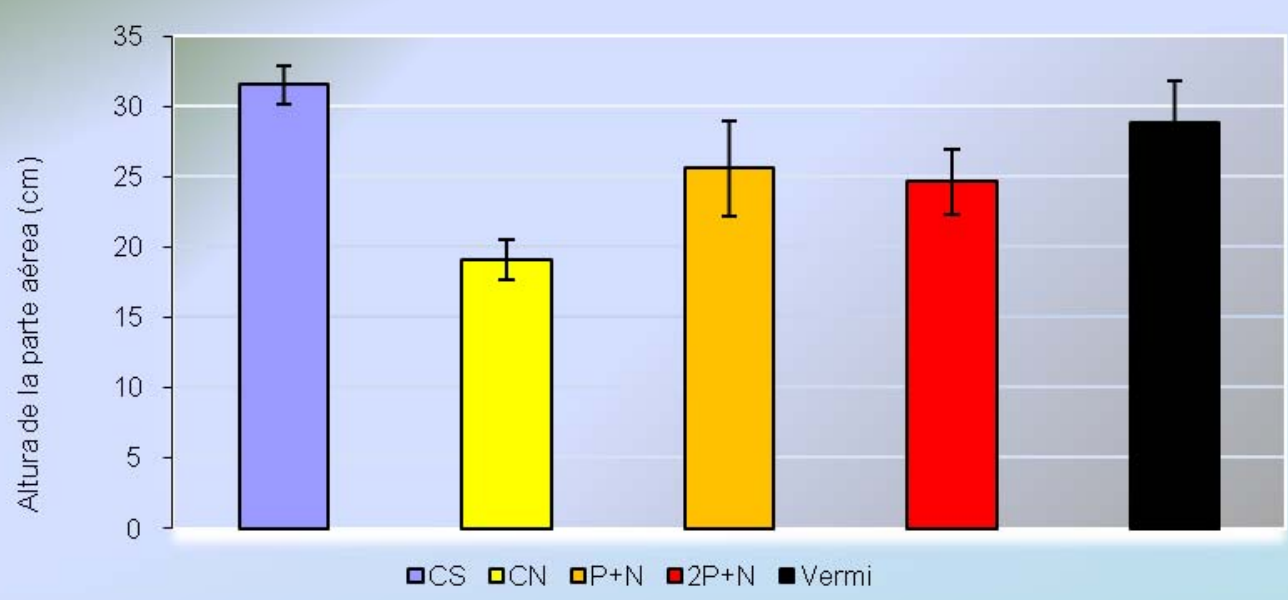

Fig.V.24.- Valor medio de la altura de las plantas de pimiento para los diferentes tratamientos (CS: Control sano; CN: Control infectado con $M$. incognita; $\mathrm{P}+\mathrm{N}$ : inoculado con $P$. lilacinus e infectado con $M$. incognita; $2 \mathrm{P}+\mathrm{N}$ : inoculado dos veces con $P$. lilacinus e infectado con $M$. incognita; Vermi: inoculado dos veces con $P$. lilacinus e infectado con $M$. incognita, en vermiculita).

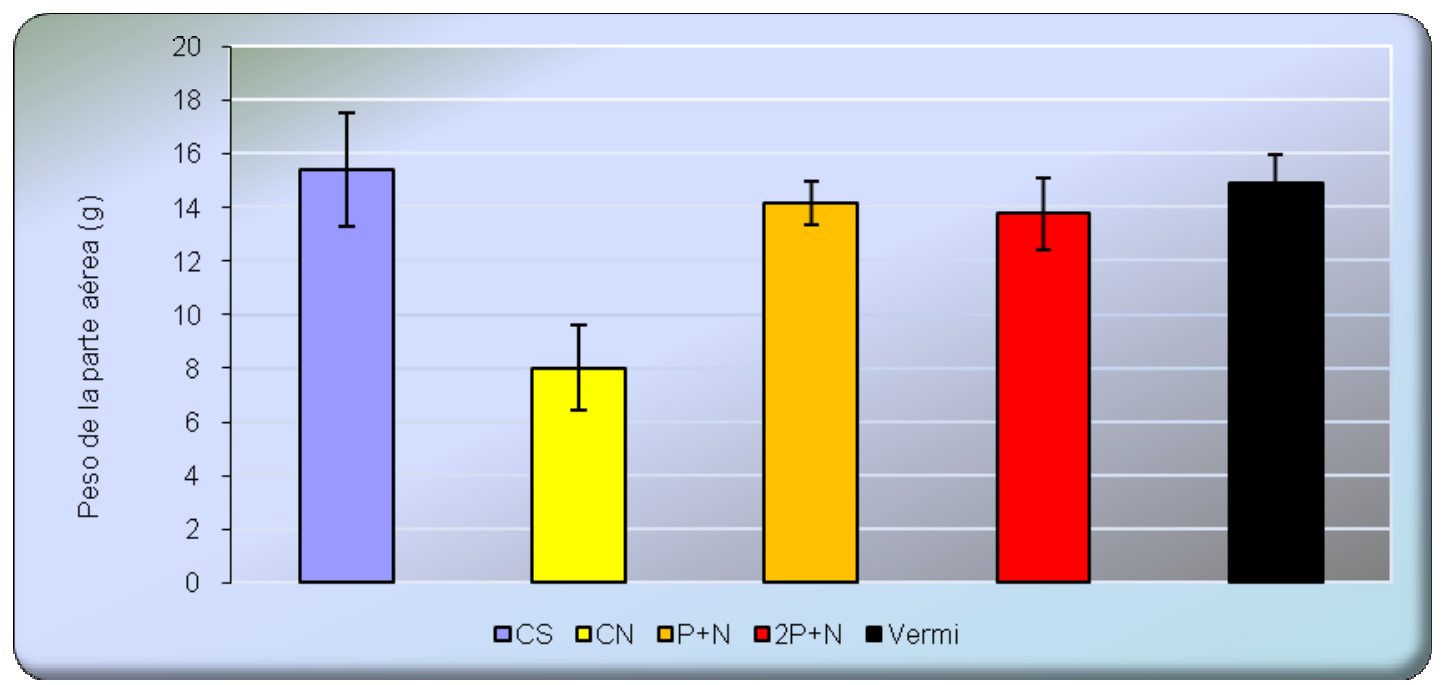

Fig.V.25.- Valor medio del peso fresco de la parte aérea de las plantas de pimiento para los diferentes tratamientos (CS: Control sano; $\mathrm{CN}$ : Control infectado con M. incognita; P+N: inoculado con $P$. lilacinus e infectado con $M$. incognita; $2 \mathrm{P}+\mathrm{N}$ : inoculado dos veces con $\boldsymbol{P}$. lilacinus e infectado con $M$. incognita; Vermi: inoculado dos veces con $P$. lilacinus e infectado con $M$. incognita, en vermiculita). 


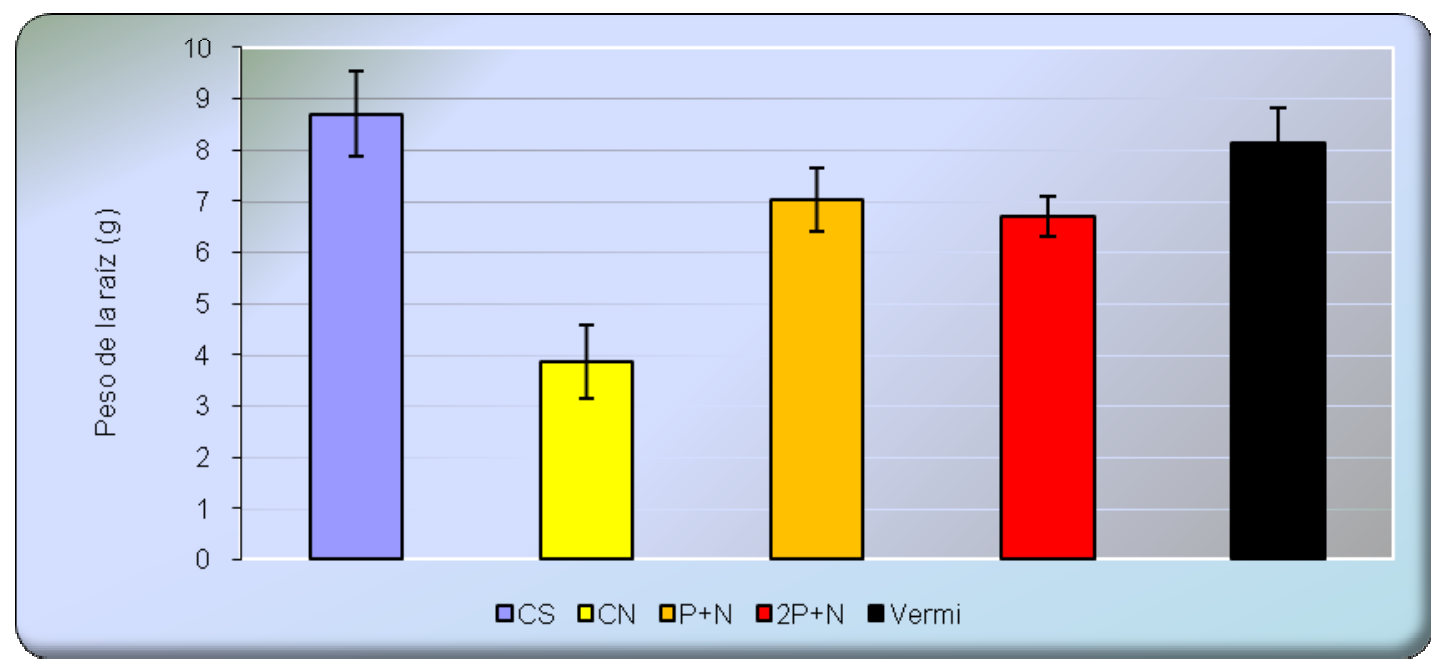

Fig.V.26.-: Valor medio del peso fresco de la raíz de las plantas de pimiento para los diferentes tratamientos (CS: Control sano; $\mathrm{CN}$ : Control infectado con $M$. incognita; $\mathrm{P}+\mathrm{N}$ : inoculado con $P$. lilacinus e infectado con $M$. incognita; $2 \mathrm{P}+\mathrm{N}$ : inoculado dos veces con $P$. lilacinus e infectado con M. incognita; Vermi: inoculado dos veces con P. lilacinus e infectado con $M$. incognita, en vermiculita).

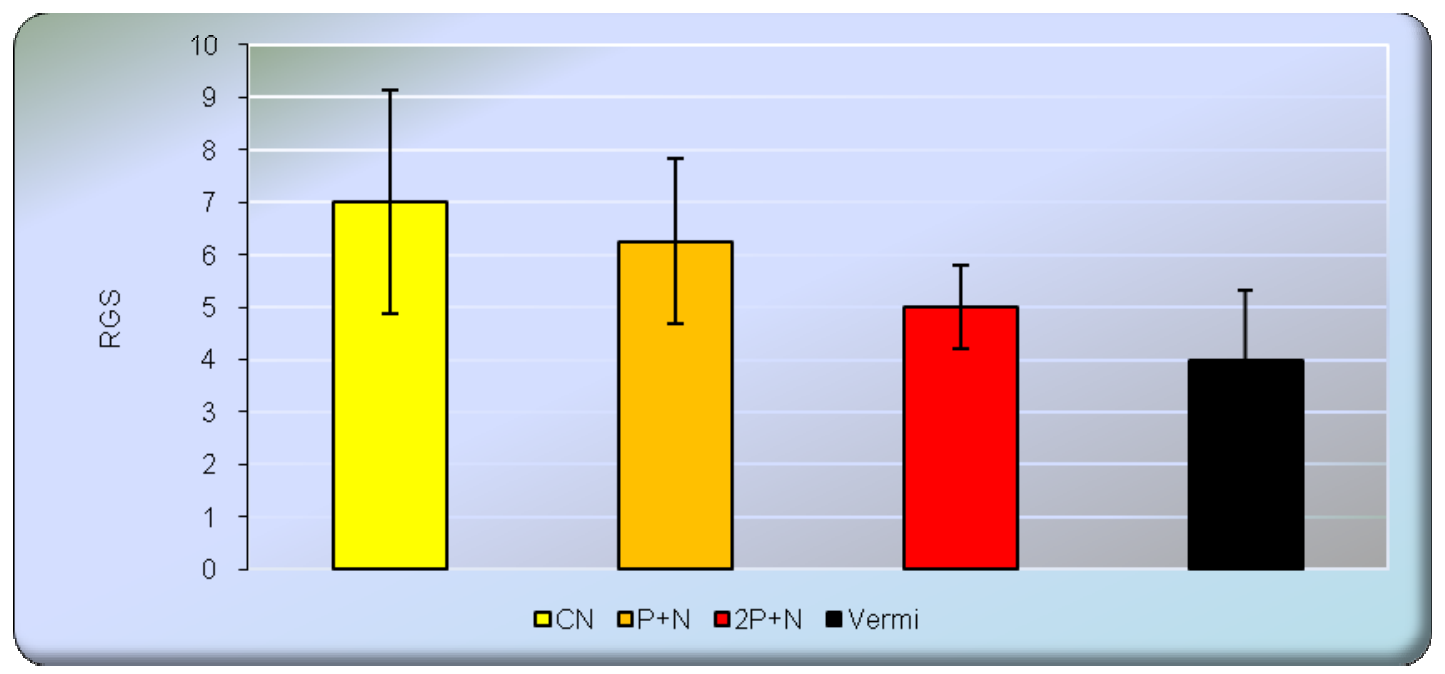

Fig.V.27.-: Valor medio de RGS (Índice de agallamiento) de las plantas de pimiento para los diferentes tratamientos (CS: Control sano; $\mathrm{CN}$ : Control infectado con $M$. incognita; $\mathrm{P}+\mathrm{N}$ : inoculado con $P$. lilacinus e infectado con $M$. incognita; $2 \mathrm{P}+\mathrm{N}$ : inoculado dos veces con $P$. lilacinus e infectado con $M$. incognita; Vermi: inoculado dos veces con $P$. lilacinus e infectado con $M$. incognita, en vermiculita). 


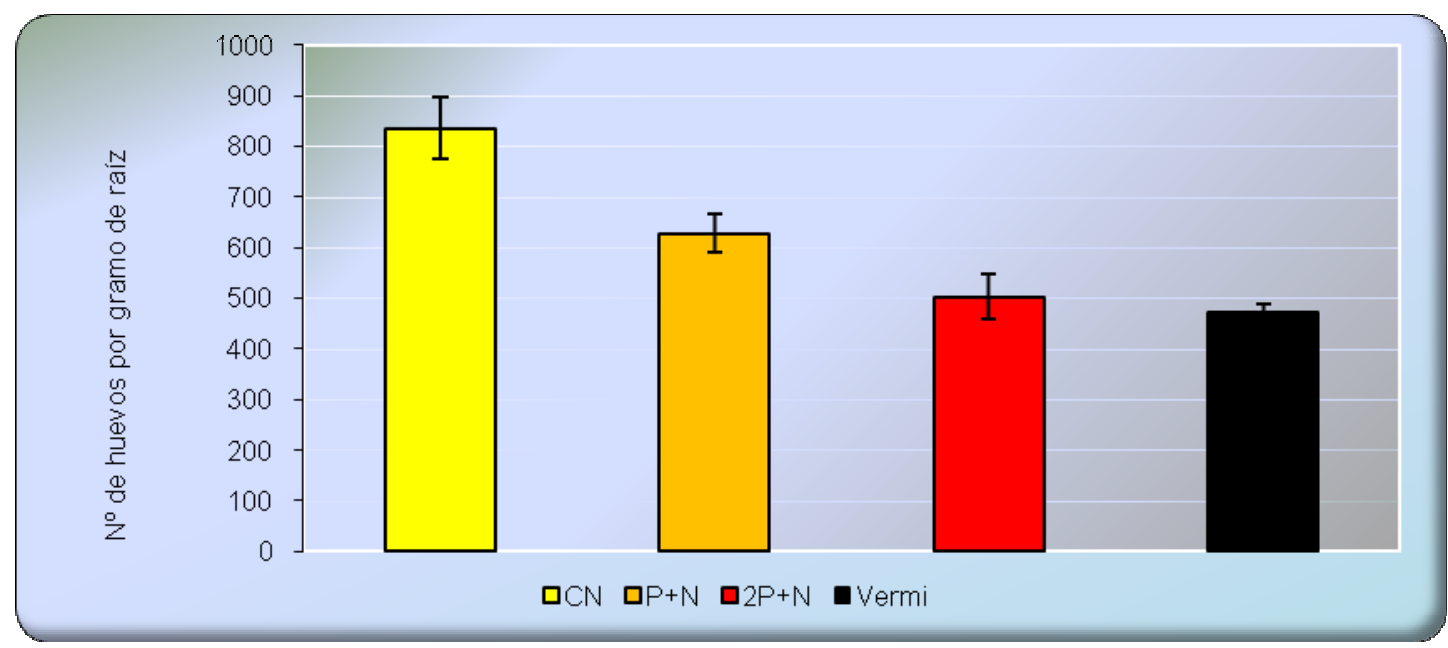

Fig.V.28.- Valor medio del número de huevos $+J_{2}$ por gramo de raíz de las plantas de pimiento para los diferentes tratamientos (CS: Control sano; CN: Control infectado con M. incognita; $\mathbf{P}+\mathrm{N}$ : inoculado con $\boldsymbol{P}$. lilacinus e infectado con $M$. incognita; $2 \mathrm{P}+\mathrm{N}$ : inoculado dos veces con $\boldsymbol{P}$. lilacinus e infectado con $M$. incognita; Vermi: inoculado dos veces con $P$. lilacinus e infectado con $M$. incognita, en vermiculita).

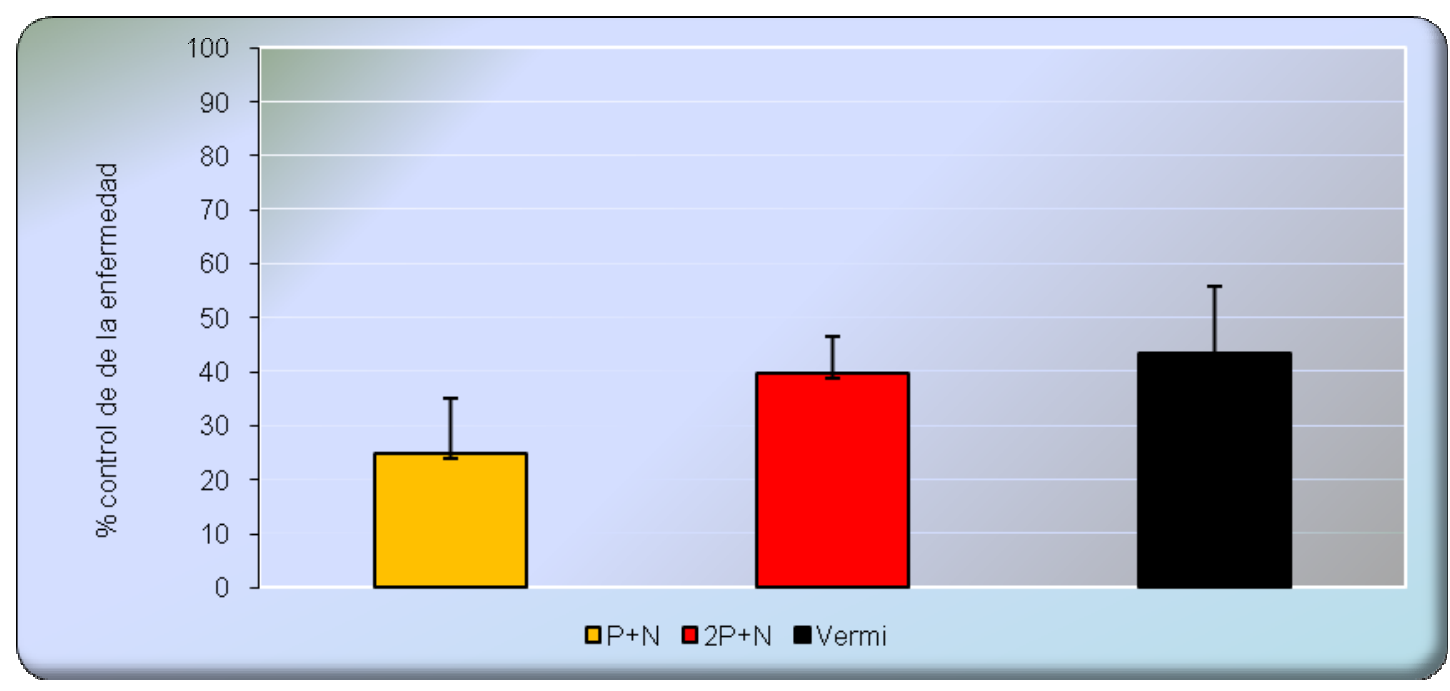

Fig.V.29.- Porcentaje de control sobre huevos+juveniles de $M$. incognita por gramo de raíz de las plantas de pimiento para los diferentes tratamientos $(\mathrm{P}+\mathrm{N}$ : inoculado con $P$. lilacinus e infectado con $M$. incognita; $2 \mathrm{P}+\mathrm{N}$ : inoculado dos veces con $P$. lilacinus e infectado con $M$. incognita; Vermi: inoculado dos veces con $P$. lilacinus e infectado con $M$. incognita, en vermiculita). 


\section{V.7. Ensayo con dos agentes de biocontrol P. lilacinus y $T$. harzianum y el nematodo $M$. incognita.}

\section{V.7.1. Ensayo sin reposición de $P$. lilacinus y $T$. harzianum}

Los resultados obtenidos al tratar las plantas de pimiento infectadas con el nematodo Meloidogyne incognita se recogen en la Fig. V.30 donde se muestra el sistema radicular sano e infectado con agallas. Los parámetros medidos se reflejan en la Tabla V.4 así como la efectividad de los tratamientos que han sido simples, sin reposición de la adición del hongo $P$. lilacinus.

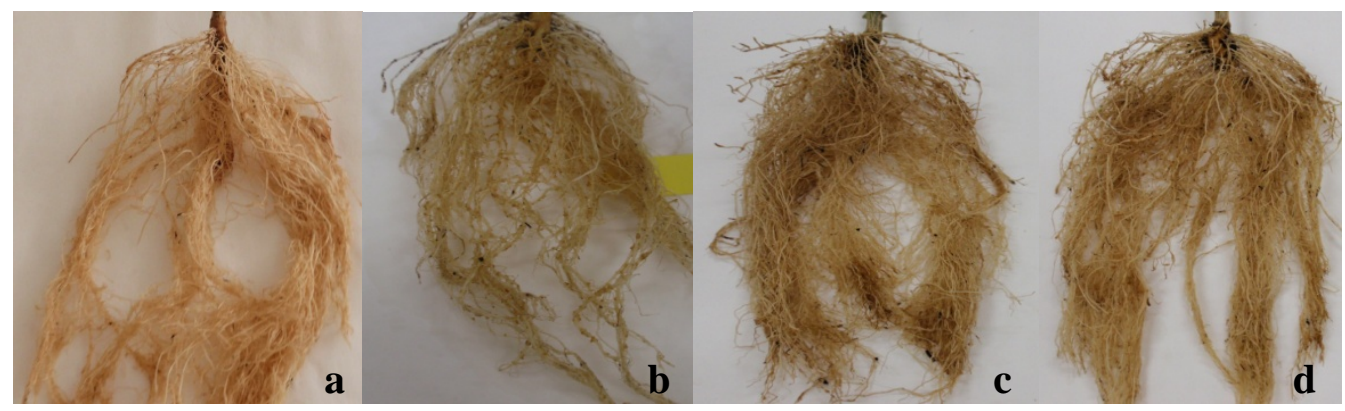

Fig.V.30.- Sistema radicular de pimiento con diferentes tratamientos; (a) no-infectada y no tratada (control sano), (b) infectada y no-tratada (control infectado), (c) infectada y tratada con P. lilacinus, (d) infectada y tratada con P. lilacinus y T. harzianum.

\begin{tabular}{|c|c|c|c|c|c|c|}
\hline $\begin{array}{c}\text { Tratamientos } \\
\text { efectuados }\end{array}$ & $\begin{array}{c}\text { Altura de la } \\
\text { planta } \\
(\mathbf{c m})\end{array}$ & $\begin{array}{l}\text { Peso fresco } \\
\text { parte aérea } \\
\text { (g) }\end{array}$ & $\begin{array}{c}\text { Peso fresco de la } \\
\text { raíz } \\
\text { (g) }\end{array}$ & RGS & $\begin{array}{l}\text { No de huevos }^{\circ} \\
\left.\text { (g peso }^{-1}\right)\end{array}$ & $\begin{array}{c}\text { Efectividad } \\
\text { de control } \\
(\%)\end{array}$ \\
\hline $\mathrm{CS}$ & $31,20 \pm 1,3 b$ & $20,1 \pm 2,7 \mathrm{a}$ & $12,69 \pm 3,9 \mathrm{a}$ & 0 & 0 & \\
\hline $\mathrm{CN}$ & $24,54 \pm 2,4 \mathrm{c}$ & $11,58 \pm 1,5 \mathrm{~b}$ & $11,42 \pm 3,7 \mathrm{a}$ & $4,00 \pm 3,5 \mathrm{c}$ & $397,65 \pm 3,7 \mathrm{c}$ & \\
\hline $\mathrm{P}+\mathrm{N}$ & $29,00 \pm 2,6 \mathrm{ab}$ & $16,65 \pm 3,2 \mathrm{a}$ & $13,00 \pm 2,5 \mathrm{a}$ & $2,60 \pm 2,7 b$ & $204,39 \pm 2,2 b$ & 48,60 \\
\hline $\mathrm{P}+\mathrm{TH}+\mathrm{N}$ & $30,21 \pm 3,8 \mathrm{a}$ & $18,55 \pm 2,6 \mathrm{a}$ & $13,71 \pm 2,4 \mathrm{a}$ & $1,50 \pm 3,1 \mathrm{a}$ & $126,61 \pm 2,1 \mathrm{a}$ & 68,16 \\
\hline
\end{tabular}

Tabla.V.3.-Valor medio ( \pm ) de parámetros de crecimiento (parte aérea y raíz), RGS (índice de agallamiento) y número de huevos por gramo de raíz de plantas de pimiento para los diferentes tratamientos (CS: Control sano; CN control infectado con $M$. incognita; P: inoculado con $P$. lilacinus e infectado con $M$. incognita; P+TH: inoculado con $P$. lilacinus y $T$. harzianum e infectado con $M$. incognita. 
En el sistema radicular los efectos de los tratamientos indican que la disminución de las agallas y el $\mathrm{n}^{\mathrm{o}}$ de huevos es significativa así como la altura y el peso fresco de la parte aérea y de la raíz. Con respecto a la acción individual la efectividad con solo $P$. lilacinus es menor del 50\% pero llega hasta el $68,16 \%$ cuando se usa la mezcla de ambos antagonistas. De todas formas, aún este tratamiento último tampoco es satisfactorio como para ser usado con éxito en plantas infectadas aun mas teniendo en cuenta que la concentración inicial de inóculo se bajó a 1500 huevos $+\mathbf{J}_{2}$.

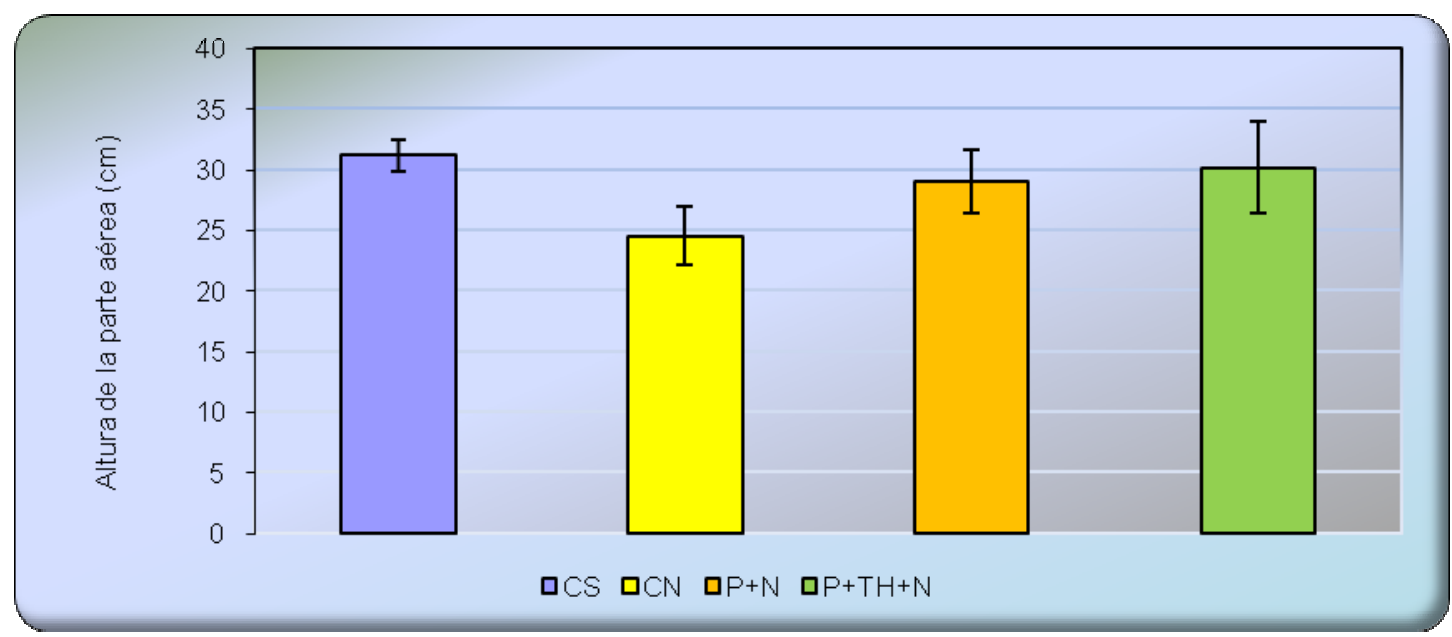

Fig.V.31.- Valor medio de la altura de las plantas de pimiento para los diferentes tratamientos (CS: Control sano; CN: Control infectado con $M$. incognita; $\mathrm{P}+\mathrm{N}$ : inoculado con P. lilacinus e infectado con $M$. incognita y $\mathbf{P}+\mathrm{TH}+\mathrm{N}$ : inoculado con $P$. lilacinus y $T$. harzianum e infectado con M. incognita).

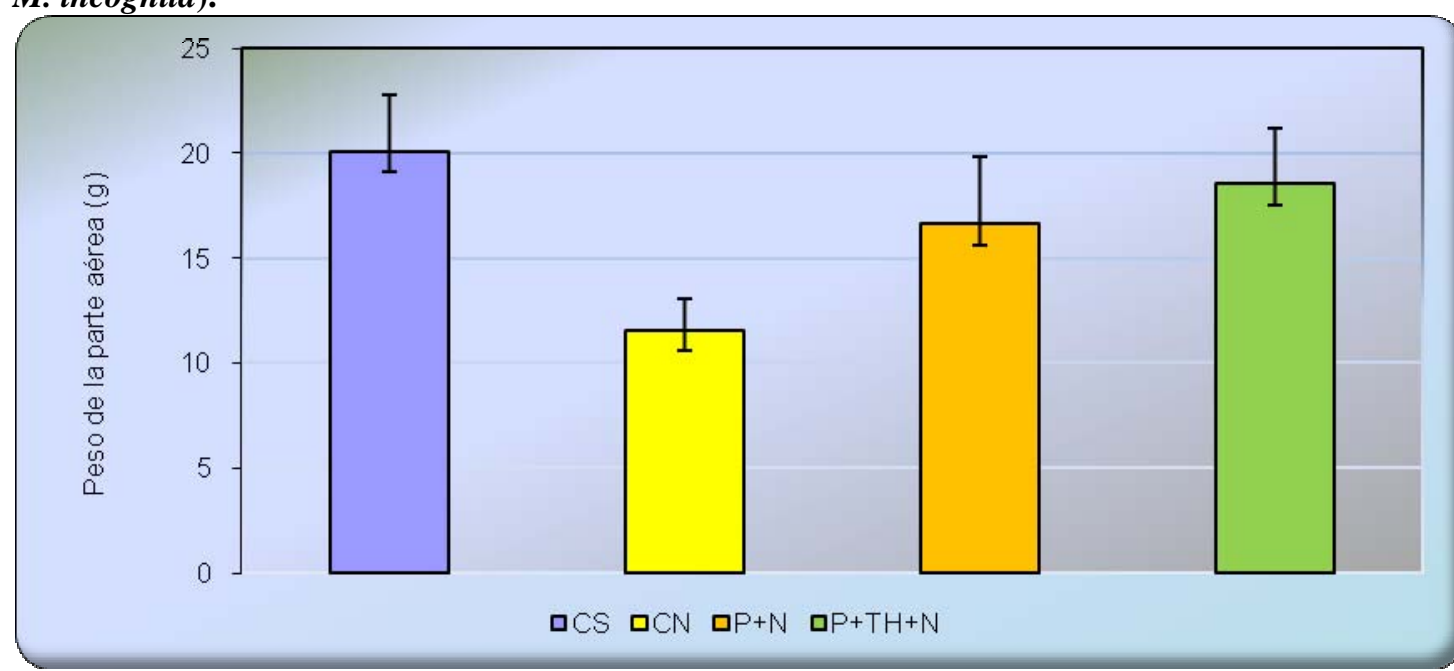

Fig.V.32 Valor medio del peso fresco aéreo de las plantas de pimiento para los diferentes tratamientos (CS: Control sano; CN: Control infectado con $M$. incognita; $\mathbf{P}+\mathrm{N}$ : inoculado con $P$. lilacinus e infectado con $M$. incognita y $\mathbf{P}+\mathrm{TH}+\mathrm{N}$ : inoculado con P. lilacinus y $T$. harzianum e infectado con $M$. incognita) 


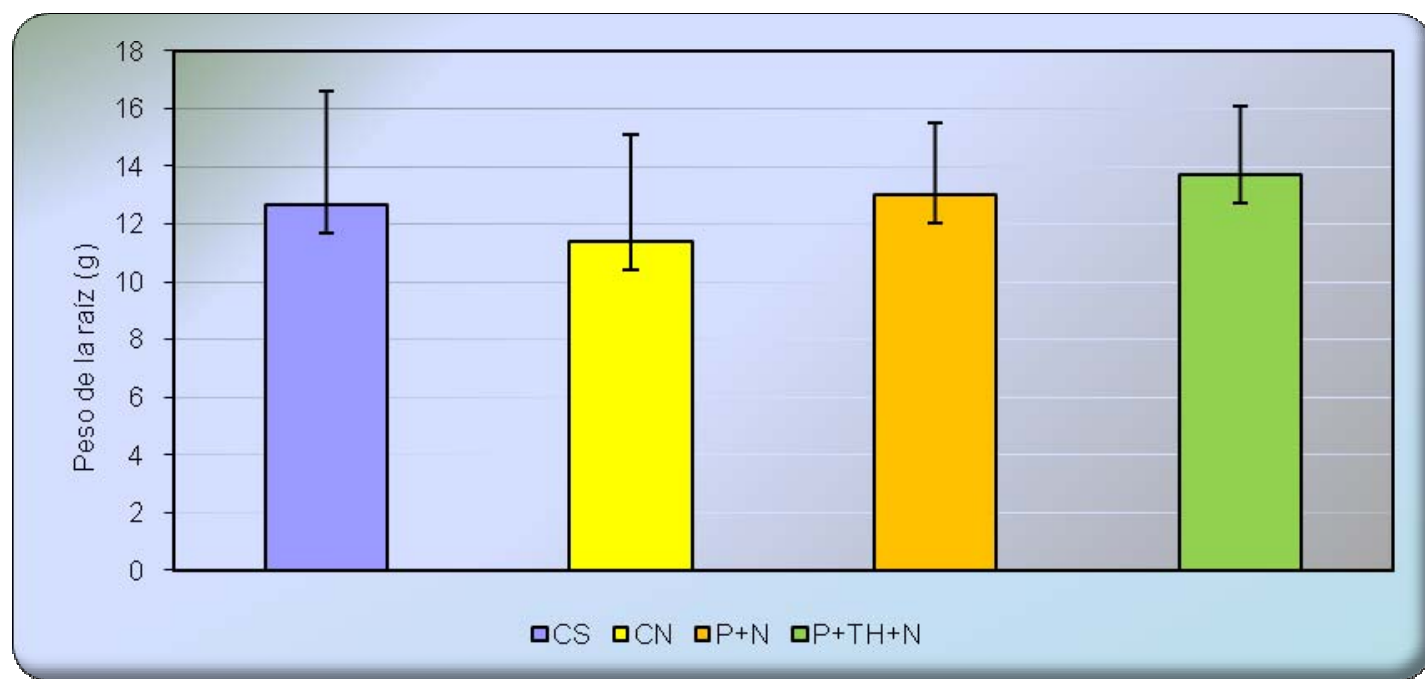

Fig.V.33.- Valor medio del peso fresco de la raíz de las plantas de pimiento para los diferentes tratamientos (CS: Control sano; CN: Control infectado con $M$. incognita; $\mathbf{P}+\mathrm{N}$ : inoculado con $P$. lilacinus e infectado con $M$. incognita y $\mathbf{P}+\mathbf{T H}+\mathrm{N}$ : inoculado con $P$. lilacinus y $T$. harzianum e infectado con $M$. incognita)

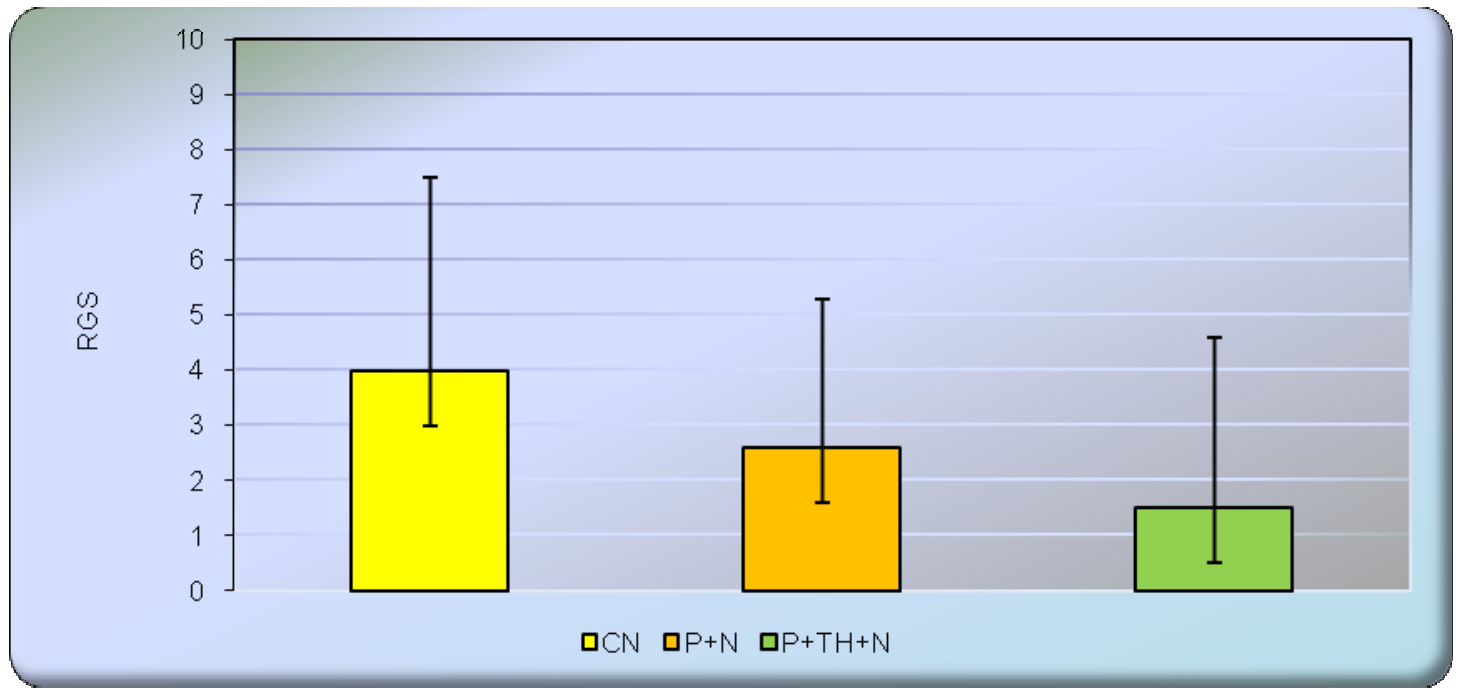

Fig.V.34. Valor medio de RGS (Índice de agallamiento) de las plantas de pimiento para los diferentes tratamientos (CS: Control sano; CN: Control infectado con M. incognita; P+N: inoculado con $P$. lilacinus e infectado con $M$. incognita y $\mathbf{P}+\mathrm{TH}+\mathrm{N}$ : inoculado con $P$. lilacinus $y$ T. harzianum e infectado con $M$. incognita) 


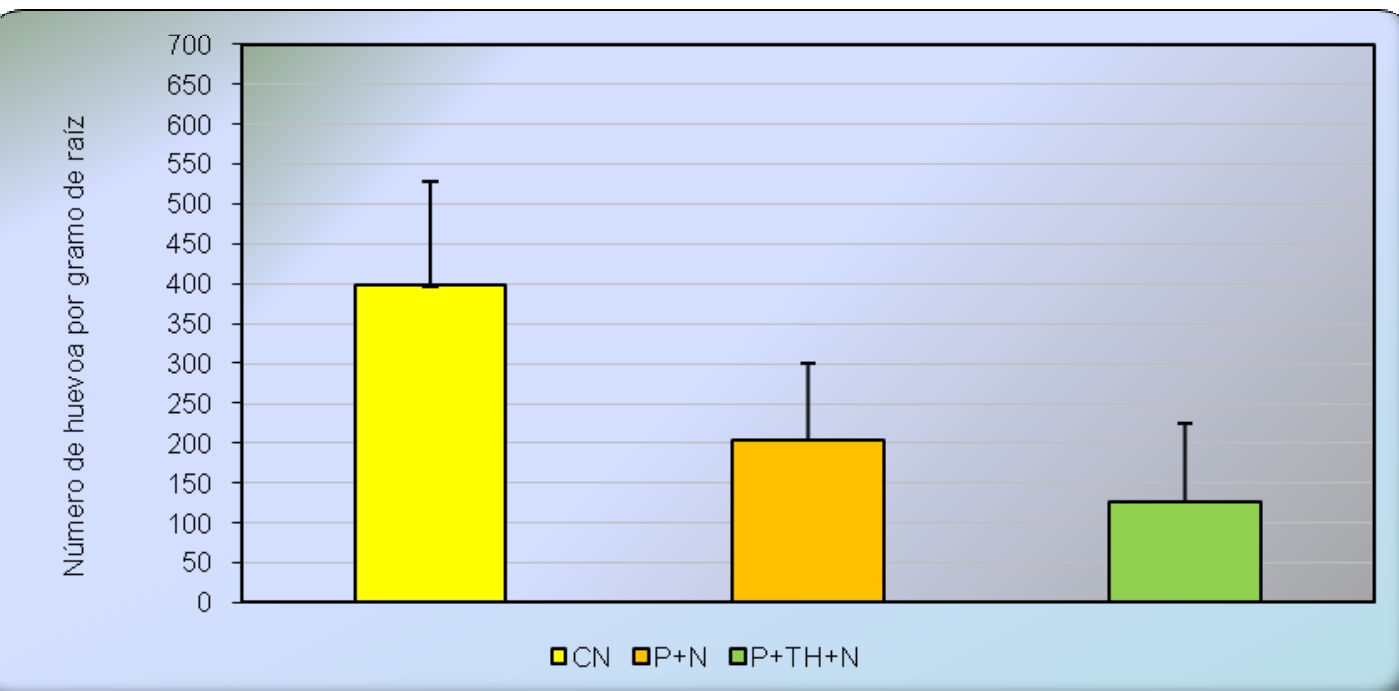

Fig.V.35.- Valor medio del número de huevos $+\mathrm{J}_{2}$ por gramo de raíz de las plantas de pimiento para los diferentes tratamientos (CS: Control sano; CN: Control infectado con M. incognita; $\mathrm{P}+\mathrm{N}$ : inoculado con $P$. lilacinus e infectado con $M$. incognita y $\mathrm{P}+\mathrm{TH}+\mathrm{N}$ : inoculado con $P$. lilacinus y T. harzianum e infectado con $M$. incognita).

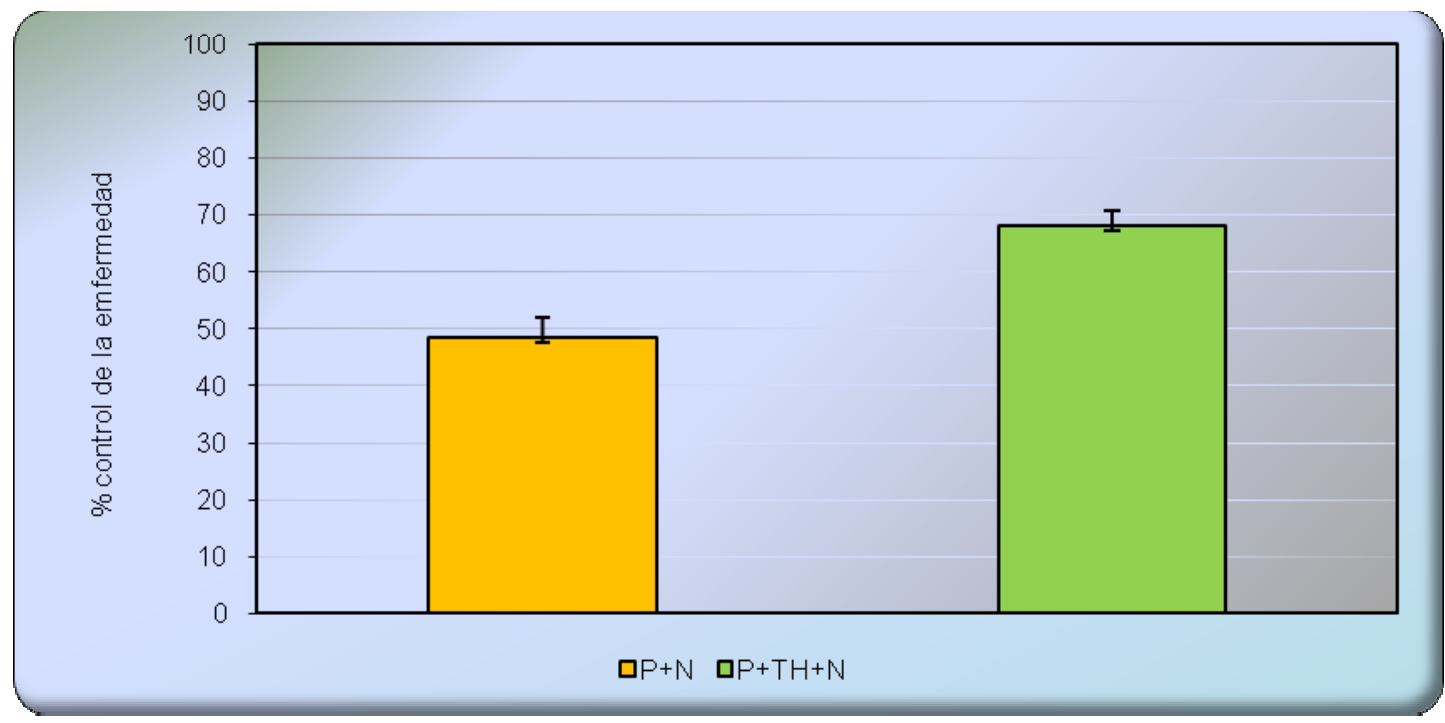

Fig.V.36.- Porcentaje de control sobre los huevos $+\mathrm{J}_{2}$ de $M$. incognita por gramo de raíz de las plantas de pimiento para los diferentes tratamientos (CS: Control sano; CN: Control infectado con $M$. incognita; $\mathrm{P}+\mathrm{N}$ : inoculado con $P$. lilacinus e infectado con $M$. incognita y $\mathrm{P}+\mathrm{TH}+\mathrm{N}$ : inoculado con $P$. lilacinus y $T$. harzianum e infectado con $M$. incognita). 


\section{V.7.2. $\quad$ Ensayo con reposición de $P$. lilacinus y $T$. harzianum}
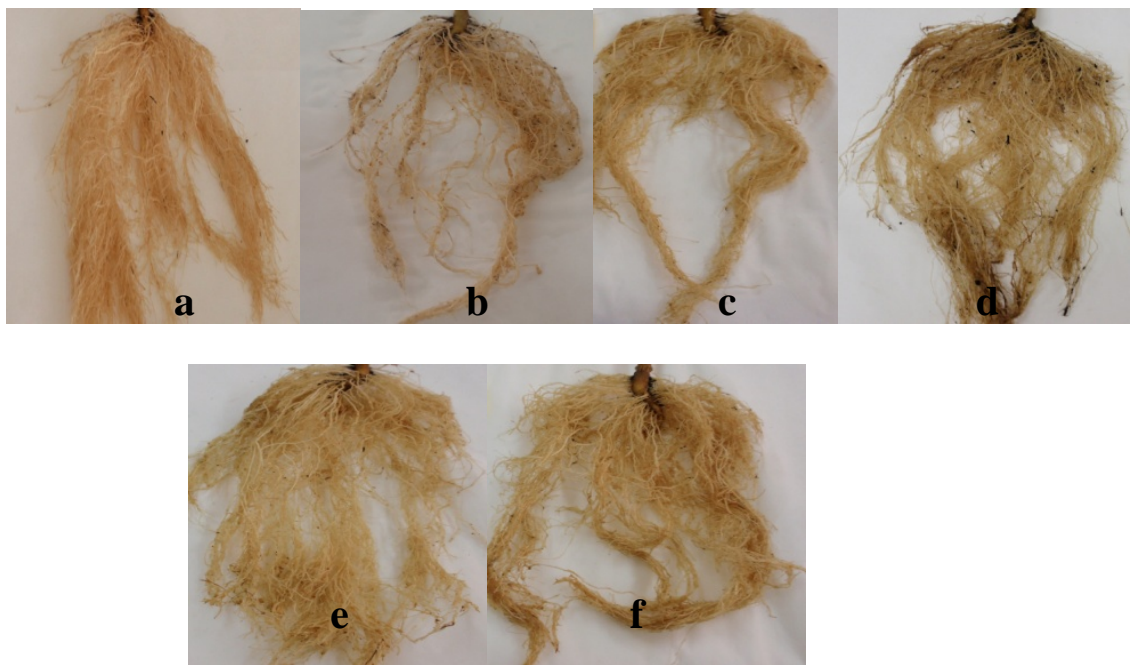

Fig.V.37.- Sistema radicular de pimiento con diferentes tratamientos; (a) no-infectada y notratada (control sano), (b) infectada y no-tratada (Control infectado), (c) infectada y tratada dos veces con $P$. lilacinus, (d) infectada y tratada con $T$. harzianum, (e) infectada y tratada con $P$. lilacinus y T. harzianum, en vermiculita, (f) infectada y tratada con P. lilacinus y T. harzianum.

\begin{tabular}{|c|c|c|c|c|c|c|}
\hline $\begin{array}{c}\text { Tratamientos } \\
\text { efectuados }\end{array}$ & $\begin{array}{c}\text { Altura de la } \\
\text { planta } \\
\text { (cm) }\end{array}$ & $\begin{array}{c}\text { Peso fresco } \\
\text { de la parte } \\
\text { aérea } \\
\mathbf{( g )}\end{array}$ & $\begin{array}{c}\text { Peso fresco } \\
\text { de la raíz } \\
\mathbf{( g )}\end{array}$ & RGS & $\begin{array}{c}\mathbf{N}^{\mathbf{0}} \text { de huevos } \\
\text { (g de peso }^{-1} \text { ) }\end{array}$ & $\begin{array}{c}\text { Efectivida } \\
\text { d de } \\
\text { control } \\
\text { (\%) }\end{array}$ \\
\hline $\mathbf{C S}$ & $36,5 \pm 0,8 \mathrm{~d}$ & $15,7 \pm 1,3 \mathrm{c}$ & $14,6 \pm 1,5 \mathrm{~b}$ & 0 & 0 & \\
\hline $\mathbf{C N}$ & $27,7 \pm 1,1 \mathrm{a}$ & $9,8 \pm 2,1 \mathrm{a}$ & $11,1 \pm 1,3 \mathrm{a}$ & $6,5 \pm 3,1 \mathrm{~b}$ & $854,6 \pm 2,8 \mathrm{~b}$ & \\
\hline $\mathbf{2 P + N}$ & $31,0 \pm 0,7 \mathrm{~b}$ & $10,5 \pm 0,9 \mathrm{a}$ & $12,4 \pm 1,3 \mathrm{ab}$ & $3,0 \pm 1,9 \mathrm{ab}$ & $508,5 \pm 2,1 \mathrm{ab}$ & 40,5 \\
\hline $\mathbf{T H}+\mathbf{N}$ & $33,0 \pm 1,6 \mathrm{bc}$ & $12,3 \pm 1,3 \mathrm{bc}$ & $13,8 \pm 0,9 \mathrm{ab}$ & $3,5 \pm 2,1 \mathrm{ab}$ & $587,8 \pm 1,7 \mathrm{ab}$ & 31,2 \\
\hline $\mathbf{V e r m i}$ & $33,2 \pm 2,8 \mathrm{bc}$ & $13,8 \pm 2,4 \mathrm{bc}$ & $18,3 \pm 2,3 \mathrm{c}$ & $2,4 \pm 2,8 \mathrm{a}$ & $347,5 \pm 1,5 \mathrm{a}$ & 59,3 \\
\hline $\mathbf{2 P + T H + N}$ & $34,6 \pm 1,8 \mathrm{~cd}$ & $14,2 \pm 1,1 \mathrm{bc}$ & $14,4 \pm 1,8 \mathrm{ab}$ & $2,8 \pm 2,4 \mathrm{a}$ & $356,5 \pm 2,9 \mathrm{a}$ & 58,3 \\
\hline
\end{tabular}

Tabla.V.4- Valor medio ( \pm SE) de parámetros de crecimiento (parte aérea y raíz), RGS (índice de agallamiento) y número de huevos por gramo de raíz de plantas de pimiento para los diferentes tratamientos (CS: Control sano; $\mathrm{CN}$ : Control infectado con $M$. incognita; $2 \mathrm{P}+\mathrm{N}$ : inoculado dos veces con $P$. lilacinus e infectado con $M$. incognita; $\mathrm{TH}+\mathrm{N}$ : inoculado con $T$. harzianum e infectado con $M$. incognita; Vermi: inoculado con $P$. lilacinus y $T$. harzianum, en vermiculita y $2 \mathrm{P}+\mathrm{TH}+\mathrm{N}$ : inoculado dos veces con $P$. lilacinus, $T$. harzianum e infectado con $M$. incognita). 
Los resultados que se muestran en la Fig. V.37 indican que con los tratamientos de los hongos antagonistas con reposición, el número de agallas en las raíces tratadas es menor que cuando no había reposiciones, pero si comparamos la efectividad del tratamiento, las diferencias no son significativas, aunque si son más efectivas si consideramos que la cantidad de inóculo en este caso es superior pues fue de 3000 huevos $+\mathrm{J}_{2}$

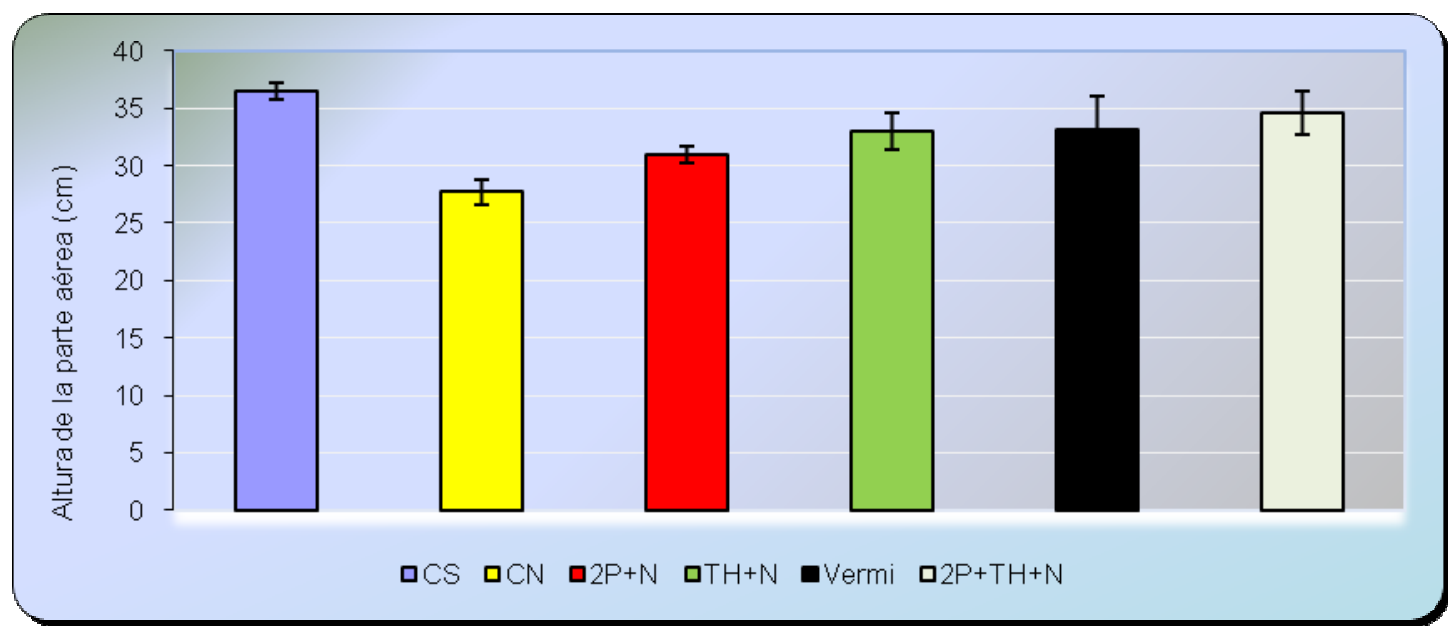

Fig.V.38.- Valor medio de la altura de las plantas de pimiento para los diferentes tratamientos (CS: Control sano; CN: Control infectado con $M$. incognita; $2 \mathrm{P}+\mathrm{N}$ : inoculado dos veces con $P$. lilacinus e infectado con $M$. incognita; $\mathbf{T H}+\mathrm{N}$ : inoculado con $T$. harzianum e infectado con $M$. incognita; Vermi: inoculado con $P$. lilacinus y $T$. harzianum, en vermiculita y $2 \mathrm{P}+\mathrm{TH}+\mathrm{N}$ : inoculado con P. lilacinus y T. harzianum e infectado con M. incognita).

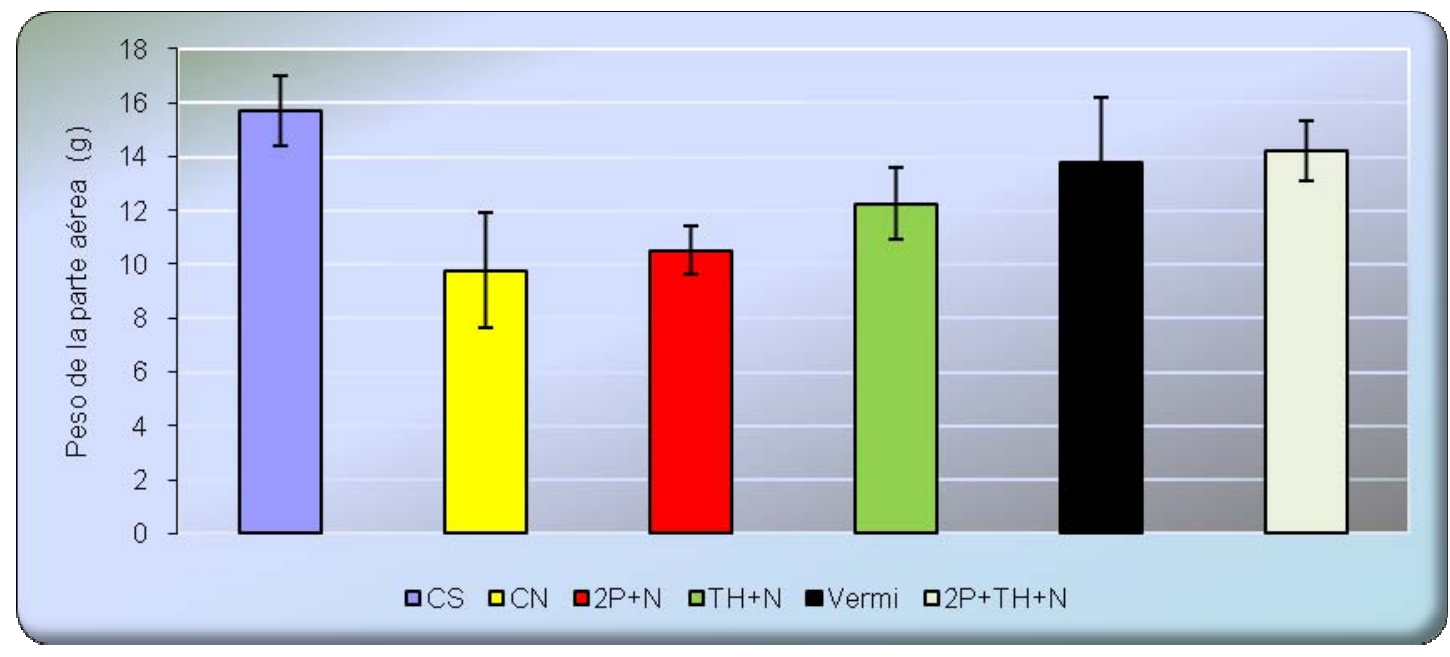

Fig.V.39.- Valor medio del peso fresco aéreo de las plantas de pimiento para los diferentes tratamientos (CS: Control sano; CN: Control infectado con $M$. incognita; $2 \mathrm{P}+\mathrm{N}$ : inoculado dos veces con $P$. lilacinus e infectado con $M$. incognita; $\mathrm{TH}+\mathrm{N}$ : inoculado con $T$. harzianum e infectado con $M$. incognita; Vermi: inoculado con $P$. lilacinus y $T$. harzianum, en vermiculita y 2P+TH+N: inoculado con P. lilacinus y T. harzianum e infectado con $M$. incognita). 


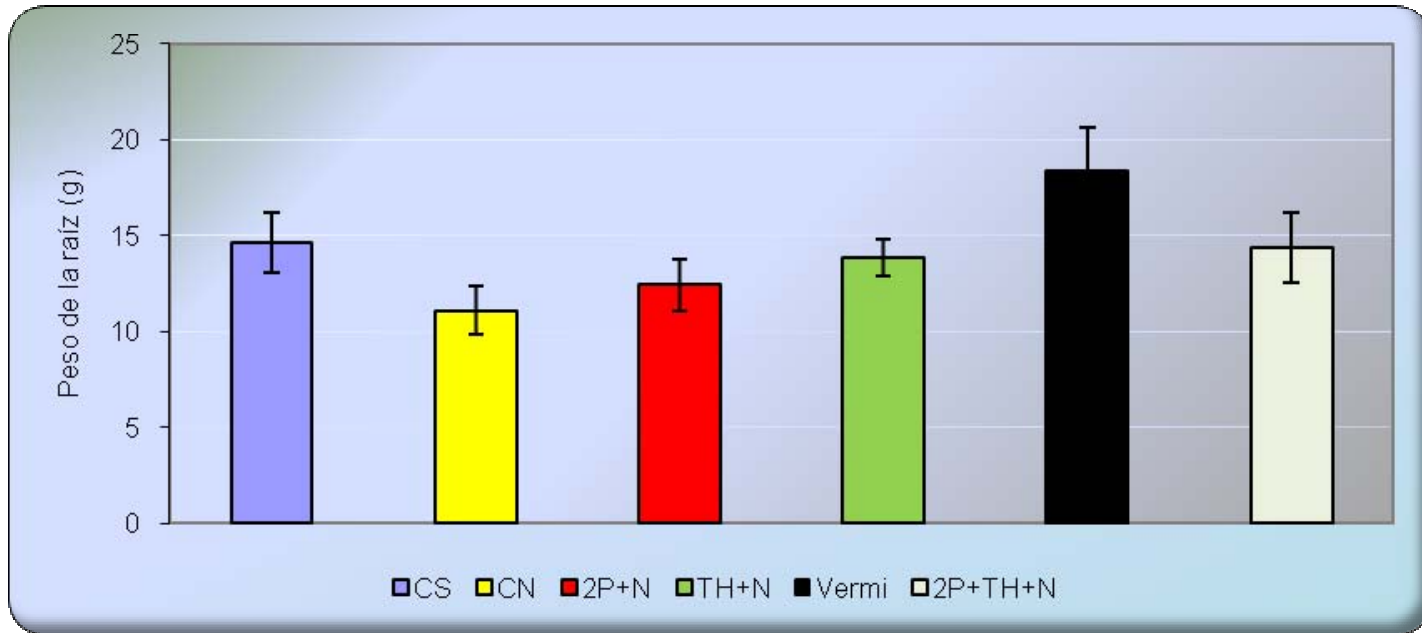

Fig.V.40.- Valor medio del peso fresco de la raíz de las plantas de pimiento para los diferentes tratamientos (CS: Control sano; CN: Control infectado con $M$. incognita; $2 \mathrm{P}+\mathrm{N}$ : inoculado dos veces con $P$. lilacinus e infectado con $M$. incognita; $\mathrm{TH}+\mathrm{N}$ : inoculado con $T$. harzianum e infectado con $M$. incognita; Vermi: inoculado con $P$. lilacinus y $T$. harzianum, en vermiculita y 2P+TH+N: inoculado con P. lilacinus y T. harzianum e infectado con $M$. incognita).

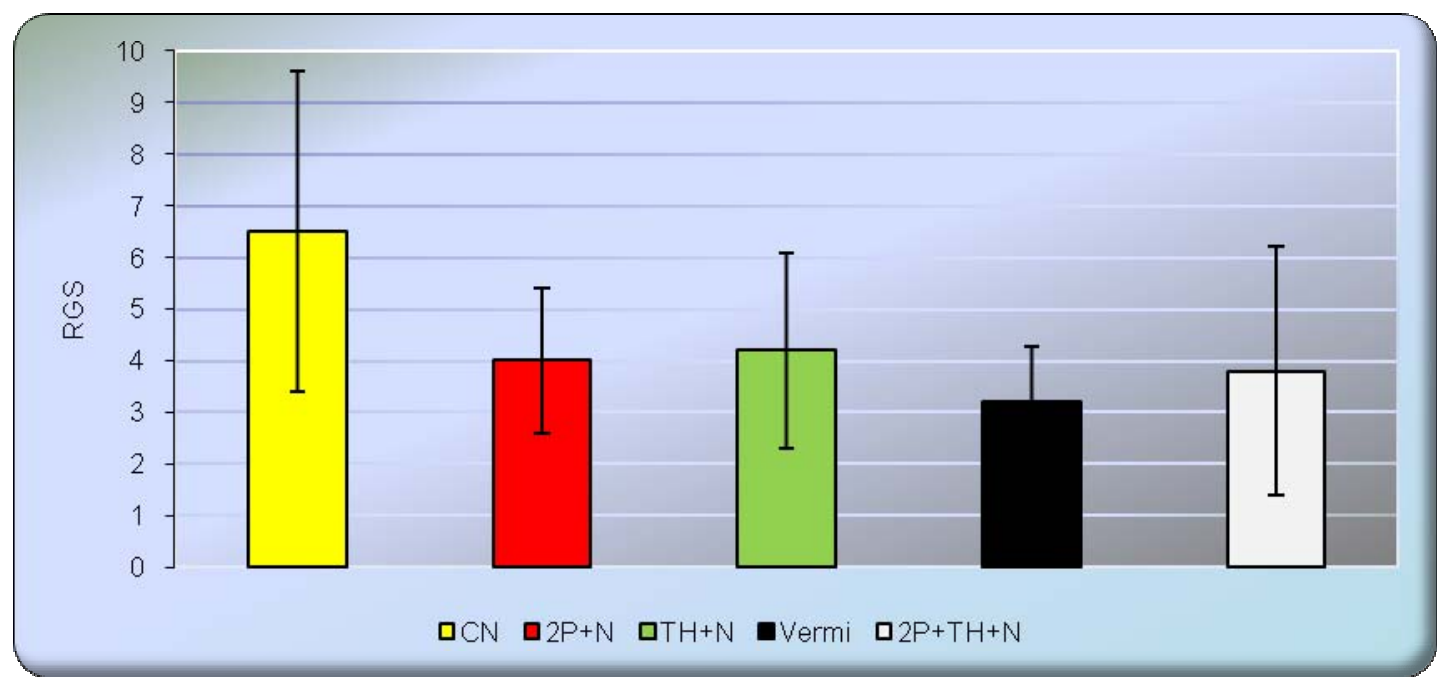

Fig.V.41.- Valor medio de RGS (Índice de agallamiento) de las plantas de pimiento para los diferentes tratamientos (CS: Control sano; CN: Control infectado con M. incognita; 2P+N: inoculado dos veces con $P$. lilacinus e infectado con $M$. incognita; $\mathrm{TH}+\mathrm{N}$ : inoculado con $T$. harzianum e infectado con $M$. incognita; Vermi: inoculado con P. lilacinus y T. harzianum, en vermiculita y $2 \mathrm{P}+\mathrm{TH}+\mathrm{N}$ : inoculado con $P$. lilacinus y $\mathbf{T}$. harzianum e infectado con $M$. incognita). 


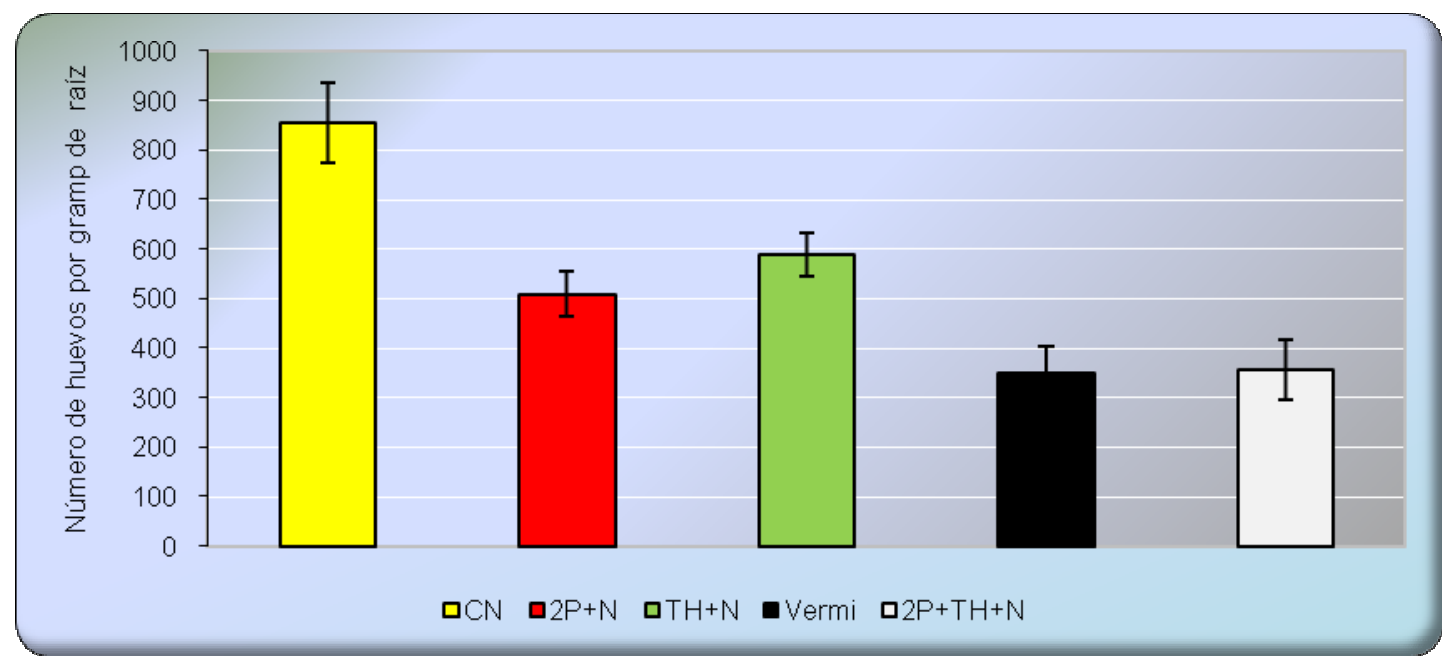

Fig.V.42.- Valor medio del número de huevos $+\mathbf{J}_{2}$ por gramo de raíz de las plantas de pimiento para los diferentes tratamientos.(CS: Control sano; CN: Control infectado con M. incognita; 2P+N: inoculado dos veces con $P$. lilacinus e infectado con $M$. incognita; $\mathbf{T H}+\mathrm{N}$ : inoculado con $T$. harzianum e infectado con $M$. incognita; Vermi: inoculado con P. lilacinus y T. harzianum, en vermiculita y $2 \mathrm{P}+\mathrm{TH}+\mathrm{N}$ : inoculado con $P$. lilacinus y $T$. harzianum e infectado con $M$. incognita).

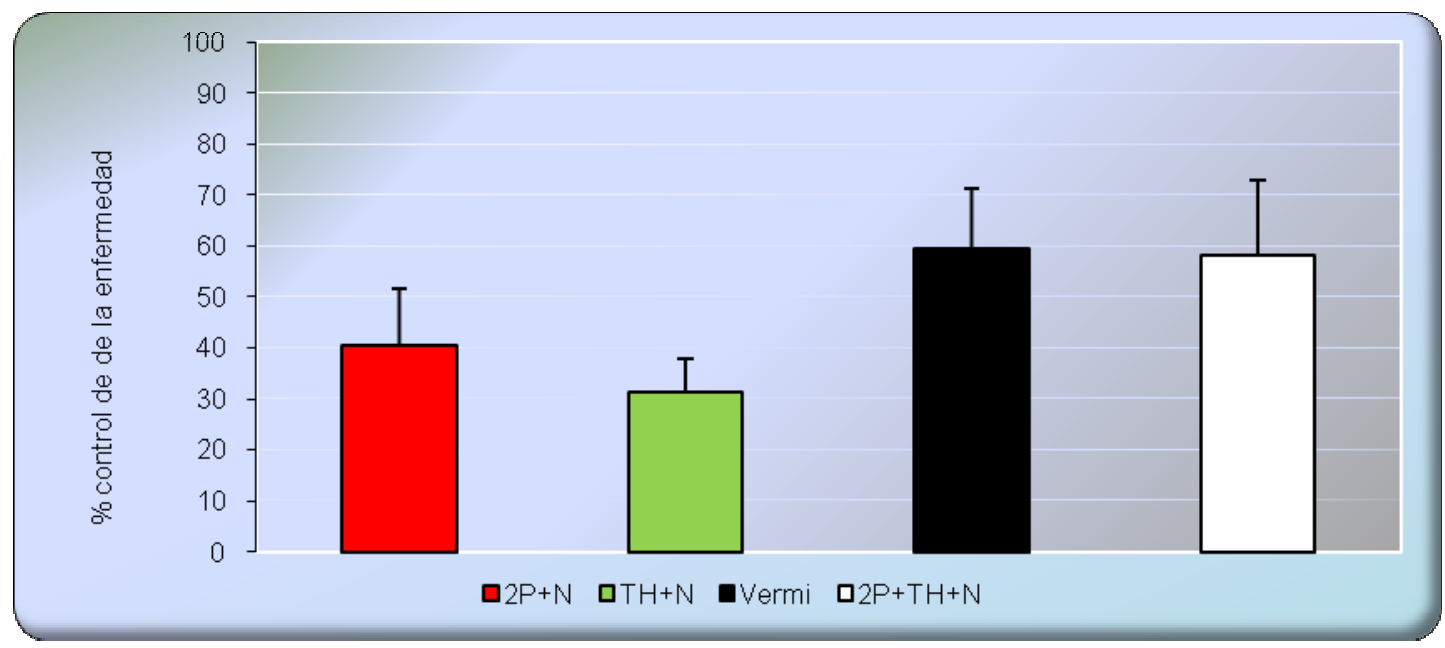

Fig.V.43.- Porcentaje de control sobre los huevos $+J_{2}$ de $M$. incognita por gramo de raíz de las plantas de pimiento para los diferentes tratamientos (CS: Control sano; CN: Control infectado con $M$. incognita; $2 \mathrm{P}+\mathrm{N}$ : inoculado dos veces con $P$. lilacinus e infectado con $M$. incognita; TH+N: inoculado con $T$. harzianum e infectado con $M$. incognita; Vermi: inoculado con $P$. lilacinus y T. harzianum, en vermiculita y $2 \mathrm{P}+\mathrm{TH}+\mathrm{N}$ : inoculado con $P$. lilacinus y $T$. harzianum e infectado con $M$. incognita). 


\section{V.8. Análisis de la eficacia de la combinación de agentes de biocontrol Paecilomyces lilacinus, Trichoderma harzianum y Bacillus firmus y del formulado Nemaout contra Meloidogyne incognita.}

\section{V.8.1. Compatibilidad “in vitro" de los antagonistas que forman la combinación.}

Los resultados obtenidos en la confrontación de TH2413, PL243 y BF342 después de 7 días se muestran en la Fig.V.44. Ambos hongos pueden crecer juntos puesto que T. harzianum no muestra hiperparasitismo sobre P. lilacinus, aunque es verdad que $P$. lilacinus crece más lentamente y es rodeado por la hifas de $T$. harzianum, éstas no lo invaden ni parasita su colonia. De todas maneras, cuando usamos la combinación de los tres antagonistas en los ensayos en suelo, PL243 se agregó al suelo, 6 días antes que TH2413 para dar tiempo a P. lilacinus a desarrollarse antes de la llegada de T. harzianum al suelo.

Los resultados de la confrontación de $T$. harzianum y de $B$. firmus y de la confrontación de P. lilacinus y B. firmus se muestran en la Fig.V.45.b, Fig.V.45.c, respectivamente. En ellos se observa que los tres microorganismos pueden vivir juntos ya que ellos crecen sin que las colonias se superpongan, incluso después de 7 días de cultivo (Fig.V.45.d).

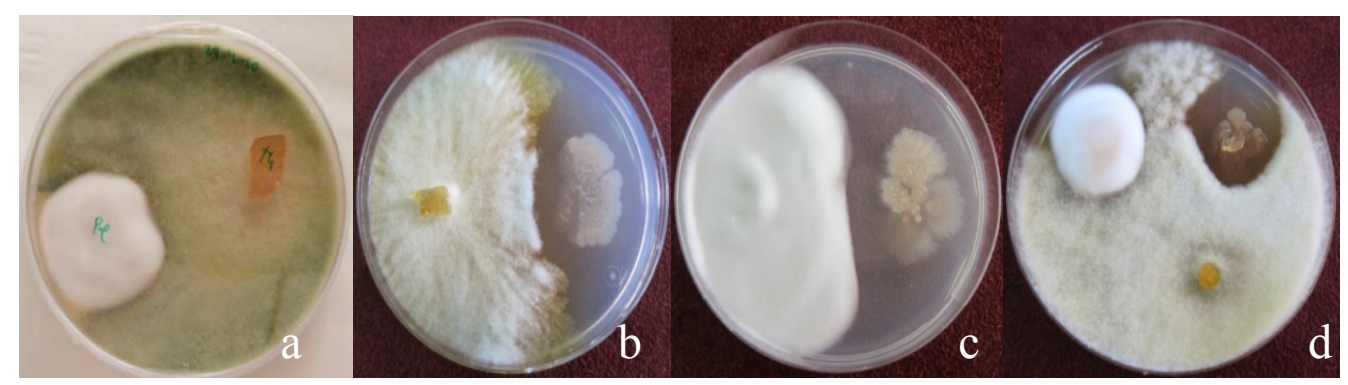

Fig.V.44.- "In vitro" confrontación en patata dextrosa agar (PDA) después de 7 días de cultivo entre hongos y bacterias antagonistas de patógenos, mostrando compatibilidad. En (a) entre Trichoderma harzianum (derecha) y Paecilomyces lilacinus (izquierda), en (b) entre Bacillus firmus (derecha) y T. harzianum (izquierda), en (c) entre B. firmus (derecha) y P. lilacinus (izquierda) y en (d) entre T. harzianum, P. lilacinus y B. firmus. 
V.8.2. Efecto de la combinación de los 3 antagonistas y del producto Nemaout sobre el crecimiento de las plantas de pimiento, infectadas con $M$. incognita

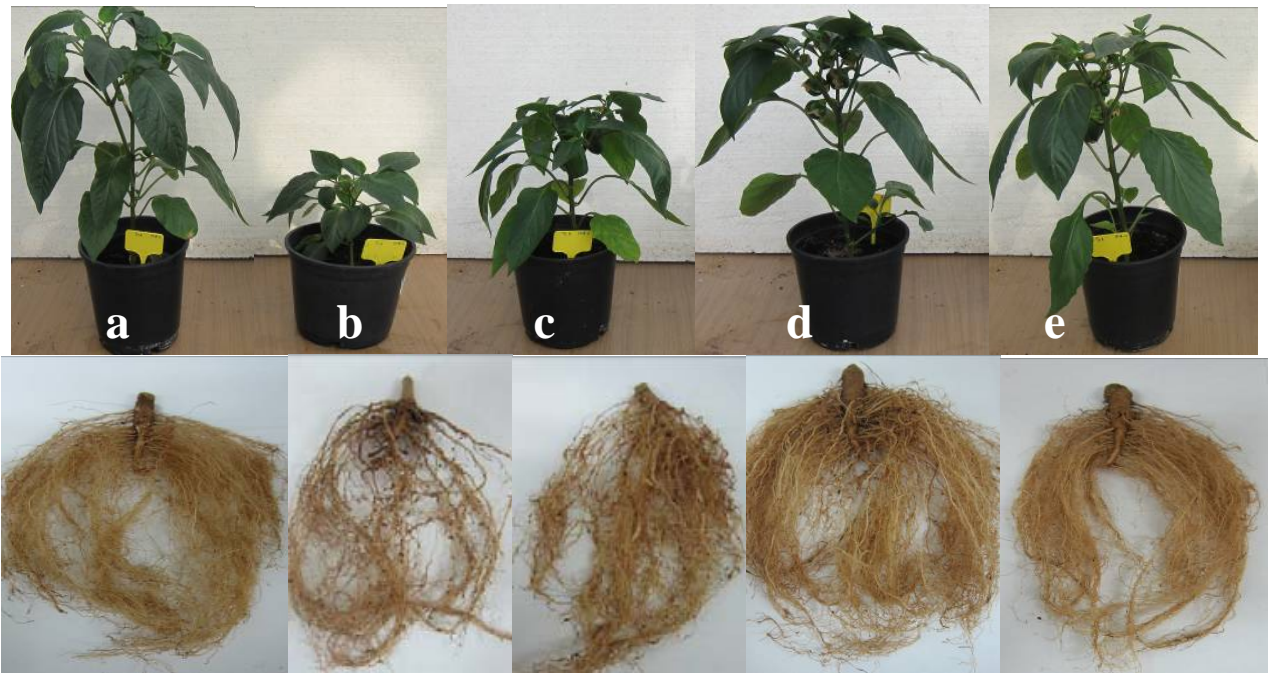

Fig.V.45.- Plantas de pimiento y su sistema radicular a los 60 días después de la infección con Meloidogyne incognita; (a) no-infectada y no-tratada (control sano), (b) infectada y no-tratada (control infectado), (c) infectada y tratada con la combinación ( $(\mathrm{P}+\mathrm{TH}+\mathrm{Bf})$, (d) infectada y tratada con Nemaout 1, (e) infectada y tratada con Nemaout 2.

\begin{tabular}{|c|c|c|c|c|c|c|}
\hline $\begin{array}{c}\text { Tratamientos } \\
\text { efectuados }\end{array}$ & $\begin{array}{c}\text { Altura de la } \\
\text { planta } \\
\text { (cm) }\end{array}$ & $\begin{array}{c}\text { Peso fresco de la } \\
\text { parte aérea } \\
\text { (g) }\end{array}$ & $\begin{array}{c}\text { Peso fresco de } \\
\text { la raíz } \\
\text { (g) }\end{array}$ & RGS & $\begin{array}{c}\mathbf{N}^{\mathbf{0}} \text { de agallas } \\
\text { (g de peso }^{-1} \text { ) }\end{array}$ & $\begin{array}{c}\text { Efectividad } \\
\text { de control } \\
\text { (\%) }\end{array}$ \\
\hline CS & $36,9 \pm 3,7 \mathrm{a}$ & $62,1 \pm 6,7 \mathrm{a}$ & $11,2 \pm 5,5 \mathrm{a}$ & 0 & 0 & \\
\hline P+TH+Bf & $23,3 \pm 2,9 \mathrm{~b}$ & $37,6 \pm 2,7 \mathrm{c}$ & $9,2 \pm 2,2 \mathrm{a}$ & $4,1 \pm 3,8 \mathrm{~b}$ & $56,2 \pm 7,3 \mathrm{~b}$ & 46,6 \\
\hline Nemaout $\mathbf{1}$ & $35,0 \pm 3,6 \mathrm{a}$ & $50,6 \pm 4,2 \mathrm{~b}$ & $11,3 \pm 2,7 \mathrm{a}$ & $2,5 \pm 3,4 \mathrm{ab}$ & $23,8 \pm 4,9 \mathrm{c}$ & 77,4 \\
\hline Nemaout 2 & $34,1 \pm 4,2 \mathrm{a}$ & $59,8 \pm 7,1 \mathrm{a}$ & $10,4 \pm 4,8 \mathrm{a}$ & $0,2 \pm 2,6 \mathrm{a}$ & $0,8 \pm 0,5 \mathrm{c}$ & 99,2 \\
\hline
\end{tabular}

Tabla V.5.- Valor medio $( \pm \mathrm{SE})$ de parámetros de crecimiento (parte aérea y raíz), RGS (índice de agallamiento) y $\mathbf{n}^{\circ}$ de agallas por gramo de peso fresco de raíz de plantas de pimiento: no infectada y no tratada (control sano), infectada y no-tratada (control infectada), infectada con M. incognita y tratada con la combinación TH2413, PL243 y BF342 (P+TH+Bf), infectada con M. incognita y tratada con Nemaout 1 e infectada con M. incognita y tratada con Nemaout 2 


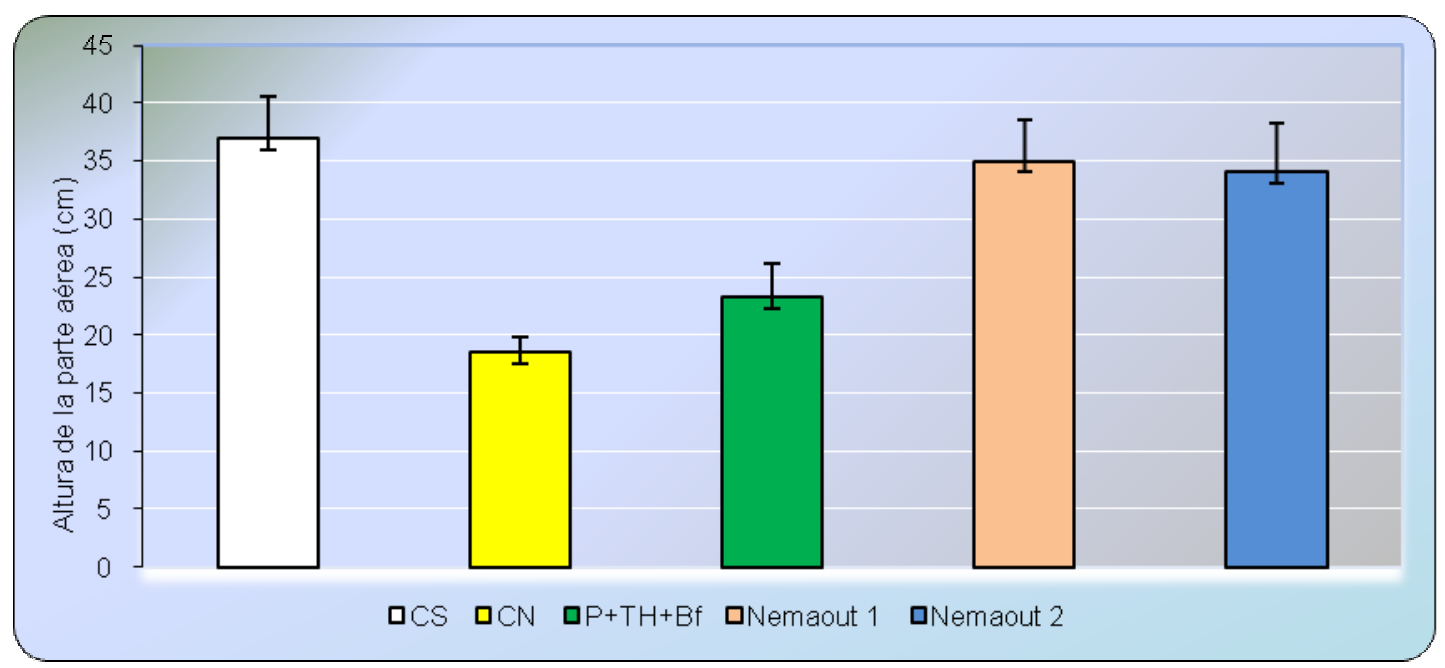

Fig.V.46.- Valor medio de la altura de las plantas de pimiento para los diferentes tratamientos (CS: Control sano; CN: Control infectado con $M$. incognita; P+TH+Bf: inoculado con $P$. lilacinus, T. harzianum y B. firmus e infectado con M. incognita; Nemaout 1: inoculado con Nemaout (100X) e infectado con M. incognita y Nemaout 2: inoculado con Nemaout (10X) e infectado con $M$. incognita

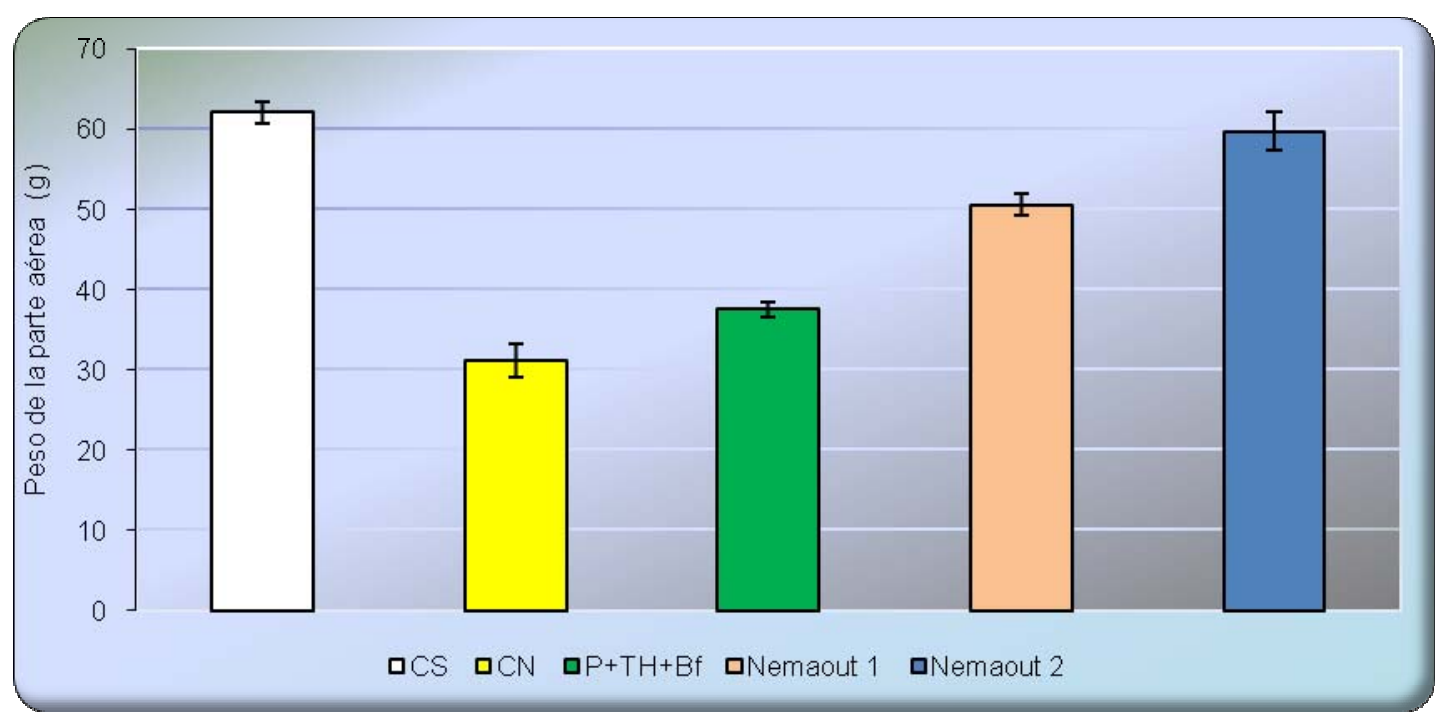

Fig.V.47.-Valor medio del peso fresco aéreo de las plantas de pimiento para los diferentes tratamientos (CS: Control sano; $\mathrm{CN}$ : Control infectado con $M$. incognita; $\mathrm{P}+\mathrm{TH}+\mathrm{Bf}$; inoculado con P. lilacinus, T. harzianum y B. firmus e infectado con $M$. incognita; Nemaout 1: inoculado con Nemaout (100X) e infectado con $M$. incognita y Nemaout 2: inoculado con Nemaout (10X) e infectado con $M$. incognita 


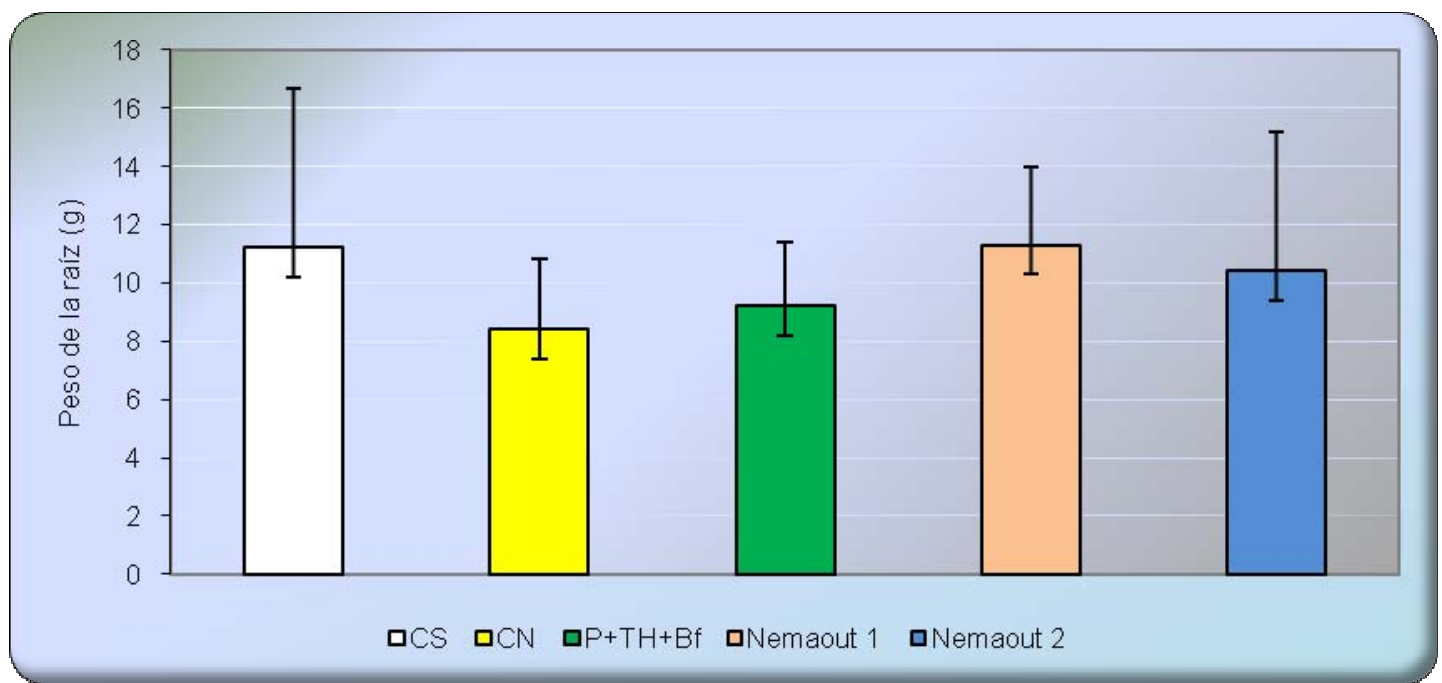

Fig.V.48.- Valor medio del peso fresco de la raíz de las plantas de pimiento para los diferentes tratamientos (CS: Control sano; $\mathrm{CN}$ : Control infectado con $M$. incognita; $\mathrm{P}+\mathrm{TH}+\mathrm{Bf}$ : inoculado con P. lilacinus, $T$. harzianum y $B$. firmus e infectado con $M$. incognita; Nemaout 1: inoculado con Nemaout (100X) e infectado con $M$. incognita y Nemaout 2: inoculado con Nemaout (10X) e infectado con $M$. incognita

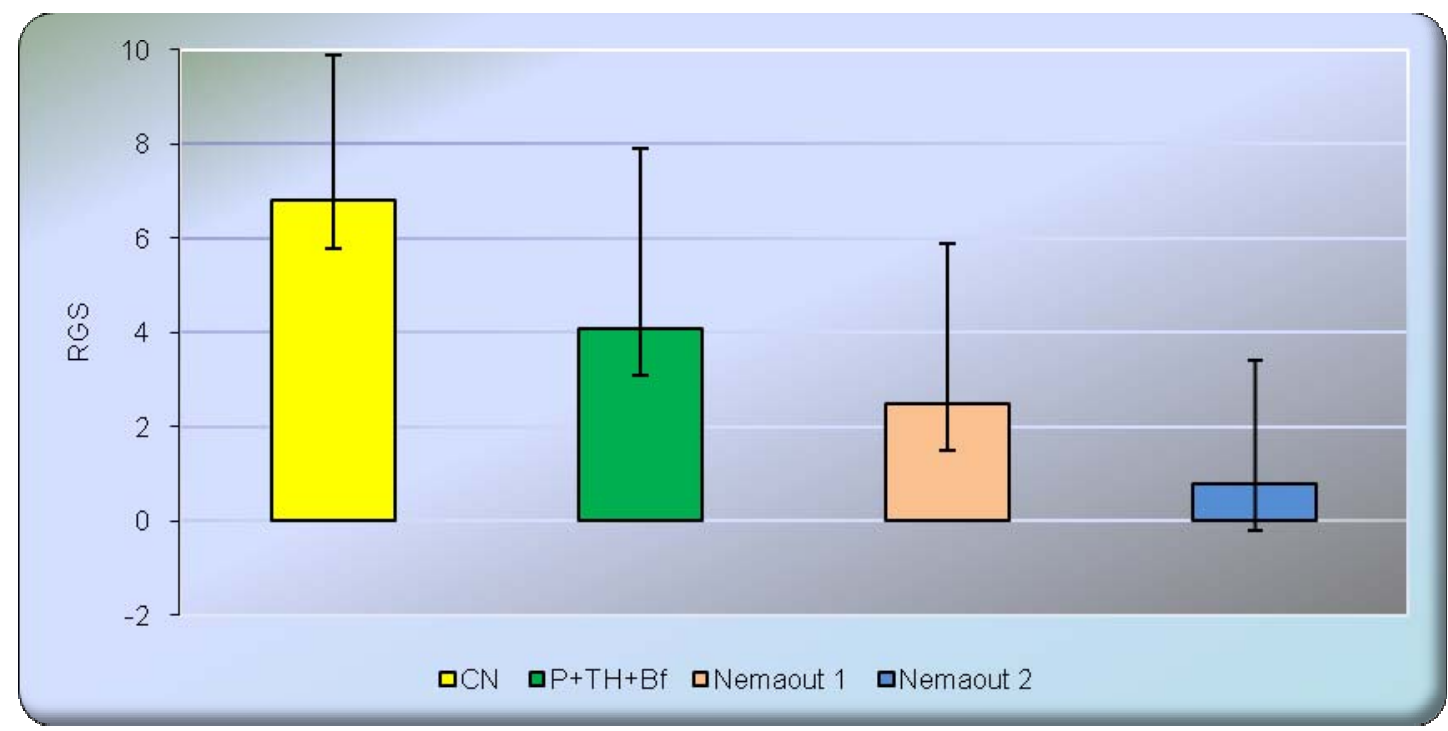

Fig.V.49.- Valor medio de RGS (Índice de agallamiento) de las plantas de pimiento para los diferentes tratamientos (CS: Control sano; $\mathrm{CN}$ : Control infectado con $M$. incognita; P+TH+Bf: inoculado con $P$. lilacinus, $T$. harzianum y $B$. firmus e infectado con $M$. incognita; Nemaout 1 : inoculado con Nemaout (100X) e infectado con $M$. incognita y Nemaout 2: inoculado con Nemaout (10X) e infectado con $M$. incognita 


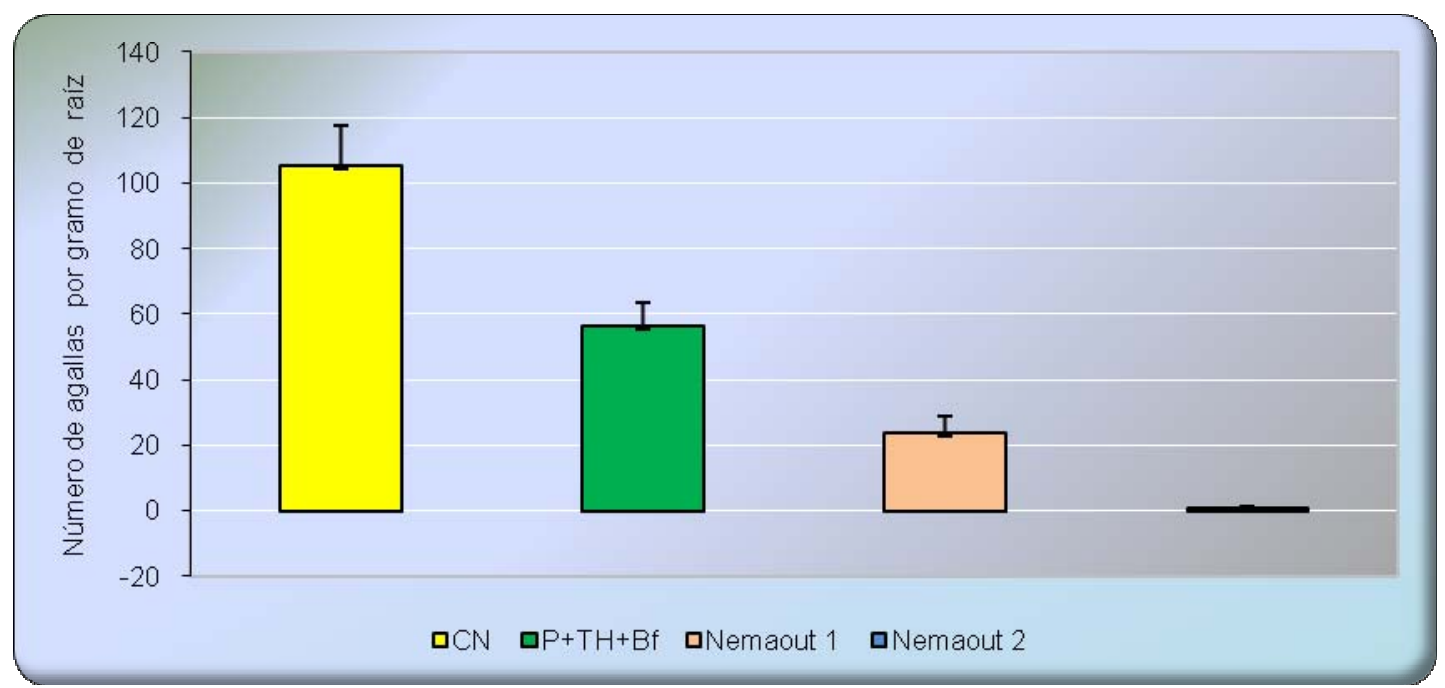

Fig.V.50.- Valor medio del número de agallas por gramo de raíz de las plantas de pimiento para los diferentes tratamientos (CS: Control sano; CN: Control infectado con M. incognita; P+TH+Bf: inoculado con P. lilacinus, T. harzianum y B. firmus e infectado con M. incognita; Nemaout 1: inoculado con Nemaout (100X) e infectado con $M$. incognita y Nemaout 2: inoculado con Nemaout (10X) e infectado con $M$. incognita.

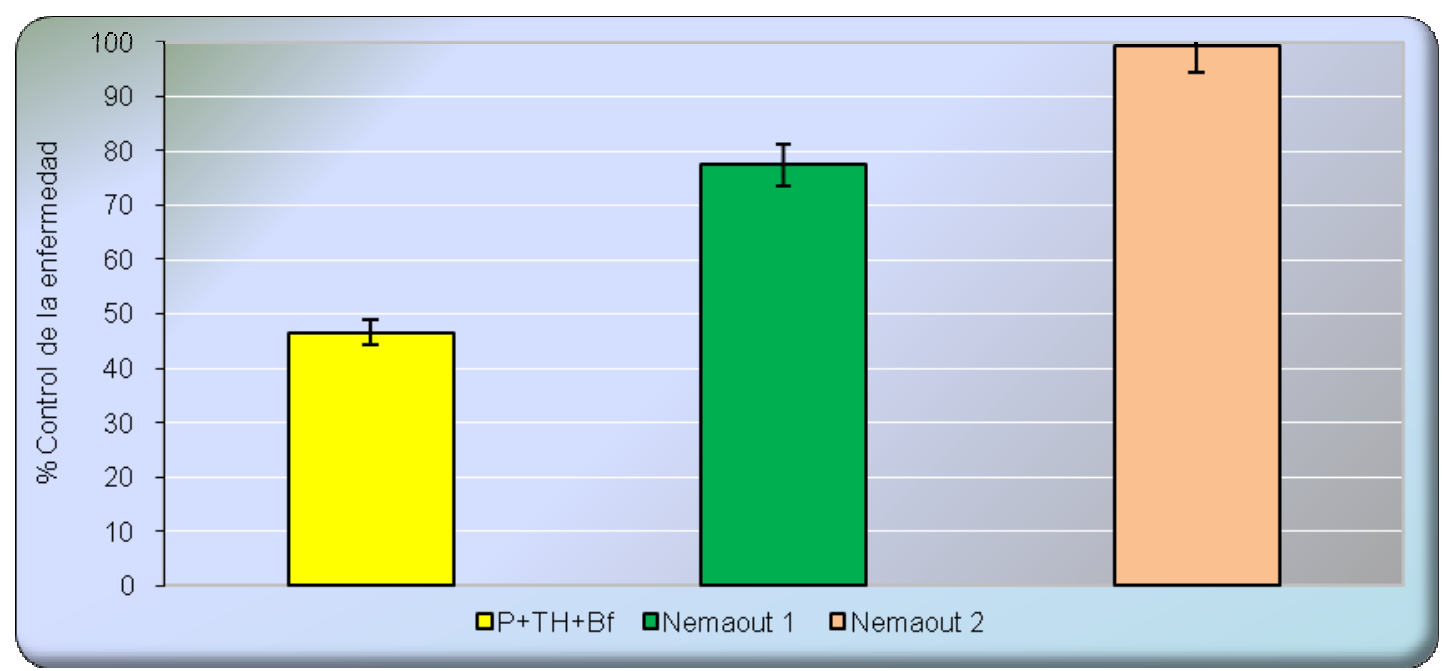

Fig.V.51.- Porcentaje de control sobre el número de agallas por gramo de raíz de las plantas de pimiento para los diferentes tratamientos (CS: Control sano; CN: Control infectado con $M$. incognita; P+TH+Bf: inoculado con P. lilacinus, T. harzianum y B. firmus e infectado con $M$. incognita; Nemaout 1: inoculado con Nemaout (100X) e infectado con $M$. incognita y Nemaout 2: inoculado con Nemaout (10X) e infectado con $M$. incognita. 
La altura de las plantas de pimiento no tratadas e infectadas $(\mathrm{CN})$ y en las plantas infectadas y tratadas con la combinación de los 3 antagonistas $(\mathrm{P}+\mathrm{TH}+\mathrm{Bf})$, fueron significativamente menores que la de las plantas no tratadas y no infectadas (Control sano) y las plantas infectadas y tratadas con Nemaout 1 o Nemaout 2 (, Fig. V.45). El peso fresco de la parte aérea de las plantas sanas y de las tratadas con Nemaout 2 fue significativamente más alto (Tabla V.5, Fig.V.45a y V.45e). Este parámetro no se afectó por la infección con el nematodo ni por el tratamiento. El sistema radicular mostró numerosas agallas en las plantas no-tratadas e infectadas (CN) (Tabla V.5, Fig. V.45b).

Las plantas tratadas con la combinación de P. lilacinus, T. harzianum y $B$. firmus y el producto Nemaout, a diferentes concentraciones, mostraron un menor número de agallas/g de peso fresco de raíces que el control infectado $(\mathrm{CN})$ (Tabla V.5).

La severidad de la agallas de raíz se estimó a partir de una escala de 0-a-10 (Bridge \& Page, 1987) y fue 3,9 cuando las plantas se trataron con la combinación de antagonistas $(\mathrm{P}+\mathrm{TH}+\mathrm{Bf})$, de 2,5 cuando se trataron con Nemaout 1 y 2 al tratarse con Nemaout 2 (Tabla V.5; Fig. V.45.c, V.45.d y V.45.e, respectivamente).

La efectividad en el control de nematodos se calculó como el porcentaje del $n^{\circ}$ de agallas /g de peso fresco de las raíces, con respecto al control infectado y fue del 99.24\% y 77.40\% para Nemaout 1 y Nemaout 2, respectivamente (Table V.5).

Aunque las plantas tratadas con la dosis más baja del compuesto Nemaout (Nemaout1) no estuvieron completamente libres de nematodos (Fig. V.45.d), el nivel de agallamiento no tuvo un gran efecto sobre el crecimiento de las plantas (Tabla V.5, Fig.V.45.e) comparado con el de las plantas control sano (CS). Por el contrario, el tratamiento con la dosis mayor de Nemaout (Nemaout2) tuvo implicaciones en el cultivo. A los 3 días de la aplicación del Nemaout 2, las plantas mostraron una visible defoliación sugiriendo que la dosis empleada era ciertamente tóxica. Sin embargo, las plantas fueron siendo regadas y en los días sucesivos nuevas hojas comenzaron a brotar y las plantas se repusieron, continuaron creciendo y a los 40 días había muy poca diferencia con respecto a las plantas sanas e incluso a los 60 días, las diferencias habían desaparecido. 
V.8.3. Efecto de la combinación TH2413, PL243 y BF342 o del producto Nemaout sobre la productividad de las plantas de pimiento infectadas con $M$. incognita

\begin{tabular}{|c|c|c|c|c|}
\hline $\begin{array}{c}\text { Tratamientos } \\
\text { efectuados }\end{array}$ & $\begin{array}{c}\mathbf{N}^{\mathbf{0}} \text { frutos } \\
\text { comerciales } \\
\text { por planta }\end{array}$ & $\begin{array}{c}\text { Peso fresco } \\
\text { de los frutos } \\
\text { (g) }\end{array}$ & $\begin{array}{c}\text { Productividad } \\
\text { (Kg planta }^{-1} \text { ) }\end{array}$ & $\begin{array}{c}\text { Efectividad } \\
\text { (\%) }\end{array}$ \\
\hline CS & $25,3 \pm 1,4 \mathrm{a}$ & $230,1 \pm 4,4 \mathrm{a}$ & $5,7 \pm 0,9 \mathrm{a}$ & 98 \\
\hline $\mathbf{C N}$ & 0 & 0 & 0 & 0 \\
\hline P+TH+Bf & $16,5 \pm 0,8 \mathrm{c}$ & $221,2 \pm 3,8 \mathrm{~b}$ & $3,5 \pm 0,7 \mathrm{c}$ & 61,5 \\
\hline Nemaout 1 & $17,3 \pm 0,9 \mathrm{c}$ & $218,9 \pm 3,9 \mathrm{c}$ & $3,71 \pm 0,4 \mathrm{c}$ & 64,5 \\
\hline Nemaout 2 & $19,1 \pm 1,3 \mathrm{~b}$ & $224,3 \pm 5,3 \mathrm{~b}$ & $4,25 \pm 0,2 \mathrm{~b}$ & 73,9 \\
\hline
\end{tabular}

Tabla V.6. El valor medio $( \pm \mathrm{SE})$ del número de frutos, peso y productividad por planta de pimiento no-infectadas y no tratadas (control sano, CS), infectadas y no tratadas (control infectado. CN), infectadas con $M$. incognita y tratadas con combinación TH2413, PL243 y BF342, infectadas con $M$. incognita y tratadas con Nemaout 1 e infectadas con $M$. incognita y tratadas con Nemaout 2, al tiempo de la recolección (180 días después del trasplante).

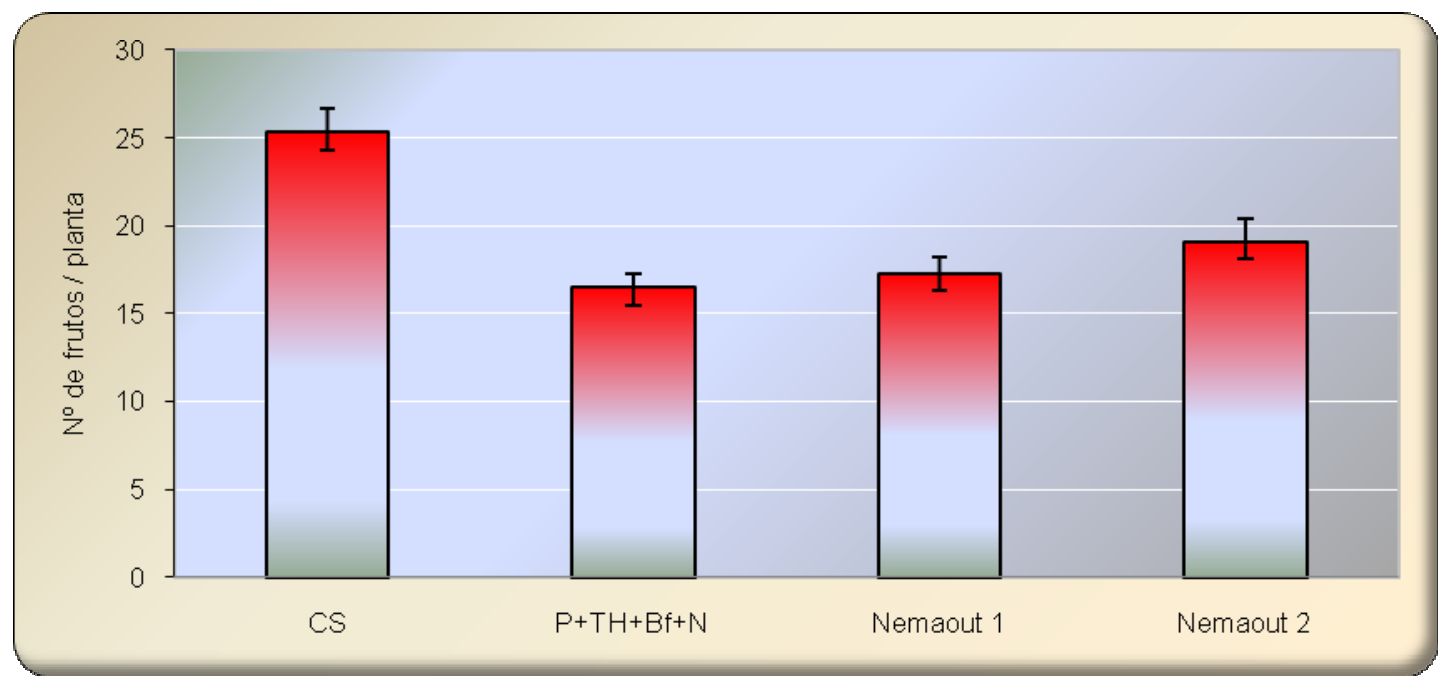

Fig.V.52.- Valor medio del número de frutos comerciales por planta de pimiento para los diferentes tratamientos (CS: Control sano; CN: Control infectado con M. incognita; P+TH+Bf: inoculado con P. lilacinus, T. harzianum y B. firmus e infectado con M. incognita; Nemaout 1: inoculado con Nemaout $(100 \mathrm{X})$ e infectado con $M$. incognita y Nemaout 2: inoculado con Nemaout (10X) e infectado con $M$. incognita 


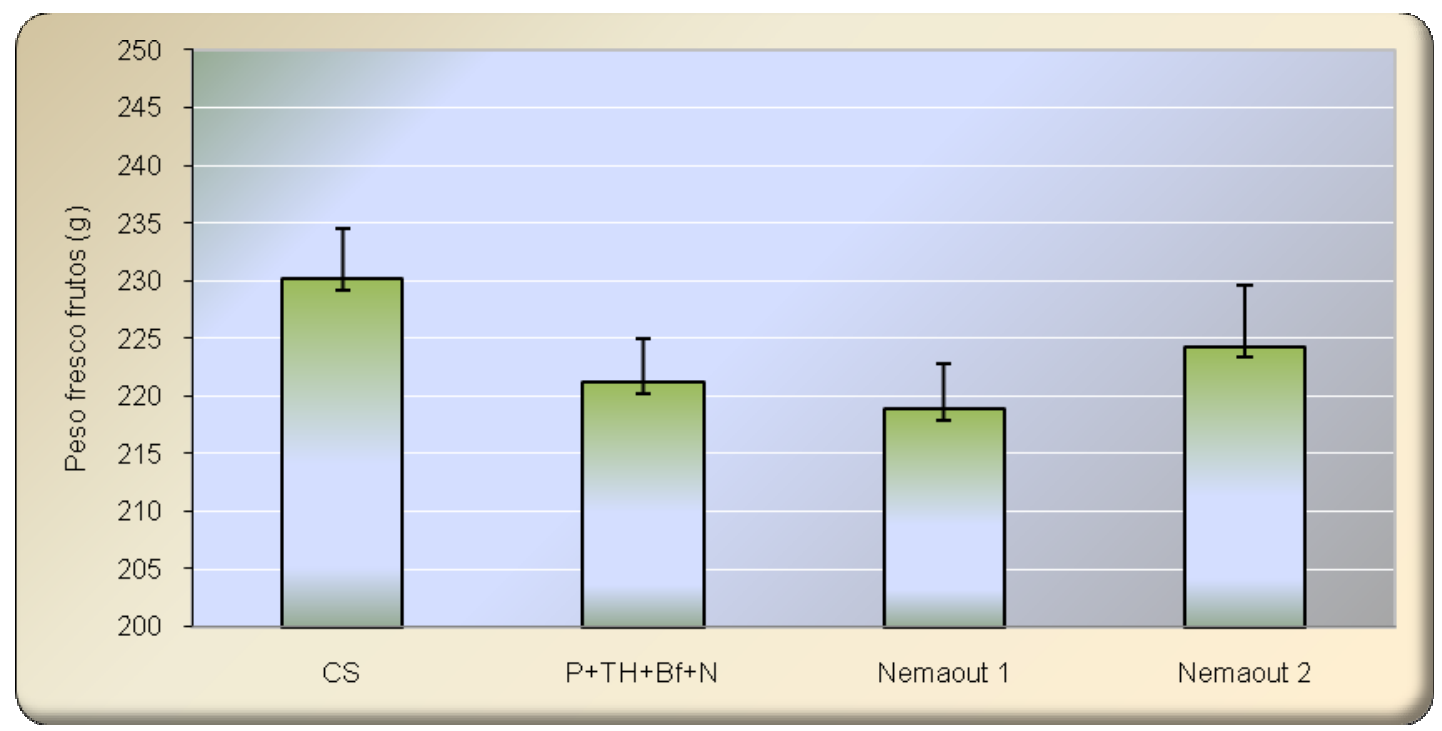

Fig.V.53.- Valor medio del peso fresco de los frutos comerciales por planta de pimiento para los diferentes tratamientos (CS: Control sano; $\mathrm{CN}$ : Control infectado con $M$. incognita; P+TH+Bf: inoculado con P. lilacinus, $T$. harzianum y B. firmus e infectado con $M$. incognita; Nemaout 1: inoculado con Nemaout (100X) e infectado con $M$. incognita y Nemaout 2: inoculado con Nemaout (10X) e infectado con $M$. incognita

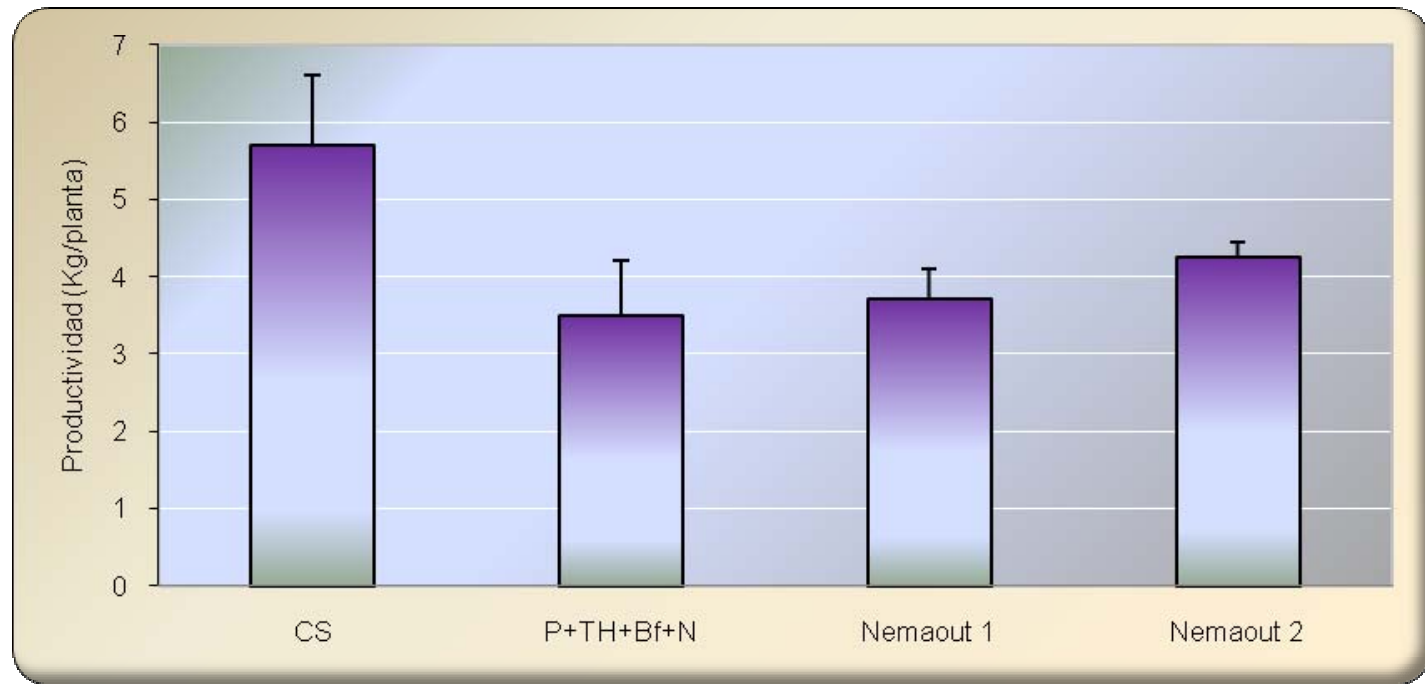

Fig.V.54.- Productividad (Kg/pl) por planta de pimiento para los diferentes tratamientos (CS: Control sano; CN: Control infectado con $M$. incognita; $\mathrm{P}+\mathrm{TH}+\mathrm{Bf}$ : inoculado con P. lilacinus, $T$. harzianum y B. firmus e infectado con M. incognita; Nemaout 1: inoculado con Nemaout (100X) e infectado con $M$. incognita y Nemaout 2: inoculado con Nemaout (10X) e infectado con $M$. incognita. 


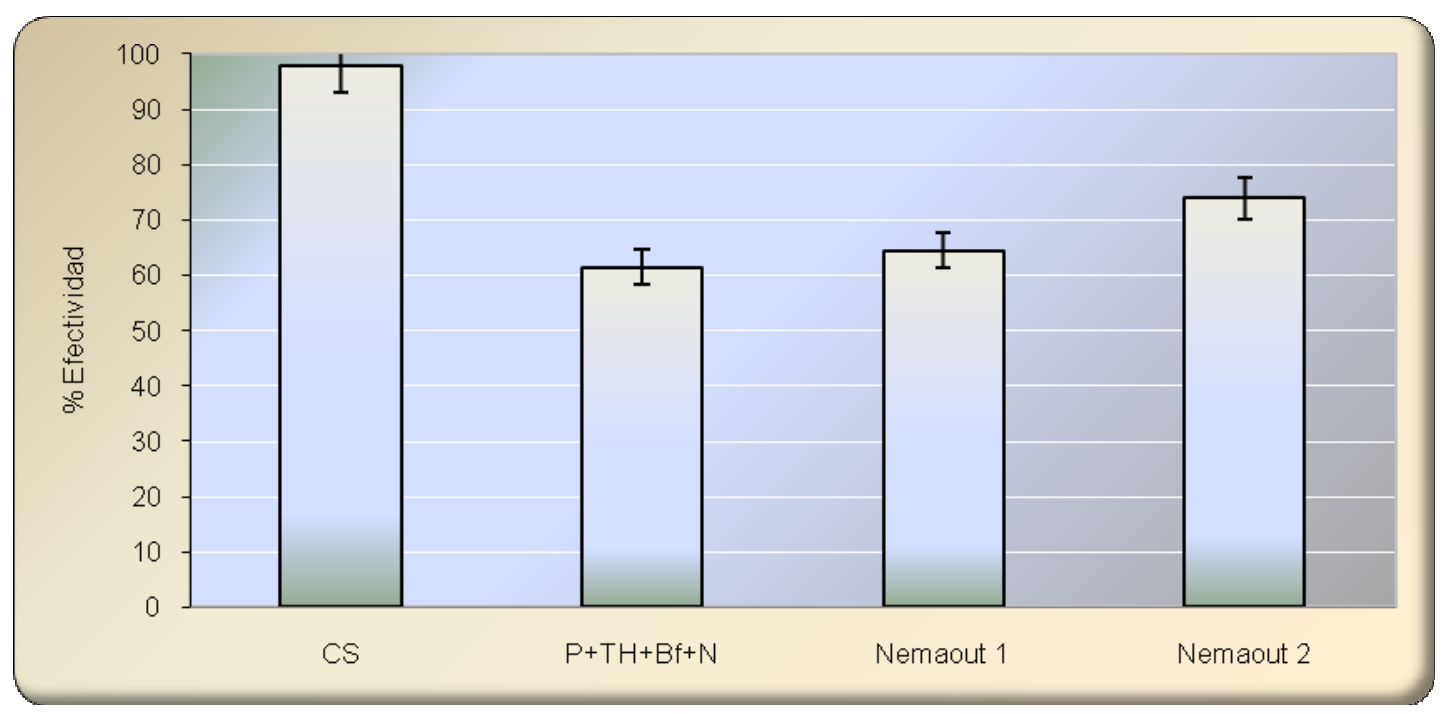

Fig.V.55.- Efectividad de los diferentes tratamientos (CS: Control sano; CN: Control infectado con M. incognita; P+TH+Bf: inoculado con P. lilacinus, T. harzianum y B. firmus e infectado con M. incognita; Nemaout 1: inoculado con Nemaout (100X) e infectado con $M$. incognita y Nemaout 2: inoculado con Nemaout (10X) e infectado con $M$. incognita.

La efectividad de los tratamientos se calculó como el porcentaje de la productividad respecto del control sano.

Al tiempo de la recolección, las plantas no-tratadas e infectadas ( $\mathrm{CN})$ no produjeron frutos, mientras que las plantas tratadas con la combinación de antagonistas $(\mathrm{P}+\mathrm{TH}+\mathrm{Bf})$ o con el Nemaout produjeron frutos (Tabla V.6). Aun cuando la concentración de Nemaout 2 parece ser tóxica al principio, las plantas tratadas con el Nemaout-2, una vez se recobraron, produjeron los rendimientos más altos en frutos con valor comercial. La combinación de los tres microorganismos $(\mathrm{P}+\mathrm{TH}+\mathrm{Bf})$ y la aplicación del Nemaout 1 dieron similares resultados a pesar de sus diferentes números de agallamiento, lo cual puede ser debido directamente a la influencia de sus respectivos componentes. La mayor efectividad en el control de los nematodos la proporcionó el Nemaout 2. 


\section{V.9. Estudios "in vitro" de los vertidos de $P$. lilacinus y $T$. harzianum}

V.9.1. Estudios de los compuestos excretados de $P$. lilacinus y $T$. harzianum sobre juveniles de $M$. incognita

Extractos metabólicos de $T$ harzianum y P. lilacinus de 4 días se utilizaron a dos dosis, 2 y $4 \mathrm{ml}$ para tratar $\mathrm{J}_{2}$ (100 juveniles de nematodo) de 5-7 días de vida, y así poder determinar su mortandad a las 24,48 y 96 horas.

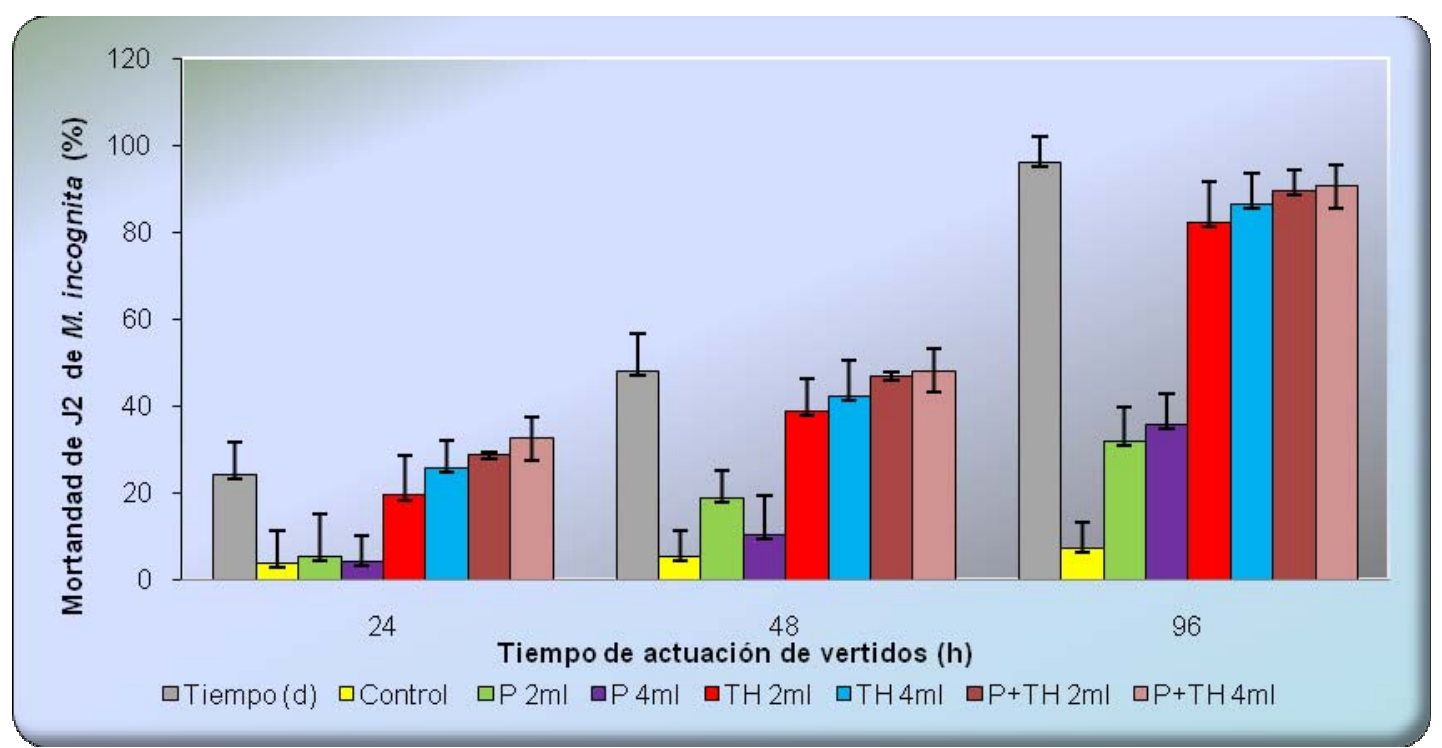

Fig. V.56: Mortandad de juveniles $\left(\mathrm{J}_{2}\right)$ de $M$. incognita con los diferentes extractos metabólicos de $T$. harzianum y $P$. lilacinus a dos dosis (2 y $\left.4 \mathrm{ml} / 100 \mathrm{~J}_{2}\right)$ de 4 días de tiempo de incubación, en los diferentes tiempos de actuación de los extractos sobre los $\mathrm{J}_{2}$ de $M$. incognita (24, 48 y 96 horas).

\begin{tabular}{|l|c|c|c|}
\cline { 2 - 4 } \multicolumn{1}{c|}{} & \multicolumn{3}{c|}{ Tiempo de actuación del extracto (h) } \\
\cline { 2 - 4 } \multicolumn{1}{c|}{} & $\mathbf{2 4}$ & $\mathbf{4 8}$ & $\mathbf{9 6}$ \\
\hline Control & $3,7 \pm 2,7 \mathrm{a}$ & $5,2 \pm 1,8 \mathrm{a}$ & $7,2 \pm 3,4 \mathrm{a}$ \\
\hline P 2ml & $5,3 \pm 1,2 \mathrm{a}$ & $18,6 \pm 2,3 \mathrm{~b}$ & $31,6 \pm 4,1 \mathrm{~b}$ \\
\hline P 4ml & $4,1 \pm 1,8 \mathrm{a}$ & $10,3 \pm 2,6 \mathrm{ab}$ & $35,6 \pm 3,8 \mathrm{~b}$ \\
\hline TH 2ml & $19,3 \pm 2,4 \mathrm{~b}$ & $38,8 \pm 3,5 \mathrm{c}$ & $82,2 \pm 4,6 \mathrm{c}$ \\
\hline TH 4 ml & $25,6 \pm 3,5 \mathrm{bc}$ & $42,2 \pm 4,7 \mathrm{c}$ & $86,3 \pm 5,3 \mathrm{c}$ \\
\hline P+TH 2 $\mathbf{~ m l}$ & $28,1 \pm 2,9 \mathrm{bc}$ & $46,9 \pm 4,2 \mathrm{c}$ & $89,3 \pm 5,6 \mathrm{~cd}$ \\
\hline P+TH 4 ml & $32,5 \pm 2,1 \mathrm{c}$ & $48,1 \pm 3,4 \mathrm{c}$ & $90,5 \pm 4,3 \mathrm{~d}$ \\
\hline
\end{tabular}

Tabla V.7: Valor medio ( \pm SE) del porcentaje de mortandad de $J_{2}$ de $M$. incognita con extractos metabólicos concentrados de $T$. harzianum y $P$. lilacinus a dos dosis de 4 días de tiempo de incubación, en diferentes tiempos de actuación de los extractos sobre los $\mathbf{J}_{2}$ (24, 48 y 96 horas). 
A la vista de los resultados de mortandad de los $\mathrm{J}_{2}$ obtenidos con la dosis máxima $(4 \mathrm{ml})$ de extractos de $P$. lilacinus y $T$. harzianum $(35,69 \%$ y $86,35 \%$ respectivamente) decidimos profundizar en el estudio de los vertidos excretados por T. harzianum, debido a que con P. lilacinus no logramos tener un control efectivo de los nematodos y al mezclar ambos, el aumento de la mortandad no se incrementó significativamente con respecto a lo obtenido con los vertidos de T. harzianum solo.

\section{V.10. Estudios "in vitro" de los vertidos de T. harzianum}

V.10.1. Estudio de los vertidos de $T$. harzianum sobre huevos de $M$. incognita

Una prueba previa con el extracto completo de T. harzianum, sin filtrar, se realiza para determinar si hay algún tipo de enrollamiento o parasitismo, por parte del hongo, en los huevos de nematodo. Los resultados se muestran en la Fig.V.57.

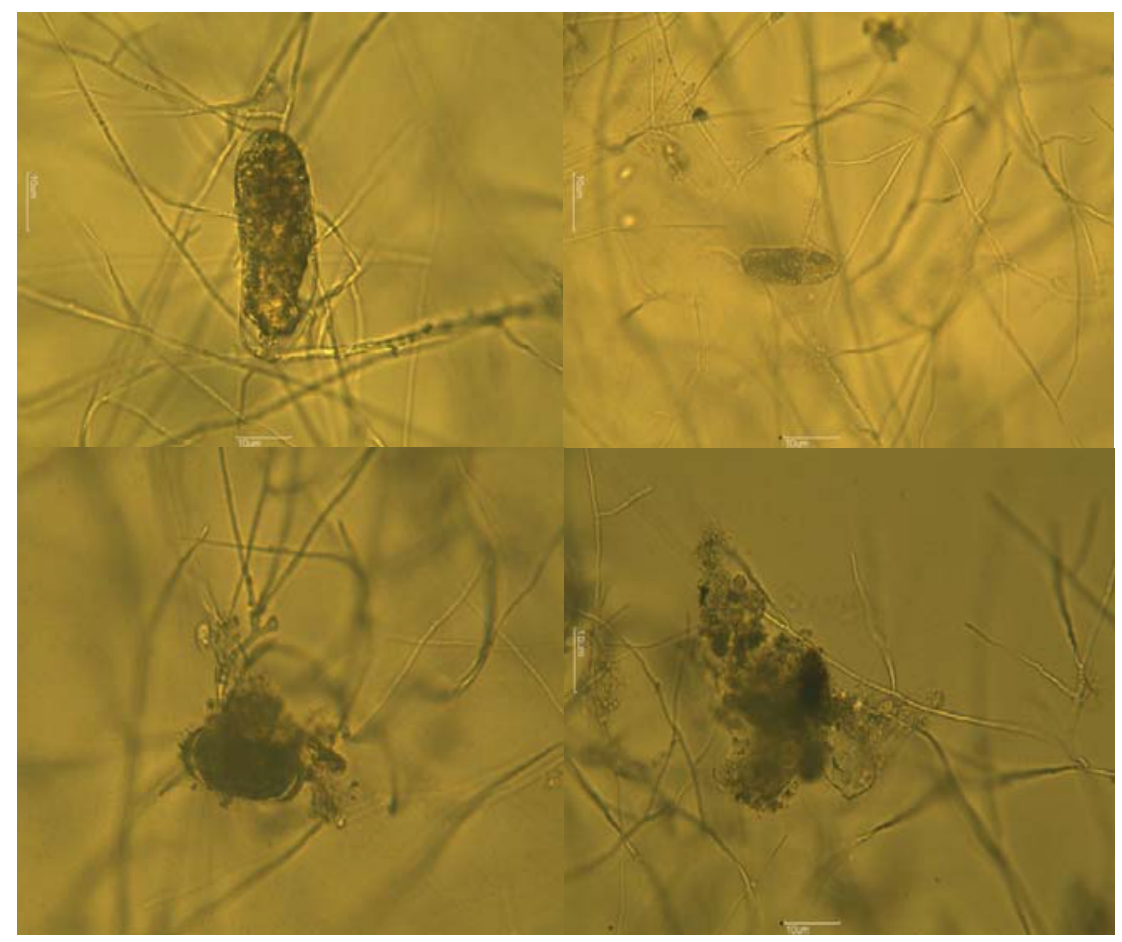

Fig. V.57: Huevos de nematodo en contacto con hifas del hongo T. harzianum después de 10 días bajo el microscopio con 100 aumentos (100X).

Como se observa bajo el microscopio, las hifas de T. harzianum no realizaron ningún tipo de enrollamiento o micoparasitismo sobre los huevos de nematodo, aunque si les provoco lisis en muchos de ellos. Debido al crecimiento miceliar del 
hongo, en el medio acuoso, y la imposibilidad de contar los huevos de nematodo afectados por T. harzianum, se eliminaron las esporas y micelio del extracto inicial a través del filtrado por papel Whatmann y filtro de 0,25 $\mu \mathrm{m}$, (Milipore), conservándose las muestras concentradas a $4^{\circ} \mathrm{C}$ hasta su uso.

La actividad mostrada por el extracto filtrado y concentrado de T. harzianum sobre la eclosión de huevos de nematodo durante 16 días se detallan en la tabla V.9 y en la Fig.V.58.

\begin{tabular}{|c|c|c|c|c|c|}
\cline { 2 - 6 } \multicolumn{1}{c|}{} & \multicolumn{5}{c|}{ Tiempo de actuación del extracto (días) } \\
\cline { 2 - 7 } \multicolumn{1}{c|}{} & $\mathbf{3}$ & $\mathbf{6}$ & $\mathbf{1 0}$ & $\mathbf{1 3}$ & $\mathbf{1 6}$ \\
\hline Control & $4,6 \pm 0,5 \mathrm{a}$ & $16,4 \pm 0,9 \mathrm{a}$ & $57,4 \pm 4,9 \mathrm{a}$ & $75,1 \pm 3,7 \mathrm{a}$ & $86,9 \pm 2,6 \mathrm{a}$ \\
\hline $\mathbf{1 ~ d}$ & $2,0 \pm 1,3 \mathrm{a}$ & $5,6 \pm 3,1 \mathrm{~b}$ & $10,2 \pm 1,7 \mathrm{~b}$ & $11,8 \pm 1,5 \mathrm{~b}$ & $12,3 \pm 1,6 \mathrm{~b}$ \\
\hline $\mathbf{2 ~ d}$ & $2,0 \pm 0,4 \mathrm{a}$ & $2,5 \pm 0,1 \mathrm{bc}$ & $2,6 \pm 0,7 \mathrm{c}$ & $7,1 \pm 0,8 \mathrm{bc}$ & $8,7 \pm 0,9 \mathrm{bc}$ \\
\hline $\mathbf{4 ~ d}$ & $3,8 \pm 0,5 \mathrm{a}$ & $4,4 \pm 0,9 \mathrm{~b}$ & $5,08 \pm 1,2 \mathrm{bc}$ & $5,0 \pm 1,2 \mathrm{bcb}$ & $5,0 \pm 1,2 \mathrm{bc}$ \\
\hline $\mathbf{6 ~ d}$ & $4,3 \pm 0,4 \mathrm{a}$ & $4,3 \pm 0,4 \mathrm{~b}$ & $4,38 \pm 0,4 \mathrm{bc}$ & $4,3 \pm 0,4 \mathrm{bc}$ & $4,3 \pm 0,4 \mathrm{bc}$ \\
\hline $\mathbf{8} \mathbf{d}$ & 0 & $0,3 \pm 0,2 \mathrm{~d}$ & $0,34 \pm 0,2 \mathrm{~d}$ & $0,3 \pm 0,2 \mathrm{~d}$ & $0,3 \pm 0,2 \mathrm{~d}$ \\
\hline
\end{tabular}

Tabla V.8: Valor medio $( \pm \mathrm{SE})$ del porcentaje de eclosión de huevos de $M$. incognita con extractos metabólicos concentrados de T. harzianum de diferentes tiempos de incubación en el medio de cultivo (1, 2, 4, 6 y 8 días), y en diferentes tiempos de actuación de los extractos sobre los huevos de nematodo (3, 6, 10, 13 y 16 días).

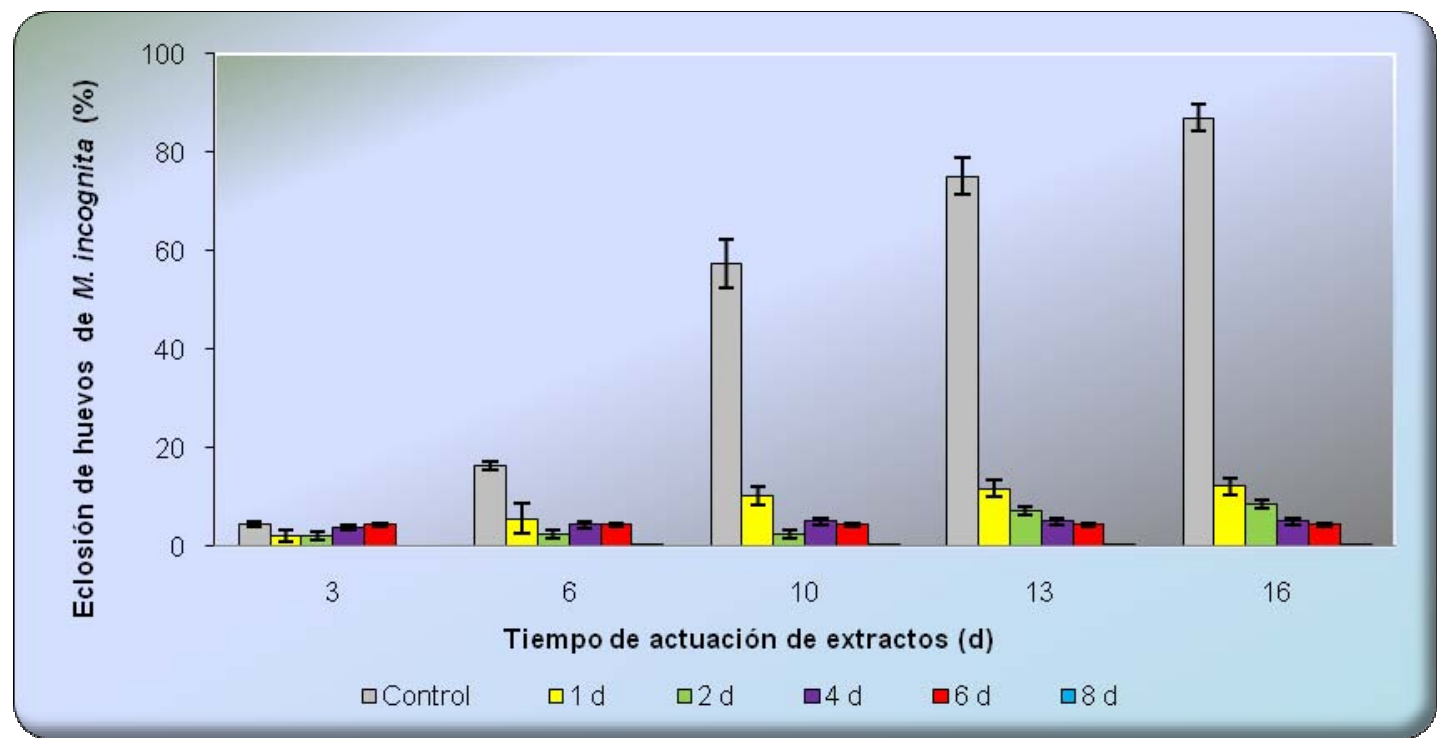

Fig. V.58: Eclosión de huevos de $M$. incognita, en porcentaje, con los diferentes extractos de $T$. harzianum, en los diferentes tiempos de incubación del hongo en los medios de cultivo (1, 2, 4, 6 y 8 días), y en diferentes tiempos de actuación de los extractos sobre los huevos de $M$. incognita (3, 6, 10, 13 y 16 días). 
Como se observa en la Tabla V.8 y en la Fig. V.58, la adición de los extractos de T. harzianum de cualquier tiempo de incubación, disminuyen la eclosión de los huevos del nematodo incluso cuando se tratan con extractos de 24 horas. Es notable que con los extractos de 8 días, no se obtienen huevos eclosionados ni siquiera al realizar el recuento a los 16 días cuando en el control se contabilizan más del $85 \%$ de los huevos eclosionados.

V.10.2. Estudio del extracto completo de $T$. harzianum sobre juveniles (J2) de M. incognita

La actividad del extracto metabólico filtrado y concentrado de $T$. harzianum sobre juveniles de 5-7 días de vida se estima como el porcentaje de mortandad durante 24, 48 y 96 horas que se detallan en la tabla V.10 y Fig. V.60.

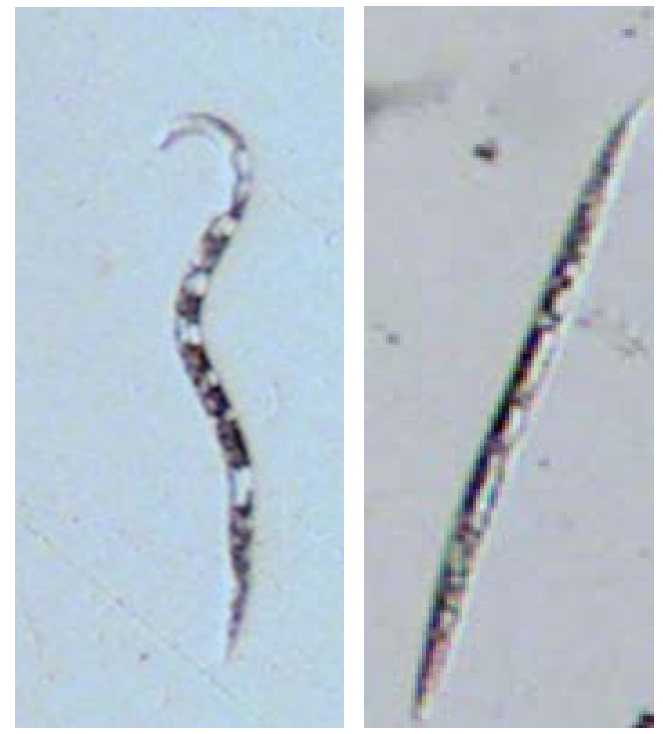

Fig. V.59 Apariencia de juveniles $\left(\mathrm{J}_{2}\right)$ sano (izquierda) y afectado (derecha) por el extracto de $T$. harzianum vistos al microscopio óptico a 60x aumentos.

En la Fig.V.59 se muestran fotografías de $\mathrm{J}_{2}$, bajo el microscopio óptico, a la derecha vivo y a la izquierda muerto. Los $\mathrm{J}_{2}$ vivos están activos continuamente, agitándose con movimientos zigzagueantes, mientras que los muertos quedan rígidos y no se mueven aun cuando se les estimule con la punta de una aguja. 


\begin{tabular}{|c|c|c|c|}
\cline { 2 - 4 } \multicolumn{1}{c|}{} & \multicolumn{3}{c|}{ Tiempo de actuación del extracto (h) } \\
\cline { 2 - 4 } \multicolumn{1}{c|}{} & $\mathbf{2 4}$ & $\mathbf{4 8}$ & $\mathbf{9 6}$ \\
\hline Control & $3,9 \pm 1,3 \mathrm{a}$ & $5,3 \pm 1,7 \mathrm{a}$ & $6,6 \pm 2,4 \mathrm{a}$ \\
\hline $\mathbf{1 ~ d}$ & $77,9 \pm 3,5 \mathrm{~b}$ & $79,5 \pm 2,3 \mathrm{~b}$ & $80,3 \pm 3,7 \mathrm{~b}$ \\
\hline $\mathbf{2 ~ d}$ & $90,1 \pm 2,3 \mathrm{c}$ & $91,7 \pm 3,4 \mathrm{c}$ & $93,5 \pm 2,5 \mathrm{bc}$ \\
\hline $\mathbf{4 ~ d}$ & $100,0 \pm 0,6 \mathrm{~d}$ & $100,0 \pm 0,6 \mathrm{~d}$ & $100,0 \pm 0,6 \mathrm{~d}$ \\
\hline $\mathbf{6 ~ d}$ & $100,0 \pm 0,8 \mathrm{~d}$ & $100,0 \pm 0,9 \mathrm{~d}$ & $100,0 \pm 0,9 \mathrm{~d}$ \\
\hline $\mathbf{8 ~ d}$ & $100,0 \pm 0,5 \mathrm{~d}$ & $100,0 \pm 0,7 \mathrm{~d}$ & $100,0 \pm 0,8 \mathrm{~d}$ \\
\hline
\end{tabular}

Tabla V.9: Datos del porcentaje de mortandad de juveniles $\left(\mathrm{J}_{2}\right)$ de $M$. incognita con los extractos metabólicos de $T$. harzianum de diferentes tiempos de incubación en el medio de cultivo (1, 2, 4, 6, y 8 días), y en diferentes tiempos de actuación de los extractos sobre los huevos de nematodo (24, 48 y 96 horas).

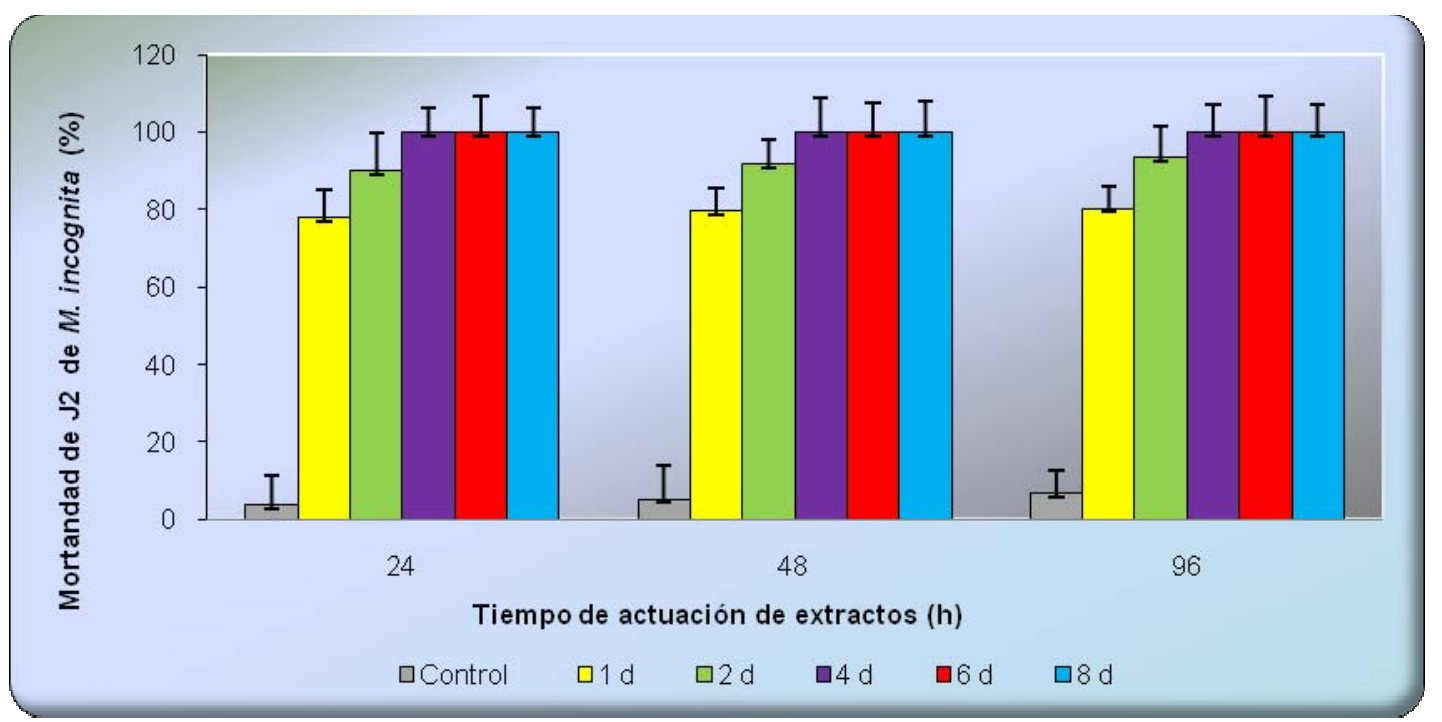

Fig. V. 60: Mortandad de juveniles $\left(\mathrm{J}_{2}\right)$ de $M$. incognita con los diferentes extractos metabólicos de T. harzianum en los diferentes tiempos de incubación del hongo en los medios de cultivo (1, 2, 4, 6,y 8 días), y en los diferentes tiempos de actuación de los extractos sobre los huevos de $M$. incognita(24, 48 y 96 horas).

En la Tabla V.9 y en la Fig. V.60 se reflejan los datos de mortandad de los $\mathrm{J}_{2}$ después de la adición de los extractos de cultivos de T. harzianum de distintos tiempos de incubación. Claramente se observa que los juveniles no sobreviven cuando son tratados con extractos de 4 días pero incluso con los de 1 día de cultivo, la mortandad es del $80 \%$, lo cual quiere decir que el hongo está vertiendo 
compuestos al medio extracelular que tiene una elevada capacidad nematicida.

\section{V.10.3. Separación mediante cromatografía en capa fina (TLC) de extractos de $T$. harzianum}

Con el propósito de analizar los extractos de vertidos extracelulares de $T$. harzianum tratando de identificar sus componentes, los siguientes resultados se basan en los obtenidos al realizar separaciones cromatográficas optimizando concentraciones del depósito para su separación y sobre todo, de la fase móvil empleada que consigue la separación óptima.

En las Figuras V.61, V.62 y V.63 se muestran la separación del extracto metabólico de diferentes tiempos de incubación (1, 2, 4, 6 y 8 días) de T. harzianum mediante cromatografía en capa fina (TLC) y las diferentes fases móviles Terbutilmetil-eter (TBME):Metanol; Cloroformo:Metanol y un gradiente de Acetato de Nitrilo (AcN) y agua del 50\% al 95\%.
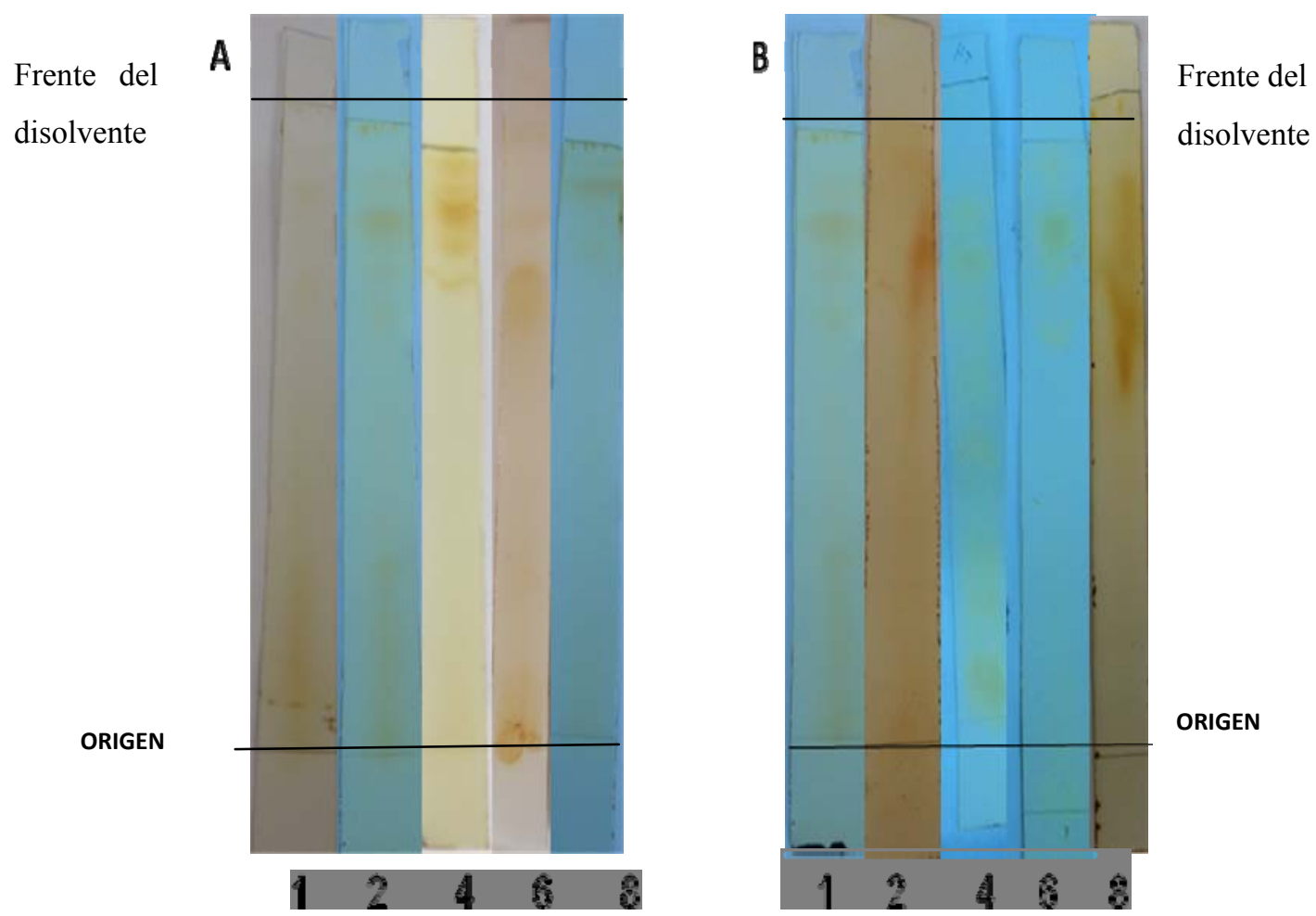

Fig. V.61 Cromatografía en capa fina de gel de sílice (TLC) de los vertidos metabólicos de $T$. harzianum en (A) PDB y (B) PDB+sales con TBME: Metanol (3:7) a tiempos de incubación del hongo de 1, 2, 4, 6, y 8 días. 
Los cromatogramas de la Fig.62 corresponden a separaciones con la fase móvil TBME:Metanol (3:7). En (A) los extractos de T. harzianum proceden de cultivos donde el hongo creció en medio líquido con patata-dextrosa (PDB) sola y en (B) donde el medio era más complejo pues contenía, además de PDB sales inorgánicas y orgánicas. Las diferencias observadas en las bandas separadas no son significativas pues se obtiene el mismo número de bandas y tampoco es destacable la diferencia de tiempo de incubación de los cultivos.

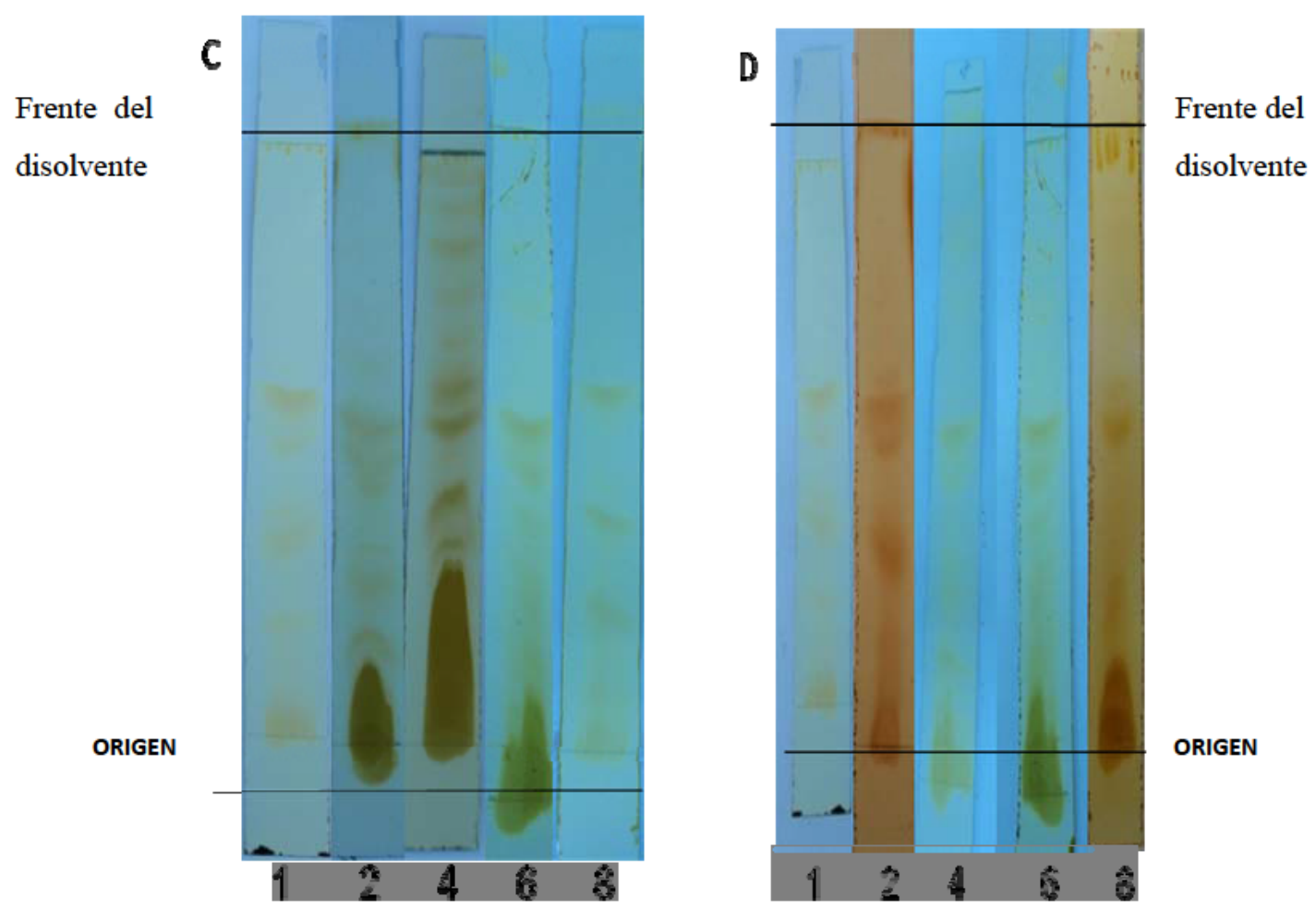

Fig. V.62 Cromatografía en capa fina de gel de sílice (TLC) de los vertidos metabólicos de $T$. harzianum en (A) PDB y (B) PDB+sales con Cloroformo: Metanol (8:2) a tiempos de incubación del hongo de 1, 2, 4, 6 y 8 días.

En la Fig. V.62 la fase móvil empleada (Cloroformo:metanol, 8:2) proporciona numerosas bandas y lo más significativo es que los extractos con cultivos en PDB y de 4 días son los que proporcionan las bandas más nítidas. El hecho de que el desarrollo no sea uniforme puede proceder de que la cantidad de extracto empleado para hacer el depósito en el origen no sea uniforme. Es sabido que la buena resolución de las separaciones cromatográficas depende de la concentración del extracto inicial, cuando ya se ha optimizado la fase estacionaria y la móvil. En nuestro caso, todas las fases estacionarias son la misma: gel de sílice en capa fina y 
las variaciones las hemos hecho mediante las diferentes fases móviles. El resultado de la Fig.V62 nos indica que también hay que optimizar la concentración del apósito en el origen para que la separación sea correcta (que no se junten bandas) y que se muestren todas las bandas posibles. Para el primer caso la concentración no debe superar un máximo y para el segundo, debe estar por encima de un mínimo. Cuando esto no se da, se obtienen manchas continuas o se pierden bandas.

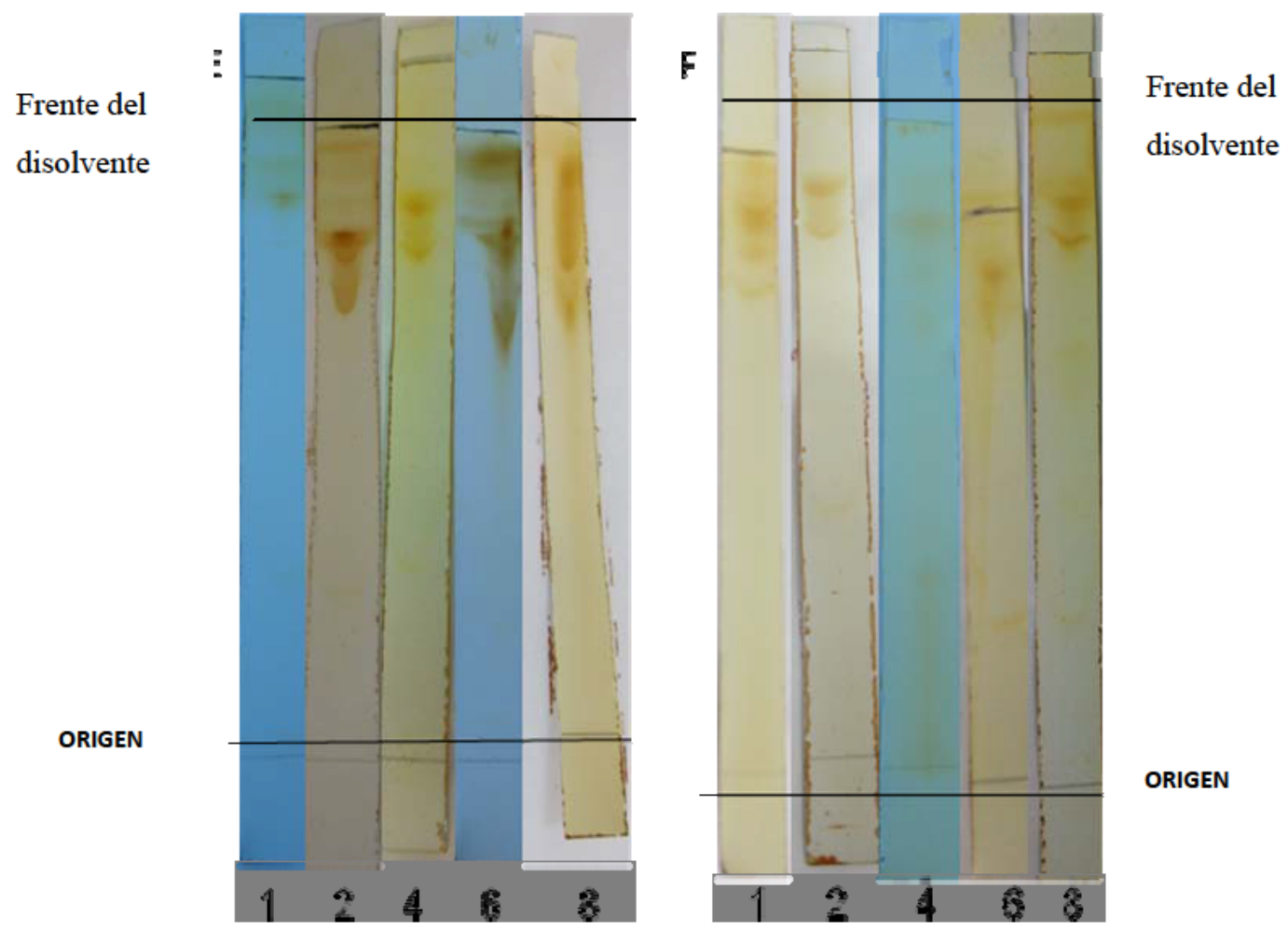

Fig. V.63 Cromatografía en capa fina de gel de sílice (TLC) de los vertidos metabólicos de $\boldsymbol{T}$. harzianum en (A) PDB y (B) PDB+sales con Acetato de nitrilo:agua (7,5:2,5) a tiempos de incubación del hongo de 1, 2, 4, 6,y 8 días.

En la Figura V.63 se muestran cromatogramas de los extractos de T. harzianum crecidos en los dos tipos de cultivo y a los mismos tiempos de crecimiento, pero que se han separado con una fase móvil específica de Acetato de nitrilo:agua (7,5:2,5). Como se observa la separación no es óptima ya que eleva las bandas a zonas cercanas al frente y las separa muy deficientemente. Esta fase móvil es la menos conveniente para separar mayor número de bandas, pero sí hay un detalle importante y es que en los extracto de PDB+sales aparecen más bandas que en los de PDB solo. Aquí también habría que comparar estos resultados en cromatogramas realizados con 
depósitos de la misma concentración, si la separación fuera muy buena.

Frente del disolvente

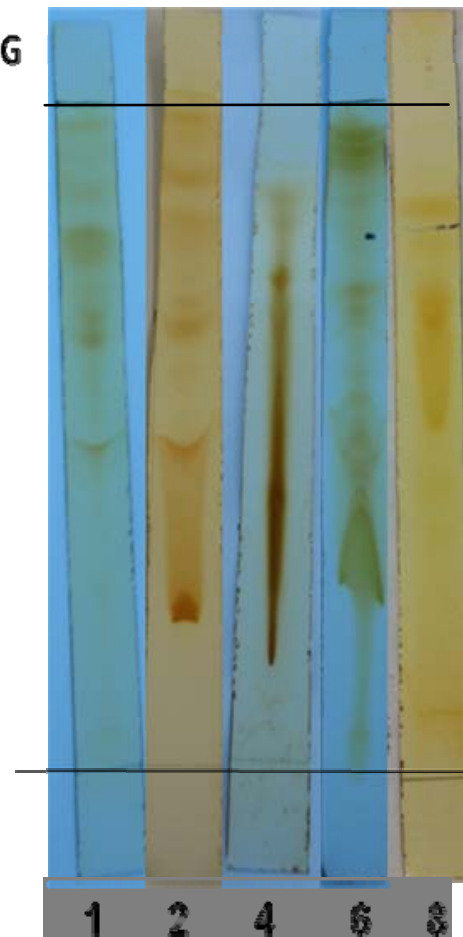

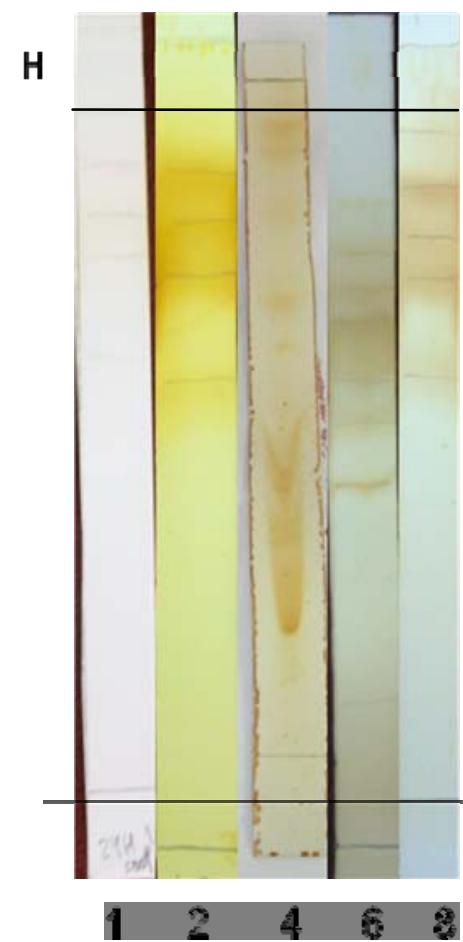

Frente del

disolvente

ORIGEN

Fig. V.64 Cromatografía en capa fina de gel de sílice (TLC) de los vertidos metabólicos de $T$. harzianum en (G) PDB y (H) PDB+sales con Acetato de nitrilo:agua (9:1) a tiempos de incubación del hongo de 1, 2, 4, 6,y 8 días.

En la Fig.V.64 se muestran los resultados de la separación de los extractos de T. harzianum con los mismos cultivos y a los mismos tiempos de incubación que anteriormente, pero optimizada la fase móvil después de los resultados obtenidos. Esta es la separación que creemos más conveniente porque se obtienen las bandas más separadas y más nítidas.

Aunque a nivel cromatográfico no hay diferencias significativas entre las bandas obtenidas en cultivos de T. harzianum de diferente composición, cuando se obtuvieron los resultados de actividad nematicida, los extracto de cultivos de $\mathrm{PDB}+$ sales dieron mucha mayor actividad antinematodos, lo cual quiere decir que el hongo está produciendo muchos más compuestos anti-nematodos en el medio enriquecido que en PDB solo y en mayor concentración en mayores tiempos de incubación. Por ello, para verificar la capacidad antipatógenos se escogió el extracto de PDB+sales incubación con la separación acetonitrilo:agua (9:1) y tiempos de incubación elevados. 
El siguiente ensayo se realizó para determinar las bandas del cromatograma que separadas, pudieran tener capacidad antipatógenos. En un principio se realizó un bioensayo sobre el propio cromatograma y frente a un hongo patógeno, para obtener un resultado inmediato de que bandas podrían estar en la/las zona/s antipatógena/s.

\section{V.10.4. Estudio de la actividad antifúngica del extracto completo de $T$. harzianum}

A

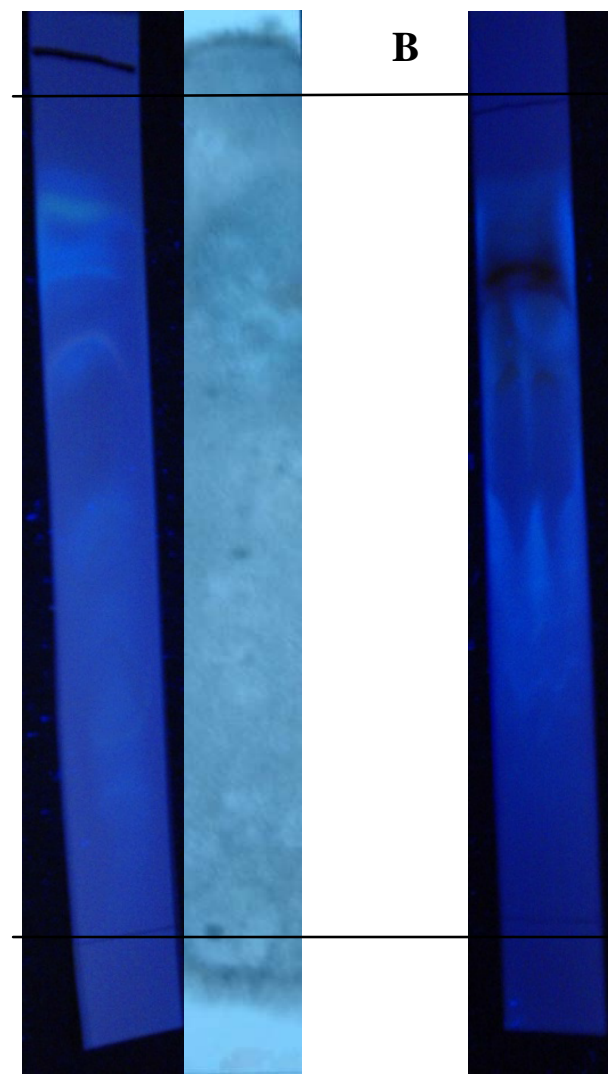

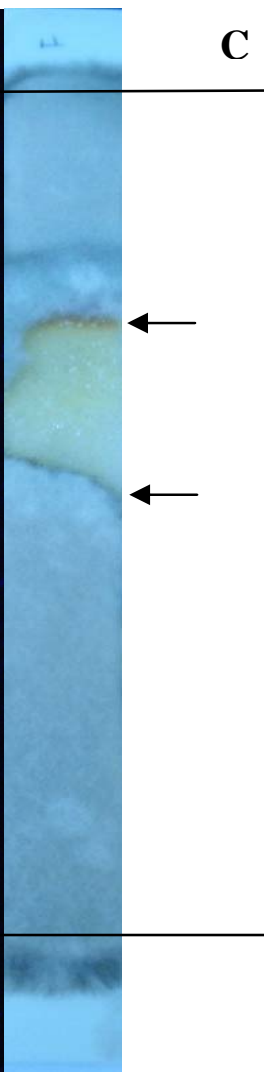

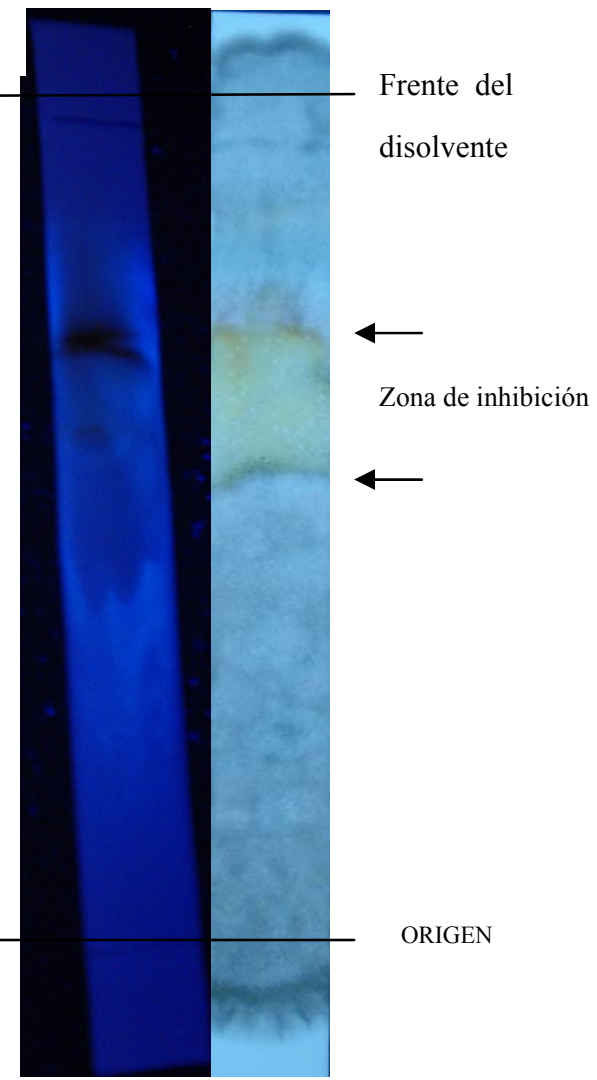

Fig. V.65 Cromatografías en capa fina de gel de sílice (TLC) con Acetato de nitrilo:agua (90:10)de diferentes tiempos de incubación, en el medio de cultivo, de T. harzianum: (A) 4 días, (B) 6 días y (C) 8 días, bajo luz ultravioleta a 360nm(izq.) y sembrado con PDA y esporas del hongo Botrytis cinérea (der.).

El bioensayo de inhibición de los extractos de T. harzianum de diferentes tiempos de incubación se realiza frente al hongo Botrytis cinérea y se muestra en la Fig. V.65. En ella se observa que extractos de cuatro días no producen inhibición del crecimiento pero a los seis y ocho días aparece una zona de inhibición de $\mathrm{Rf}=0,85$ hasta $\mathrm{Rf}=0,65$. La separación cromatográfica utilizada nos confirma que los vertidos de $T$. harzianum tienen actividad antifungica y que como posiblemente se correspondan con un compuesto que tenga también actividad nematicida, este es el 
sistema cromatográfico útil para analizar los compuestos nematicidas separados en cada banda.

\section{V.10.5. Estudio de la actividad antinematicida de fracciones del extracto}

\section{de T. harzianum}

Con los resultados obtenidos en los ensayos previos elegimos los siguientes componentes para el análisis de la actividad nematicida. El extracto procede de $\mathrm{PDB}+$ sale incubado durante 8 días, que es el que da mayor mortandad de

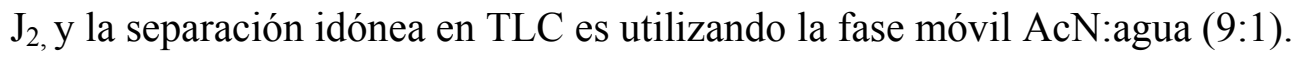

La optimización de la separación se realiza analizando la cantidad de muestra que se deposita en la capa fina del gel de sílice. Las cantidades analizadas fueron $500 \mu 1,800 \mu 1$ y $1 \mathrm{ml}$. Los resultados obtenidos se muestran en la Fig. V.66, donde se observa que la mayor definición y separación de las bandas se obtiene con la concentración de $800 \mu \mathrm{l}$ (Fig. V.66, B). La concentración menor da una buena separación, pero las bandas son muy tenues y por tanto su capacidad nematicida individual puede ser tan baja que no la detectemos en las bandas separadas y nos induzca a error por su insuficiencia. La máxima concentración utilizada, $1 \mathrm{ml}$, resuelve la cromatografía muy deficientemente y aunque para la actividad nematicida sería más idónea, no se puede utilizar.

A

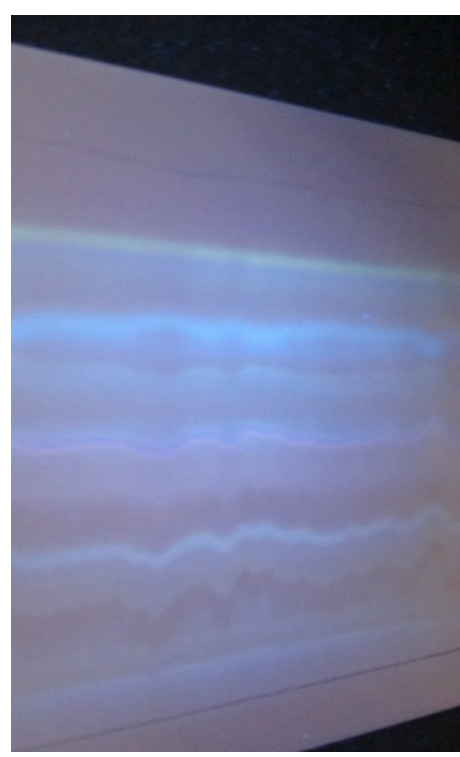

B

C

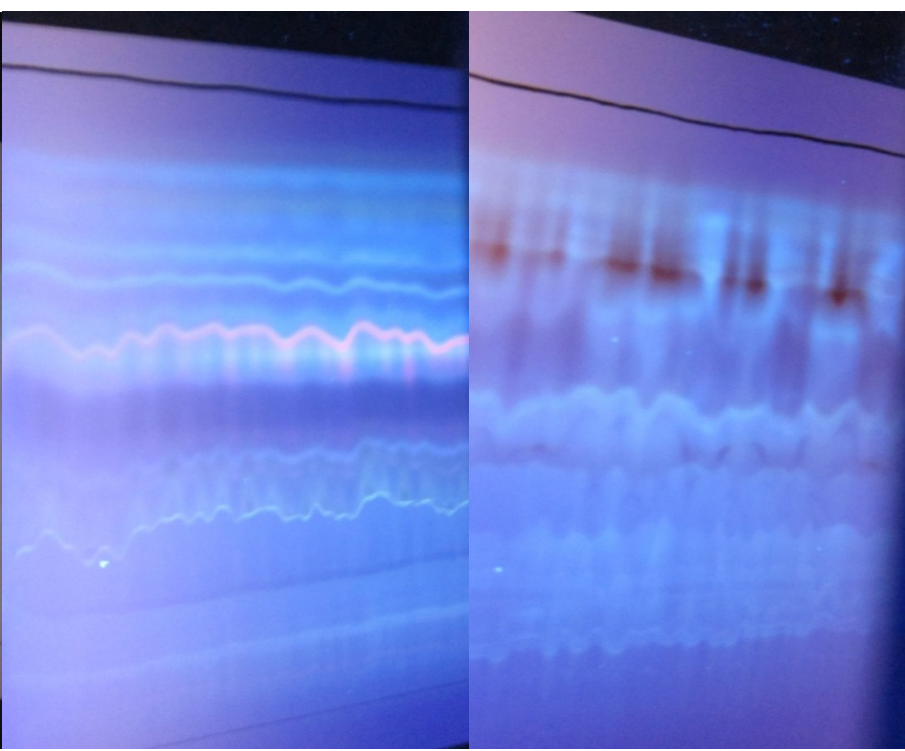

Fig. V.66. Cromatografía en capa fina de gel de sílice (TLC) con AcN:agua (9:1) de 8 días de incubación, en el medio de cultivo, de T. harzianum, con diferente cantidad de muestra: (A) 500

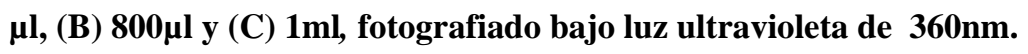


Una vez resuelto la cantidad de muestra de extracto de $T$. harzianum que necesitamos para obtener las bandas bien definidas, realizamos 8 cromatografías de $800 \mu 1$, que se corresponde con un total de $6,4 \mathrm{ml}$ de muestra concentrada. En cada cromatografía se señalan las bandas, identificadas con su Rf y una vez separadas y recuperadas con la mezcla de Metanol: Cloroformo: Acetato de etilo: Acetona $(2: 1: 1: 2)$, se lleva a sequedad, se resuspenden en agua y se añaden a los nematodos "in vitro".

Los resultados obtenidos de la capacidad nematicida analizada como \% de mortandad de los juveniles, se muestra en la tabla V.10 y la Fig. V.67.

\begin{tabular}{|c|c|c|c|c|}
\cline { 3 - 5 } \multicolumn{2}{c}{} & \multicolumn{3}{|c|}{ Tiempo de actuación del extracto (h) } \\
\cline { 3 - 5 } \multicolumn{2}{c}{} & $\mathbf{2 4}$ & $\mathbf{4 8}$ & $\mathbf{9 6}$ \\
\hline Control & Rf & $3,6 \pm 1,9 \mathrm{ab}$ & $5,4 \pm 2,3 \mathrm{a}$ & $9,1 \pm 3,5 \mathrm{a}$ \\
\hline F1 & 0,89 & $25,3 \pm 6,4 \mathrm{~d}$ & $47,9 \pm 6,5 \mathrm{~d}$ & $73,8 \pm 4,1 \mathrm{e}$ \\
\hline F2 & 0,82 & $14,6 \pm 4,4 \mathrm{c}$ & $33,4 \pm 4,2 \mathrm{~cd}$ & $52,64 \pm 5,0 \mathrm{~d}$ \\
\hline F3 & 0,74 & $8,4 \pm 2,6 \mathrm{bc}$ & $16,2 \pm 5,9 \mathrm{~b}$ & $30,35 \pm 5,2 \mathrm{c}$ \\
\hline F4 & 0,67 & $6,4 \pm 2,4 \mathrm{ab}$ & $15,7 \pm 3,1 \mathrm{~b}$ & $27,9 \pm 4,1 \mathrm{bc}$ \\
\hline F5 & 0,61 & $4,7 \pm 2,3 \mathrm{ab}$ & $11,7 \pm 5,6 \mathrm{ab}$ & $21,4 \pm 3,5 \mathrm{cb}$ \\
\hline F6 & 0,48 & $5,9 \pm 2,1 \mathrm{ab}$ & $12,7 \pm 4,5 \mathrm{ab}$ & $24,6 \pm 3,2 \mathrm{cb}$ \\
\hline F7 & 0,34 & $3,7 \pm 1,6 \mathrm{a}$ & $5,8 \pm 3,2 \mathrm{a}$ & $13,1 \pm 3,1 \mathrm{ab}$ \\
\hline F8 & 0,21 & $2,8 \pm 1,4 \mathrm{a}$ & $6,9 \pm 3,7 \mathrm{a}$ & $10,7 \pm 5,3 \mathrm{~b}$ \\
\hline
\end{tabular}

Tabla V.10: Valor medio $( \pm \mathrm{SE})$ del porcentaje de mortandad de $\mathbf{J}_{2}$ de $M$. incognita con las diferentes fracciones separadas por TLC del extracto de 8 días de incubación de $T$. harzianum, en los diferentes tiempos de actuación de los extractos sobre $\mathrm{J}_{2}$ de nematodo (24, 48 y 96 horas). 


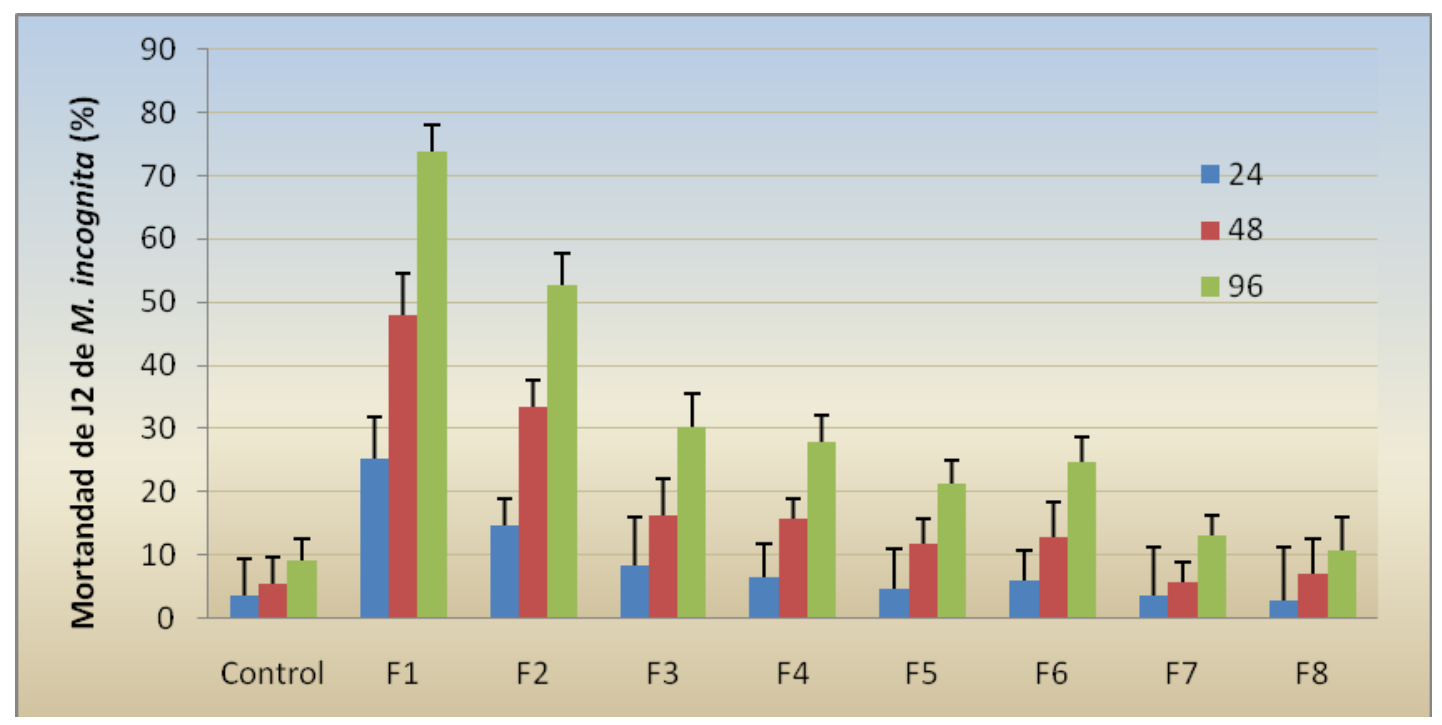

Fig. V.67: Mortandad de juveniles $\left(\mathrm{J}_{2}\right)$ de $M$. incognita con las diferentes fracciones separadas por TLC del extracto de 8 días de incubación de T. harzianum, en los diferentes tiempos de actuación de los extractos sobre $\mathrm{J}_{2}$ de nematodo (24, 48 y 96 horas).

En la Fig. V.67. se puede observar que la banda $F_{1}$ (con un $R f=0,89$ ), del extracto de 8 días de incubación de T. harzianum en el medio de cultivo, a las 96 horas de actuación sobre los $\mathrm{J}_{2}$ es la que tiene mayor capacidad nematicida $(73,8 \%)$. También la banda $\mathrm{F}_{2}$ con un $\mathrm{Rf}=0,82$ produce una alta mortandad de los $\mathrm{J}_{2}(52,6 \%)$. Las zonas de inhibición de los nematodos se corresponden, aproximadamente, con las zonas de inhibición fúngica obtenidas anteriormente.

Las restantes bandas recogidas del gel también tienen un cierto grado de actividad nematicida, pero no superan en ningún caso el $30 \%$ de mortandad de $\mathrm{J}_{2}$ de nematodos.

Como conclusión de los resultados de actividad nematicida de los extractos de T. harzianum hay que señalar que el hongo produce compuestos de metabolismo extracelular que se vierten en el medio de cultivo de PDB+sales, en mayor concentración cuanto más tiempo permanezca el cultivo. El más idóneo por su mayor capacidad nematicida es el de 8 días. La separación de este extracto se ha optimizado en TLC de gel de sílice con la fase móvil, acetato de nitrilo:agua (9:1) que da 8 bandas de las cuales la $\mathrm{F}_{1}$ de $\mathrm{Rf}=0,89$ seguida de la $\mathrm{F}_{2}$ de $\mathrm{Rf}=0,82$ producen la más elevada mortandad de los $\mathrm{J}_{2}$ de $M$. incognita 


\section{DISCUSIÓN}

Cuando en un campo de pimientos, las plantas muestran síntomas de decaimiento y amarillamiento que conduce a la baja producción de frutos, se debe identificar convenientemente el origen de la alteración para poder seguir usando esos campos en un cultivo productivo. Una vez que en las raíces de las plantas de pimiento afectadas se observaron agallas y se relacionaron con las producidas por nematodos, su identificación era el prerrequisito necesario para el uso de medidas de saneamiento y control de la enfermedad. De manera similar también fue esencial el conocimiento de las relaciones entre la población inicial de nematodos en suelo y el crecimiento de la planta, de modo que se puedan evaluar las pérdidas en el rendimiento de la cosecha de pimientos, causada por el nematodo parásito y poder escoger las estrategias de lucha contra la enfermedad.

Una de las posibilidades más atractivas para obtener buenos rendimientos en la cosecha, de pimientos, utilizando campos infectados de nematodos es plantar variedades resistentes, lo cual no es siempre posible porque no existen en el mercado pimientos con total resistencia a $M$. incognita. Se ha publicado la existencia de genes de resistencia al nematodo, pero esta no es total y además en algunos casos se ha comprobado la existencia de nuevas cepas del nematodo que han sobrepasado la 
resistencia y atacan a las variedades de pimiento que antes toleraban al nematodo.

La siguiente estrategia consiste en la utilización de una lucha en la que se integren elementos de biocontrol, habida cuenta de que no existen nematicidas postemergencia y lo que se ha estado utilizando hasta ahora es una desinfección del suelo pre-cosecha con compuestos muy eficaces pero dañinos como el bromuro de metilo. El problema es que actualmente no se puede utilizar pues está prohibido por la resolución de Montreal de 2005, ya que tanto el bromuro de metilo como otros compuestos organo-clorados se evaporan, traspasan la troposfera y ascienden hasta la estratosfera, afectando la capa de ozono que protege la tierra de las radiaciones de $230 \mathrm{~nm}$, las que inciden sobre nuestro ADN y que pueden provocar mutaciones cancerígenas.

Así pues, era necesario implementar tratamientos de lucha integrada que contemplen el uso de desinfecciones del suelo pre-cosecha de manera no dañina para el medio ambiente lo cual podría incluir el uso de vapor de agua, la biosolarización y también el uso de microorganismos antagonistas de nematodos. Este último punto es el que realizamos en este trabajo.

Para establecer la lucha biológica, que sin el uso de productos químicos pueda conseguir el biocontrol, era preciso identificar inequívocamente el nematodo y sobre todo determinar el límite de tolerancia del pimiento al nematodo. En esta Memoria se han establecido las bases para utilizar el control biológico, al haber obtenido un mayor conocimiento de la interacción pimiento-Meloidogyne incognita.

De esta interacción los primeros trabajos se encaminaron a identificar el nematodo responsable de la enfermedad de la agalla de la corona que se detectó en plantas de pimiento. La diagnosis morfológica y los ensayos de ADN (Willianson et al., 1997; Tesařová et al., 2003; Qiu et al., 2006) revelan los rasgos típicos de $M$. incognita (Fig. V.6, Fig. V.5) (Orton Williams, 1973). Así mismo, los resultados de los estudios de histopatología revelan una reacción susceptible típica de las plantas de pimiento a la infección por M. incognita (Figs. V.11-14). Las células gigantes y la modificación de los tejidos producidos por los nematodos, secuestran nutrientes de la planta hospedadora y limitan la traslocación de agua y nutrientes desde las raíces infectadas hasta los tejidos superiores de la planta. El desarrollo del hábitat parasítico de $M$. incognita observado en pimiento es similar al encontrado en otros vegetales (Potter \& Olthof, 1993). 
Si comparamos nuestros datos con los publicados por otros autores, vemos que en la interacción entre la mora blanca y Meloidogyne arenaria (Castillo et al., 2001) han encontrado que a partir de una infección inicial (Pi) de 2 a 4 huevos $+\mathrm{J}_{2} / \mathrm{cm}^{3}$ de suelo y hasta 64 es donde la densidad de nematodos afecta más directamente a las plantas. A partir de 128 la planta ya tiene rendimiento 0 y muere. La tasa de reproducción $(P f / P i)$ dio el máximo valor de 434,8 cuando $P i=0$ 0,25 y $P f=108,7$ huevos $+\mathrm{J}_{2} / \mathrm{cm}^{3}$ de suelo. En la interacción M. incognita y espinacas (Di Vito et al., 2004) obtienen que (T) el límite de tolerancia es 0,5 huevos $+\mathrm{J}_{2}$ por $\mathrm{cm}^{3}$ de suelo. La mayor tasa de reproducción del nematodo es con $\mathrm{Pi}=8$ huevos $+\mathrm{J}_{2} / \mathrm{cm}^{3}$ de suelo y obtienen $P f=10.010$ huevos $+\mathrm{J}_{2}$ por $\mathrm{cm}^{3}$ de suelo. Si en la mora blanca se partía de una densidad inicial de nematodos de $P i=1$ huevos $+\mathrm{J}_{2} / \mathrm{cm}^{3}$ de suelo y obtenían una densidad final de $P f=99.2$ a los 90 días, en espinacas de $P i=1$ se obtienen $P f=6.720$ huevos $+\mathrm{J}_{2} / \mathrm{cm}^{3}$ de suelo a los 50 días. En la interacción $M$. incognita con apio (Vovlas et al., 2008) el límite de tolerancia al nematodo es 0,15 huevos $+\mathrm{J}_{2} / \mathrm{ml}$ de suelo y la tasa de reproducción máxima (Pf/Pi) fue de 407,6 desde una población inicial (Pi) de 4 huevos $+\mathrm{J}_{2} / \mathrm{ml}$ de suelo. En tomate sin embargo, M. incognita (Chan \& López, 1992) tiene una tasa de reproducción máxima a la densidad inicial de 600 huevos/100 $\mathrm{ml}$ de suelo y la mínima productividad la obtienen para valores de 0,73 y 0,75 de peso fresco en parte aérea y raíces respectivamente en cultivos en invernadero durante 65 días. En este caso el límite de tolerancia de los tomates al nematodo es de 200 huevos/100 ml de suelo. En frijol, la variedad Ojito Negro, a un límite de tolerancia de 0,74 (huevos $+\mathrm{J}_{2}$ ) de $M$. incognita $/ \mathrm{cm}^{3}$ de suelo y a la mayor densidad de población del nematodo estudiada (32 huevos $+\mathrm{J}_{2} / \mathrm{cm}^{3}$ de suelo) el peso de la semilla y la parte aérea de las plantas se reducen solo el $20 \%$ y el $10 \%$ respectivamente, lo cual demuestra que el nematodo afecta muy levemente a esta variedad de frijoles .

Al analizar los datos mencionadas en las interacciones de Meloidogyne incognita con las distintas plantas estudiadas, se llega a la conclusión de que en cada interacción planta-nematodo hay que calcular la incidencia de la dosis inicial del nematodo y su densidad al final del cultivo para obtener los límites de tolerancia al patógeno y que para evaluar el desarrollo de la enfermedad, es decisivo el tipo de planta hospedadora pero también las condiciones de cultivo, tipo de suelo, $\mathrm{pH}$, grado de humedad y temperatura. Se suele confirmar que la tasa de reproducción de 
nematodos está inversamente relacionada con la población inicial de estos, pero que hay un límite de tolerancia al patógeno que puede variar desde 0,15 en apio, 0,5 en espinacas, 0,74 en frijol, 0,75 en tomate y 1,38 en la mora blanca.

A partir de los datos obtenidos en este trabajo comprobamos que el límite de tolerancia del pimiento a $M$. incognita es de 1,5 huevos $+\mathrm{J}_{2} / \mathrm{mL}$ de suelo para la altura de la parte aérea de la planta, densidad inicial máxima (Pi) que un suelo podría tolerar para obtener una cosecha de pimientos que no se afectara en demasía en su rendimiento. La tasa de reproducción $(P f / P i)$ dio el máximo valor de 315,4 (Tabla V.1) cuando $P i=4$ y $P f=1261,8$ huevos $+\mathrm{J}_{2} / \mathrm{cm}^{3}$ de suelo. También hemos visto que una densidad inicial de la población del nematodo que exceda de 32 huevos $+\mathrm{J}_{2} / \mathrm{mL}$ de suelo es la que proporcionaría la máxima reducción en el crecimiento de las plantas de pimiento, aunque a partir de una Pi de 4 huevos $+\mathrm{J}_{2} / \mathrm{mL}$ de suelo las plantas muestran un índice de agallamiento superior a 5 que según Bridge \& Page (1980) significa que más del 50\% de las raíces están infectadas y que el sistema radicular está reducido. El pimiento "California Wonder" usado en este estudio muestra ser muy sensible a $M$. incognita y que desde una $P i$ de 3 huevos $+\mathrm{J}_{2} / \mathrm{mL}$ de suelo la productividad cae en picado y ese suelo no debe usarse para cultivar pimiento si no se procede a sanearlo antes de la nueva plantación.

La búsqueda de estrategias de control fue el siguiente paso para intentar resolver los ataques de nematodos en campos que estén infectados, teniendo en cuenta que el uso de la lucha integrada por el uso de nematicidas legales, la biosolarización del suelo y el control biológico pueden ayudar a una reducción progresiva del nivel de infección hasta conseguir delimitarlo por debajo del límite de tolerancia y poder usar los campos para el cultivo productivo de pimientos.

Comenzamos utilizando una combinación de dos antagonistas, $P$. lilacinus y $T$. harzianum, para el control de $M$. incognita que resultó ser una opción eficaz en todos los tratamientos realizados hasta ahora, llegando a una reducción del 59\% de los huevos de nematodos por gr de raíz. En la bibliografía hay muchos ejemplos del uso de microorganismos antagonistas en las técnicas de biocontrol y nuestros resultados con los dos hongos antagonistas están en consonancia con los obtenidos con otros autores (Siddiqui and Mahmood, 1993; Siddiqui and Akhtar, 2008; Sharma y Pandey, 2009), en que la adición de estos antagonistas reduce la incidencia de la enfermedad pero no la mejora mas allá de un porcentaje alrededor del $42 \%$. A la 
vista de estos resultados y sabiendo que el biocontrol puede hacerse más efectivo si se integran varios microorganismos antagonistas con diferentes modos de acción, analizamos la actuación de combinaciones de hongos y bacterias, incluso de la actuación de bacterias promotoras de crecimiento combinadas con amino-ácidos de origen vegetal. Para estos fines realizamos un preparado que llamamos Nemaout que está pendiente de patente.

De los resultados obtenidos cuando se utiliza la combinación de tres microorganismos T. harzianum (TH2413), P. lilacinus (PL243) y Bacillus firmus (BF 342) o del preparado Nemaout, contra Meloidogyne incognita llegamos a la conclusión de que el uso de microorganismos antagonistas, permite una disminución de las agallas que el nematodo produce en las raíces de plantas de pimiento. Aunque en la bibliografía hay comunicaciones del uso de un solo antagonista en la lucha biológica contra M. incognita (Spiegel et al., 2007; Bokhari et al., 2009; Kiewnick et al., 2011) es bien sabido que la disminución de la enfermedad es muy baja, resultados que están en consonancia con los obtenidos por nosotros cuando usamos cada antagonista individualmente contra el patógeno. Con estos resultados se probaron combinación de dos hongos en conjunto y después una combinación de los dos hongos y una bacteria. Esta combinación de tres antagonistas, usados en conjunto, fue beneficiosa, pues produjo una disminución de las agallas de raíz del $46,6 \%$. De todas formas, esta reducción no fue totalmente satisfactoria teniendo en cuenta que los efectos nematicidas aún son bajos y como constatan Goswami et al., (2006), puede deberse a la baja permanencia en el suelo tanto de T. harzianum como de $P$. lilacinus, por lo que los efectos nematicidas no son persistentes y habría que tratar las plantas repetidamente. Quizás lo más interesante de esta combinación haya sido los efectos inmediatos que produce $T$. harzianum ya que uno de sus mecanismos de acción es la producción de metabolitos tóxicos (Bokhari 2009) que destruyen huevos disminuyendo el inóculo del suelo al inhibir la eclosión de Juveniles ( $\left.\mathrm{J}_{2}\right)$ y por tanto el grado de infección. Este mecanismo confirma la idea de que la principal actividad de $T$. harzianum como nematicida se ejerce en el suelo y no en el interior de las raíces por lo que estamos de acuerdo con Brants et al. (2000) quienes afirman que cuando los $\mathrm{J}_{2}$ logran penetrar en las raíces de las plantas, ya no tiene efecto la acción de T. harzianum. De todas formas, la capacidad de colonizar a los huevos de nematodos en el suelo hace, como observaron Sharon et al. (2001), que finalmente 
disminuya el número de hembras en los tejidos radiculares de las plantas y por tanto decrezca la incidencia de la enfermedad. La actuación del hongo antagonista $P$. lilacinus también es destacable pues es uno de los hongos que parasita huevos de nematodos al mismo tiempo que excreta quitinasas que degradan la capa de quitina de la cubierta de los huevos y disminuye la concentración de inóculo infectivo (Nguyen et al., 2009).

El uso del preparado Nemaout también disminuye la enfermedad producida por el nematodo y en diferente intensidad dependiendo de la concentración. La mayor efectividad se obtiene cuando se usa el Nemaout con la dosis mayor (como Nemaout2), pero esta dosis hay que aplicarla con cuidado ya que produce fitotoxicidad, muy evidente en los primeros días de aplicación, aunque luego la planta se recupera y el efecto sobre los nematodos es muy deseable. Las bacterias promotoras del crecimiento y los amino-ácidos de origen vegetal, que integran el formulado Nemaout han demostrado tener un efecto notable en la disminución de la enfermedad. Este hecho nos puede explicar los buenos resultados obtenidos con su uso, con lo que estamos de acuerdo con Radwan et al. (2012) cuando afirman que las bacterias degradan los huevos y los $\mathrm{J}_{2}$ de los nematodos por antibiosis y los aminoácidos vegetales incrementan la resistencia de la planta como explicación de su eficacia. El uso de residuos vegetales en la composición de un biopreparado es una alternativa al uso de compuestos químicos porque además estos compuestos no afectan a la microflora beneficiosa y nuestros resultados en la disminución de las agallas de las raíces está de acuerdo con los resultados obtenidos por Rao et al., (1998) usando extractos acuosos de Azadiracha indica, Ricinus communis o Pongamis pinnata o los obtenidos por Oka et al., (2000) o Pérez et al., (2003) utilizando aceites esenciales de plantas en que, en todos los casos se reduce el número de agallas en raíces ocasionadas por M. incognita. Es de notar que el uso de extractos vegetales para usarlos en preparados de biocontrol debe ser contemplado con rigor, pues estos autores advierten que, al igual que ocurre con nuestros resultados el uso de estos extractos en concentraciones elevadas produce fitotoxicidades. Nuestros resultados con el uso de Nemaout están en consonancia con otros autores que utilizan mezclas de microorganismos antagonistas y restos de vegetales (Haseeb et al., 2005; Pandey et al., 2005) en que los rendimientos de estos productos son satisfactorios si se añaden antes del trasplante para que la 
concentración óptima, para disminuir la reproducción de los nematodos, no afecte a las plantas, pues el elevado nivel necesario como nematicida suele ser fitotóxico si además se añade a plántulas en el momento del trasplante (Oka et al., 2012).

Como los resultados obtenidos con el uso de microorganismos antagonistas para biocontrolar el nematodo $M$. incognita nos han llevado a concluir que uno de los más activos y mas profusamente utilizados es el hongo T. harzianum, no solo por su capacidad de aumentar la resistencia de la planta (Ezziyyani et al., 2004) induciendo proteínas de defensa (Loganathan et al., 2010) sino también por la secreción de compuestos en la rizosfera de la planta con capacidad nematicida. Estos compuestos pueden ser metabolitos resistentes al calor pertenecientes a una fracción de bajo peso molecular (Sharon et al., 2001) o enzimas hidrolíticos como proteínas tipo proteasaserina con actividad tripsina (Suarez et al, 2004) o como colagenasas y quitinasas (Yang et al., 2007).

Para finalizar este trabajo se ha tratado de dilucidar la posibilidad de usar la producción de compuestos del metabolismo extracelular de los cultivos líquidos de T. harzianum como compuesto nematicida. Para ello la puesta a punto de medios de cultivo del hongo de diferente composición y de diferente longitud de tiempo de crecimiento nos ha llevado a concluir que el más idóneo es el de un medio de PDB mas sales y 8 días de crecimiento. Nuestros resultados están en consonancia con los obtenidos por otros autores que usaron filtrados de los cultivos de los antagonistas y comprobaron que inhiben la eclosión de los huevos y la movilidad de los $\mathrm{J}_{2}$ (Meyer et al., 2000; Loganathan et al, 2010). El estudio de los extractos de los cultivos de $T$. harzianum nos ha llevado a tratar de separar los componentes y dilucidar el o los responsables de la capacidad nematicida. La separación por cromatografía de capa fina en gel de sílice fue el sistema utilizado, después de optimizar la fase móvil y la concentración del aposito en el origen de la cromatoplaca y nuestros resultados indican que el hongo produce numerosos compuestos que le dan la mayor actividad nematicida al extracto entero. Las ocho bandas separadas del extracto entero muestran diferente capacidad de mortandad de $\mathrm{J}_{2}$ cuando se dejan en contacto, los vertidos de T. harzianum con los nematodos en tiempos crecientes. Hasta donde nosotros sabemos no hay resultados similares a los obtenidos por nosotros con el sistema de separación cromatográfica, habiendo constatado que de las bandas obtenidas, la que mayor actividad nematicida tiene es la $\mathrm{F}_{1}$ de $\mathrm{Rf}=0,89$ seguida de la 
$\mathrm{F}_{2}$ de $\mathrm{Rf}=0,82$. Esta zona del cromatograma que comprende el rango de los $\mathrm{Rf}$ mencionados, también tiene capacidad antifúngica lo que nos insta a pensar que los compuestos ahí separados pueden ser los publicados por los autores que han analizados extractos de cultivos de T. harzianum y que comprueban que contienen enzimas hidrolíticos que son capaces, no solo de degradar esporas o micelio fúngico (El-Hasan et al., 2009) sino también, de inmovilizar nematodos al degradar la quitina de las cáscaras de los huevos (Khan et al., 2003) o producir una proteasa-serina que arruga la cutícula del nematodo (Chen et al., 2009).

Con los resultados de este trabajo esperamos haber dado un humilde paso en la lucha contra los nematodos sin utilizar compuestos químicos que dañan el medio-ambiente, afectando finalmente a las personas que lo habitamos. 


\section{VII- CONCLUSIONES}

1.- La enfermedad de la "agalla de la raíz" en las plantas de pimiento analizadas en el campo de Cartagena es causada por un nematodo identificado como Meloidogyne incognita. La identificación se ha llevado a cabo sobre $M$. incógnita utilizando técnicas moleculares, mediante PCR con cebadores específicos para esta especie, y técnicas histológicas, que han permitido la observación de las masas de huevos, de las hembras y los Juveniles $\left(\mathrm{J}_{2}\right)$ así como del tejido infectado de la raíz de pimiento.

2.- Los ensayos encaminados a obtener el límite de tolerancia (T) en California Wonder al nematodo $M$. incógnita han dado como resultado un valor de 1,5 huevos y $\mathrm{J}_{2}$ por $\mathrm{ml}^{-1}$ de suelo.

3.- Para el control biológico de $M$. incognita se han probado microorganismos antagonistas del patógeno de manera individual o en combinaciones de hongos y bacterias. El uso de microorganismos aislados resultó ser poco efectivo.

4.- La combinación de dos microorganismos como P. lilacinus y T. harzianum se realizo con dos concentraciones de inoculo inicial de de Meloidogyne incognita, en el suelo. Para la concentración de 1500 huevos $+\mathrm{J} 2 /$ planta se obtuvo una efectividad de control de la enfermedad del $68,16 \%$. Mientras que para la concentración de 3000 huevos $+\mathrm{j} 2 /$ planta se obtuvo un $58,3 \%$. De este ensayo y del anterior podemos 
deducir que la concentración inicial de inóculo del nematodo en el suelo, es influyente sobre la efectividad en el control de la enfermedad.

5.- La combinación de tres antagonistas: dos hongos $P$. lilacinus y $T$. harzianum y una bacteria $B$. firmus tiene la ventaja de ser sólida, se puede almacenar y su acción es inmediatamente visible debido a los mecanismos de acción de sus componentes. En cambio concluimos que la inclusión de la bacteria no mejora la efectividad de la combinación de los dos hongos antagonistas, pues es solo del 46,6\% aunque hay que tener en cuenta que concentración del inóculo inicial para esta experiencia fue de 3000 huevos $+\mathrm{J}_{2}$ de $M$. incognita.

6. El uso del formulado Nemaout que contiene bacterias promotoras del crecimiento y aminoácidos de origen vegetal, es el que ha proporcionado los mejores rendimientos en disminuir el efecto de la enfermedad. Se ha utilizado en dos dosis, y ambos proporcionan una reducción del número de agallas /gr de peso fresco de raíces con respecto a los controles de plantas infectadas y no tratadas. Nemaout 2 lleva a proporcionar un 99,24\% de reducción de las agallas medidas a los 60 días del trasplante, aunque para obtener un alto nivel de erradicación del nematodo, las plantas tratadas necesitan un período de adaptación para superar la fitotoxicidad del formulado. Nemaout 1 fue menos agresivo y aunque el grado de control de los nematodos fue menos a los 60 días $(77,4 \%)$ la producción de las plantas a los 180 días fue similar para ambas dosis $(64.5 \%$ and $73.9 \%$ con Nemaout1 y Nemaout 2 , respectivamente).

7.- Los compuestos excretados (vertidos) por los hongos antagonistas utilizados $T$. harzianum y $P$. lilacinus en los cultivos "in vitro", contienen compuestos nematicidas. Los extractos acuosos de los cultivos líquidos producen la mortandad de $\operatorname{los} \mathrm{J}_{2}$. La suma de los extractos de ambos es la más efectiva ya que llega a producir una mortandad de los $\mathrm{J}_{2}$ del $90,5 \%$ en comparación con la producida por P. lilacinus solo $(35,6 \%)$ y de $T$. harzianum solo $(89,3 \%)$.

8.- Suspensiones miceliares de T. harzianum degradan las paredes de los huevos del nematodo y los destruyen. Cuando se filtran a través de papel Whatman $\mathrm{n}^{\circ} 2$ y de 
microfiltros de $0,25 \mu$ los vertidos producen la inhibición de la eclosión de los huevos con tiempos de cultivo tan bajos como 1 día.

9.- Los extractos metabólicos concentrados de las suspensiones miceliares de $T$. harzianum producen una mortandad que llega al $100 \%$ de los $\mathrm{J}_{2}$ cuando se utilizan los obtenidos incluso desde 4 días de cultivo y con un tiempo de contacto de $24 \mathrm{~h}$.

10.- La separación por cromatografía en capa fina de gel de sílice, optimizada con la fase móvil de aceto-nitrilo: agua (9:1) permitió la separación de los componentes de los vertidos de $T$. harzianum en 8 bandas, de las cuales la $F_{1}$ de $R f=0,89$ y la $F_{2}$ de $\mathrm{Rf}=0,82$ mostraron la mayor capacidad nematicida con un $73,8 \%$ y un $52,6 \%$ de mortandad de los $\mathrm{J}_{2}$ de $M$. incognita, respectivamente. 


\section{VIII.- BIBLIOGRAFÍA}

Abbott, W.S. (1925). A method of computing the effectiveness of an insecticide. J. Econ. Entomol., 18: 265-267.

Abd-Elgawad, M. M. M., Kabeil, S. S. A., (2010). Management of the root knot nematode, Meloidogyne incognita on tomato in Egypt. Journal of American Science. 6: $256-262$.

Agrios, G.N. (2005). Plant Pathology 5º edición. Ed. Elsevier, Academic Press, San Diego, California, USA.

Aminazzuman, F., Duan, W.J., Xie, H. Y., Liu, X.Z. (2009). Biological control of root-knot nematode Meloidogyne incognita by alginate pellets of Paecilomyces lilacinus and Pochonia chlamydosporia. Journal of Nematology. 41(4): 302-302

Anastasiadis, I.A., Giannakou, I.O., Prophetou-Athanasiadou, D.A. \& Gowen, S.R. (2008). The combined effect of the application of a biocontrol agent Paecilomyces lilacinus, with various practices for the control of root-knot nematodes. ScienceDirect. 27:352-361. 
Badi, M., Schuster R.P., Kopcke, B., Mayer, AS., Sikora, R.A. and Anke, H. (2001). Screening of fungi for control activity towards root knot nematode Meloidogyne incognita and studies on the mode of action. Proceedings 52 International Symposium on Crop Protection. 65(2A-B): 481-490.

Baermann, G. (1917) Eine e infache Methode zur Auffindung von Ankylostomum (nematoden) Larven in Erproben. Geneesk. Tijdschr. Ned-Indie. 57: 131-137.

Bailey, L.H. (1977). Manual of cultivated plants. Ed. Mc. Millan Co. Inc., New York, USA.

Bailey, D. J., Biran, G. L., Kerry, B. R., \& Gilligan, C. A. (2008). Pathozone dynamics of Meloidogyne incógnita in the rhizosphere of tomato plants in the presence and absence of the nematophagus fungus, Pochonia chlamydosporia. Plant Pathology. 57: 354-362.

Baker, R. and Cook, R. (1974). Biological control of plant pathogens. San Francisco USA, W. H. Freeman. 433 p.

Baker, R. and Cook, R., (1983). The nature and practice of biological control of plant pathogens. American Phytopathological Society. 539p.

Blaxter, M.L. and Robertson, W.M. (1998). The cuticle. In: Perry R.N., Wright D.J. (eds). The Physiology and Biochemistry of free-living and plant-parasitic nematodes. CABI, Wallingford, UK, pp 25-48.

Bokhari, F.M. (2009). Efficacy of some Trichoderma species in the control of Rotylenchus reniformis and Meloidogyne javanica. Archives of Phytopathology and Plant Protection. 42: 361-369.

Bosland, P.W. (1992). Chiles: a diverse crop. Hort. Technology. 2: 6-10. 
Bosland, P.W. (1994). Chiles; history, cultivation, and uses.. En Spices, herbs, and edible fungi. G. Charalambous. Ed. Elsevier Publ. New York, USA. pp: 347-366.

Bosland, P.W., Votaca, E.J. (1999). Peppers: Vegetable and Spice. Capsicum. CABI Publishing, Wallingford, U.K.

Brants A., Brown, C.R. and Earle (2000). Trichoderma harzianum endochitinase does not provide resistance to Meloidogyne hapla in transgenic tobacco. J. Nematol. 32: 289-296.

Bridge, J., \& Page, S. L. J. (1980). Estimation of root-knot nematode infestation levels on roots using a rating chart. Tropical Pest Management. 26: 296-298.

Bridge, J., Starr, J.L. (2007). Plant Nematodes of Agricultural Importance. London, UK: Manson Publishing Ltd.

Cabanillas, E., Barker, K.R. and Nelson, L.A. (1989). Survival of Paecilomyces lilacinus in selected carries and related effect on Meloidogyne incognita on tomato. Journal of Nematology. 21(1):121-130.

Caillaud, M-C., Dubreuil, G., Quentin, M., Perfus-Barbeoch, L., Lecomte, P., de Almeida Engler, J., Abad, P., Rosso, M-N., Favery, B. (2008). Root-knot nematodes manipulate cell functions during a compatible interaction. Journal of Plant Physiology. 165: 104-113.

Castillo, P., Di Vito, M., Vovlas, N., \& Jimenez-Diaz, R. R. (2001). Host-parasite relationships in root-knot disease of white mulberry. Plant Disease. 85: 277-281.

Castillo, P., Nico, A.I., Azcón-Aguilar, C., Del Rio Rincón, C., Calvet, C., JiménezDíaz, R.M. (2006). Protection of olive planning stocks against parasitism of rootknot nematodos by arbuscular mycorrhizal fungi. Plant Patholog. 55: 705-713. 
Cayrol, J.C.,Dijan, C., and Pijarowsky, L. (1989). Study of the nematocidal properties of the culture filtrate of the nematophagus fungus Paecilomyces lilacinus. Revue Nematologie. 12, 331-336.

Chan, S., López, R. (1992). Efecto de diferentes densidades iniciales de Meloidogyne incógnita sobre el crecimiento del tomate. Agronomía Costarricense. 16: 165-169.

Chen, L.-L.; Liu, L.-J.; Shi, M.; Song, X.-Y.; Zheng, C.-Y.; Chen, X.-L. and Zhang, Y.-Z. (2009). Characterization and gene cloning of a novel serine protease with nematicidal activity from Trichoderma pseudokoningii SMF2. Federation of European Microbiological Societies (FEMS) Microbiol. Lett. 299: 135-142.

Chitwood, D.J. (2002). Phytochemicals based strategies for nematode control. Annu. Rev. Phytopathol, 40: 221-249.

Coolen, W.A. (1979). Methods for the extraction of Meloidogyne spp. And other nematodes from roots and soil. In: Lamberti F, Taylor CE, eds. Root-Knot Nematodes (Meloidogyne Species Systematics, Biology and Control. London, UK: Academic Press. Pp. 317-29.

Cortada, L., Sorribas, F. J., Ornat, C., Kaloshian, I., \& Verdejo-Lucas, S. (2008). Variability in infection and reproduction of Meloidogyne javanica on tomato rootstocks with the mi resistance gene. Plant Pathology. 57: 1125-1135.

Costa García, J. (1989). Estudio sectorial de pimiento para pimentón.. Ed. Consejería de Agricultura. Comunidad Autónoma de la Región de Murcia. pp. 33-45.

Di Vito, M., Vovlas, N., \& Castillo, P. (2004). Host-parasite relationships of Meloidogyne incógnita on spinach. Plant Pathology. 53: 508-514.

Dickson, D.W., Struble, B.F. (1965). A sieving staining technique for extraction of egg masses of Meloidogyne incógnita from soil. Phytopathology. 55: 497 (abstract). 
Djian Caporalino, C.; Fazari, A.; Arguel, M.J.; Vernie, T.; VandeCasteele, C.; Faure, I.; Brunoud, G.; Pijarowski, L.; Palloix, A.; Lefebvre,V.; Abad, A. (2007). Root-knot nematode (Meloidogyne spp.) Me resistance genes in pepper (Capsicum annum L.) are clustered on the P9 chromosome. Theor. Appl. Genet. 114: 473-486.

Dos Santos, Ferraz, M.A.S. and Muchovez, J.J. (1992). Evaluation of 20 species of fungi from Brazil for biocontrol of Meloidogyne incognita race-3. Nematropica. 22:183-192.

Droby, S., Jacoby, B., Prusky, D. (1987). Lack of involvement of nutrients in the latency of Alternaria alternata in unripe Mango fruits. Journal of PhytopathologyPhytopathologische Zeitschrift. 120: 85-89.

Duan, W., Yang, E., Xiang, M. and Liu, X. (2008). Effect of storage conditions on the survival of two potential biocontrol agents of nematodes, the fungi Paecilomyces lilacinus and Pochonia chlamydosporia. Biocontrol Science and Technology. 18: 613-620.

Dube, B. and Smart, Jr. (1987) Biological Control of Meloidogyne incognita by Paecilomyces lilacinus and Pasteuris penetrans. Journal of Nematology. 19(2): 222227.

Elbadri, G.A., Lee, D.W., Parl, J.C., Yu, H.B., Choo, H.Y., (2008). Evaluation of various plant extracts for their nematicidal efficacies against juveniles of Meloidogyne incognita. Journal of Asia-Pacific Entomolgy. 11:99-102.

El-Hasan, A., Walker, F., Schöne and Buchenauer, H. (2009). Detection of viridiofungin $\mathrm{A}$ and other antifungal metabolites excreted by Trichoderma harzianum active against different plant pathogens. Eur. J. Plant Pathol. 124: 457470. 
Estañol, E., Ferrera, R., Sosa, C., Santizo, J. A., \& Quintero, R. (1999). Interacción del nematodo Meloidogyne chitwoodi con tres especies de hongo Glomus sp. en la producción y distribución de materia seca de plantas jóvenes de maíz. Terra. 17: 1725.

Ezziyyani, M., Pérez Sánchez, C., Sid Ahmed, A., Requena, M. E., Candela, M. E., 2004. Trichoderma harzianum como biofungicida para biocontrol de Phytophthora capsici en plantas de pimiento(Capsicum annuum L.). Anales de Biología. 26, 35-45.

Fravel, D.R. (1988). Role of antibiosis in the Biocontrol of plant-diseases. Annual Review of Phytopathology. 26:75-91.

Giannakou, I.O., Karpouzas, D.G. and Prophetou-Athanasiadou, D. (2004). A novel non-chemical nematicide for the control of root-knot nematodes. Applied Soil Ecology. 26: 69-79.

Ghisalberti, E.L. and Sivasithamparam, K. (1991). Antifungal antibiotics produced by Trichoderma spp. Soil Biol. Biochem. 23: 1011-1020.

Goswami, B. K., Pandey, R. K., Rathour, K. S., Bhattacharya, C., \& Singh, L. (2006). Integrated application of some compatible biocontrol agents along with mustard oil seed cake and furadan on Meloidogyne incognita infecting tomato plants. Journal of Zhejiang University SCIENCE B, 7: 873-875.

Goswami,J., Pandey, R.K., Tewar, J.P. and Goswami, B.K. (2008). Management of root knot nematode on tomato through application of fungal antagonists, Acremonium strictum and Trichoderma harzianum. Journal of Environmental Science and Health Part B. 43: 237-240.

Haran, S., Schickler, H., Chet, I., (1996). Molecular mechanisms of lytic enzymes involved in the biocontrol activity of Trichoderma harzianum. Microbiology. 142:2321-2331. 
Haseeb, A.; Sharma, A.; Shukla, P.K. (2005). Studies on the management of rootknot nematode Meloidogyne incognita- wilt fungus, Fusarium oxysporum disease complex of gree gram, Vigna radiate cv ML-1108. J. Zhejiang Univ. SCI. 6(8): 736742.

Holland, R. J., Williams, K. L., Khan, A., (1999). Infection of Meloidogyne javanica by Paecilomyces lilacinus. Nematology. 1: 131-139.

Hussey, R.S., Barker, K.R. (1973). A comparison of methods of collecting inoculation of Meloidogyne spp., including a new technique. Plant Disease Reporter. 57: $1025-1028$

Javed, N., Gowen, S. R., Inam-ul-Haq, M., \& Anwar, S. A. (2007). Protective and curative effect of neem (Azadirachta indica) formulations on the development of root-knot nematode Meloidogyne javanica in roots of tomato plants. Crop Protection. 26: $530-534$.

Javed, N., El-Hassan, S., Gowen, S., Pemproke, B., Inam-ul-Haq, M., (2008). The potential of combining Pasteuria penetrans and neem (Azadirachta indica) formulations as a management system for root-knot nematodes on tomato. European Journal of Plant Pathology. 120: 53-60.

Johansen, D.A. (1940). Plant Microtechnique. New Yprk, USA. McGraw-Hill Book Co.

Kamala, Th. and Indira, S. (2012). Prospect of Trichoderma as a potential fungicide. International Journal of Human Genetics medical Biotechnology and Microbiological Studies. vol 1: (ISSN Online 2319-1732) Issue 3, December.

Karssen, G., van Hoenselaar, T.,Verkerk-Bakker, B., Janssen, R. (1995) Species identification of cyst and root-knot nematodes from potato by electrophoresis of individual females. Electrophoresis. 16 : 105-109. 
Khan, A., Williams, K.L., Molloy, M.P. and Nevalainen, H. (2003). Purification and characterization of a serine protease and chitinases from Paecilomyces lilacinus and detection of chitinasa activity on 2D gels. Protein Expr. Purif. 32: 210-220.

Khan, A., Williams, K. L., \& Nevalainen, H. K. M. (2006). Control of plant-parasitic nematodes by Paecilomyces lilacinus and Monacrosporium lysipagum in pot trials. Biocontrol. 51: 643-658.

Kiewnick, S., Sikora, R.A. (2006a). Biological control of the root-knot nematode meloidogyne incognita by Paecilomyces lilacinus strain 251. Biol. Control. 38: 178187.

Kiewnick, S., Sikora, R.A. (2006b). Evaluation of Paecilomyces lilacinus strain 251 for the biological control of the northern root-knot nematode Meloidogyne hapla Chitwood. Nematol. 8: 69-78

Kiewnick, S., Neumann, S., Sikora, R.A. and Frey, J.E. (2011). Effect of Meloidogyne incognita Inoculum Density and Aplication Rate of Paecilomyces lilacinus Strain 251 on Biocontrol Efficacy and Colonization of Egg Masses analyzed by Real-Time Quantitative PCR. Phytopathology. 101(1). 105-112.

Kobayashi, I., Tokuda, M., Hashimoto, H., Konda, T., Nakano, H., Kitahata, S. (2003). Purification and Characterization of a New Type of a $\alpha$-Glucosidase from Paecilomyces lilacinus that has Transglucosylation Activity to produce $\alpha-1,3$-and $\alpha$ 1,2- linked Oligosaccharides. Biosci. Biotecnol. Biochem.67: 29-35.

Kuhnhold, V.; Kiewnick, S.; Sikora, R.A. (2006). Development of an in vivo bioassay to identify sugar beet resistance to the stem nematode Ditylenchus dipsaci. Nematology. 8: 641-645

Lamberti, F. (1979). Economic importance of Meloidogyne spp. In subtropical and Mediterranean climates. In: Lamberti, F., Taylor, C.E. eds. Ed. Root-knot Nematodes (Meloidogyne Species) Systematics, Biology and Control. London, UK: Academic Press, 341-358. 
Loganathan, M., Sible, G.V., Maruthasalam, S., Saravanakumar, D., Raguchander, T., Sivakumar, M. and Samiyappan, R. (2010). Trichoderma and chitin mixture based bioformulation for the management of head rot (Sclerotinia sclerotiorum (Lib.) de Bary)- root knot (Meloidogyne incognita Kofoid and White; Chitwood) complex diseases of cabbage. Archives of Phytopathology and Plant Protection. 43: 1011-1024.

Maurhofer, M. Reimmann, C. and Schmidli-Sacherer, P. (1998) Salicylic acid biosynthetic genes expressed in Pseudomonas fluorescens strain P3 improve the induction of systemic resistance in tobacco against tobacco necrosis virus. Phytopathology. 88: 678-684.

Maroto, B.J.V. (1989). Horticultural Herbacea Espacial. Maroto, B.J.V. Ediciones Mundi-Prensa, Madrid.

Mashela, P. W., Mphosi, M. S., Shimelis, H., \& Mokgalong, N. M. (2007). Interactions of Cucumis myriocarpus, Lippia javanica and Ricinus communis Organic amendments on suppresssion of Meloidogyne incógnita. Journal of Phytopathology, 155: 690-693.

Meera, M.S., Shivana, M.B., Kageyama, K. and Hyakumachi, M. (1994). Plant growth promoting fungi frim zoysiagrass rhizosphere as potencial inducers of systemic resistance in cucumbers. Phytopatology. 84: 1399-1406.

Mendoza, A.R., Sikora, R.A. (2008). Biological control of Radopholus similis in banana by combined application of the mutualistic endophyte Fusarium oxysporum starin 162, the egg pathogen Paecilomyces lilacinus strain 251 and the antagonistic bacteria Bacillus firmus. Biocontrol, x, RM1666, 1-9

Meyer, S.L.F., Massoud, S.I., Chitwood, D.J. and Roberts, D.P. (2000). Evaluation of Thrichoderma virens and Burkholderia cepacia for antagonistic activity against root-knot nematode, Meloidogyne incognita. Nematology 2: 871-879. 
Monfort, E., Lopez-Llorca, L. V., Jansson, H. B., Salinas, J., (2006). In vitro soil receptivity assays to egg-parasitic nematophagous fungi. Mycol Progress. 5: 18-23. Montreal (2005). Protocolo de la Reunión de Montreal. Canada.

Morrison, R. A., Koning, R. E., Evans, D. A., (1986). Pepper. In: Evans, D. a., Sharp, W. R., Amirato (Eds.). Handbook of Plant Cell culture. Macmillan, New York. 4: 552-573.

Nico, A. I., Jiménez-Díaz, R. M., \& Castillo, P. (2003). Solarization of soil in piles for the control of Meloidogyne incognita in olive nurseries in southern Spain. Plant Pathology. 52: 770-778.

Nguyen, V.N., Oh, In.J., Kim, K.Y., Kim, Y.C. and Park, R.D. (2009). Purification and characterization of chitinases from Paecilomyces lilacinus variotti DGparasitizing on Meloidogyna incognita eggs. J. Ind. Microbiol. Biotechnol. 36:195203.

Omwega, C., Thomason, I.J., Roberts, P.A. (1988). A non-destructive technique for screening bean germ plasm for resistance to Meloidogyne incógnita. Plant Disease. 72: 970-972.

Orton Williams, K.J. (1973). Meloidogyne incógnita. St Albans, UK: Commonwealth Agricultural Bureau: C.I.H. Descriptions of Plant Parasitic Nematodes. Sec. 2, no. 18.

Oka, Y., Nacar, S., Putievsky, E., Ravid, U., Yaniv, Z. and Spiegel, Y. (2000). Nematicidal activity of essential oils and their components against the root-knot nematode. Phytopathology. 90: 710-715.

Oka, I.,Ben-Daniel, B, Cohen, Y., (2012). Nematicidal activity of the leaf powder and extracts of Myrtus communis against the root-knot nematode Meloidogyne javanica. Plant Pathology. 61: 1012-1020. 
Pandey, R. (2005). Management of Meloidogyne incognita in Artemisia pallens with Bio-organics. Phytoparasitica. 33(3): 304-308.

Pandey, R.; Kalra, A. \& Gupta, M.L. (2009). Evaluation of bio-agents and pesticide on root-knot nematode development and oil yield of patchouli. Archives of Phytopathology and Plant Protection 42: 419-423.

Pandey, R.K., Sinigh, S.R., Gupta, P.K., Goswami, B.K., Singh, D.V. and Gharde, Y. (2011). Effect of different bioformulations of Paecilomyces lilacinus against rootknot nematode (Meloidogyne incognita) infecting tomato (Solanum esculentum). Indian J. of Agricultural Sciences. 81(3): 261-267.

Papavizas, G.C. and Lumsden, R.D. (1982). Improved medium for isolation of Trichoderma spp. from soil. Plant Disease 66: 1019-1020.

Park, J.-O., Hargreaves, J.R., McConville, E.J., Stirling, G.R., Ghisalberti, E.L. and Sivasithamparam, K. (2004). Production of leucinostatins and Nematicidal activity of Australian isolates of Paecilomyces lilacinus (thom) Samson. Letters of Applied Microbiology. 38: 271-276.

Pegard, A.; Brizzard, G.; Fazari, A.; Soucaze, O.; Abad, P.; Djian-Caporalino, C (2004). Histological Characaterization of Resistance to different Root-knot Nematode Species Related to phenolics Accumulation in Capsicum annuum. Phytopathol. 95: 158-165.

Pérez, M. P., Navas-Cortés, J. A., Pascual-Villalobos, M. J. and Castillo, P. (2003). Nematicidal activity of essentials oils and organic amendments from Astaraceae against root-knot nematodos. Plant Pathology. 52: 395-401.

Perry, R.N. and Trent, M.W. (1986). Ultra structure of the egg shell of Heterodera schatii and H. glycines (Nematoda: Tylenchida). Rev. Nematol. 9: 399-233. 
Potter, J.W., Olthof, T.H.A. (1993). Nematode pests of vegetable crops. In: Evans K., Trudgill D.L., Webster J.M., eds. Plant Parasitic Nematodes in Temperate Agriculture. Wallingford, UK: CAB International, 171-207.

Proite, K.; Carneiro, R.; Falcao, R.; Gomes, A.; Leal-Bertioli, S.; Guimaraes, P.; Bertioli, D. (2008). Post-infection development and histopathology of Meloidogyne arenaria race 1 on Arachis spp. Plant Pathology. 57: 974-980

Qiu, J.J.; Westerdahl, B.B.; Anderson, C.; Williamson, V.M. (2006). Sensitive PCR detection of Meloidogyne arenaria, $M$. incognita and $M$. javanica extracted from soil. Journal of Nematology 38: 434-441.

Radwan, M. A., Farrag, S. A. A., Abu-Elamayem, M. M., Ahmed, N. S., (2012). Biological control of the root-knot nematode, Meloidogyne incognita on tomato using bioproducts of microbial origin. Applied Soil Ecology. 56: 58-62.

Rao, M.S., Reddy, P.P. and Nagesh, M. (1997). Management of root-knot nematode, Meloidogyne incognita on tomato by integration of Trichoderma harzianum with neem cake. J. Plant Diseases and Protection. 104(4): 423-425.

Rao, M.S., Reddy, P.P. and Nagesh, M. (1998). Evaluation of plant based formulations of Trichoderma harzianum for de management of Meloidogyne incognita on egg plant. Nematology mediterranea. 26: 59-62.

Rumbos, C.; Reimann, S.; Kiewnick, S.; Sikora, R.A. (2006). Interactions of Paecilomyces lilacinus strain 251 with the mycorrhizal fungus Glomus intraradices: Implications for Meloidogyne incognita control on tomato. Biocon. Sci \& Tech. 16: 981-986.

Rumbos, C., Mendoza, A., Sikora, R. and Kiewnick S. (2008). Persistence of the nematophagous fungus Paecilomyces lilacinus strain 251 in soil under controlled conditions. Biocontrol Science and Technology. 18: 1041-1050. 
Sahebani, N. and Hadavi, N. (2008). Biological control of root-knot nematode Meloidogyne javanica by Trichoderma harzianum. Soil Biology \& Biochemistry 40: 2016-2020.

Sasser, J.N., Carter, C.C. (1985). An Advanced Treatise on Meloidogyne. Vol.I. Biology and Control. Raleigh, NC. USA: North Carolina State University Graphics.

Seinhorst, J.W. (1965). The relationship between nematode density and damage to plants. Nematologica 11:137-154.

Seinhorst, J.W. (1979). Nematodes and growth of plants: formulation of the nematode-plant system. In: Lamberti, F., Taylor, C.E. eds. Root-knot Nematodes (Meloidogyne Species) Systematics, Biology and Control. London, UK: Academic Press, 231-256.

Shaban, G.M. \& El-Komy, H.M.A. (2000). Survival and proliferation of alginate encapsulated Trichoderma spp. In Egyptian soil in comparasion with allyl alcohol soil fumigation. Mycopathologia 151: 139-146.

Sharma, P. \& Pandey, R. (2009). Biological control of root-knot nematode; Meloidogyne incognita in the medicinal plant; Withania somnifera and the effect of biocontrol agents on plant growth. African J. of Agricultural Research. 4(6): 564567.

Sharon, E. Bar-Eyal, M, Chet, I., Herrera-Estrella, A., Kleifeld, O. and Spiegel, Y. (2001). Biological Control of the Root-Knot Nematode Meloidogyne incognita by Trichoderma harzianum. Phytopatology, 91: 687-693.

Sharon, E., Chet, I., Viterbo, A., Bar-Eyal, M., Nagan, H., Samuels, G.Jr., Spiegel, Y. (2007). Parasitism of Trichoderma on Meloidogyne javanica and role of the gelatinous matrix. Eur. J. Plant Pathol. 118 : 247-258. 
Siddiqui, Z.A. and Mahmood, I. (1993).- Biological control de Meloidogyne incognita race 3 and Macrophomina phaseolina by Paecilomyces lilacinus and Bacillus subtilis alone and in combination on chickpea. Fundamental and Applied Nematology 16 (3): 215-218.

Siddiqui , I.A. and Shaukat, S.S. (2004). Thrichoderma harzianum enhances the production of nematicidal compounds in vitro and improves biocontrol of Meloidogyne javanica by Pseudomonas fluorescens in tomato. Letters in Applied Microbiology 38: 169-175.

Siddiqui, I.A., Haas, D. and Heeb S. (2005). Extracellular Protease of Pseudomonas fluorescens CHA0, a Biocontrol Factor with Activity against Root-Knot Nematode Meloidogyne incognita. Applied and Environmental Microbiology. 71(9): 56465649 .

Siddiqui, Z.A. and Akhtar, M.S. (2008). Synergistic effects of antagonistic fungi and a plant growth promoting rhizobacterium, an arbuscular mycorrhizal fungus, or composted cow manure on populations of Meloidogyne incognita and growth of tomato. Biocontrol Science and Technology, 18: 279-290.

Sikora, R.A., Fernández, E. (2005). Nematode parasite of vegetables. In: Luc, M., Sikora, R.A., Bridge, J. eds. Plant Parasitic Nematodes in Subtropical and Tropical Agriculture. Wallingford, UK: CAB International, 319-392.

Sikora, R.A., Schäfer, K and Dababat, A.A. (2007). Modes of action associated with microbially induced in planta suppression of plant-parasitic nematodes. Aust. Plant Pathol. 36: 124-134.

Sögüt, M.A. and Elekçioglu, I.H. (2007). Methyl Bromide alternatives for controlling Meloidogyne incognita in pepper cultivars in the Eastern Mediterranean Region of Turkey. Turk. J. Agric. For. 31: 31-40. 
Spiegel, Y., Sharon, E., Bar-Eyal, M., Maghodia, A., Vanachter, A., van Assche, A., van Kerckhove, S., Viterbo, A. and Chet, I. (2007). Evaluation and mode of action of Trichoderma isolates as biocontrol agents against plant-parasitic nematodes. Biological control of fungal and bacterial Plant pathogens. 30(6):129-133.

Suarez, B., Rey, M., Castillo, P., Monte, E. and Llobell, A. (2004). Isolation and Characterization of PRA1, a trypsin-like protease from the biocontrol agent Trichoderma harzianum CECT 2413 displaying nematicidal activity. Appl. Microbiol. Biotecnol. 65: 46-55.

Tesařová, B.; Zouhar, M.; Ryšánek, P. (2003). Development of PCR for specific determination of root-knot nematodo Meloidogyne incognita. Plant Protec. Sci. 39: 23-28.

Thoden, T.C.; Halmann, J.; Boppre, M. (2009). Effects of plants containing pyrrolizidine alkaloids on the northern root-knot nematode Meloidogyne hapla. Eur.J.Plant Pathol.123: 27-36.

Tosi, S., Anovazzi, L., Tosi, I., Iadrola, P. and Caretta, G. (2001). Collagenase production in an Antarctic strain of Arthrobotrys tortor Jarawaja. Mycopathologia 153: $157-162$.

Verdejo-Lucas, S., Sorribas, F.J., Ornat, C., Galeano, M. (2003). Evaluating Pochonia chlamydosporia in a double-cropping system of lettuce and tomato in plastic houses infested with Meloidogyne javanica. Plant Pathology. 52: 521-528.

Vovlas, N., Lucarelli, G., Sasanelli, N., Troccoli, A., Papajova, I., Palomares-Rius, J. E., et al. (2008). Pathogenicity and host-parasite relationships of the root-knot nematode Meloidogyne incógnita on celery. Plant Pathology, 57: 981-987. 
Wei, J.Y., Cohen, E.D. and Yan, Y.Y. (1996). Identification of competitive antagonists of the rod photoreceptor cGMP-gated cation channel: beta-phenyl-1, n-2etheno substituted cGMP analogues as probes of the cGMP- binding site. Biochemestry. 35:16815-16823.

Wesemael, W.M.L. and Moens, M. (2008). Vertical distribution of the plant-parasitic nematode, Meloidogyne chitwoodi, under field crops. European Journal of Plant Pathology. 120: 249-257.

Whitehead, A.G. and Hemming, J.R. (1998). A comparison of some quantitative methods of extracting small vermiform nematodes from soil. Ann. Appl. Biol. 55:2538.

Willianson, V.M.; Caswell-Chen, E.P.; Westerdahl, B.B., Wu, F.F.; Caryl, G. (1997). A PCR assay to identify and distinguish single juveniles of Meloidogyne hapla and M. chitwoodi. Journal of Nematology 29: 9-15.

Yang, J., Tian, B., Liang, L. and Zhang, K.-Q. (2007). Extracellular enzymes and the pathogenesis of nematophagous fungi. Appl. Microbiol. Biotecnol. 75: 21-31.

Yang, Z.-S Li, G.-H, Zhao, P.-J., Zheng, X., Luo, S.-L., Niu, X.-M., Zhang, K.-Q. (2010). Nematicidal activity of Trichoderma spp. and isolation of an active compound. World J. Microbiol. Biotechnol. 26: 2297-2302.

Yeyidia, I., Benhamou, N. and Chet, I. (1999).Induction of defense responses in cucumber plants (cucumis sativa L.) by biocontrol agent Trichoderma harzianum. Appl. Environ Microbiol. 65:1061-1070.

Zareen, A, Siddiqui, I.A., Aleem, F., Zaki, M.J. and Shaukat, S.S. (2001). Observations on the nematicidal effect of Fusarium solani on the root-knot nematodes Meloidogyne javanica. Journal of Plant Pathology. 83:207-214. 
Zaki, F.A. (1994). Effect of culture filtrates of Paecilomyces lilacinus on Meloidogyne javanica. Nematol. Medit. 22:41-43.

Zhu, M.L.; Mo, M.H.; Xia, Z.Y.; Li, Y.H.; Yang, S.J.; Li, T.F. and Zhang, K.Q. (2006). Detection of two fungal biocontrol agents against root-knot nematodes by RAPD markers. Mycopathologia. 161: 307-316.

Zijlstra, C., Donkers-Venne, D. T. H. M., Farguette, M., 2000. Identification of Meloidogyne incognita, M. javanica and M. arenaria using sequence characterised amplified region (SCAR) based PCR assays. vol. 2. Nematology, pp. 847-853. 